Portland State University

PDXScholar

\title{
Affecting Absenteeism Through School-Based Health Services Delivery: A Configurational Comparative Methods Study of Oregon's Public Secondary Schools
}

Kelly Elizabeth Coates

Portland State University

Follow this and additional works at: https://pdxscholar.library.pdx.edu/open_access_etds

Part of the Education Commons, and the Public Health Commons Let us know how access to this document benefits you.

\section{Recommended Citation}

Coates, Kelly Elizabeth, "Affecting Absenteeism Through School-Based Health Services Delivery: A Configurational Comparative Methods Study of Oregon's Public Secondary Schools" (2021). Dissertations and Theses. Paper 5753.

https://doi.org/10.15760/etd.7624

This Dissertation is brought to you for free and open access. It has been accepted for inclusion in Dissertations and Theses by an authorized administrator of PDXScholar. Please contact us if we can make this document more accessible: pdxscholar@pdx.edu. 
Affecting Absenteeism Through School-Based Health Services Delivery:

A Configurational Comparative Methods Study of Oregon's Public Secondary Schools

By

Kelly Elizabeth Coates

A dissertation submitted in partial fulfillment of the requirements for the degree of

\author{
Doctor of Philosophy \\ in
}

Health Systems and Policy

\author{
Dissertation Committee: \\ Sherril B. Gelmon, Chair \\ Julia M. Goodman \\ Debra C. Harris \\ Moti Hara \\ Edward J. Miech
}

Portland State University 2021 
(C) 2021 Kelly Elizabeth Coates 


\begin{abstract}
A student's ability to attend school regularly can be profoundly affected by poor health-related behaviors, illnesses, and chronic diseases that are left unaddressed and unattended. The delivery of health services in the school environment is uniquely positioned to interrupt the effects these health barriers to learning (HBLs) can have on subsequent diminished educational and health outcomes. The literature widely acknowledges the intersectionality between health and education, but no comprehensive overview exists of how different structures and processes within a school work (or do not work) together to lead to higher or lower student absenteeism. This research sought to fill that gap by exploring how the structural elements of the school system and the process elements of school-based health services (SBHS) delivery can mitigate the ways in which HBLs affect a student's ability to attend school regularly.

Secondary data from multiple publicly available data sources and from the 2018 administration of the Centers for Disease Control and Prevention's School Health Profiles Surveys were used to describe characteristics of a subset of secondary schools in Oregon. These data were utilized to create a unique characterization of the structural elements of the secondary school system and the process elements of SBHS delivery, which in combination lead to the absenteeism outcome. This categorization aided in the identification of elements that may influence the availability, delivery, and quality of health services in secondary schools. Using a comparative configurational method known as coincidence analysis, configurations with different combinations of the structural and process elements (solution pathways) were identified and compared to examine their contributions to both higher and lower rates of chronic absenteeism.
\end{abstract}


This research found that the combination of elements needed for both higher and lower student absenteeism varied by a school's grade level. This finding suggests that despite grade level being a nonmodifiable element, giving attention to the grades served by a school can inform where and how programs and resources are targeted. Additionally, SBHS delivery that was more comprehensive, coordinated and consistent was found to actively support students by addressing the effects various health problems and issues can have on school attendance. Finally, purposeful coordination of comprehensive in-school health services delivery can also decrease the barriers and problems associated with seeking care off-site. Most recent efforts to address the academic achievement gap have largely focused on educational reform that target in-classroom activities, teacher preparation, and test preparation. An increased emphasis on student health and well-being may be complementary to those efforts, by supporting rather than detracting from academics. Opportunities can be created for new collaborations among players in both the health services and educational systems, which may need to be supported by policy reforms in either or both sectors. The process by which well-designed, coordinated health services are provided within the structure of the school environment can synergistically improve student academic achievement and health outcomes in the short-term, as well as employment, health, and wellness opportunities over the life course. 


\section{Dedication}

For Fredo, Llandon and the Littlest Bean 


\section{Acknowledgements}

Although the intention of the U.S. public education system is to provide all children with a strong educational foundation, funding, student tracking, and a continued emphasis on test scores and grades maintain a system that has historically been inequitable, unfair, and imbalanced. Learning about these inequities sparked a passion within me to build upon my experience, background and skills by pursuing a degree that would enable me to create sustainable, widespread, meaningful change. My efforts to persevere through this work would have never happened without that burning drive. To the students in the U.S. public education system - I dedicate my continued efforts and focus to do everything in my power to increase health services delivery in schools, to improve cross-sectoral education and health equity efforts, and to keep your needs centered in all I do.

Mom, Dad, and Brandon - I owe everything I am and everything I have become to the three of you. I would be nowhere without you loving me, encouraging me, being patient with me, and caring about me. Mom - You are my partner-in-crime, my provider of hugs, my listening ear, and my cheerleader. Dad - In your eyes, I will always be your little girl, but I hope you realize that it was through your support and encouragement that I became the woman I am. Brandon - To be the person who gets to call you my little brother makes me one lucky lady. Thank you for teaching me many meditation tricks, as they came in handy along this journey. Love all three of you to the moon and back.

My framily and village - Each and every one of you lift me up, bring me joy, make me laugh, and remind me that the world is always something worth fighting for. I am immensely grateful for your friendships, inspiration, generosity, kindness, encouragement, laughter, and love. Thank you. 
Sherril - Who knew that a glass of wine at Aquariva on a wintery evening would change the trajectory of my life? The list of things I can thank you for along this journey we have been on together is lengthy: for believing in me, for pushing me when I needed it, for helping me to see the bigger picture when I was lost in a rabbit hole, for being gentle when my anxiety was on overload, for guiding me when I was off-path, for reassuring me when my self-doubts were running rampant, and more than anything, for being my mentor. There is simply no way I could have done this without you.

Julia - It feels like lifetimes ago when I first took your Health Policy class in Spring 2016. I am grateful to have you by my side as I get to the end of this chapter in life, just five short (long?) years later. Your perspectives, knowledge, support, and encouragement taught me more than anything I could have learned in a textbook. Thank you.

Deb - From PHE 550 in Summer 2001 to 20 years later...we made it! You are one of the people on my academic journey who stuck around to help me get here, and I am eternally grateful. I appreciate your real-world knowledge about what is happening with health in schools, your belief about all the places I will go once I am done, and your continued friendship.

Moti - The first slap of a point on a projector screen. An enthusiastic "Exactly!!" when someone gave the right answer. The thoughtful support and encouragement as we worked through a problem. Your enthusiasm for teaching is infectious, and I feel lucky to have caught the bug. Thank you for joining me on my dissertation journey.

Edward - From a work project to a CCMs course to All Things Configured to my dissertation committee...through it all, I am grateful you agreed to be a part of this with me. I am even more grateful that you were so responsive and supportive in my moments of 
panic when I was certain that I was losing my mind. Your mentorship, guidance, encouragement and kind words helped me feel I could do it, and I am deeply appreciative.

Dawn - Thank you for the help, support, and guidance you provided throughout my comp exams and through my proposal. Your perspective always helped me to think about things in a different way.

Sarah - As an HS\&P classmate, an OHA contact, and a friend, I am deeply indebted to you for your support, guidance and knowledge. I distinctly remember chatting before seminar in March 2019, and you suggested chronic absenteeism as an education system and health system outcome of interest. You set me on my path, and supported me with every step...thank you.

All of my co-workers at all of my jobs - Putting up with me and my challenging schedule was no easy feat; however, your understanding, flexibility, kindness and encouragement helped to get me through. Thank you for loving this journey for me.

Everyone who I met with along the way - I am grateful to the many individuals who spent time with me over the last several years to guide my efforts, thoughts, perspectives, and approach. In ways big and small, you helped me to get here, and for that, I thank you.

CCM PhD workgroup - Though we have only known each other a short time, I cannot imagine getting through these last few months without you. I feel like I was on mile 23 of the marathon, and this core group were the friends who jumped into the race to get me to the end. I am appreciative to each and every one of you, and am looking forward to starting that consulting agency!

My fellow HS\&P students - I am deeply appreciative for the encouragement and support you provided through each stage of this journey, and for our text strings full of 
GIFs and puppy pictures; our friendships will last a lifetime. I am so excited to see all the "good trouble" we get into as we spread our wings and change the world.

Hummingbirds - Speaking of wings, I need to thank the visiting hummingbirds who make it a point to stop by my window each day for a sip of sugary nectar. Some may consider it a friendship based on bribery, but I would like to think that each one of you stopped by to make sure I am okay and to give me a little something to smile about.

Pandemic - There is no way I could have finished my dissertation without the pandemic forcing me to stay home, so in the weirdest twist of fate, thank you COVID-19. Not sure I would have got this done without it!

Oh... and hey Georgie...I really have grad-u-ated! 


\section{Table of Contents}

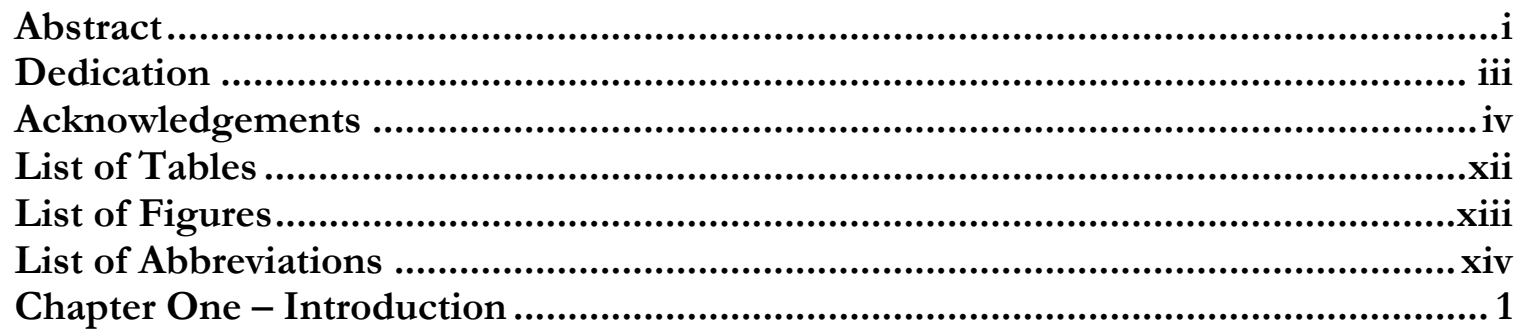

Web of Influence Surrounding Schools and Children ............................................................2

The Link Between Education and Health ............................................................................. 5

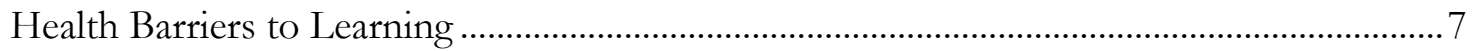

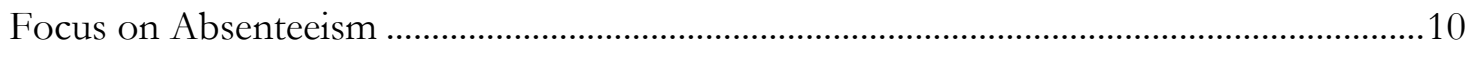

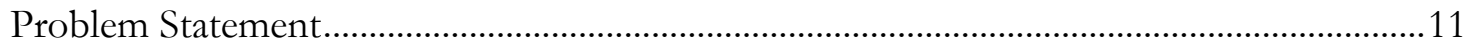

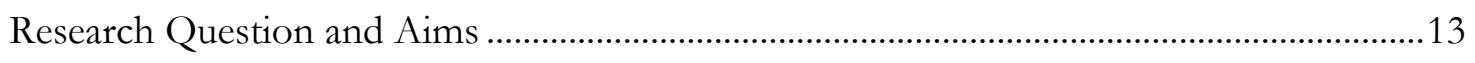

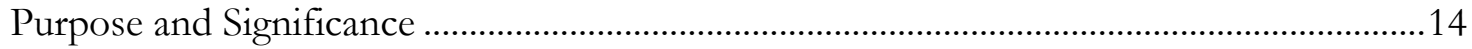

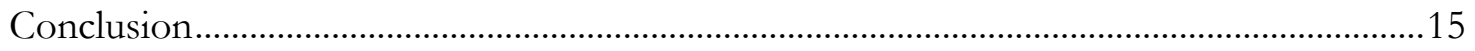

Chapter Two - Review of Related Literature ......................................................... 16

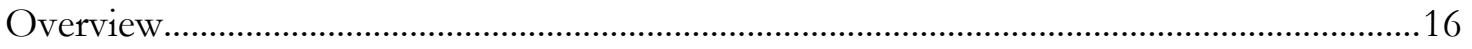

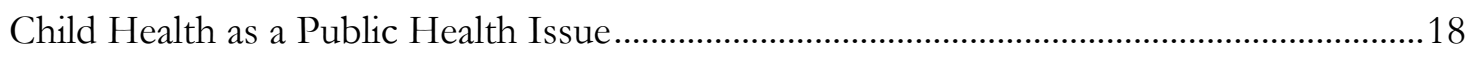

Relationship Between Health and Education ........................................................................19

Schools as a Leverage Point for Child Development .............................................................24

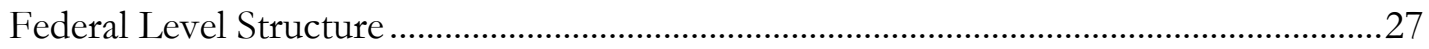

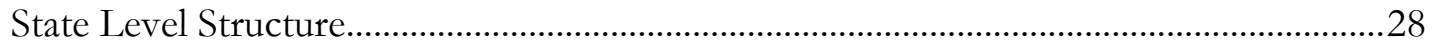

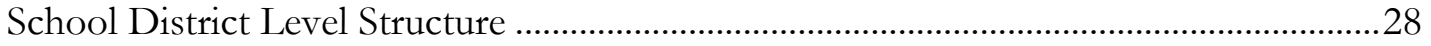

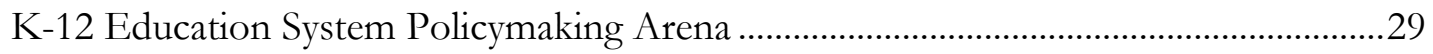

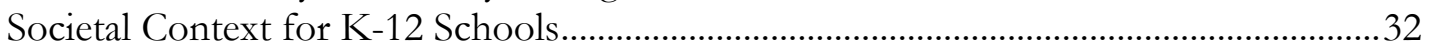

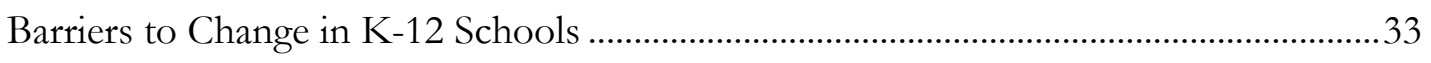

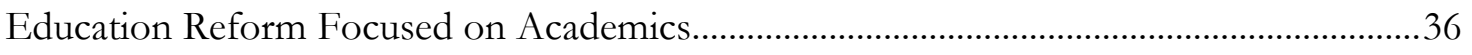

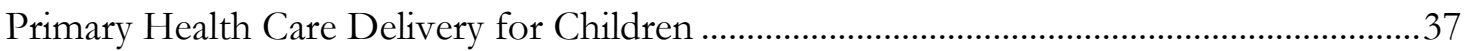

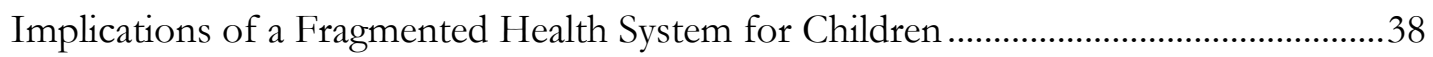

Primary Care Utilization and Movement to Medical Homes ...............................................39

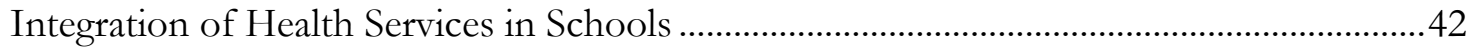

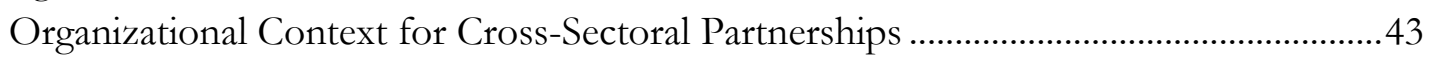

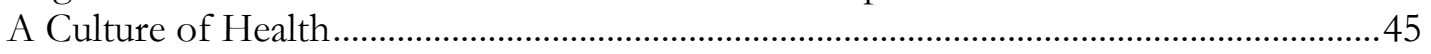

History of School-Based Health Services Delivery .................................................................. 46

Centers for Disease Control and Prevention's School Health Services Model ................50 
Whole School, Whole Community, Whole Child Model.............................................................52

U.S. Government's Study of School Health ..........................................................................57

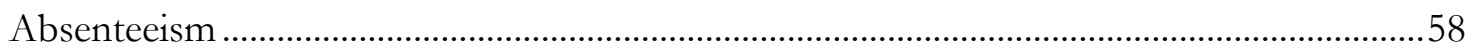

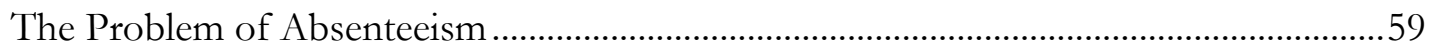

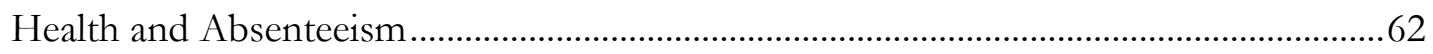

American Academy of Pediatrics Policy Statement on Health and Absenteeism ...........62

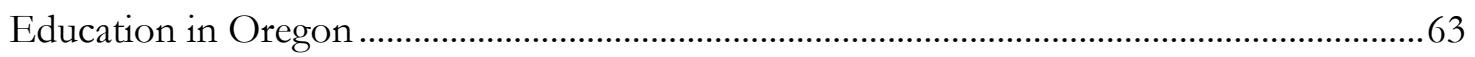

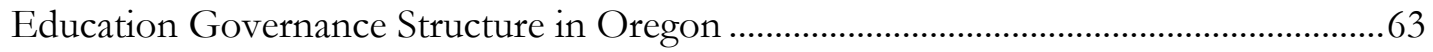

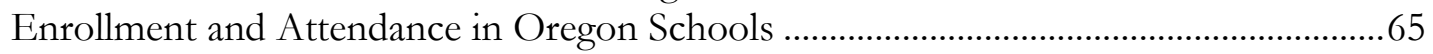

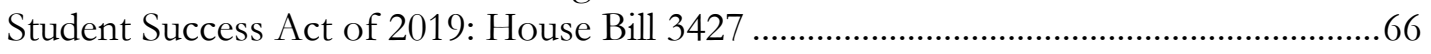

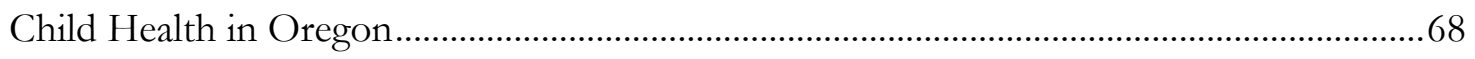

Oregon's School-Based Health Services Variation and Chronic Absenteeism .....................71

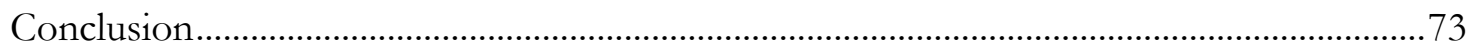

Chapter Three - Design, Methodology and Initial Findings .................................. 75

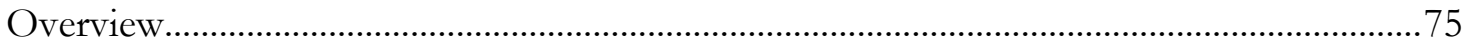

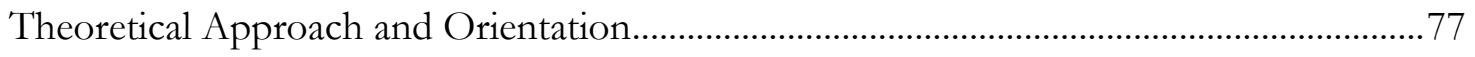

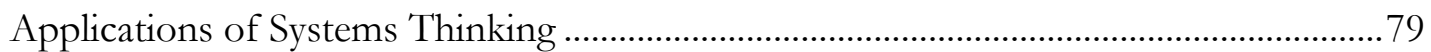

Research Approach: Configurational Comparative Methods and Regularity Theory ....80

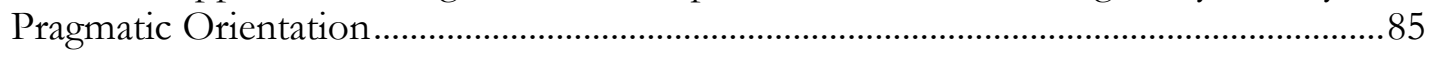

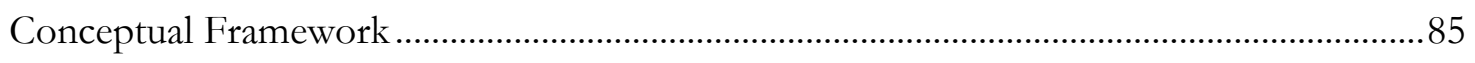

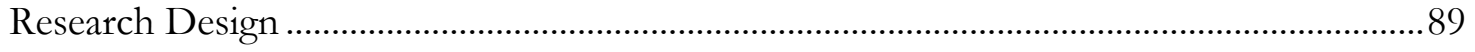

Secondary Data Collection and Case Selection .....................................................................90

Secondary Data File............................................................................................................ 90

School-Based Health Services Secondary Data Source …....................................................92

Case Selection Rationale and Initial Exclusion Criteria ...................................................... 94

Coincidence Analysis .............................................................................................................96

Step 1: Define, Operationalize and Calibrate the Outcome of Interest.............................97

Step 2: Perform Initial Data Reduction and Calibration to Create Data Matrix ............. 98

Step 3: Identify Initial Key Factors Through Condition Table Creation..........................100

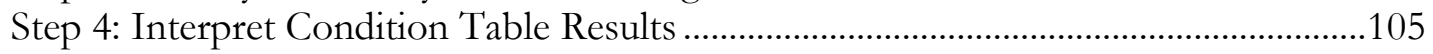

Step 5: Create Final Data Set for Model Development .......................................................108

Step 6: Perform Coincidence Analysis Using the cna Package in R...............................111

Step 7: Interpret Results ...................................................................................................112

General Observations About Positive and Negative Outcome Findings.........................116

Protection of Human Participants .........................................................................................117

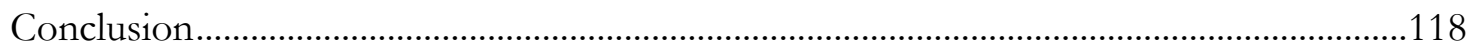

Chapter Four - Discussion ..................................................................................120 
Overview.

Aim One: Unique Categorization of Structures and Systems of School-Based Health

Services Delivery

Aim Two: Elements Affecting Health Services Availability, Delivery, and Quality ..........125

Structural Elements: Features of the Secondary School System ....................................128

Process Elements: Features of School-Based Health Services Delivery ..........................133

Inclusion of Factors in Association with Higher or Lower Absenteeism .......................136

Absence of Factors in Association with Higher or Lower Absenteeism.........................139

Aim Three: Configurations of Conditions That Contribute to Absenteeism.......................140

Key Dimensions of Configurational Comparative Methods in This Research .............141

Schools with 20\% or More Students Chronically Absent.................................................143

Schools with Less Than 20\% Students Chronically Absent .............................................144

Conditions Linked to Higher and Lower Student Absenteeism .........................................146

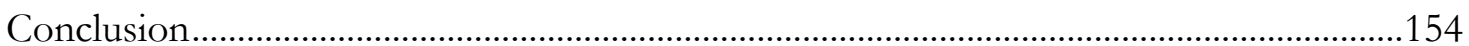

Chapter Five - Recommendations and Conclusions ............................................155

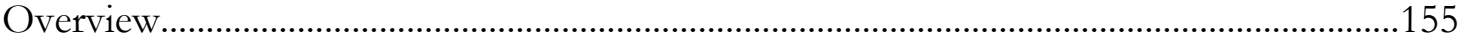

Implications of the Current Social Context ……...................................................................156

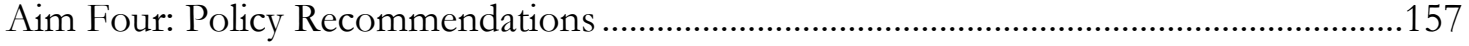

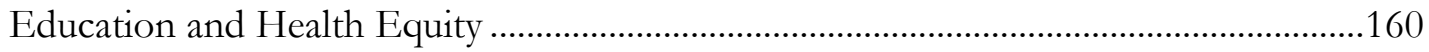

Recommendations for Federal Governmental Agencies .................................................161

Recommendations for State-Level Governmental Agencies ..............................................165

Regional Partnerships Among Social Service Agencies, the Oregon Health Authority and the Oregon Department of Education .....................................................................168

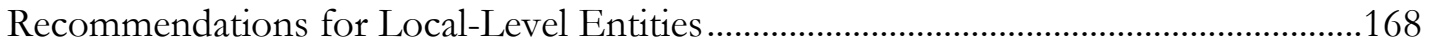

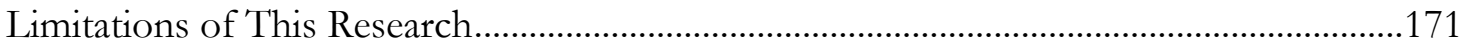

Limitations as a Result of the COVID-19 Pandemic .........................................................171

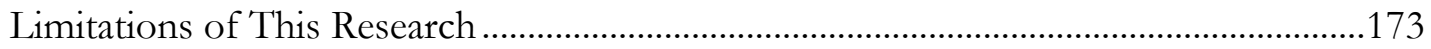

Limitations of Configurational Comparative Methods.......................................................174

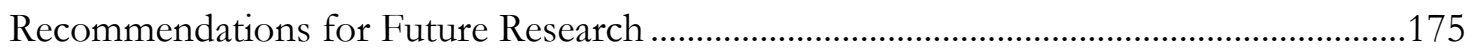

Unblind the Data for a More In-Depth Analysis .............................................................176

Replicate the Analysis with Inclusion of Other Endogenous Factors or Cases .............176

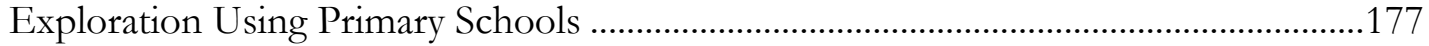

In-Depth Analysis of Schools at the Absenteeism Extremes.............................................178

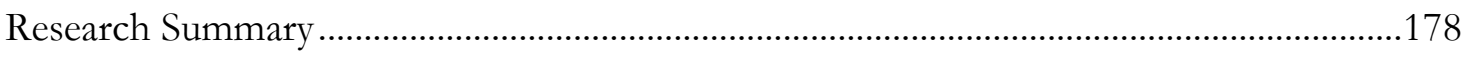

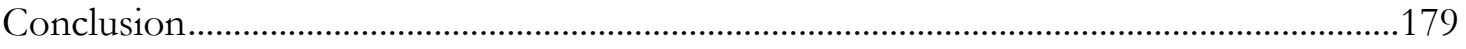

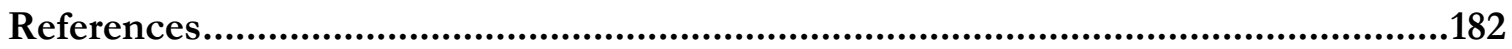

Appendix A: Data File Mock-Up ......................................................................216

Appendix B: Variables, Data Sources and Citations .................................................217

Appendix C: Oregon Health Authority Data Use Agreement .................................218 
Appendix D: Questions From 2018 School Health Profiles Surveys......................... 220

Questions From the 2018 SHPS School Principal Questionnaire ....................................220

Questions From the 2018 SHPS Lead Health Education Teacher Questionnaire .......225

Appendix E: Calibration for Assignment of Set Membership Scores ...................... 226

Appendix E: Negative Outcome Models ........................................................... 230

Appendix F: Positive Outcome Dataset with Solution Pathways and Model ...........231

Appendix G: Negative Outcome Dataset with Solution Pathways and Model ........ 234

Appendix H: Institutional Review Board Exemption Certificate............................. 237 


\section{List of Tables}

Table 2.1. Children's Health Insurance Coverage by Type in Oregon.....................................69

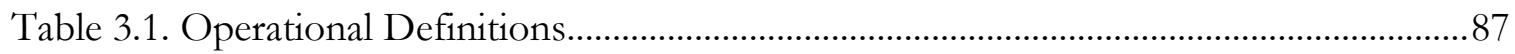

Table 3.2. Features of Secondary Schools Data by Exclusion Criteria ..................................... 95

Table 3.3. Candidate Factors for Positive Outcome Preliminary Model Iteration..................105

Table 3.4. Factors for Final Model Development for the Positive Outcome $(\mathrm{O}=1)$............106

Table 3.5. Candidate Factors for Negative Outcome Preliminary Model Iteration ................107

Table 3.6. Factors for Final Model Development for the Negative Outcome $(\mathrm{O}=0) \ldots \ldots . . . . .108$

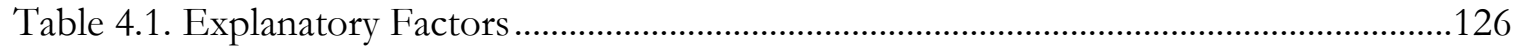

Table 4.2. Summary of Factors Included in Final Model Development..................................138

Table 4.3. Elements Attributed to Higher and Lower Chronic Absenteeism..........................147 


\section{List of Figures}

Figure 1.1. Educationally Relevant Health Disparities Mapped to Causal Pathways That Affect Educational Outcomes

Figure 1.2. Health Barriers to Learning and Causal Pathways That Affect Educational

Outcomes

Figure 1.3. School-Based Health Services as Mediator Between Health Barriers to Learning and Causal Pathways That Affect Educational Outcomes

Figure 2.1. Educationally Relevant Health Disparities Mapped to Causal Pathways That

Affect Educational Outcomes

Figure 2.2. Health Barriers to Learning and Causal Pathways That Affect Educational Outcomes

Figure 2.3. U.S. System for K-12 Educational Governance and Responsibility.......................26

Figure 2.4. Seven Key Elements of the Pediatric Medical Home .................................................41

Figure 2.5. School Health Services Model .....................................................................................50

Figure 2.6. Coordinated School Health Model ...............................................................................53

Figure 2.7. Whole School, Whole Community, Whole Child Conceptual Model.....................56

Figure 2.8. Structure, Process, Outcome Framework for Secondary Schools, School-Based

Health Services Delivery, and Education and Health Outcomes ................................................73

Figure 3.1. Structure, Process, Outcome Framework for Secondary Schools, School-Based

Health Services Delivery, and Education and Health Outcomes ................................................76

Figure 3.2. Focused Structure, Process, Outcome Framework for This Research ..................86

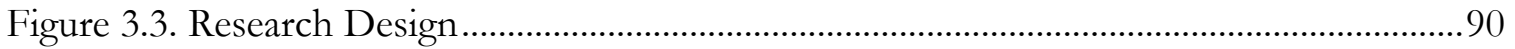

Figure 3.4. Excerpt from Data Matrix ........................................................................................ 100

Figure 3.5. Condition Table for Positive Outcome $(\mathrm{O}=1)$.........................................................103

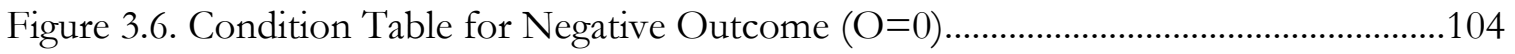

Figure 3.7. Data Reduction and Factor Selection ...................................................................... 110

Figure 3.8. Positive Outcome Solution Model with Solution Pathways ..................................113

Figure 3.9. Negative Outcome Solution Model with Solution Pathways..................................115

Figure 4.1. Focused Structure, Process, Outcome Framework for This Research ................124

Figure 4.2. Solution Pathways Attributed to Higher Student Absenteeism .............................143

Figure 4.3. Solution Pathways Attributed to Lower Student Absenteeism ..............................145 


\section{List of Abbreviations}

AAP American Academy of Pediatrics

AHRQ Agency for Healthcare Research and Quality

AMA American Medical Association

ASCD Formerly known as the Association for Supervision and Curriculum Development

CCO Coordinated care organization

CCM Configurational comparative method

CDC Centers for Disease Control and Prevention

CNA Coincidence analysis

$\mathrm{CSH} \quad$ Comprehensive school health

DASH Division of Adolescent and School Health

ESD Education service district

FTE Full-time equivalent

HASP Higher absenteeism solution pathway

HBL Health barrier to learning

HIV Human immunodeficiency virus

HPV Human papillomavirus

ID Identification

INUS Insufficient but Necessary parts of a configuration that is itself Unnecessary but Sufficient

IRB Institutional Review Board

K-12 Kindergarten through Grade 12

LASP Lower absenteeism solution pathway

NEA National Education Association

ODE Oregon Department of Education

OHA Oregon Health Authority

PCMH Patient-centered medical home

PCPCH Patient-centered primary care home

PISA Programme for International Student Assessment

QCA Qualitative comparative analysis

SBHC School-based health center 
SBHS School-based health services

$\mathrm{SDH} \quad$ Social determinants of health

SHPPS School Health Policies and Practices Study

SHPS School Health Profiles

SIA Student Investment Account

SSA Student Success Act

STD Sexually transmitted disease

Title 1-A Title 1, Part A of the Elementary and Secondary Education Act of 1965

WC Whole Child

WSCC Whole School, Whole Community, and Whole Child

YRBSS Youth Risk Behavior Surveillance System 


\section{Chapter One - Introduction}

"Schools are the only institution that touches all our youths that we can wholly influence. We cannot regulate parenthood. We cannot desegregate neighborhoods. We cannot regulate the media. Yet we can use schools to create possibilities and environments that would not otherwise exist for our children" (Yogan, 2000, p. 120).

Children's mental and physical health experiences can predict their health status in adolescence and adulthood - healthy adults develop from healthy children (Braveman \& Barclay, 2009; Ferguson et al., 2009; Repetti et al., 2002; Van Lerberghe et al., 2005). Illnesses experienced in childhood affect critical aspects of development, including cognition and intellectual performance, (Wadsworth, 1999). Children who are healthy become adults who are healthy, adults who are healthy create families who are healthy, and families who are healthy produce children who are healthy; health is cultivated across lifetimes and generations (Braveman \& Barclay, 2009; Halfon et al., 2014). Human capital - "the knowledge, skills, competencies, and attributes that allow people to contribute to their personal and social well-being" - is significant for the economic and social development of communities and for the countries in which people live (Keeley, 2007, p. 3); the formation of human capital has healthy children at its core (Van Lerberghe et al., 2005). As stated by Wadsworth (1999), "Child health is of the greatest importance for the future of health of a nation, not only because today's children grow up to become the next generation of parents and workers, but also because...early life health is, for each child, the basis of health in adult life" (p. 44). 


\section{Web of Influence Surrounding Schools and Children}

As young people grow into adulthood they are surrounded by a complex web of peer, familial, community, societal, and cultural influences (Ferguson et al., 2009; Viner et al., 2012). The complexity of that web can be simplified to focus on certain individual and environmental factors that disproportionately influence health outcomes (Grzywacz \& Fuqua, 2000). With consideration for children as students in educational systems, these factors function as opportunistic leverage points; for those seeking to address student health, learning, and overall well-being, these leverage points provide spaces for focused attention, action, and efforts (Grzywacz \& Fuqua, 2000). Just as various aspects of the workplace can be used to influence adult health, schools operate as an important focal point for addressing the psychosocial and physical environment which surrounds child health (Grzywacz \& Fuqua, 2000).

As the organizational entity with the most sustained and ongoing contact with children outside of the family setting, schools provide a convenient, critical, and accessible organizational context for the implementation and operationalization of policies and programs designed to improve the lives of children (Richardson, 2007; Smrekar, 1998). In Fall 2018, approximately 56.6 million students attended kindergarten through Grade 12 (K12) schools in the United States, with almost $90 \%$ of those students enrolled in public schools (National Center for Education Statistics, n.d.). Public schools provide a logical physical and social location for addressing the needs of children, especially those who are most at-risk, as they not only serve as a center for learning and a place for focused efforts to address, improve and rebuild the problems of society (B. C. Fusarelli \& Lindle, 2011; Smrekar, 1998). 
Increasing organizational and professional demands on educators and administrators within schools, along with decreased funding, have dramatically affected the teaching and learning environment (L. D. Fusarelli \& Fusarelli, 2015). Class sizes are larger and reporting standards are more time-intensive; teachers face increased demands for their time and attention (Darling-Hammond, 2010; Goldstein, 2014; Sacks, 2007). In addition, federal and state reform efforts have increasingly emphasized academically focused achievement standards and approaches, including programs designed to shape teacher preparation, educational standards, and instructional practices; these demands on time, effort and energy essentially force teachers to create curricula that "teach to the test" (Darling-Hammond, 2010; Goldstein, 2014; Michael et al., 2015; Sacks, 2007). The combination of the organizational environment and the occupational pressures experienced by teachers creates circumstances that can appear discouraging, if not insurmountable.

This educational landscape sits in a societal context where racial and ethnic discrimination, the effects of poverty, and inequitable resource distribution permeate teachers' and school administrators' abilities to deliver on their professional commitment to educate children. Differences in educational attainment between white students and students of color continue to be profound and persistent. "In 2012, nationwide, 19\% of students (1 in 5) did not graduate on time; the percentage is higher for Hispanic (24\%) and Black (32\%) students" (Michael et al., 2015, p. 740). In addition to the racial divide in student academic outcomes, the academic achievement gap between high- and low-income families has widened in recent years; "The achievement gap between children from high- and lowincome families is roughly 30 to 40 percent larger among children born in 2001 than among those born twenty-five years earlier" (Reardon, 2011, p. 93). 
With teachers' occupational pressures related to academic benchmarks and an everwidening achievement gap as a backdrop, the United States continues to perform poorly when compared to other industrialized nations in student achievement in the core subject areas of reading, math, and science (Michael et al., 2015). Every three years, the Programme for International Student Assessment (PISA) tests 15-year-old students around the world in the core subjects of reading, math, and science (Organisation for Economic Co-operation and Development, n.d.). Although not without its criticisms as a predominantly economic tool used to "blame and shame school systems" rather than one used to measure, compare, and rank national education systems, PISA is widely used as a means for comparing student academic achievement, and identifying best practices globally (Andrews et al., 2014; Niyozov \& Hughes, 2019). According to PISA’s 2018 assessment, the United States spends more money than other countries on education, yet, ranks $13^{\text {th }}$ in reading, $36^{\text {th }}$ in math, and $18^{\text {th }}$ in science (Schleicher, 2019). Based on student academic performance and the resources allocated toward the education system, Basch (2011d) acknowledges that "the status quo does not bode well for the economic security and quality of life of future generations or for maintaining the vitality of American democracy" (p. 650).

In the last quarter-century, the benchmark for schools and the focus for federal education policy has continued to emphasize student outcomes, evidenced in President George W. Bush's No Child Left Behind Act of 2001 (No Child Left Bebind Act of 2001, 2002) and President Obama's signature education program, Race to the Top (U.S. Department of Education, 2009). These federal-level educational reform efforts placed an increased focus on student academic performance and continued to tie test scores, graduation rates, and other educational outcomes to federal funding and resource allocation based on school 
benchmark achievement (Darling-Hammond, 2010; L. D. Fusarelli \& Fusarelli, 2015; Goldstein, 2014; Richardson, 2007; Sacks, 2007). Although these reform efforts were intended to improve student learning and to hold schools accountable, only minimal improvements in academic achievement have been measured (Basch, 2011d; Michael et al., 2015).

Compounding these challenges, educational reform often occurs in the absence of the provision of social supports for children and their families, such as stable parental employment, and the provision of appropriate health care, affordable housing, and/or childcare for families (Goldstein, 2014). The presence of these social supports allow for both teaching and learning to be more effective by enhancing students' motivation and ability to learn. Given that recent educational reform efforts have been largely ineffective with minimal overall academic improvements, a focus on different approaches to improve student outcomes may be needed.

\section{The Link Between Education and Health}

The intricate relationship between health and education is widely discussed in the literature, with numerous studies demonstrating that childhood health influences a student's ability to learn and that years of completed formal schooling are a powerful correlate of good health in adulthood (Basch, 2011d; Gracy et al., 2018; Grossman, 2008; Kawachi et al., 2010; Michael et al., 2015). Academic achievement and educational attainment are critical determinants of health at every stage in life; disparities in education levels contribute to disparities in health and vice versa (Fiscella \& Kitzman, 2009). Despite the strong, recognized connection between the two, federal, state, and local policies often treat health 
and education as separate domains to be addressed independently (Fiscella \& Kitzman, 2009).

Recent efforts have sought to shift that view, including the Whole School, Whole Community, and Whole Child framework which is designed to encourage the health and education sectors to partner and leverage their resources (Michael et al., 2015). Integrative, cross-sectoral approaches to policymaking, program design and implementation, and strategic interventions may address child health, student achievement, and adult health in a multiplicative fashion. Healthy students are better learners, and better learners are more equipped to succeed academically and become healthy members of the adult workforce (Basch, 2011e; Bradley \& Greene, 2013; Michael et al., 2015).

Despite this increased awareness of the need for integrative approaches that more directly link health and education, schools tend to shift time away from student health and well-being primarily due to: 1) increased pressure to focus on academic core subject areas (i.e., the aforementioned "teaching to the test"); and 2) concern that time spent on student health and well-being takes time away from educational achievement activities (Bonell et al., 2014; Humphrey et al., 2013). A false narrative exists whereby academics and student health and well-being occur within a "zero-sum game," such that when one area wins, the other must lose (i.e., class time spent on social and emotional learning takes away from time dedicated to math, science or reading).

Conversely, schools in other parts of the world (such as Finland, Sweden, Australia, and Singapore) place a broader emphasis on the holistic development of students as people; this is largely due to their views on student health and well-being, as well as each country's different approaches to social policy and safety nets (Bonell et al., 2014). Personal, social, 
and health education are provided in specific lessons or integrated into academic learning, and these focused efforts are designed to intentionally support and promote students' overall well-being and health (Bonell et al., 2014). These countries have higher levels of academic attainment than the United States, suggesting that the investment in students' academics, social well-being, and mental and physical health can be synergistically beneficial, such that the investment in one is not a detraction from the other (Bonell et al., 2014). Rather than separating health and education, the two areas of focus are purposefully combined with the recognition that improvements in one are likely to lead to improvements in the other.

\section{Health Barriers to Learning}

Myriad childhood health conditions exist; however, some are likely to be more influential on a child's motivation and ability to learn than others. Health-related problems that are untreated and unmanaged can diminish a student's ability to learn and succeed; these conditions have been described as "health barriers to learning" (HBLs; Gracy et al., 2017, 2018). Students' poor health behaviors (such as poor nutrition and lack of physical activity) and health problems (such as poorly controlled asthma and vision impairments) can be linked to educational outcomes through specific causal pathways and mechanisms (Basch, 2011e; Michael et al., 2015).

Described in his work as "educationally relevant health disparities," Basch (2011e) identified seven strategic areas of focus for programmatic, school-based interventions: aggression and violence, asthma, breakfast consumption, inattention and hyperactivity, physical activity, teen pregnancy, and vision. Basch (2011e) described five causal pathways through which each of these health disparities affects a child's motivation and ability to 
learn: absenteeism, cognition, dropping out, school connectedness and engagement, and sensory perception. As shown in Figure 1.1, each of the seven different health disparities can be linked to one or more causal pathways, potentially leading to poor educational outcomes (Basch, 2011e).

\section{Figure 1.1. Educationally Relevant Health Disparities Mapped to Causal Pathways} That Affect Educational Outcomes

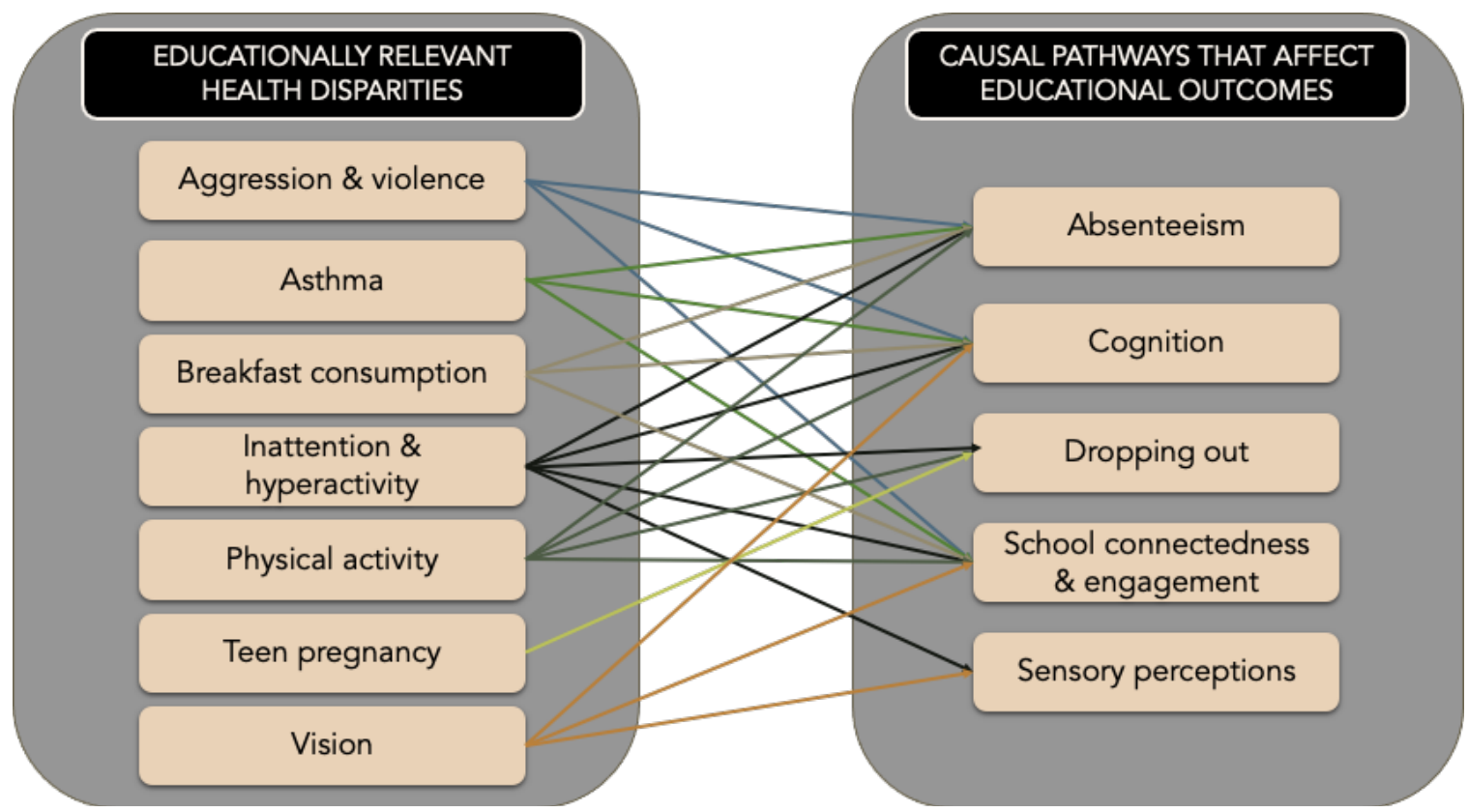

(Adapted from Basch, 2011a, 2011b, 2011c, 2011f, 2011g, 2011h, 2011i)

Basch identified the seven educationally relevant health disparities based upon their ability in negatively affecting the lives of youth, the evidence of their causal effect on educational outcomes, and their potential to be feasibly addressed through school-based programs and policies (Basch, 2011e). Beyond Basch's work in identifying these factors, a number of other health behaviors and issues have been discussed in the literature which also have a demonstrated effect on student educational performance, including drug and alcohol use, hearing problems, hunger, lead exposure, mental health disorders, oral health, and risky 
sexual behaviors (Bersamin et al., 2016; Busch et al., 2014). Broadening the focus from what Basch has termed "educationally relevant health disparities" to HBLs allows for a comprehensive understanding of the potential influence these health-related conditions and issues can have on a student's ability to learn (Dilley, 2009; Gracy et al., 2018). The relationship between HBLs and causal pathways that affect educational outcomes is illustrated in Figure 1.2.

\section{Figure 1.2. Health Barriers to Learning and Causal Pathways That Affect Educational Outcomes}

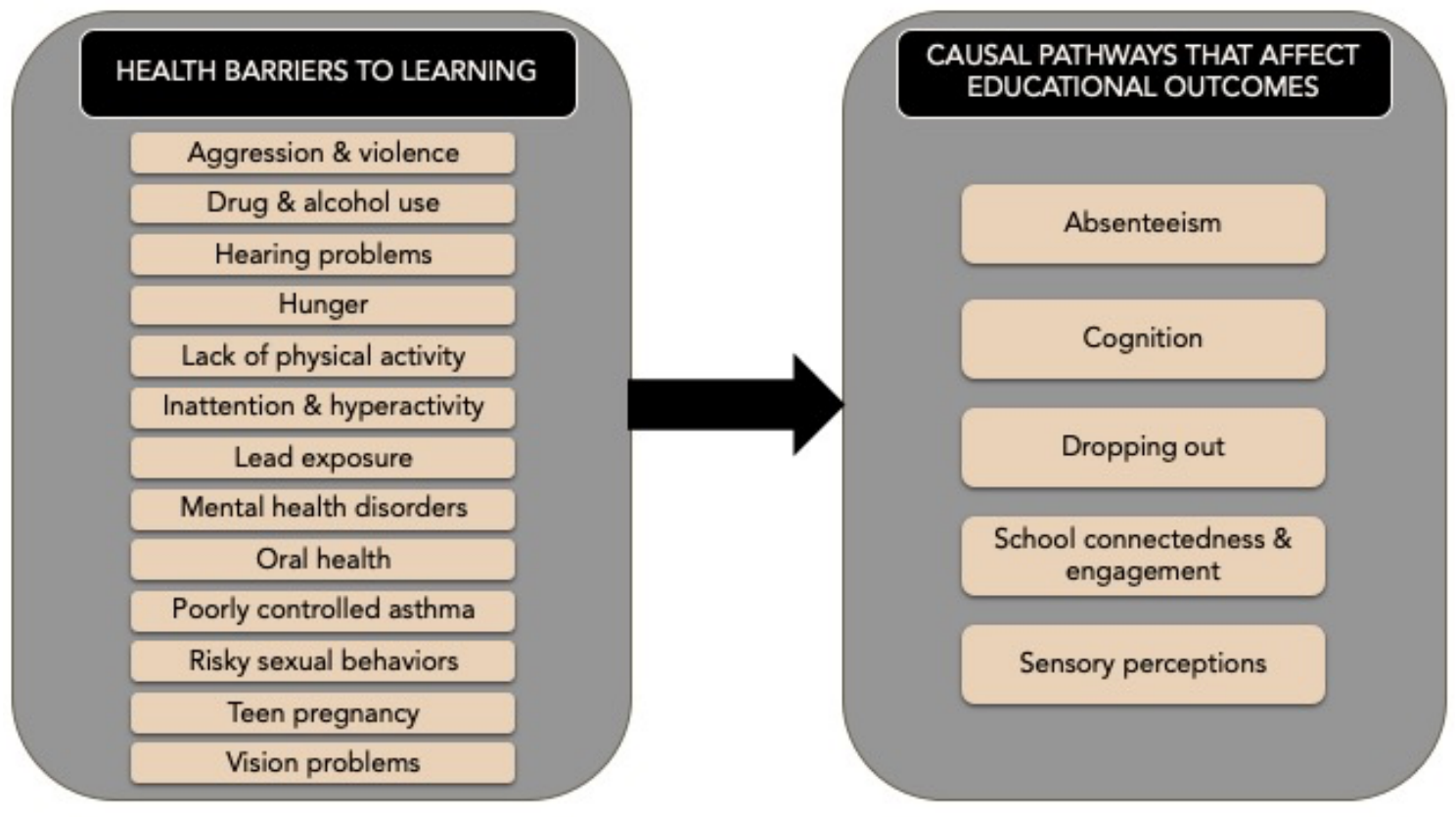

Helping students be healthier, motivated learners sets them up for academic achievement and long-term success. Educators and health professionals have an opportunity to change the trajectory of the lives of students with poor health by addressing HBLs, ultimately improving educational outcomes, individual well-being, and community health. Focusing on HBLs may be a better approach for reforms designed to affect the academic achievement gap, as opposed to those that solely address more strictly defined educational 
activities (Basch, 2011e; Gracy et al., 2018; Michael et al., 2015). Despite the understanding of the link between health and education, strategies intended to address HBLs have not been widely employed to date by those involved in educational reform as a means of change (Basch, 2011d).

Although health and education have a synergistic relationship, it is important to not lump "health problems" together to be solely addressed by the school system using a single approach. Instead, evidence from the literature advocates for educators and health professionals to recognize and act on multiple, specific health barriers that can affect a student's ability to learn, with attention paid to the causal mechanisms by which those health problems affect academic outcomes (Basch, 2011e; Bradley \& Greene, 2013; Dilley, 2009; Gracy et al., 2018; Michael et al., 2015). The provision of school-based health services (SBHS) designed to address students' HBLs efficiently and comprehensively can strategically reduce the effect those barriers have on critical causal pathways that affect educational outcomes.

\section{Focus on Absenteeism}

Of the causal pathways associated with poor educational outcomes, absenteeism has been identified as a critical factor due to its damaging effect on student performance.

Absenteeism increases the likelihood of poor academic outcomes, exacerbates behavioral and socio-emotional problems in school, and increases the potential for negative behaviors and activities outside of school (Sprick \& Sprick, 2018). The U.S. Department of Education Office for Civil Rights dataset for the 2015-2016 school year (the most recent available) indicates that more than seven million students across the United States (approximately 
$16 \%$, or about one in six) missed 15 days or more of school during a single school year (U.S. Department of Education, 2016a). Although slightly below the benchmark used to identify chronic absence $(10 \%$ of a standard 180-day school year, or 18 days of absence), these data show that many students are missing critical amounts of school (Attendance Works, n.d.; U.S. Department of Education, 2016). Gaps in attendance throughout a student's academic career can significantly affect school performance, which leads to longer-term gaps in achievement and, ultimately, graduation rates (Allison \& Attisha, 2019; Jordan \& Chang, 2015).

Beyond the social and behavioral effects of absenteeism on a child, it is important to recognize that five of the seven educationally relevant health disparities identified by Basch affect educational outcomes through the absenteeism causal mechanism (see Figure 1.1; Basch, 2011e, 2011a, 2011b, 2011c, 2011f, 2011g). Given its widespread effects, chronic absenteeism is a measurable outcome of interest to educators and school administrators, as well as to health professionals.

\section{Problem Statement}

The complex and interrelated health, educational, and social issues faced by children require comprehensive services that are delivered with greater coordination and collaboration (B. C. Fusarelli \& Lindle, 2011; Michael et al., 2015; Smrekar, 1998). SBHS, situated between HBLs and the causal pathways that affect educational outcomes, serve as a leverage point for mitigating the effects that HBLs have by breaking the causal chain that connects them, as demonstrated in Figure 1.3. 


\section{Figure 1.3. School-Based Health Services as Mediator Between Health Barriers to Learning and Causal Pathways That Affect Educational Outcomes}

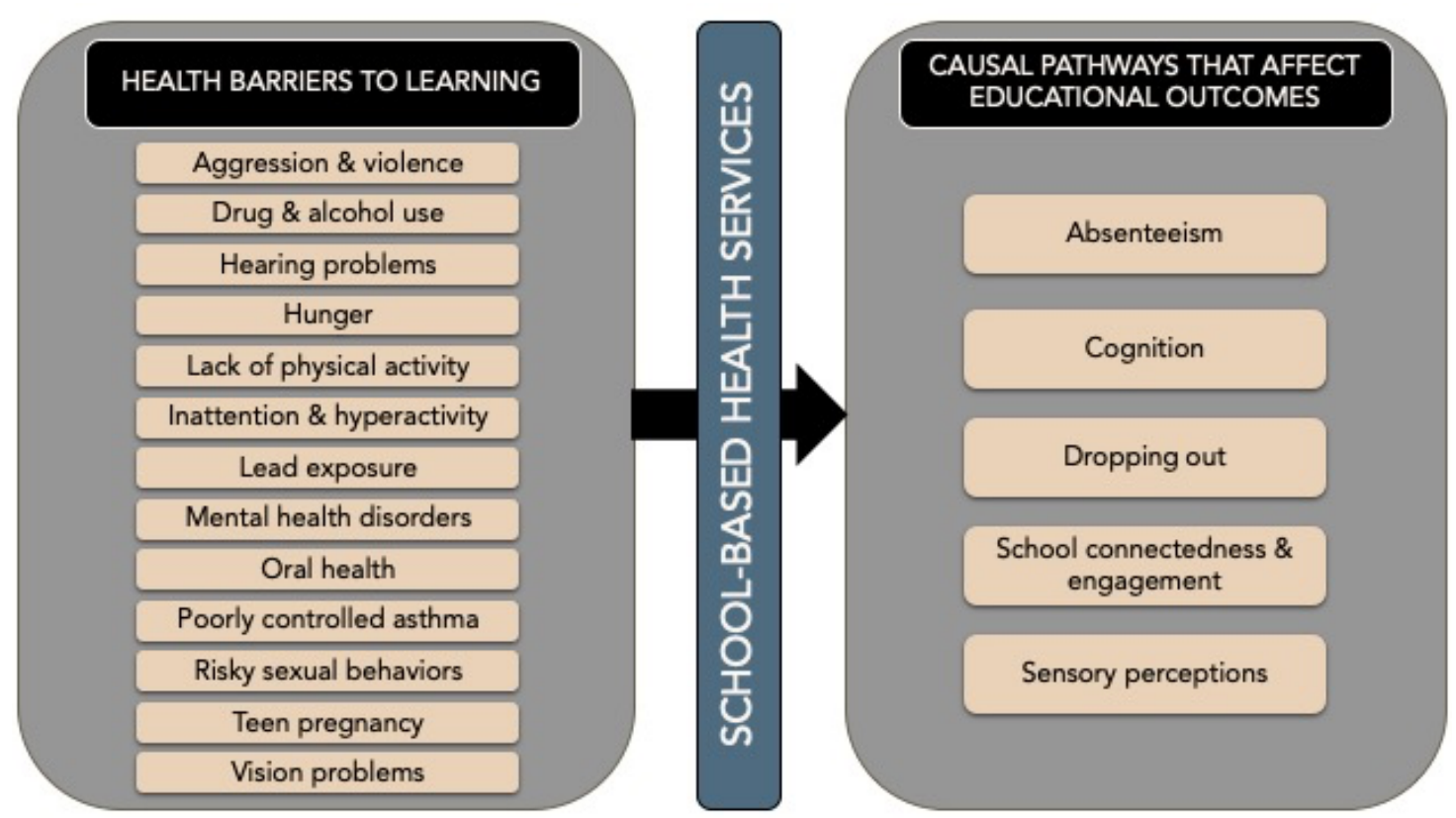

Just as the workplace serves as a focal point for adults, schools play a critical role in

the lives of communities, families, and students, and serve as a prime location for the

provision and delivery of health services (B. C. Fusarelli \& Lindle, 2011). Comprehensive and coordinated SBHS provision may address the many complex, overlapping conditions and issues that contribute to students missing school. Therefore, an examination of SBHS delivery and its effects on absenteeism is warranted and was the focus of this research.

SBHS ranging from the most basic elements of in-school health services provision to comprehensive, integrated school-based health centers (SBHCs), can aid in affecting student health and well-being by addressing risk and protective factors in both the short- and longterm (Albright et al., 2016; Riley et al., 2016). The provision of health services in the educational environment varies widely from school to school and across school districts and jurisdictions. 
Although the literature clearly indicates that linkages between health and education exist, it was important for this research to explore and understand the contexts and structures where those linkages are most likely to occur. There was no comprehensive understanding of SBHS as a means for addressing and mitigating the effects of HBLs on chronic absenteeism prior to this research. Structural, strategic, and policy approaches were explored as options for addressing how HBLs influence student chronic absenteeism.

\section{Research Question and Aims}

This study explored the following: How do elements of school-based health services contribute to the ability of the public secondary school education system to address chronic absenteeism? In addressing this question, the study pursued the following four aims:

1. Create a unique categorization of the structures and systems of school-based health services delivery in Oregon's public secondary schools;

2. Identify elements that potentially influence availability, delivery, and quality of health services in secondary schools in Oregon;

3. Examine and compare configurations of the structural and process elements derived from this understanding of school-based health services delivery that contribute to absenteeism; and

4. Develop policy recommendations that will inform system-level redesign of schoolbased health services and help integrate delivery across education and health services systems.

The proposal for this dissertation was defended in May 2020, slightly more than two months after the COVID-19 pandemic began in the United States. The original data 
collection plan was to distribute a unique survey to all K-12 public schools throughout Oregon, which would have allowed for questions to be tailored to the specific needs of the researcher. With schools in modified operations while attempting to maintain quality education delivery in a virtual, online environment, the data collection strategy was modified to use secondary data from the 2018 administration of the Centers for Disease Control and Prevention's (CDC's) School Health Profiles Survey (SHPS). This modification in data source required a subsequent shift in the research population from all public K-12 schools in Oregon to a subset of secondary public schools in Oregon that responded to the CDC's SHPS administration in 2018. It also required revisions of the research aims to match the focus of this research to the available secondary data.

\section{Purpose and Significance}

The overarching objective of this study was to explore how the structure and delivery of SBHS can aid in mitigating the effects of HBLs, which can lead to chronic absenteeism. This review of the SBHS landscape of Oregon's public middle and high schools provided critical insights into the elements that may influence the availability, delivery, and quality of those services. The focused ability of SBHS to address HBLs as a means for addressing chronic absenteeism has been largely unexplored. Moreover, a comprehensive understanding of the variability in health services delivery has not been fully described. Absenteeism was used as a single proxy measure for the educational outcomes affected by HBLs, as the scope of this dissertation did not allow for the study of multiple outcomes. The recommendations that stem from this research (presented in Chapter Five) can inform future action for how policies intended to address the linkages between health 
and education may be designed, and how education systems might redesign the delivery of health services within the school environment.

\section{Conclusion}

The mutually synergistic effects of education and health are widely known and recognized in the literature (Basch, 2011d; Fiscella \& Kitzman, 2009; Gracy et al., 2018; Grossman, 2008; Kawachi et al., 2010; Michael et al., 2015). Specifically, various HBLs have been identified as creating impediments to a student's motivation and ability to learn (Basch, 2011e; Bradley \& Greene, 2013; Dilley, 2009; Gracy et al., 2018; Michael et al., 2015). These impediments often result in missed days of school that can affect schoolchildren's emotional, academic, and social well-being in the short- and long-term. However, an exploration of the structure and context for the employment of strategies meant to mitigate that connection through health services delivered in the school environment does not exist. A more thorough understanding of the role of SBHSs provided specific recommendations for the future design of health systems and services, as well as for policies that affect both the health and education of students. Chapter Two presents a detailed review of the literature and provides the foundation for this research, Chapter Three discusses the design and methodology that was used in this study, Chapter Four provides a detailed discussion of the study's results and findings, and Chapter Five presents the policy recommendations that stem from this study's findings, a discussion of study limitations, implications for future research, and conclusions. 


\section{Chapter Two - Review of Related Literature}

\section{Overview}

Unaddressed poor health-related behaviors, illness, and chronic disease can affect a student's ability to attend school regularly, leading to more missed days of school. Chronic absenteeism is a major contributor to poor student academic achievement, which has strong implications for outcomes across the life course. As an individual misses more days of school, their education level tends to decrease, which can affect their socioeconomic status and subsequently, their health. The integration of health services in schools may serve as the means by which chronic absenteeism, diminished educational outcomes, and poor health could be addressed.

This study sought to explore the following question: How do elements of schoolbased health services contribute to the ability of the public secondary school education system to address chronic absenteeism? An exploration of the context and structure of how health services embedded in the school environment mitigate the effects that health problems and illness have on a student's ability to attend school regularly may lead to a better understanding of structural, strategic, and policy approaches that are effective.

This chapter opens with an overview of child health as a public health issue, addressing social determinants of health (SDH), the importance of healthy children in the formation of human capital, and how health-related problems can negatively affect human development over the life course. In addition, a discussion of the linkages between health and education is provided. 
A brief review of the U.S. kindergarten through Grade 12 (K-12) educational system provides an understanding of schools and the place they hold as a key leverage point in a child's life. Schools serve as a logical place for addressing problems experienced by children and adolescents, and aid in the healthy development of their mental, physical, and emotional well-being. The review includes a description of the federalist, state-focused heritage of the U.S. K-12 education system, which has created a fragmented, complicated structure with multiple points of oversight, accountability, and responsibility. This review aims to provide insight into the gaps where opportunities exist for health services delivery in schools within that disjointed structure.

Based on the belief that healthier students are better learners, the chapter then provides an exploration of the integration of health services in schools, including how those services aid in addressing various health barriers to learning (HBLs).

The chapter then describes chronic absenteeism as an educationally relevant outcome that can present issues to a child's short- and long-term academic success. The discussion of absenteeism includes an overview of the health-related problems and issues that can contribute to a child's ability to regularly attend school, and how chronic student absenteeism may serve as a signal for interventions provided through school-based health services (SBHS).

This chapter concludes with a discussion of Oregon's current educational structure and policy landscape, as well as mechanisms for health services delivery to Oregon's children. 
This chapter, in its entirety, provides a foundational understanding for why a more complete exploration of the variation in the structures and processes of SBHS is necessary for addressing and mitigating chronic absenteeism.

\section{Child Health as a Public Health Issue}

SDH are "the conditions in which people are born, grow, work, live, and age" (World Health Organization, n.d.). The social environment and its associated SDH, including education, housing, transportation, access to food, social supports, and employment, are considered to be largely responsible for the differences in health status observed and experienced within and between countries (Marmot, 1999; World Health Organization, n.d.). Many public health activities, strategies, and interventions work to address SDH as a means of improving health equity. Human capital is defined as "the knowledge, skills, competencies, and attributes that allow people to contribute to their personal and social well-being" (Keeley, 2007, p. 3); improving the economic and social circumstances for people and the countries in which they live depend on the cultivation of human capital. SDH and the development of human capital should be addressed in tandem, as the economic and social development of communities, cities, states, and countries largely depends on the ability of individuals, most specifically children, within those areas to fully cultivate and foster their personal and collective potential (Grzywacz \& Fuqua, 2000; Halfon et al., 2014; Van Lerberghe et al., 2005; Wadsworth, 1999).

The formation of human capital has healthy children at its core (Van Lerberghe et al., 2005). The mental, physical, and emotional experiences of children, which are largely shaped by SDH, can predict their health status through adolescence and into adulthood; 
healthy adults develop from healthy children (Bartley et al., 1999; Braveman \& Barclay, 2009; Egerter et al., 2011; Ferguson et al., 2009; Van Lerberghe et al., 2005). Moreover, health is cultivated across lifetimes and generations, with SDH and the physical environment creating opportunities (or not) which can influence health (Braveman \& Barclay, 2009; Halfon et al., 2014). Wadsworth (1999) summarizes the importance of child development at the center of the cultivation of human capital: "Child health is of the greatest importance for the future of health of a nation, not only because today's children grow up to become the next generation of parents and workers, but also because ... early life health is, for each child, the basis of health in adult life" (p. 44). Improvements in SDH and human capital lead to long-term economic benefits not only for individuals, but also for families, communities, and countries (Van Lerberghe et al., 2005).

\section{Relationship Between Health and Education}

The intricate relationship between health and education is widely discussed in the literature as having a bidirectional relationship; numerous studies demonstrate that childhood health influences a student's ability to learn (health leads to education), and that increased years of completed schooling are a powerful correlate of good health in adulthood (education leads to health; Basch, 2011d; Cutler \& Lleras-Muney, 2006; Glymour et al., 2014; Gracy et al., 2018; Grossman, 2008; Jackson, 2015; Kawachi et al., 2010; Michael et al., 2015). Throughout the life course, the relationship between health and education is reciprocal, with advantages (and disadvantages) cumulatively contributing to each (Fiscella \& Kitzman, 2009). 
Educational attainment is a critical determinant of health at every stage in life, and health can have a significant influence on an individual's ability to achieve academic success (Braveman \& Barclay, 2009; Fiscella \& Kitzman, 2009). Illness experienced in childhood influences various aspects of a child's development, including cognition and intellectual performance, which can negatively affect a child's ability to succeed in school (Wadsworth, 1999). The relationship between health and academic achievement emerges very early in life, and persists across the life course (Jackson, 2015). More years of education allow an individual to secure a better job, have improved access to health insurance, and earn higher wages; in general, individuals who are well educated have an increased number of resources from which to draw (Cutler \& Lleras-Muney, 2010; Fischer, 2017; Virginia Commonwealth University Center on Society and Health, 2014). Not only is education largely related to income-earning potential and occupation choice, but increased education levels have been shown to lead to improved critical thinking skills and decision-making patterns (Cutler \& Lleras-Muney, 2006; Glymour et al., 2014). Less engagement in risky health behaviors during adolescence leads to higher achievement later in life, and earlier academic achievement during the same periods leads to fewer risky behaviors later in life (Rasberry et al., 2017). Healthier students are better learners, and better learners are more equipped to succeed academically and become healthier members of the adult workforce (Basch, 2011e; Bradley \& Greene, 2013; Michael et al., 2015; Richardson, 2007). As stated previously, healthy children beget healthy adults, healthy adults beget healthy families, and healthy families beget healthy children; the cycle of health and education works across the lifespan.

Children with untreated and unmanaged health-related problems can experience diminished motivation and a decreased ability to learn (Basch, 2011e; Michael et al., 2015). 
Many different childhood health conditions exist, and some are more likely to influence a child's motivation and ability to learn than others. These health-related problems and issues, which have a strong influence on student motivation and learning, have been described as HBLs (Gracy et al., 2017, 2018). The connection between health and learning is further explored below.

Based upon the prevalence of HBLs which can negatively affect the lives of youth, the evidence of their causal impact on educational outcomes, and their potential for being addressed through school-based programs and policies, Basch (2011e) identified seven HBLs (what he refers to as "educationally relevant health disparities"): aggression and violence, asthma, breakfast consumption, inattention and hyperactivity, physical activity, teen pregnancy, and vision. As illustrated in Figure 2.1, each of these educationally relevant health disparities can affect a child's motivation and ability to learn through one or more of the five causal pathways (as described by Basch, 2011e), which can lead to poor educational outcomes: absenteeism, cognition, dropping out, school connectedness and engagement, and sensory perception. 


\section{Figure 2.1. Educationally Relevant Health Disparities Mapped to Causal Pathways That Affect Educational Outcomes}

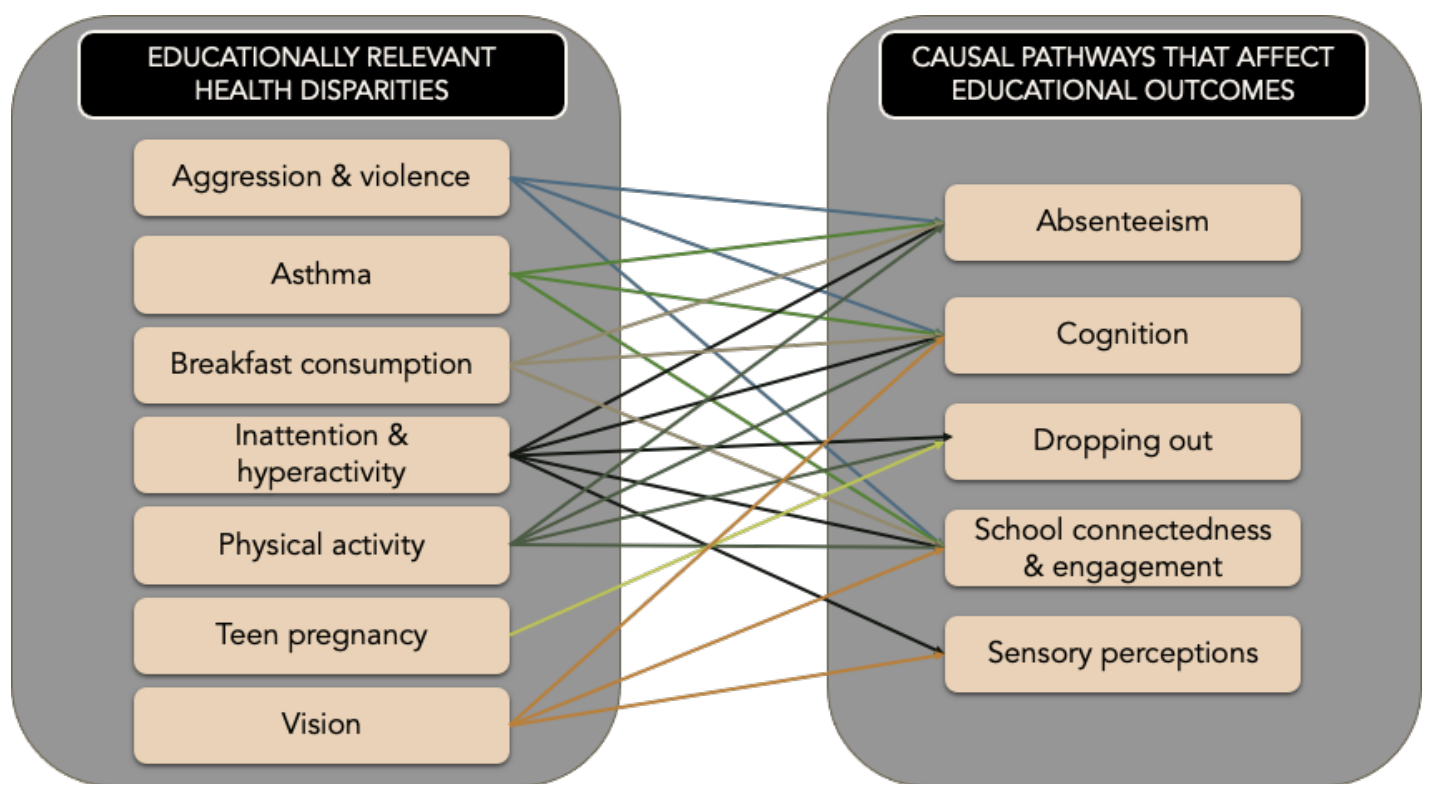

(Adapted from Basch, 2011a, 2011b, 2011c, 2011f, 2011g, 2011h, 2011i)

These causal pathways are largely interrelated. For example, a child who is struggling in school due to cognitive issues may be less likely to feel connected and engaged in school, which may contribute to being at increased risk of missing school or dropping out (Basch, 2011e). Children with more than one of the educationally relevant health disparities are likely to experience a compounding effect on their motivation and ability to learn, which can increasingly affect their educational outcomes in a multiplicative fashion (Basch, 2011e). Of interest, Basch himself never discusses the specific interplay among the different causal pathways, which provides an opportunity for future research.

Beyond Basch's work in identifying these seven HBLs, a number of other healthrelated behaviors and issues have been discussed in the literature that also have a demonstrated effect on student educational performance. These additional HBLs include drug and alcohol use, hearing problems, hunger, lead exposure, mental health disorders, oral 
health, and risky sexual behaviors (Bersamin et al., 2016; Busch et al., 2014; Gracy et al., 2017). Widening the focus from what Basch termed "educationally relevant health disparities" to HBLs allows for a broader understanding of the various health-related conditions, problems and issues that may affect a student's ability to learn (Dilley, 2009; Gracy et al., 2018). Created for this research and built upon the work of Basch (2011e), Bersamin et al. (2016), Busch et al. (2014), and Gracy et al. (2017), the relationship between HBLs and the causal pathways that affect educational outcomes is illustrated in Figure 2.2.

Figure 2.2. Health Barriers to Learning and Causal Pathways That Affect Educational Outcomes

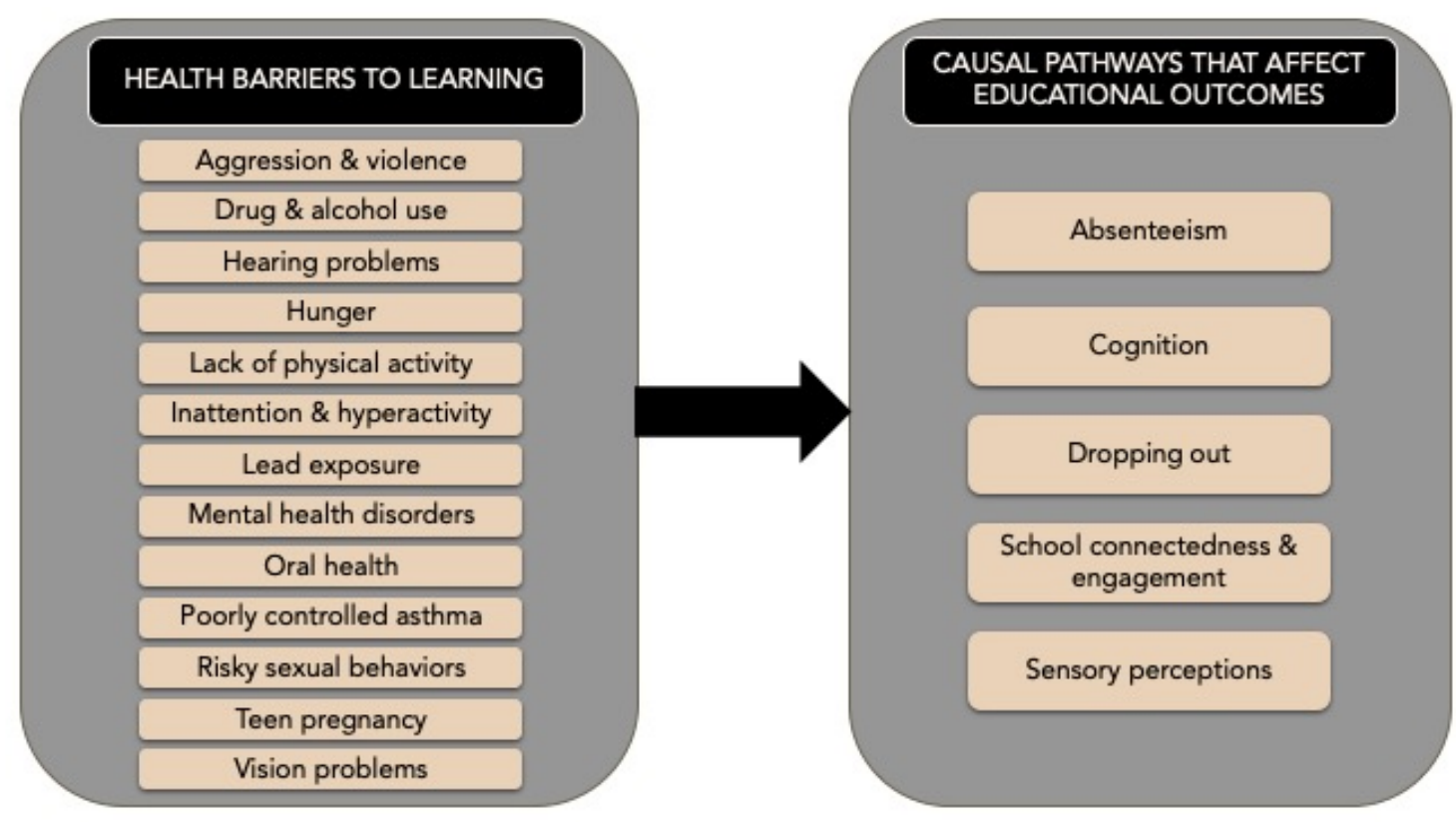

Interrupting the ways in which HBLs negatively affect educational outcomes provides educators and health professionals with an opportunity to help students be healthier in both the short- and long-term. Healthier students are more motivated and able to learn, making them more capable of succeeding academically. Although students come to school with myriad problems that can influence their ability to learn, breaking the 
connection between HBLs and educational outcomes can be a means for changing the trajectory poor health can have on academic success.

\section{Schools as a Leverage Point for Child Development}

A complex web of peer, familial, community, societal, and cultural influences surround young people as they grow into adulthood (Ferguson et al., 2009; Viner et al., 2012). The complexity of that web can be simplified to focus on certain individual and environmental factors that disproportionately influence health outcomes (Grzywacz \& Fuqua, 2000). These factors function as leverage points for those seeking to address student health, learning, and overall well-being, by providing distinct opportunities for focused attention, action, and efforts (Grzywacz \& Fuqua, 2000). Just as the workplace can influence adult health, schools serve as an important, influential leverage point for child health (Grzywacz \& Fuqua, 2000).

Approximately 56.6 million students attended K-12 schools in the United States in Fall 2019, with approximately 90\% of those students enrolled in public schools (National Center for Education Statistics, n.d.). As the entity with the most sustained contact with children outside of the family setting, public K-12 schools provide a logical, convenient, critical, and accessible organizational context for the implementation and operationalization of policies and programs designed to aid in the healthy development of a child's mental, physical, and emotional well-being (B. C. Fusarelli \& Lindle, 2011; Richardson, 2007; Smrekar, 1998). 


\section{K-12 Education System Organization and Authority}

K-12 schooling is mandatory for all U.S. children through state laws (with some minor exceptions for kindergarten and allowances for dropping out at a certain age), and consequently forms the core of an individual's educational trajectory (Rippner, 2016). The goal of public K-12 schooling is to provide all students with an equitable and excellent education; however, complex organizational, structural, and political issues; increasingly diverse student needs; and high expectations for student and teacher performance create circumstances that complicate the system's ability to deliver high quality educational services to all students (Butts, 1978; Rippner, 2016).

The U.S. Constitution has no specific provisions of publicly funded education as a right (Butts, 1978; Goldstein, 2014; Richardson, 2007; Rippner, 2016). However, the Constitution's $10^{\text {th }}$ amendment provides the foundational basis for the responsibility of schooling to be assigned to the states: "Powers not delegated to the United States by the Constitution nor prohibited by it to the states are reserved to the states, respectively, or to the people” (U.S. Const. amend. X). This Constitutional provision places the responsibility for the K-12 system largely under the authority of states and other local jurisdictions (Butts, 1978; Goldstein, 2014; Richardson, 2007; Rippner, 2016; Wong, 2015). The federalist, statefocused heritage of the U.S. education system has led to a uniquely fragmented, complicated structure with multiple points of accountability and responsibility, with many policymaking and political entities exerting their prerogatives with regard to public school governance, as shown in Figure 2.3 (Richardson, 2007; Rippner, 2016). 


\section{Figure 2.3. U.S. System for K-12 Educational Governance and Responsibility}

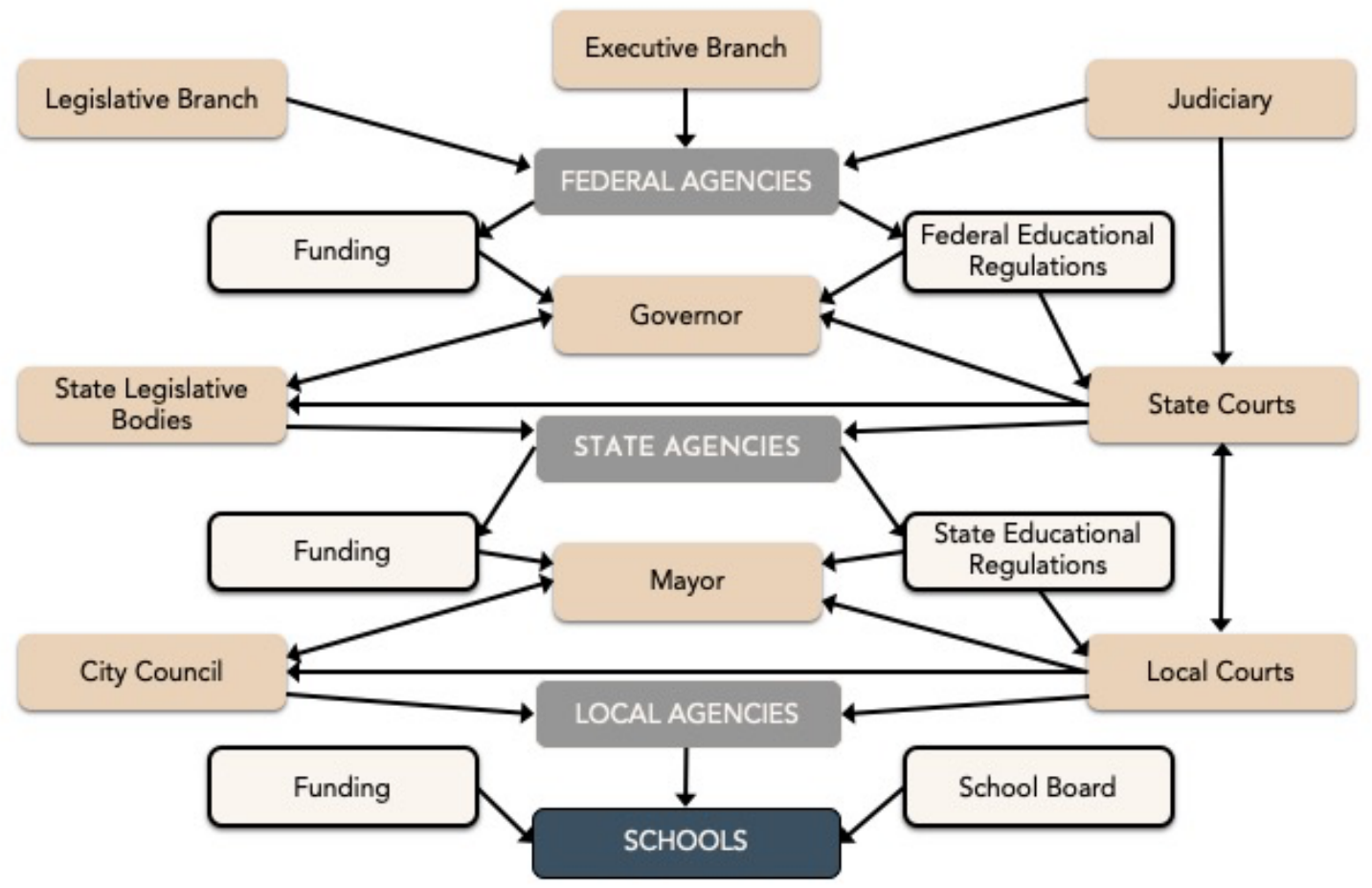

(Adapted from Richardson, 2007)

In some instances, the authority exerted by local, state, and/or federal governments is shared, and in other cases, the provision of funding determines how and where authority is granted (Rippner, 2016). Rippner (2016) summarizes the interplay among local, state, and federal governments as: “...The federal government [leverages] its provision of funding to states for increased power over policies, states [accept] more responsibility for the performance of schools, and local boards [try] to hold on to their traditional purview over education" (p. 90). The structure of power and governance in the context of the U.S. K-12 education system is complicated. 


\section{Federal Level Structure}

Despite no "right" to education in the U.S. Constitution, federal legislative bodies and agencies are largely able to influence educational programs and policies through funding tied to certain incentive programs and policies (Richardson, 2007). The Executive Branch exerts its influence over education in largely indirect ways through executive orders, approval of legislation from Congress, and appointments to key positions such as the U.S. Secretary of Education and the U.S. Secretary of the Interior (Richardson, 2007; Rippner, 2016). The Department of Education, headed by the Secretary of Education, is "responsible for policy development, program oversight, evaluation, research, and ensuring the enforcement of legislated mandates through the establishment of regulations that prescribe measurable performance expectations" (Richardson, 2007, p. 339).

Congress's main point of control over schools is through the linkage of standards to funding (Richardson, 2007). For example, schools, districts, and states can receive funding based on their ability to meet certain compliance criteria or enrollment benchmarks, thereby incentivizing state and local governments to employ certain activities or programs (Richardson, 2007). As will be discussed later, these criteria and benchmarks have given rise to an increased tendency for school administrators to emphasize core academic subject areas (e.g., reading, writing, math), in conjunction with decreased awareness of, and credence for, student health and well-being. The Judicial Branch exercises its influence over schools by mandating changes in practice based on the interpretation of the law, including school desegregation (Richardson, 2007). In its most simplified form, the purview of the federal government concerning the public education system is largely focused on, and tied to, the allocation of, and incentives related to, school funding. 


\section{State Level Structure}

States are the entities with the greatest oversight of, and responsibility for, schools and the provision of public K-12 education (Richardson, 2007). Each state's constitution provides the essential details for the creation and structure of the K-12 public education system within its borders, which creates a considerable degree of governing nuance and variability from state to state (Richardson, 2007). The influence of a state's governor is largely indirect, with most of their power related to the state budget, the approval/veto of bills, and the authority to make appointments to key positions in various policymaking bodies (Richardson, 2007). Some governors possess line-item veto power with regard to the state budget, which increases the amount of control they have over education budget items and allocations (Richardson, 2007).

State legislative bodies generally hold more power over their K-12 education system's activities, programs, and policies than other branches within a state's government. This is largely due to their ability to create and amend state law and to distribute federal funds earmarked for school districts, as well as state and local revenue funds, throughout the state (Richardson, 2007). State boards of education are tasked with the implementation and operationalization of mandates from the federal government, state legislature, and other designees from the federal and state level (Richardson, 2007). Each state holds a large degree of oversight and responsibility over its system of educational structure, system, and governance.

\section{School District Level Structure}

The discretion with which states structure and operationalize their education system is most evident at the school district (i.e., local) level. At this level, school boards interpret 
the state mandates given by the state board of education and manage the allocated state-level funds (Richardson, 2007). In the 2016-2017 school year, K-12 public school revenues totaled $\$ 736$ billion, with $8 \%$ coming from federal sources, $47 \%$ from state sources (taxes and possibly lottery proceeds), and 45\% from local sources (mostly property taxes; National Center for Education Statistics, 2020; Richardson, 2007). In many cases, funds are distributed at the local level at the direction of the local school board; however, some districts require the approval of their budget through a local popular vote that can occur with variable frequency (Richardson, 2007). School districts are led by a district superintendent; superintendents are hired by the local school board and have the direct responsibility of overseeing the district administrators, faculty, and staff (Richardson, 2007).

In some cases, educational service districts (ESDs) are created within a state to provide regional direction and support for their component school districts. These local structures and individuals have the most direct control over a school's activities and priorities; however, they often experience pressure from the state and national levels given the connection between academic outcomes, and resources and funding (Darling-Hammond, 2010; Michael et al., 2015).

\section{K-12 Education System Policymaking Arena}

Just as the U.S. K-12 education system structure is complicated, so is its policymaking arena. Multiple agencies, legislative bodies, and individuals have some degree of jurisdiction over, and oversight of, the U.S. K-12 education system, resulting in many entities having, or attempting to have, an influence over policies affecting the education system. Elected officials are the most visible (e.g., the President, governors, mayors, school board members); however, several different appointed bodies (each comprised of multiple 
individuals) also affect education policy at every level of the system (Rippner, 2016). Beyond those who operate in an official, outward-facing capacity, there are professional staff members who function within various federal, state, and local agencies and entities, as well as interest groups and general public opinion, which separately and collectively can dramatically influence policymaking and budget allocation (Rippner, 2016). The complex U.S. K-12 policymaking arena directly reflects the fragmented, complicated educational structure in which it lives.

From a federal perspective, an important landmark to begin the examination of education policy in the United States is the 1966 Equality of Educational Opportunity Study, known as the Coleman Report, for its lead author, sociologist James Coleman (Coleman et al., 1966; Goldstein, 2014; Hanushek, 2017). The Civil Rights Act of 1964 mandated that the U.S. Department of Education produce this report to describe the differences between the educational opportunities for white students and black students in elementary and secondary education across the United States (Hanushek, 2017).

Despite its original intent and purpose, the Coleman Report "fundamentally altered the lens through which analysts, policymakers, and the public at large view and assess schools" (Hanushek, 2017, p. 19). The main conclusion of the report was that the socioeconomic status of a student's family was the most significant driver of the child's educational attainment, and it exceeded almost everything else that could be accounted for when examining a student's academic outcomes (Butts, 1978; Darling-Hammond, 2010; Goldstein, 2014; Sacks, 2007). The report's findings shifted educators', policymakers', and the public's focus from what happens in the classroom to what students bring into the 
classroom, which had marked effects on debates about how to address issues and find solutions for poor educational outcomes.

However, Hanushek (2017) argues that the longer-lasting effect of the Coleman Report has been the articulation of factors and criteria used to measure school success or failure. Quality of education prior to the Coleman Report was largely defined by indicators that addressed the allocation of resources for student education (Hanushek, 2017). After the Coleman Report, what constituted a good school was measured by “'outputs' or 'outcomes' - the amount its students know, the gains in learning they experience each year, the years of further education graduates pursue, and their longer-term employment and earnings opportunities" (Hanushek, 2017, p. 20).

In the years since the Coleman Report, the benchmark for schools and the focus for federal education policy has continued to emphasize student outcomes, as is evident through President George W. Bush's No Child Left Behind Act of 2001 (No Child Left Bebind Act of 2001, 2002) and President Obama's signature education program, Race to the Top (U.S. Department of Education, 2009). These federal-level policies placed an increased focus on student academic performance, and actors within the national policy landscape have continued to tie test scores, graduation rates, and other educational outcomes to funding and resource allocation when schools do not achieve certain benchmarks (Darling-Hammond, 2010; L. D. Fusarelli \& Fusarelli, 2015; Goldstein, 2014; Richardson, 2007; Sacks, 2007). As described above, academic standards created at the national level have largely dictated priorities and activities at the state, district, school and classroom levels. Concurrent with federal and state achievement standards and annual testing mandates forcing teachers to create curricula that "teach to the test," class sizes have become larger, causing teachers to 
face increased demands for their time and attention (Darling-Hammond, 2010; Goldstein, 2014; Sacks, 2007). These continued policy shifts that prioritize student outcomes and benchmarks, along with increasing organizational and professional demands within schools, have dramatically affected the teaching and learning environment (L. D. Fusarelli \& Fusarelli, 2015).

\section{Societal Context for K-12 Schools}

In addition to this continued attention to specific measurable educational outcomes, the K-12 educational landscape sits in a societal context where racial and ethnic discrimination, resource distribution, budget cuts and decreased funding, and the effects of poverty permeate teachers' and school administrators' abilities to achieve their professional commitment of educating future generations. Differences in educational attainment between white students and students of color continue to be profound and persistent. During the 2017-2018 school year, approximately 15\% of high school students did not graduate on time, which is less than the 21\% reported for the 2010-2011 school year (Annie E. Casey Foundation, 2020a). Furthermore, disparities between white students and students of color are pervasive. During the 2017-2018 school year, 11\% of white students did not graduate from high school on time, whereas rates for students of color were approximately two to three times higher: 27\% for American Indian students, 21\% for African-American students, and 19\% for Latino students (Annie E. Casey Foundation, 2020b). In addition to the racial divide, the academic achievement gap between high- and low-income families has widened in recent years; "The achievement gap between children from high- and low-income families is roughly 30 to 40 percent larger among children born in 2001 than among those born twenty-five years earlier” (Reardon, 2011, p. 93). 
Taking all of this into consideration, the United States continues to perform poorly when compared to other industrialized nations in student achievement in core subject areas (Michael et al., 2015). Every three years, the Programme for International Student Assessment (PISA) tests 15-year-old students around the world in the core subjects of reading, math, and science (Organisation for Economic Co-operation and Development, n.d.). Designed to measure, compare, and rank national education systems, PISA is widely used as a means for comparing student academic achievement, and identifying best practices globally, despite its criticisms as a predominantly economic tool used to "blame and shame school systems” (Andrews et al., 2014; Niyozov \& Hughes, 2019). According to PISA’s 2018 survey, the United States spends more than other countries on education, yet according to results from the 2018 survey, yet ranks $36^{\text {th }}$ in math, $18^{\text {th }}$ in science, and $13^{\text {th }}$ in reading (Schleicher, 2019). Poor performance by students, schools, and the larger system has concerning long-term implications, including on the continued development of human capital; "The status quo does not bode well for the economic security and quality of life of future generations or for maintaining the vitality of American democracy" (Basch, 2011e, p. 650).

\section{Barriers to Change in K-12 Schools}

The fragmented structural and policy landscape of K-12 schools in the U.S. creates several tension points that are worth noting in order to understand the difficulties in creating change in schools. First, the structure itself creates barriers for improvements, from the flow of students through the system to who controls education structure, policy, and delivery (Darling-Hammond, 2010; Rippner, 2016). Federal education policy reform can drive change to a certain extent through regulations, incentives, and benchmarks that are tied to funding, 
but the decentralization of the education system often leaves these reforms falling short of their intended goals due to the federal Department of Education's general lack of power and direct influence over state education departments, state legislatures, and local school districts (Goldstein, 2014; Rippner, 2016). Moreover, the focus required for schools to achieve federally determined measurements of educational success and meet benchmarks can affect a school's ability or desire to change the way things are done, as shifting course can require effort and resources that are already stretched thin (Pfeffer \& Salancik, 2003). Given that significant effort would be required to overhaul the entire system (including potentially changing the U.S. Constitution), a more feasible solution is to address the lack of bridging instruments and tools through increased allocation of resources to states and school districts to aid in meeting the required federal mandates, and reducing the burden placed on educators and school administrators (Goldstein, 2014).

Second, the United States' deeply held values create tension. By and large, the values which suggest that education is an opportunity for all individual students to be given the equal chance to succeed sit in direct opposition with the United States' capitalist, marketbased system; "While we want everyone to have a chance, we know that some will 'win' and others will 'lose”" (Rippner, 2016, p. 29). However, simply providing all students with an open opportunity to access education is not where the problem ends. According to DarlingHammond (2010), the larger issue is that certain groups of students within the United States do not have:

Access to an empowering form of education - one that can enable people to think critically and powerfully, to take control of the course of their own learning, and to 
determine their own fate - rather than merely to follow dictates prescribed by others. (p. 28)

These inequities are seen in many facets of the education system, from the ways in which schools are funded (such as by local property taxes) to the unequal allocation of curricula, learning environments, and teaching methods (Darling-Hammond, 2010; Sacks, 2007).

Finally, when teachers and schools are not able to close academic achievement gaps, a child's family often serves as the next focal point for change and intervention. However, American families are often left without a full range of social supports, which further leaves children without what they need to succeed and thrive academically (Goldstein, 2014). In the absence of policies that improve the overall social and economic conditions of students and their families, schools will be limited in what they are able to accomplish to raise the achievement levels of all children (Goldstein, 2014; Sacks, 2007).

It is also worth noting that the barriers for education system change identified here have been exacerbated during the COVID-19 pandemic. Educational practices, procedures, and policies have shifted dramatically due to the pandemic, including various in-school and out-of-school student interactions such as extracurricular activities, club involvement, and sports participation. At the time of the writing of this chapter (Spring 2021), back-to-school practices are still being discussed and determined, often changing on a day-to-day basis. Short-term priorities related to safely returning students to in-person instruction have largely been the focus of educators and school administrators; however, attention will also need to be paid to the issues and problems that the pandemic has highlighted that dramatically and disproportionately affect some students and families more than others (National Academies of Sciences, Engineering, and Medicine, 2020). 


\section{Education Reform Focused on Academics}

As mentioned above, federal education policy, such as President George W. Bush's No Child Left Behind Act of 2001 (No Child Left Behind Act of 2001, 2002) and President Obama's signature education program, Race to the Top (U.S. Department of Education, 2009), has continued to emphasize outcomes and benchmarks, with increased attention and focus on student academic performance. Actors within the national policy landscape have continued to tie test scores, graduation rates, and other educational outcomes to funding and resource allocation when schools do not achieve certain standards (Darling-Hammond, 2010; L. D. Fusarelli \& Fusarelli, 2015; Goldstein, 2014; Richardson, 2007; Sacks, 2007). These educational reforms intended to influence the academic achievement gap through academically-focused approaches, including programs designed to shape teacher preparation, educational standards, and instructional practices (Michael et al., 2015). Despite these efforts, only minimal improvements in academic achievement have been measured over the past few decades (Basch, 2011d; Fiscella \& Kitzman, 2009; Michael et al., 2015).

These education reform efforts, identified as a tension point in the prior section, are often emphasized and encouraged without any efforts directed to improve social supports for children and their families, such as stable parental employment or the provision of appropriate health care, affordable housing, and/or childcare (Fiscella \& Kitzman, 2009; Goldstein, 2014). These social supports can make teaching and learning more effective for students, but are often sacrificed due to limited resources and funding (B. C. Fusarelli \& Lindle, 2011; Smrekar, 1998). Although the goal of public K-12 schooling is to provide students with an equitable and excellent education, it is aspirational at best if attention is not also given to the social needs of children. 
Education policies and reforms that largely assess a school's success or failure based on academic performance, test scores, and similar metrics have caused schools to devote less time to student health and well-being. This is due to two primary reasons: 1) there is increased pressure to focus on academic core subject areas (i.e., the aforementioned "teaching to the test"); and 2) schools operate under the misconceived idea that time spent on student health and well-being takes time away from activities focused on educational achievement (Bonell et al., 2014; Humphrey et al., 2013). Bonell et al. (2014) suggest this kind of thinking produces a false narrative that leads schools to believe that academics and student health and well-being exist within a "zero-sum game," whereby when one area wins, the other must lose. Instead, schools in other parts of the world (such as Finland, Sweden, Australia, and Singapore) place a greater emphasis on the development of students as holistic beings, with targeted efforts to support and promote students' overall well-being and health (Bonell et al., 2014). All of these countries have higher levels of academic attainment than the United States, suggesting that investment in students' educational achievement, social well-being, and mental and physical health is potentially beneficial in a synergistic manner (Bonell et al., 2014). According to Basch (2011d), "No matter how well teachers are prepared to teach, no matter what accountability measures are put in place, no matter what governing structures are established for schools, educational progress will be profoundly limited if students are not motivated and able to learn" (p. 593).

\section{Primary Health Care Delivery for Children}

The World Health Organization (1946) defines health as "a state of complete physical, mental, and social well-being and not merely the absence of disease or infirmity" (p. 
1). Despite this all-encompassing definition of health, health professionals and the systems in which they operate have traditionally focused on issues related to the diagnosis, treatment and management of individual illness and disease (Woolf, 2009). Beyond those in the health professions, those in the policymaking arena have approached health problems with solutions focused primarily on medical care and improving access to personal health services, while neglecting important social and economic causes of population health disparities (Lantz et al., 2007). Research estimates that as little as 10-20\% of the health status of a population is determined by the factors focused on by traditional medical and health services, whereas the commonly cited SDH related to the broader behavioral, social, and environmental factors may account for 80-90\% (Booske et al., 2010; Dahlgren \& Whitehead, 1991; McGinnis et al., 2002; McGovern et al., 2014). Inefficiencies within the structures of the health care system, along with fragmented care delivery and a focus on individualized medical care, have caused inconsistencies, gaps, and duplications in the provision and delivery of health care, and implications for the subsequent health of populations (Axelsson \& Axelsson, 2006; Dzau et al., 2017).

\section{Implications of a Fragmented Health System for Children}

The challenges that permeate the fragmented health care system affect the lives of children, who are "increasingly burdened by conditions that create chronic needs and that require a whole child ... approach to prevention and care that draws in social supports as much as it does clinical medicine" (Weil, 2014, p. 2094). According to Weil (2014), the fragmented health system needs to evolve to meet the needs of today's children.

Over the past century, the incidence of serious childhood infectious diseases has substantially declined in the United States (Perrin et al., 2014). However, rates of chronic 
health conditions, such as asthma, obesity, and mental health disorders, in children and youth have continued to rise. More than $30 \%$ of children in the United States have chronic health problems or special health needs, with rising numbers of children with chronic mental and behavioral health conditions of increased concern (Van Cleave et al., 2010). In 1960, health conditions serious enough to interfere with daily activities were reported in $1.8 \%$ of children; in 2010, more than $8 \%$ of children had such health conditions (Perrin et al., 2014). The context that surrounds the social and physical environments in which children are growing up, including the SDH, is largely to blame (Halfon et al., 2014).

According to Halfon, Wise, and Forrest (2014), the current network of health and social services needed by children with these chronic conditions is developing too slowly to respond effectively to their associated complex challenges. It is necessary and important to decentralize the provision of care for common, chronic conditions, by moving away from regionalized subspecialty centers of care, and instead, encouraging the majority of care be delivered in primary care settings (Perrin et al., 2014). Access to primary care provides a wide range of benefits, from achievement of better health at a lower cost to reductions in health disparities across various population subgroups, including children (Starfield et al., 2005). The vast majority of children need ready access to consistent and comprehensive primary care services to thrive.

\section{Primary Care Utilization and Movement to Medical Homes}

Using data from the 2014 Medical Expenditure Panel Survey, Rand and Goldstein (2018) performed a secondary data analysis to explore primary care utilization rates among adolescents, ages 9 to 21 years, and found that $46 \%$ had no visits to a primary care physician in a 12-month period. Additionally, only one-third of adolescents had a preventive visit, used 
to provide screening and immunizations, and to evaluate and counsel about risky behaviors, in the past 12 months, and preventive visit rates declined dramatically after age 16 (Rand \& Goldstein, 2018). This indicates a gap in the utilization of primary care at a time when children need those preventive services the most. The literature acknowledges that many children and adolescents underuse the health care system because of access-related barriers, including health insurance restrictions, limited transportation, financial constraints, decreased appointment availability, and/or lack of age-appropriate care (Fothergill \& Ballard, 1998; Gibson et al., 2013; Gregg et al., 2019).

The Agency for Healthcare Research and Quality (AHRQ) recognizes the medical home as a model for the delivery of these critically-important, core functions of primary care services (Agency for Healthcare Research and Quality, n.d.). Primary care medical homes $(\mathrm{PCMH})$ incorporate five functions and attributes: 1) provide comprehensive care, 2) have a patient-centered orientation, 3) provide coordinated care, 4) deliver accessible services, and 5) are committed to quality and safety (Agency for Healthcare Research and Quality, n.d.). Primary care services delivered through PCMHs are necessary for children. An AAP 2002 policy statement (built upon a 1992 AAP policy statement defining the medical home) clearly describes the belief that physicians should work to reach every child in their community to provide them with a medical home (American Academy of Pediatrics, 2002). As shown in Figure 2.4, the American Academy of Pediatrics (AAP) asserts that "medical care of infants, children and adolescents should be accessible, continuous, comprehensive, family centered, coordinated, compassionate, and culturally effective" (American Academy of Pediatrics, 2002, p. 184). 
Figure 2.4. Seven Key Elements of the Pediatric Medical Home

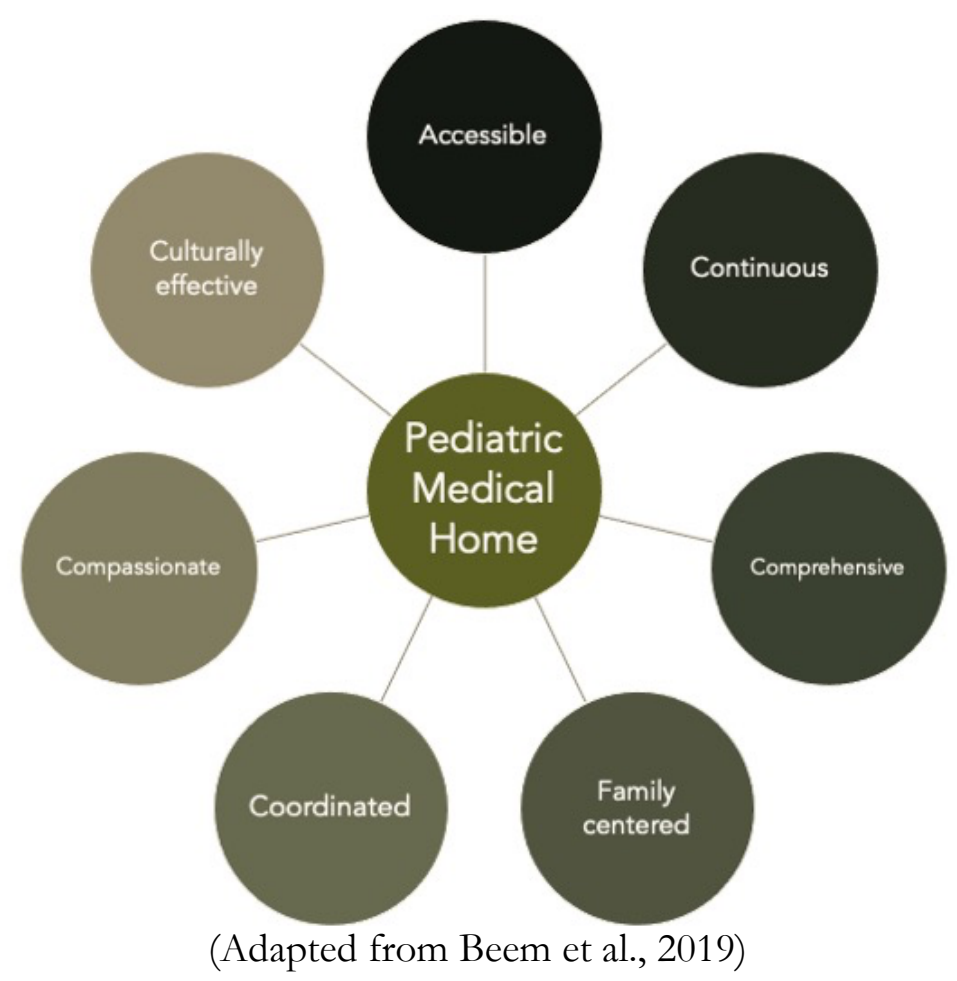

Individuals who receive care through a PCMH are less likely to have unmet medical needs (Gregg et al., 2019). Despite this emphasis on medical homes for children, data from the 2018-2019 National Survey of Children's Health indicates that only $47.7 \%$ of care provided to children ages 0-17 years met medical home criteria (Child and Adolsescent Health Measurement Initiative, n.d.).

The delivery of a range of health services in schools, a setting where children normally spend five days per week during the school year, may serve as a critical, effective, and convenient opportunity to address the primary care needs of children. SBHS and school-based health centers (SBHCs) provide an effective supplement to more traditional primary care, and offer an opportunity for addressing SDH, improving human capital, and decreasing the fragmented care delivery experienced by children by increasing availability of 
and access to meaningful, age-appropriate, comprehensive care (Albright et al., 2016; Beem et al., 2019; O'Leary et al., 2014). The provision of collaborative, comprehensive health and social services in schools may go beyond simply increasing child health and well-being in the short-term, and may also improve health and well-being into adulthood, by increasing the potential for improved individual educational outcomes.

\section{Integration of Health Services in Schools}

The complex set of overlapping, interrelated health-related issues and problems faced by children drives the need for comprehensive services that are delivered with greater coordination and collaboration (Basch, 2011e; Chiang et al., 2015; B. C. Fusarelli \& Lindle, 2011; Michael et al., 2015; Smrekar, 1998). Several researchers believe that collectively addressing HBLs through a single, sweeping approach is largely ineffective and misguided (Basch, 2011e; Bradley \& Greene, 2013; Dilley, 2009; Gracy et al., 2018; Michael et al., 2015).

Evidence from the literature advocates for educators and health professionals to recognize and focus on each of the HBLs as separate entities, with targeted attention paid to the mechanisms by which each health problem affects academic outcomes (Basch, 2011e; Bradley \& Greene, 2013; Dilley, 2009; Gracy et al., 2018; Michael et al., 2015). Efficient and comprehensive SBHS delivery designed to screen for, address, and manage students' HBLs can strategically reduce the effect those health barriers have on critical causal pathways to key educational outcomes (Association for Supervision and Curriculum Development, 2007; Basch, 2011e; Bradley \& Greene, 2013; Chiang et al., 2015; Gracy et al., 2017; Kolbe, 2005; Love, Schlitt, Panchal, et al., 2019; Love, Schlitt, Soleimanpour, et al., 2019; Michael et al., 2015). 


\section{Organizational Context for Cross-Sectoral Partnerships}

Despite providing the means for achieving desired health and educational outcomes, the delivery of health services in schools presents organizational challenges, given the crosssectoral partnerships required between the providers of health services and the education system. Additionally, the multifaceted web surrounding children, their families, schools, and the larger community exemplifies an open systems model orientation. An open systems model can directly affect how service delivery is differentiated and segmented, which creates additional tension points and problems (Lorsch \& Lawrence, 1970; Scott, 2003; Thompson, 1967). Although the creation of cross-sectoral partnerships between health and education within a complex open systems model orientation presents challenges that need to be understood and addressed, the potential benefits of their far-reaching effects may outweigh the tension points and struggles.

Service fragmentation that occurs when organizations are discrete entities may be easier for each organization from an operational standpoint; however, this siloed approach ultimately fails children by creating gaps in services and care (Adler, 1993). Historically, when service agencies or organizations have operated independently, two major problems surface: 1) resources are underutilized due to a lack of awareness of their availability, and 2) there is a potential for the duplication of services by agencies working in tandem (B. C. Fusarelli \& Lindle, 2011). These problems force organizations to operate in environmental circumstances that can seem unclear, ambiguous or uncertain, whereby an organization can reactively become more siloed. The open systems model and the reciprocal interdependence between organizations demand the use of partnerships, integrators and boundary spanners to effectively navigate the ever-changing, dynamic environments, thereby stabilizing that 
which feels ambiguous or unbalanced (Burns et al., 2012; Lawrence \& Lorsch, 1967; Thompson, 1967).

Organizational partnerships, joint ventures, and strategic alliances provide a purposeful approach for the mitigation of environmental risks and threats to the organization, by serving as a coordinating strategy to overcome the challenges where organizational differentiation and silos create gaps in services and care (Burns et al., 2012; Pfeffer \& Salancik, 2003). Given their unique relationship with students, families, and the larger community, schools are often viewed as a critical physical and social linkage point for partnerships with service agencies that serve this target population (Cohen-Vogel et al., 2011; Smrekar, 1998). The cooperation of organizations through partnerships, though potentially fragile and risky in their own right, provides a coordinating approach that reduces uncertainty and ambiguity, and provides an adaptive strategy for the management of environmental pressures (Lawrence \& Lorsch, 1967; Pfeffer \& Salancik, 2003).

Schools and social services, including health services, have traditionally functioned as part of distinctive institutionalized networks of organizations with different norms, dialects, and missions (Adler, 1993; Perrow, 2014). Professionals from each network face tension when attempting to partner and collaborate as they work to negotiate their roles, understand each other's professional vocabulary and terminology, and find ways to work together (Adler, 1993). The coordination of services in the school environment creates new expectations for both schools and the entities with which they partner, and "as a result there is an increase in organizational demands, ambiguities, potential loss of control, and greater responsibilities” (B. C. Fusarelli \& Lindle, 2011, p. 404). However, the cooperative strategies of partnerships and strategic alliances can effectively balance these potential risks against the 
expected benefits provided through innovation and organizational learning (Burns et al., 2012).

Partnerships can go beyond simply managing or mitigating risks to synergistically leveraging and capitalizing on each entity's strengths and capabilities "by combining the individual perspectives, resources, and skills of the partners, the group creates something new and valuable together-a whole that is greater than the sum of its individual parts" (Lasker et al., 2001, p. 184). Although these types of partnerships and collaborations can be time-consuming, difficult and resource-intensive, the synergistic benefit and advantage that comes from successful, effective collaborations between schools and social service agencies can make the barriers and challenges worth the investment of time and resources of both parties (Adler, 1993; Lasker et al., 2001; Mawhinney, 1993). According to Adler (1993), "Linking schools and social services posits that integrating services once provided by separate organizations will result in substantially better services for children than the services provided by separate organizations which do not collaborate" (p. 2). Additionally, service integration and partnerships allow for the provision of more comprehensive, efficient, and seamless service delivery to address the complex needs of children and their families (Hassett \& Austin, 1997). Education and health have a shared interest in promoting student health and well-being, as collaborative efforts have the potential to make important strides in improving both health outcomes and academic achievement of youth (Rasberry et al., 2017).

\section{A Culture of Health}

In 2015, the Robert Wood Johnson Foundation developed a 20-year strategy, called

a Culture of Health, which "envisions a national movement toward better health where individuals, communities, and organizations take action to improve health in America" 
(Trujillo \& Plough, 2016, p. 206). The Culture of Health framework allows for multiple paths toward improving individual, community, and population health, with the understanding that people and organizations need meaningful information, effective partnerships, and viable resources to achieve these goals (Chandra et al., 2016; Trujillo \& Plough, 2016; Weil, 2016). The Culture of Health vision and framework places health as the central focus by making it a national priority, and encourages collaborative efforts across various sectors and players beyond the health sector, in order to improve health and wellbeing for all Americans (Robert Wood Johnson Foundation, 2019a; Weil, 2016). The integration of health services in schools speaks directly to the intention of the Culture of Health framework and each of its four Action Areas: 1) making health a shared value; 2) fostering cross-sector collaboration to improve well-being; 3) creating healthier, more equitable communities; and 4) strengthening integration of health services and systems (Robert Wood Johnson Foundation, 2019b; Weil, 2016). SBHS offer a direct response to the Culture of Health's call for new opportunities that encourage cross-sectoral collaboration, partnership, and integration (Towe et al., 2016).

\section{History of School-Based Health Services Delivery}

To better understand the current landscape of SBHS delivery, along with its benefits and struggles, it is important to understand the history of the delivery of such services in U.S. K-12 schools. A report produced in 1850 by the Sanitary Commission of Massachusetts is what many consider as the beginning of the "modern school health era," with the recognition that schools could play a role in promoting public health and preventing disease (as cited in Allensworth et al., 1997). At the beginning of the $20^{\text {th }}$ century, school nurses were recognized as a primary means for reducing the number of children excluded from school 
due to communicable diseases, either by treating students in school for more minor conditions or by visiting students in their homes for more major illnesses (Allensworth et al., 1997; Gustafson, 2005). In the early 1900s, school nurses worked to educate teachers, parents, and children about disease control and prevention and were instrumental in the decline in the number of absent students (Gustafson, 2005).

A turning point in the history of school health programs in the United States occurred after World War I, with a shift from an emphasis on health inspection and hygiene to one that recognized the problems of poverty as a reason for the poor health and welfare of many children (Allensworth et al., 1997). In 1911, the National Education Association (NEA) and the American Medical Association (AMA) joined together to form the Joint Committee on Health Problems of the National Education Association and the American Medical Association (Allensworth et al., 1997). The group published a paper in 1927, titled Health Supervision and Medical Inspection of Schools, which called for the coordination between health services, physical education, and health education as a critical step for a school health programs (as cited in Allensworth et al., 1997). The NEA-AMA collaboration largely defined the role of SBHS from World War I to the middle of the $20^{\text {th }}$ century, with a focus on screening activities, the direct provision of care for immediate problems, and referrals to family physicians for more complex health concerns (Allensworth et al., 1997). In general, it was the work of school nurses to execute the NEA-AMA call for focus through the early identification of illnesses and associated health problems, and subsequent referrals (Allensworth et al., 1997; Gustafson, 2005).

The work of school nurses was enhanced in the mid 1960s. Title I of the federal Elementary and Secondary Education Act of 1965 not only tripled the number of school 
nurses but also defined the role of the school nurse practitioner, a new position in the school health services realm (Allensworth et al., 1997). Despite the increase in the number of nurses, the belief within the education system was that the diagnosis and treatment of illness and disease had no place in school-delivered services, and the role of school nurses should remain limited with efforts focused on health education and screening activities (Allensworth et al., 1997; Gustafson, 2005). Practices were changed, however, with the release of results of a state-by-state survey sponsored by the Robert Wood Johnson Foundation in 1972; the survey showed that no state had legislation that prohibited the delivery of diagnosis and treatment services by any primary care provider (Allensworth et al., 1997). Concurrently, the public started pushing for the diagnosis and treatment of health problems at school, which was in direct contrast to the beliefs expressed within the education system (Igoe, 1975). To meet the requests of the public, the introduction of school nurse practitioners in schools in the 1970s allowed for the provision of primary care services to students, which increased rates of problem resolution and a better means for keeping children who were experiencing illness and injury in school (Allensworth et al., 1997). School nurses continue to be uniquely positioned at the intersection of student health and education, with many of the benefits only realized if the nurse has full-time employment within the school to more fully develop relationships and rapport with students (McGowan Lowrey, 2018).

The simultaneous creation of SBHCs further advanced the work of school nurse practitioners. Through its Community Access to Child Health (CATCH) program, the AAP encouraged the development of the first SBHCs in Cambridge, MA, Dallas, TX, and Minneapolis-St. Paul, MN in the late 1960s and early 1970s (Gustafson, 2005). By the first National School-Based Health Care Census in 1985, a total of 31 SBHCs existed in 18 urban 
communities across the United States (Love, Schlitt, Soleimanpour, et al., 2019). According to the School-Based Health Alliance, a nonprofit organization dedicated to the implementation of school-based health care, the 2016-2017 National School-Based Health Care Census (the most recent available) identified 2,584 SBHCs in 48 of 50 states, the District of Columbia, and Puerto Rico, an 83-fold increase in just over three decades (Love et al., 2018; Love, Schlitt, Soleimanpour, et al., 2019).

SBHCs have many demonstrated benefits given their unique positionality between health and education. SBHCs can serve as a collaborative strategy for the intersections among schools, local health systems, and care providers (Love, Schlitt, Panchal, et al., 2019). Beyond SBHS delivery, partnerships between SBHCs and community health systems/primary care providers have been used to establish an expanded medical home, which promotes greater coordination and continuity of care for adolescents through shared responsibility (Beem et al., 2019). Additionally, research has shown that the presence of a SBHC in a school with a large proportion of medically underserved students, where health conditions are likely to be more prevalent, can reduce barriers to health care access, resulting in less time away from school with less missed work for parents and caregivers (Padula et al., 2018). SBHC users have been shown to have higher levels of school connectedness, including student bonding and attachment to school, attachment, as well as commitment to an educational future (Strolin-Goltzman et al., 2014).

School nurses often work across multiple systems, and can provide students with direct access to various health services, including disease-specific education which can improve health and academic outcomes, especially for students with chronic health conditions (Leroy et al., 2017). School nurses can serve as the bridge to SBHC access and 
utilization through active referrals to the SBHC and care coordination between SBHCs and community health providers (Gregg et al., 2019). The development of SBHCs and the expanded role of school nurses has helped to ensure that a large portion of school-aged children have access to quality health care where they spend most of their days (Friedrich, 1999; Gustafson, 2005; Love, Schlitt, Soleimanpour, et al., 2019).

\section{Centers for Disease Control and Prevention's School Health Services Model}

As SBHS delivery has ebbed and flowed over the past century, the growth and proliferation of SBHCs throughout the country has been substantial. However, despite the existence of sophisticated SBHCs in certain schools and districts, school-to-school variability exists in the availability of a full spectrum of SBHS. As illustrated in Figure 2.5, the Centers for Disease Control and Prevention's (CDC) model for school health services delivery includes four components: acute and emergency care, care coordination, family engagement, and chronic disease management (Centers for Disease Control and Prevention, 2019i).

Figure 2.5. School Health Services Model

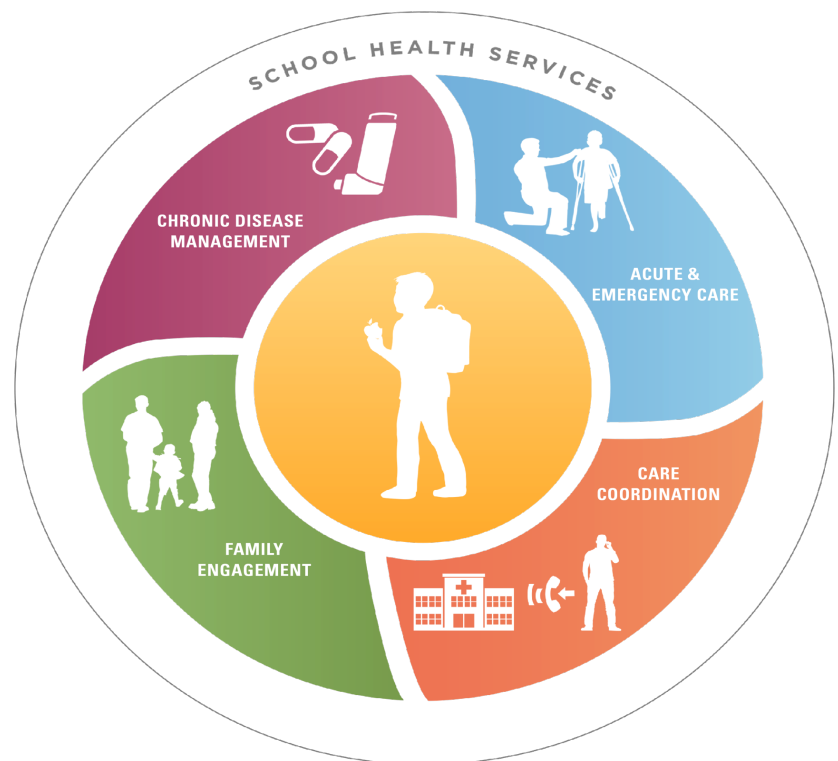

(Centers for Disease Control and Prevention, 2019f) 
Acute and emergency care addresses injury or illness events that happen during the school day, as well as the provision of care during larger emergency events or disasters (Centers for Disease Control and Prevention, 2019a). Care coordination and chronic disease management for students allows for information to be shared with the various individuals or groups concerned with the needs and care of students who have chronic health conditions; this coordination provides for improved medical management, more detailed follow-up, and identification of needed additional resources (Centers for Disease Control and Prevention, 2019b, 2019c). In addition, the designation of family engagement as a part of the SBHS model demonstrates an important strategy to encourage families and school health personnel to engage in conversations about health status updates, medication distribution, and dietary and/or physical considerations, with the intent of improving a student's ability to succeed in school (Centers for Disease Control and Prevention, 2019d). Comprehensive SBHS delivery would include all four components of the CDC's model, but as mentioned above, there is a large degree of variability in the delivery of services from school to school and/or from district to district (and state to state).

Crowson and Boyd argue that "the rationale for integration [of health and social services with schooling] is that children have multiple and interconnected needs, yet the current service delivery system tends to be specialized and disjointed, with various service providers often functioning nearly at cross-purposes" (as cited by B. C. Fusarelli \& Lindle, 2011, p. 403). SBHS delivery addresses the specialized and disjointed nature of care delivery for children in a space where children normally spend five days a week during the school year. This kind of cross-sectoral work, though not without its challenges and degrees of 
variability, can serve as an effective means for improving student access to health care services and academic achievement.

\section{Whole School, Whole Community, Whole Child Model}

Since the early $20^{\text {th }}$ century, programs designed to affect school health have been largely focused on three components: school health services, school health education, and the school health environment (Allensworth \& Kolbe, 1987). As society has changed over time, the health needs of students have shifted to health issues caused by behaviors such as tobacco use, food consumption, and motor vehicle use (Kolbe, 2005). In addition, there has been an increase in understanding how these health and health behaviors not only affect student learning and educational achievement in the short term but also establish behaviors that might persist well into adulthood (Allensworth \& Kolbe, 1987; Kolbe, 2005). To address how school health programs could address the shifting needs of students, Allensworth and Kolbe (1987) introduced the comprehensive school health (CSH) program. With the recognition that schools provide a logical and meaningful place to do more for children, the CSH approach (see Figure 2.6) outlined eight components to encourage school health programs to be more expansive and comprehensive in nature (Allensworth \& Kolbe, 1987; Kolbe, 1986). 


\section{Figure 2.6. Coordinated School Health Model}

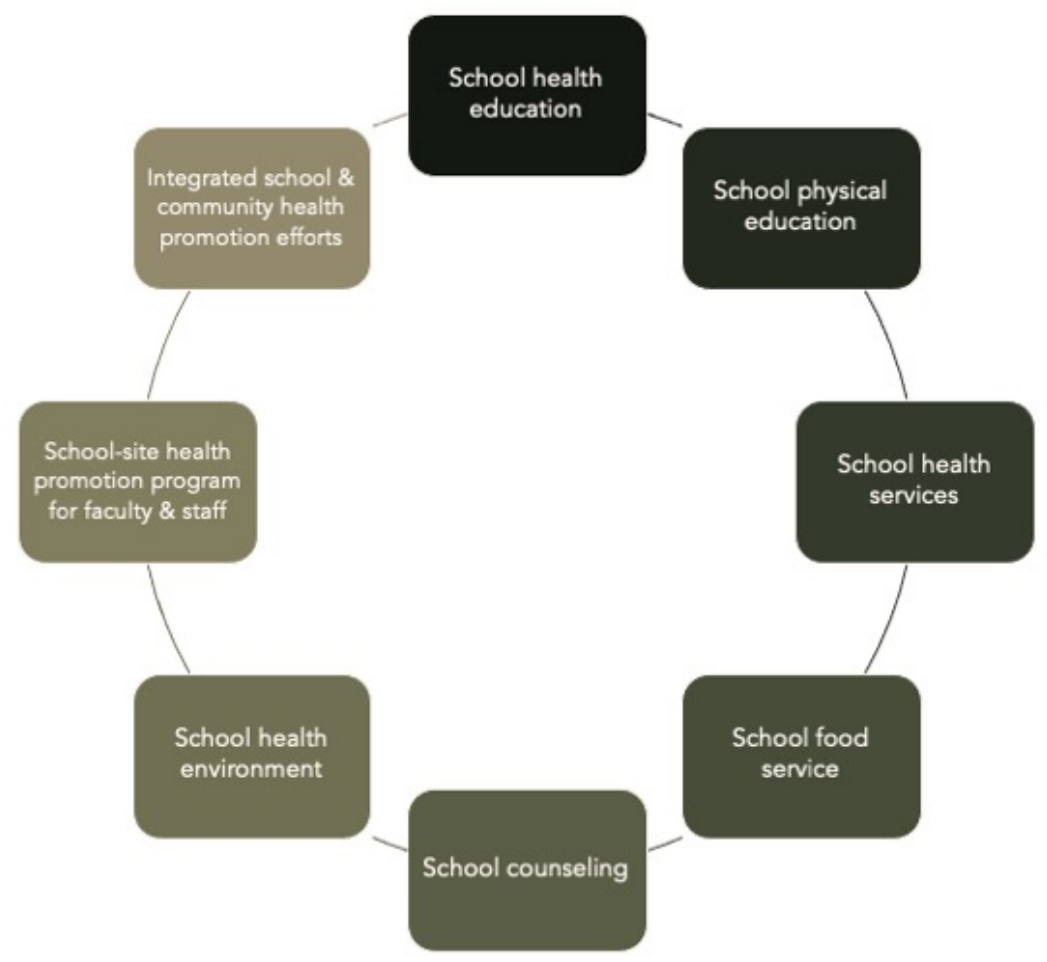

(Allensworth \& Kolbe, 1987; Kolbe, 1986)

Over time, the names of the specific components in the CSH model have been altered in various publications. In a recent article by Lewallen et al. (2015), the titles of the eight were: a) health education, b) physical education, c) school health services, d) healthy and safe school environment, e) counseling, psychological, and social services, f) family and community involvement, g) health promotion for staff, and h) nutrition services. Although the exact titles have been modified, the intention and focus of the eight components has been consistent: to encourage school health programs to be more expansive and comprehensive nature. With that goal in mind, the CSH model was widely disseminated by the CDC beginning in 1987 as a concise framework for shaping an inclusive approach to all aspects of school health (Lewallen et al., 2015; Michael et al., 2015). Despite its acceptance in 
the health services community, educators viewed the model as largely focused on health outcomes; it did not resonate with educators as an education-relevant model and gained limited acceptance at the school level (Lewallen et al., 2015).

In 2006, the ASCD (formerly known as the Association for Supervision and Curriculum Development), a professional organization for educators, convened two meetings of the Commission on the Whole Child to:

[recast] the definition of a successful learner from one whose achievement is measured solely by academic tests, to one who is knowledgeable, emotionally and physically healthy, civically inspired, engaged in the arts, prepared for work and economic self-sufficiency, and ready for the world beyond formal school. (Association for Supervision and Curriculum Development, 2007, p. 4) ASCD's intent was not to diminish the focus on academics, but rather to increase attention on the conditions in which children can be more successful in their learning (Association for Supervision and Curriculum Development, 2007). In The Learning Compact Redefined: A Call to Action, the Whole Child (WC) approach provided five tenets to ensure the holistic, healthy development of children:

- Each student enters school healthy and learns about and practices a healthy lifestyle.

- Each student learns in an intellectually challenging environment that is physically and emotionally safe for students and adults.

- Each student is actively engaged in learning and is connected to the school and broader community.

- Each student has access to personalized learning and qualified, caring adults. 
- Each graduate is prepared for success in college or further study and employment in a global environment. (Association for Supervision and Curriculum Development, 2007, p. 20)

ASCD's call to action encouraged key decision-makers, community members, and educators to partner and take action with the whole child in mind (Association for Supervision and Curriculum Development, 2007; Lewallen et al., 2015).

A similar call for partnerships to better the lives of students came from those in the health sector. Kolbe (2002), who was the director of the CDC's Division of Adolescent and School Health (DASH), emphasized this need for collaboration by saying:

...If American schools do not coordinate and modernize their school health programs as a critical part of education reform, our children will continue to benefit at the margins from a wide disarray of otherwise unrelated, if not underdeveloped, efforts to improve interdependent education, health, and social outcomes. (p. 10) Given the ever-evolving educational demands on students and the need for them to be treated as holistic, multi-faceted beings, both the education sector and the health sector recognized the need for change. Individuals and agencies from both sectors called for schools, organizations, and communities to work together to recognize the interconnected and interdependent health and education needs of students to improve children's health and academic achievement (Kolbe, 2005).

In Spring 2013, those calls for a coordinated approach were answered when a panel of experts from education, public health, and higher education was convened by ASCD and the CDC with two main purposes: 1) to examine what had been learned from the implementation of the $\mathrm{WC}$ and $\mathrm{CSH}$ approaches, and 2) to investigate opportunities for 
revising and/or developing a model that incorporated the learning to date (Lewallen et al., 2015). A product of the panel was the Whole School, Whole Community, Whole Child (WSCC) model, shown in Figure 2.7 (Lewallen et al., 2015).

\section{Figure 2.7. Whole School, Whole Community, Whole Child Conceptual Model}

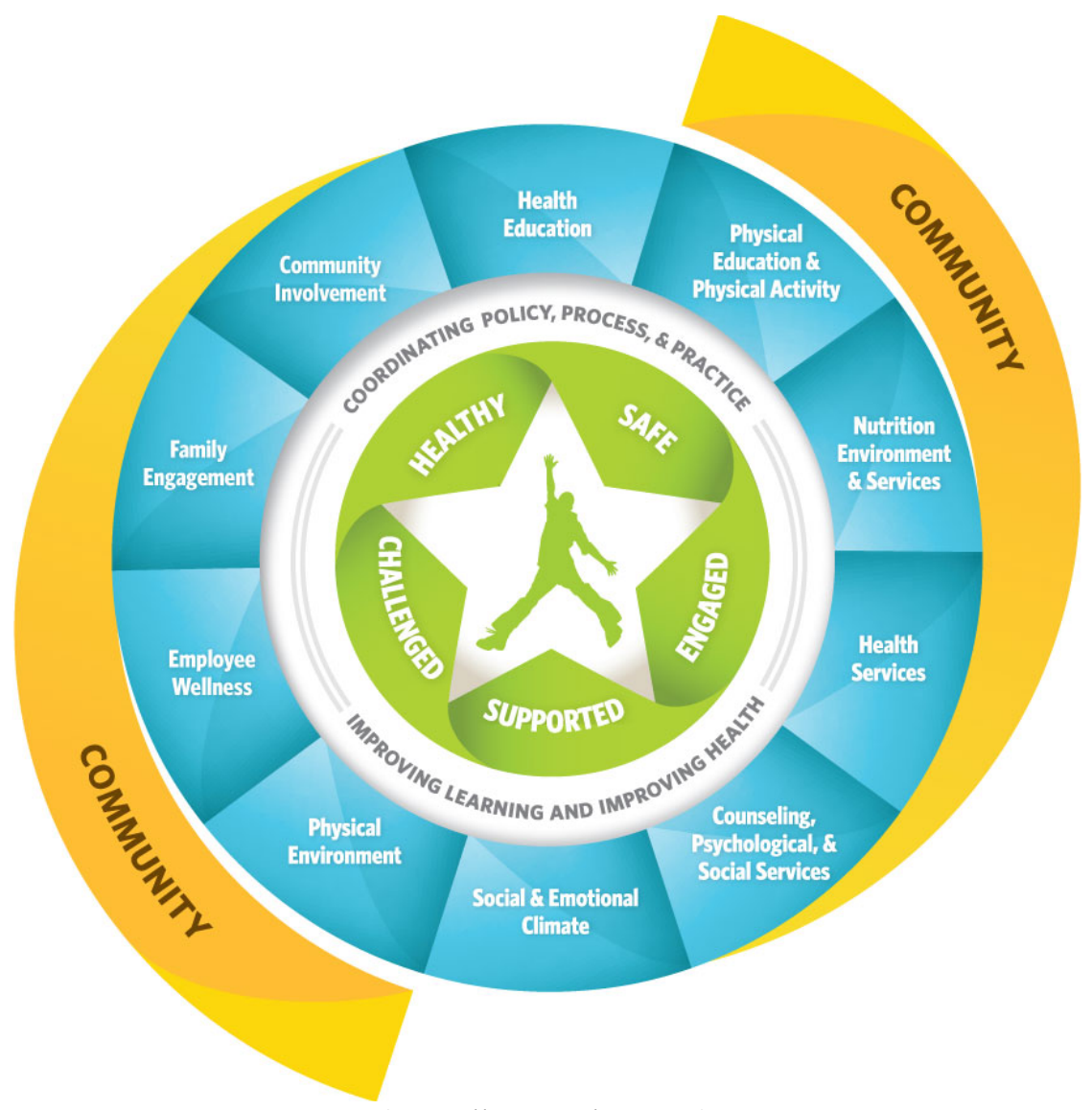

(Lewallen et al., 2015)

The WSCC model combines the WC approach and the CSH model to give a holistic view of students, schools, and the community in a single framework for improving student health and learning (Lewallen et al., 2015). Moreover, the WSCC provides educators and administrators with a comprehensive framework designed to encourage the health and education sectors to partner and leverage their resources, such that students are provided 
with more effective and efficient programs that better meet their holistic needs (Michael et al., 2015).

The five tenets of the WC approach (healthy, safe, engaged, supported, and challenged) are placed at the center, such that the student is the primary focus of all efforts (Lewallen et al., 2015; Morse \& Allensworth, 2015). Coordinated policy, process, and practice form a ring around the child to explicitly call out the importance of such coordination in the creation of a school environment that supports both education and health (Lewallen et al., 2015). The WSCC model's outer ring replicates the eight original components of the CSH, with two additional components: the healthy and safe school environment was split into "social and emotional climate" and "physical environment," and the family and community involvement component was split into "community involvement" and "family engagement" (Lewallen et al., 2015). "The focus of the WSCC model is a socioecological approach that is directed at the whole school, with the school, in turn, drawing its resources and influences from the whole community and serving to address the needs of the whole child" (Lewallen et al., 2015, p. 734). This comprehensive, integrated, and coordinated model provides a collaborative approach and framework for the design of health and education interventions, policies, programs, and supports (Lewallen et al., 2015).

\section{U.S. Government's Study of School Health}

As one of the primary governmental institutions that studies school health, the CDC's DASH works to maximize the opportunities for primary prevention that will support the development of healthy children and teens (Centers for Disease Control and Prevention, 2016). DASH achieves that goal through data collection, the translation of science into the 
development of new programs, and funding education agencies that work in primary prevention (Centers for Disease Control and Prevention, n.d.).

DASH collects data using three school-based surveillance systems: The Youth Risk Behavior Surveillance System (YRBSS), the School Health Profiles surveys (SHPS), and the School Health Policies and Practices Study (SHPPS; Centers for Disease Control and Prevention, 2018). The YRBSS monitors six categories of priority health-risk behaviors among adolescents to determine the prevalence of, and assess trends in, those behaviors (Centers for Disease Control and Prevention, 2017a). SPHS provide data on health policies and activities in schools, using a self-administered biennial questionnaire that is sent to a representative sample of public middle schools and high schools in each state, territory, or school district (Centers for Disease Control and Prevention, 2017a). SHPPS seeks to provide national-level data on various components of school health at the state, district, school, or classroom level by conducting surveys at one or more levels during each cycle of its administration (Centers for Disease Control and Prevention, 2019f). Each of these three school-based surveillance systems provides important data and insights for better understanding current health services delivery in schools.

\begin{abstract}
Absenteeism
Student absenteeism has been increasingly focused on by educators for its academic effects, as well as by health professionals for the health-related reasons why students miss school. Many students experience adverse circumstances in their lives, including poverty, health problems, challenging family environments, and violence, any of which can result in missing substantial days from school (U.S. Department of Education, 2019). In recent years,
\end{abstract}


absenteeism has been identified as an important indicator of educational outcomes for its critical, damaging effects on short- and long-term student performance. This is due to the potential that absenteeism will increase the likelihood of poor academic outcomes, exacerbate behavioral and socio-emotional problems in school, and increase the potential for negative behaviors and activities outside of school (Allison \& Attisha, 2019; Sprick \& Sprick, 2018; U.S. Department of Education, 2019). The short- and long-term effects of absenteeism on a student's ability to succeed can be substantial.

\section{The Problem of Absenteeism}

Attendance Works, a non-profit organization that advocates for better policies and practices to improve school attendance, defines chronic absenteeism as a student missing $10 \%$ of a standard 180-day school year, or 18 days of absence (Attendance Works, n.d.). The U.S. Department of Education's Office for Civil Rights dataset for the 2015-16 school year (the most recent available) indicated that more than seven million K-12 students (approximately $16 \%$, or about 1 in 6 ) were chronically absent from school, according to their definition of missing 15 days or more during that single school year (U.S. Department of Education, 2019). Students in high school experience the highest rates of chronic absenteeism (21.1\%, or 1 in 5 students), compared to $14.1 \%$ of middle school students and 13.6\% of students in elementary school (U.S. Department of Education, 2019).

Moreover, significant disparities exist based on income, race, and ethnicity; children who are living in poverty and/or children from specific racial and ethnic minority groups miss school more often (Allison \& Attisha, 2019; U.S. Department of Education, 2019). Factors such as unstable housing, difficulty in obtaining reliable transportation, poverty, and poor parental health are implicated in the disproportionate absenteeism rates for students 
from racial and ethnic minority groups and tie directly to the SDH and the effects they can have over the life course (Allison \& Attisha, 2019). Whether the benchmark is 15 or 18 days of missed school, these data show that a large number of students throughout the United States are missing critical amounts of school (Attendance Works, n.d.; U.S. Department of Education, 2019).

The reasons for student absenteeism can be separated into three categories: 1) students cannot attend school, 2) students will not attend school, or 3) students do not attend school (Balfanz \& Byrnes, 2012). Illness, family responsibilities, a need to work, or involvement in the juvenile justice system are reasons often provided by students who cannot attend school (Balfanz \& Byrnes, 2012). Students who will not attend school often do so to avoid bullying, harassment, embarrassment, or other unsafe conditions (Balfanz \& Byrnes, 2012). Other students simply do not go to school because they (or their parents or caregivers) would prefer to be elsewhere (Balfanz \& Byrnes, 2012). HBLs often affect students in the first category (students who cannot attend school); however, it is reasonable to recognize how students who will not or do not attend school could often do so due to health-related reasons (e.g., a large number of missed days due to a health condition could set a child behind which leads to embarrassment (will not attend), or the problems that arise from an illness lead to the feeling that attending school is not time well spent (do not attend)). While the separation into cannot, will not, or do not can help educators or administrators in organizing a response to the absenteeism, the reality is that many students miss school for different reasons on different days based on different situations (Balfanz \& Byrnes, 2012). 


\section{The Effects of Absenteeism}

Schools provide a setting for students to progress academically, engage in a languagerich environment, develop socially through relationships, and experience opportunities that nurture work-related skills, including persistence, problem-solving, and the ability to work with others toward a common goal (Kearney \& Graczyk, 2014). Gaps in attendance throughout a student's academic career can affect immediate, short-term school performance within a school year, which may lead to longer-term gaps in achievement and graduation rates, as well as long-term consequences that extend into adulthood (Allison \& Attisha, 2019; Jordan \& Chang, 2015; Kearney \& Graczyk, 2014). Research also suggested a negative spillover effect for students in classrooms with a higher percentage of chronically absent students; one student's chronic absenteeism can have an impact on the learning outcomes of others (Gottfried, 2019).

Chronic absence serves as a warning sign of academic risk at all grade levels. Patterns of absence when children are younger can lead to weaker reading and math skills, reduced engagement with their education, and decreased social engagement (Gottfried, 2014, 2019; Jordan \& Chang, 2015). Children with weaker reading skills early in their educational careers are more likely to struggle with the transition from "learning to read" to "reading to learn" by fourth grade, which increases the likelihood that they will continue to struggle academically throughout middle school and high school (Gottfried, 2014; Jordan \& Chang, 2015). Hernandez (2012) reported that $16 \%$ of children who are not reading proficiently by the end of third grade do not graduate from high school on time, which is a rate that is four times greater than the rate for proficient readers. The effects of losses that begin in a child's 
early years of education can accumulate throughout their education in profound ways with serious consequences.

\section{Health and Absenteeism}

Students with poorer health and special health care needs often have difficulty in attending school regularly, which can compound the educational, social, and behavioral effects of absenteeism on a child (Jordan \& Chang, 2015; Stempel et al., 2017). Many absences can be tied directly to health-related factors, including problems associated with asthma, learning disabilities, oral health, and trauma and community violence-related mental health issues (Jordan \& Chang, 2015). Additionally, five of the seven specific educationally relevant health disparities identified by Basch can affect educational outcomes through various causal mechanisms, of which absenteeism is one (see Figure 2.1; Basch, 2011e, 2011a, 2011b, 2011c, 2011f, 2011g). The causal connections that tie the more broadlydefined HBLs to poor educational outcomes are largely interrelated, with health factors influencing educational performance along multiple, interrelated pathways (Basch, 2011e; Jordan \& Chang, 2015).

\section{American Academy of Pediatrics Policy Statement on Health and Absenteeism}

Increasingly, national, state, and local agencies, organizations, and stakeholders have been invested in multidisciplinary, cross-sectoral efforts to address school attendance, given its multi-faceted ability to affect both health and education outcomes. For example, in February 2019, the AAP issued a policy statement to demonstrate the role pediatricians can play in addressing absenteeism (Allison \& Attisha, 2019). Within the policy statement, Allison and Attisha (2019) specifically identify physical and mental health interventions and organizational strategies that have been used to address chronic absenteeism, including 
infection prevention, school nurses, SBHCs, mental health care, school policies and programs to promote a positive school climate and school connectedness, parent-focused interventions and involvement, and coordinated school health as outlined by the WSCC. The focus on comprehensive, coordinated, and consistent SBHS can play a critical role in students attending school on a regular basis. The ability of each specific health-focused intervention or strategy to reduce absenteeism has been demonstrated, providing continued opportunities for pediatricians and other health professionals to partner in the educational environment to improve school attendance.

\section{Education in Oregon}

\section{Education Governance Structure in Oregon}

The education governance structure in Oregon and relevant policies are important to understand for a study conducted in this state. In 1951, the Oregon State Board of Education was created by the Oregon Legislature to oversee the state's schools by setting educational policies and standards for the $197 \mathrm{~K}-12$ public school districts and 19 ESDs (State of Oregon, n.d.-b). Oregon's governor serves as the chief state school officer, or superintendent, and appoints a deputy superintendent to manage day-to-day activities (Education Commission of the States, 2017). The Governor also appoints all seven voting members of the Oregon State Board of Education, who are subsequently confirmed by the state Senate (Education Commission of the States, 2017; State of Oregon, n.d.-b). The Oregon Department of Education (ODE) oversees the students enrolled in Oregon's K-12 public education system, which also includes "early learning, public preschool programs, the state School for the Deaf, regional programs for children with disabilities, and education 
programs in Oregon youth correction facilities" (State of Oregon, n.d.-c). Through the development of key strategies, the Oregon State Board of Education and the ODE help districts achieve local, statewide, and national goals and priorities (State of Oregon, n.d.-c).

The 197 school districts in Oregon's 36 counties include more than 1,200 K-12 schools (Oregon Department of Education, 2020). Fifty-six percent of the districts are comprised of fewer than 1,000 students (small districts), 36\% are medium school districts (1,000 to 6,999 students), and 9\% are large districts (more than 7,000 students; Oregon Department of Education, 2020). The large school districts house the majority of Oregon's students, and comprise 54\% of the state's total K-12 enrollment (Oregon Department of Education, 2020).

In addition to the school/district structure in Oregon, there are 19 ESDs, each with its own board (Education Commission of the States, 2017; State of Oregon, n.d.-a). These ESDs provide regional services to their associated school districts by assisting with the provision of services that a school district would not be able to adequately and equitably provide on its own, including high-cost technology systems and services for children with severe disabilities (State of Oregon, n.d.-a). In 2000, Senate Bill 259 reestablished the primary mission of ESDs, and recognized that the ESDs exist to help:

- Ensure an equitable and excellent education for all children in the state

- Implement the Oregon Educational Act for the $21^{\text {st }}$ Century

- Foster the attainment of high standards of performance by all students in Oregon's public schools 
- Facilitate inter-organizational coordination and cooperation among educational, social service, health care, and employment training agencies. (State of Oregon, n.d.-

b)

The regional services provided by ESDs fall into four main categories: special needs children, school improvement, technology, and administrative services (State of Oregon, n.d.-a).

\section{Enrollment and Attendance in Oregon Schools}

According to the Oregon Statewide Report Card 2019-2020 (the most recent available), produced by the ODE as an annual report to the Oregon Legislature, there were 582,661 students enrolled in Oregon public schools on the first school day in October 2019 (Oregon Department of Education, 2020). The percentage of chronically absent students (absent for $10 \%$ or more in their total enrolled days) in Oregon's K-12 education system was 20.4\% in 2018-2019, the most recent available (Oregon Department of Education, 2019b).

During the 2018-2019 school year, the ODE implemented the Chronic Absenteeism Statewide Plan in school districts and ESDs to focus on and monitor student attendance (Oregon Department of Education, 2019b). In the first year of the plan, the focus was on “accurate reporting and use of attendance data, building strong attendance teams, and implementing positive, two-way communication processes with parents, caregivers, and schools" (Oregon Department of Education, 2019b, p. 70). The plan was intended to be partnered with the Every Day Matters initiative, which was launched in October 2018; the initiative requested that school districts analyze the climate and culture of each school, such that strong supports could be put into place for students and families who have been historically underserved (Oregon Department of Education, 2019b). With the 
implementation of this plan, the ODE recognized that regular attendance was key to meeting Oregon Governor Kate Brown's vision to have 90\% of students graduating from high school within four years of starting their freshman year (Oregon Department of Education, 2019b). Efforts for the Every Day Matters campaign have not been updated in recent months to acknowledge the effects the COVID-19 pandemic may have on regular student attendance.

\section{Student Success Act of 2019: House Bill 3427}

In May 2019, Oregon Governor Kate Brown signed House Bill 3427, the Student Success Act (SSA), into law (Oregon Department of Education, n.d.-d). Beginning in the 2020-2021 school year, the SSA was expected to invest $\$ 2$ billion in each biennium, with funds divided among three accounts: 1) Student Investment Account (SIA; 50\%), 2) Early Learning Account (20\%), and 3) Statewide Education Initiatives Account (30\%). The SSA intends to make investments in programs and services that support Oregon's children and their families through increased instructional time, the provision of mental and behavioral health supports, reduced class size, and improvements to school safety (Oregon Department of Education, n.d.-d). It is worth noting that at the time of this dissertation's publication, the COVID-19 pandemic has affected the funds intended for the three accounts above, but its full effect on SSA implementation has not been well-described in any publicly available resources. To that end, the description of the SSA below is based on the understanding and intent prior to the pandemic.

The SIA is the investment that may have the greatest significance and importance to the provision of health services in schools. The SIA is intended to fund nearly $\$ 500$ million annually in non-competitive grants throughout the state. The SIA has a two-fold purpose: 
- Meet students' mental or behavioral health needs, and

- Increase academic achievement for students, including reducing academic disparities for:

- Economically disadvantaged students;

- Students from racial or ethnic groups that have historically experienced academic disparities;

- Students with disabilities;

- Students who are English language learners;

- Students who are foster children;

- Students who are homeless; and,

- Any other student groups that have historically experienced academic disparities, as determined by the State Board of Education. (Oregon Department of Education, n.d.-d)

The intention of the SIA (and the larger SSA) is to make significant and specific investments in programs that support historically underserved students (Oregon Department of Education, n.d.-d).

Districts interested in receiving SIA grant funds must have a spending plan focused on any, some, or all of the four allowable use categories: reducing class size, instructional time, health and safety, and well-rounded education (Oregon Department of Education, n.d.-d). Grant money given to address student health and safety needs can be used for:

- Social-emotional learning and development,

- Student mental and behavioral health, 
- Improvements to teaching and learning practices or organizational structures that lead to better interpersonal relationships at the school,

- Student health and wellness,

- Trauma-informed practices,

- School health professionals and assistants, or

- Facility improvements directly related to improving student health or safety. (House Bill 3427, 2019)

With this historic, substantial investment in Oregon's schools and students as a backdrop, a thorough study of the range of SBHS offered in Oregon's schools and their connection to absenteeism should prove helpful in understanding opportunities for how health-focused efforts can affect educational outcomes.

\section{Child Health in Oregon}

According to the Annie E. Casey Foundation's KIDS COUNT® 2020 Data Center, an estimated 866,562 children were living in Oregon in 2019, comprising 21\% of Oregon's total population (Annie E. Casey Foundation, 2020c). Of these, an estimated 111,000 children were living in poverty, which is defined as children under the age of 18 who are living in families with incomes below the federal poverty level (Annie E. Casey Foundation, 2020c). In calendar year 2019, the definition of the federal poverty level was a family of four (two adults and two children) with an annual combined income of less than $\$ 25,926$ (Annie E. Casey Foundation, 2020c).

Children who grow up in poverty face multiple threats to healthy development, as poverty and financial stress can impede children's cognitive development, affect their ability 
to learn, and contribute to behavioral, social, and emotional problems and poor health (Annie E. Casey Foundation, 2019b). When children have regular and appropriate access to comprehensive health care, such as care provided in PCMHs as described above (Agency for Healthcare Research and Quality, n.d.), the health effects of poverty can be mitigated.

Children are more likely to have a regular source of health care if they have health insurance (Annie E. Casey Foundation, 2019a). Table 2.1 illustrates the numbers and percentages of children under age 19 in Oregon who were covered by health insurance in 2019, often depending on a parent's health insurance coverage, at any point during the year by health insurance type.

Table 2.1. Children's Health Insurance Coverage by Type in Oregon

\begin{tabular}{lcc}
\hline Insurance type & Number & Percent \\
\hline Employer-based only & 479,000 & $52 \%$ \\
Direct-purchase only & 42,000 & $5 \%$ \\
Other private coverage & 12,000 & $1 \%$ \\
Public only & 302,000 & $33 \%$ \\
Both public and private coverage & 41,000 & $4 \%$ \\
Uninsured & 38,000 & $4 \%$ \\
\hline \multicolumn{2}{c}{ (Annie E. Casey Foundation, 2020c) }
\end{tabular}

Beginning in 2012, Oregon implemented coordinated care organizations (CCOs) as part of its health systems transformation strategy, which created networks of all types of health care providers to serve people who have public health insurance coverage through the Oregon Health Plan (Medicaid; Oregon Health Authority, 2012). The work of CCOs is intended to be local, with their performance measured by the health outcomes of the populations they serve (Oregon Health Authority, n.d.). This coordination of care is intended to reduce health disparities for the state's most vulnerable populations through care that is patient-centered and team-focused, while also seeking to hold down Medicaid 
expenditures (Oregon Health Authority, n.d.). From 2012 through 2017, the work of Oregon's CCOs “improved access to primary care, reduced costly emergency room visits, and saved the state an estimated $\$ 2.2$ billion in avoided health care costs" (Oregon Health Policy Board, 2018b, p. 2).

In 2018, the Oregon Health Authority charged the Oregon Health Policy Board to create plans and strategies that would address continuing gaps and challenges that persist in Oregon's system of health services delivery, despite the prior five years of efforts of the CCO model; the next phase of this work is referred to as "CCO 2.0" (Oregon Health Policy Board, 2018b). Given the unique needs of children with regard to their health care, one of the specific elements of CCO 2.0 is a focus on children, with the recognition that working to affect children's health requires approaches that are distinct from care delivery for adults (Oregon Health Policy Board, 2018b). Strategies that were explicitly designed to improve child and family outcomes were integrated into multiple policies in CCO 2.0; specifically, 26 of the 43 CCO 2.0 policies have the potential to positively affect the lives of children (Oregon Health Policy Board, 2018b, 2018a). This impact potentially could be consistent across all 16 CCOs recognized in CCO 2.0.

Beyond the specific policies outlined in CCO 2.0, Oregon's 2019 House Bill 2267 requires that "a community health improvement plan adopted by a coordinated care organization and its community advisory council ... shall include a component for addressing the health of children and youth in the areas served by the coordinated care organization” (House Bill 2267, 2019, p. 12). House Bill 2267 specifically calls for a strategy and plan to "[coordinate] the effective and efficient delivery of health care to children and adolescents in the community" (House Bill 2267, 2019, p. 12). CCO 2.0 and House Bill 2267 
give prominent, focused attention to coordinated, effective, and efficient health care delivery for children and adolescents.

While specific elements of CCO 2.0 are intended to primarily affect the health of children covered by publicly-provided health insurance, the changes assumed by the larger health services delivery system will likely change the way that care is delivered to children on employer-provided and private health insurance. Changes made within the education system through the implementation of the Student Success Act and the Every Day Matters campaign, and within the larger health system through CCO 2.0 and the operationalization of House Bill 2267 have the potential to lead to synergistic efforts that improve the lives of children throughout Oregon.

\section{Oregon's School-Based Health Services Variation and Chronic Absenteeism}

The comprehensive WSCC model provides a collaborative approach and framework for the design of health and education interventions, policies, programs, and supports with two of the 10 components specifically focused on addressing school health services: [physical] health services and counseling, psychological, and social services (Lewallen et al., 2015; Michael et al., 2015). Although various methods for studying SBHS and communitybased health services exist, they do not provide the complete picture of SBHS delivery throughout Oregon's K-12 school system. A full exploration of how SBHS are employed, along with the variation that exists from school to school, will provide a more complete understanding of how health services provided in schools might mitigate the interaction between HBLs and educational outcomes. 
Many different HBLs can create circumstances that make it more difficult for a child to attend school regularly. Absenteeism is an important component of the long-term educational equation due to its potential to set the stage for other problems that can affect a child's academic performance. However, a comprehensive understanding of the full range of SBHS as a means of mitigating the effects that health problems and illness have on a student's ability to attend school regularly is largely missing from the literature.

While the Donabedian model of health care organization $(1966,1990)$ has been extensively used and applied in the assessment of health services organization, delivery, and quality, it has not been used to explore the cross-sectoral environment of health service delivery within schools. The three components of Donabedian's model (structure, process, and outcome) provide the framework by which to explore the elements embedded within the system that may influence a school's ability to deliver quality, meaningful SBHS in its specific environment.

Donabedian's model can inform an understanding of how the variations of elements of the secondary school system (structure) and SBHS delivery (process) create education and health outcomes (outcomes). Various elements of the secondary school system and SBHS delivery, along with a selection of education and health outcomes, are categorized using Donabedian's structure-process-outcome model, as illustrated in Figure 2.8. 


\section{Figure 2.8. Structure, Process, Outcome Framework for Secondary Schools, School- Based Health Services Delivery, and Education and Health Outcomes}
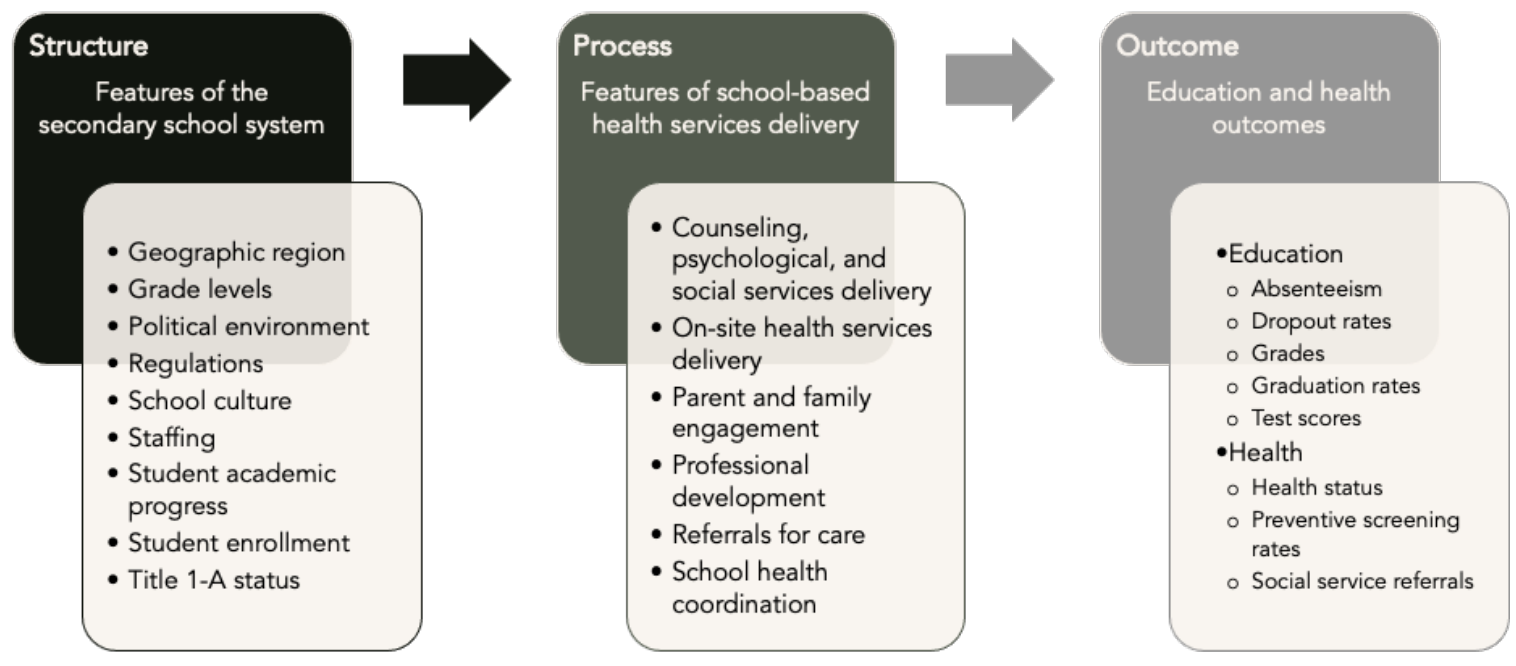

Although different studies have addressed how each type of health intervention might decrease absenteeism, no research to date provides a comprehensive overview of how these different structural and process features do (or do not) work together to achieve improved student attendance. An exploration of how the structure of schools and the delivery of SBHS can aid in affecting students' HBLs, which can lead to chronic absenteeism, is missing from the literature; this study seeks to address that gap. The Donabedian model was used throughout this research to categorize the different elements related to the absenteeism outcome.

\section{Conclusion}

Child health is a critical issue of consideration for the public's health, as it sits at the core of the development of healthy adults, a healthy workforce, and future healthy generations. The mutually synergistic effects of education and health are widely recognized 
in the literature, and specific HBLs have been identified as creating impediments to a student's motivation and ability to learn, which can result in missed days of school. These absences can affect schoolchildren's emotional, academic, and social well-being in the shortand long-term. While it is understood that these linkages between health and education exist, an understanding and exploration of the context and structures that exist in the places where those linkages are most likely to occur does not exist, and this study may contribute to building knowledge of these factors.

With an understanding of the organizational and policy structure of the education system as a foundation, an exploration of the structures and contexts for the employment of strategies to mitigate that connection through SBHS delivery was warranted. Gaining a more thorough understanding of the role of SBHS as a means for addressing chronic absenteeism can inform specific recommendations for the future design of health systems and services, as well as for policies that affect both the health and education of students. Chapter Three discusses the design and methods that were used for this study. 


\section{Chapter Three - Design, Methodology and Initial Findings}

\section{Overview}

As discussed in Chapter Two, this dissertation was conducted during the COVID-19 pandemic, which necessitated a change in the strategy for data collection soon after the successful dissertation proposal defense in May 2020, as well as minor modifications to the research question and the study aims.

This chapter begins with the research study design and methodology that were used to answer the following question: How do elements of school-based health services contribute to the ability of the public secondary school education system to address chronic absenteeism? As described in Chapter One, this study has four aims:

1. Create a unique categorization of the structures and systems of school-based health services delivery in Oregon's public secondary schools;

2. Identify factors that potentially influence the availability, delivery, and quality of health services in secondary schools in Oregon;

3. Examine and compare configurations of the structural and process elements derived from this understanding of school-based health services delivery that contribute to the outcome of absenteeism; and

4. Develop policy recommendations that will inform system-level redesign of schoolbased health services and help integrate delivery across education and health services systems.

The confluence of multiple structural elements within public secondary schools creates an environment that can potentially influence the processes related to SBHS delivery 
as a means for addressing students' health barriers to learning (HBLs), which may in turn lead to a range of educational outcomes (see Figure 3.1 below). However, no research to date provides a comprehensive overview of how the different structures within schools and the processes of SBHS interventions work (or do not work) together to achieve certain educational and health performance outcomes. More specifically, the literature lacks a comprehensive description of the structures and systems within public schools that influence the delivery of SBHS, which can then serve as a means for mitigating the effects that health problems and illness have on, among other factors, a student's ability to attend school regularly. An understanding of the variations of features of the public secondary school education system that aid in the delivery of SBHS is needed to ensure that these services are effective in addressing specific health issues, such that students attend school and are motivated and able to learn.

\section{Figure 3.1. Structure, Process, Outcome Framework for Secondary Schools, School- Based Health Services Delivery, and Education and Health Outcomes}
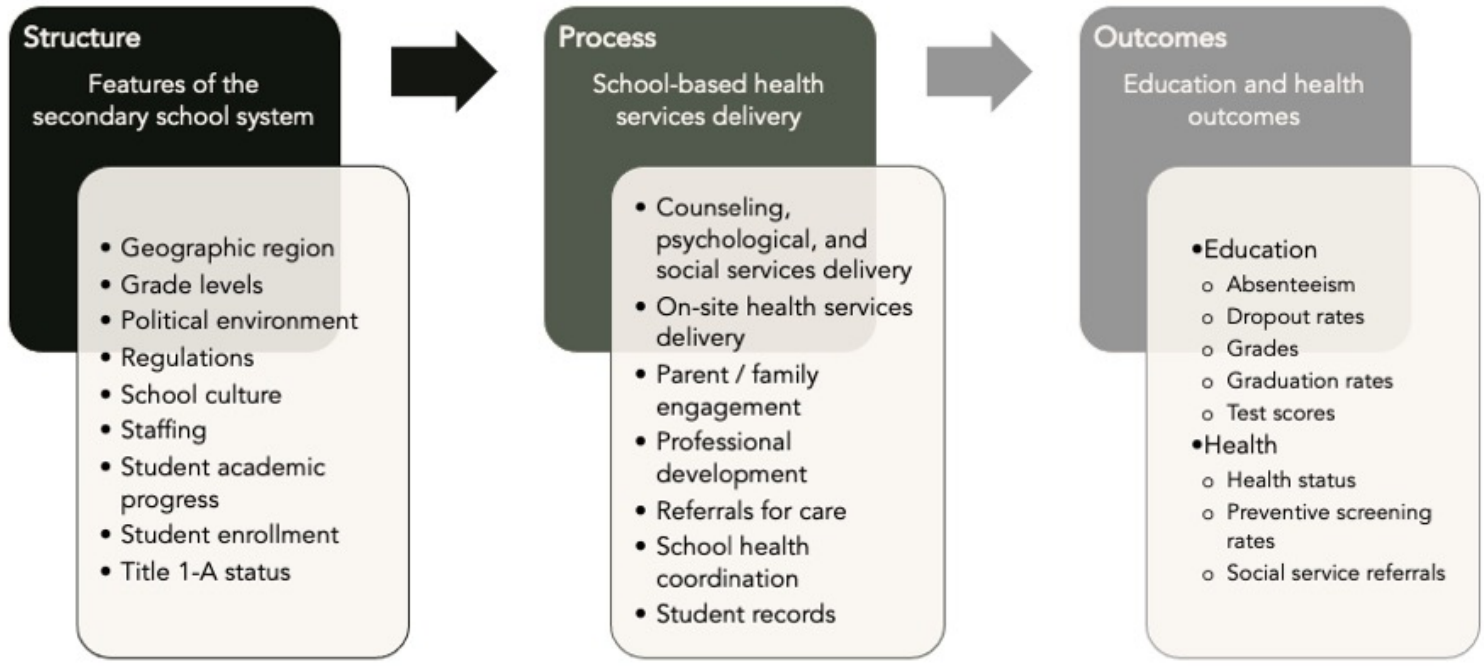
This chapter describes the theoretical approach and orientation for the research, the study design, strategies for data collection, the methodological approach and analysis, and protections of data to ensure privacy.

\section{Theoretical Approach and Orientation}

Historically, much of the research to understand disease causation and potential treatment mediation through health policies, systems, and interventions has used a narrow cause-and-effect, linear approach (Esensoy \& Carter, 2015). This knowledge has drawn upon correlational theorizing, which assesses cause and effect relationships by controlling variables (i.e., holding them constant) to evaluate the "net effects" of unit differences in independent variables on the outcome (Furnari et al., 2020; L. W. Green, 2006). By contrast, configurational theorizing seeks to evaluate how combinations of specific conditions can yield an outcome of interest, as well as how different combinations, or pathways, can lead to the same outcome (Furnari et al., 2020).

Additionally, in the study of various issues related to health and well-being, individual disciplines often work in silos to create specialty-specific knowledge with little collaboration and few cross-sectoral applications (LeVine, 2016). Research communities from different disciplines may not recognize the value that disciplines outside their own can bring to their research (LeVine, 2016). Due to individualized terminology, frameworks, and concepts, working in a siloed, specialized manner attempts to eliminate the messiness that can come from working across disciplinary lines. The inward focus can shut out considerations of the interrelated nature of real-life experiences, and as with the controlled atmosphere of correlational theorizing, it can limit how discoveries can be applied to more practical 
circumstances. Exploring the disciplinary overlaps of knowledge and working collaboratively to gain shared perspectives about the mechanisms that give rise to practical, every day circumstances are critical to expanding a shared understanding of real-life phenomena. An interdisciplinary, collaborative orientation can more fully examine the ways in which the structures of secondary schools and the processes of health services delivery affect and influence educational outcomes. In the late 1960s, Campbell proposed a concept known as the "fish-scale model of omniscience" (Campbell, 1969; LeVine, 2016). He viewed disciplines in the social sciences as scales on a fish, each unique unto itself but overlapping with neighboring specialties, and "the mutual relatedness of topics and data was mediated through shared boundaries, guaranteeing that specialists could use knowledge generated by adjacent specialists" (Campbell, 1969; LeVine, 2016, p. 4). However, as universities expanded in the mid $20^{\text {th }}$ century, "disciplinary orthodoxies hardened, not only in doctrine but also in the institutionalization of departments and journals with sharp boundaries and vested interests" (LeVine, 2016, p. 5). The mutual relatedness of topics and data caused by disciplinary overlap was increasingly stifled or eliminated, leading to understandings that "may be correspondingly restricted and distorted" (Thomas, 2016, p. 407).

Configurational theorizing (as opposed to correlational theorizing) identifies how multiple conditions work together in configurations through important connections that operate jointly as a whole, and allows for assessing for equifinality, which is when multiple paths lead to an outcome (Furnari et al., 2020). A research approach grounded in systems thinking and case-oriented configurational comparative research recognizes, embraces, and strives to explain real-world complexity, as well as the ways in which different solutions can meaningfully achieve the same outcome. Shared, interdisciplinary perspectives on health, the 
causes of disease and illness, and potential interventions require a different basis of knowledge: one that demonstrates and understands the complexities that exist between health problems and issues and their causes and interventions.

\section{Applications of Systems Thinking}

Best et al. (2003) suggest that an increased use of systems theory by those in the health field would better incorporate key concepts of other disciplines for a more complete, integrated and realistic view of the dynamic complexity that surrounds people's lives, health, and well-being. Systems science, thinking, and modeling treat a situation's multiplicity of variables as a means for conducting a deeper analysis, "rather than as a nemesis to be controlled” (L. W. Green, 2006, p. 406). Complex systems are comprised of heterogeneous elements that interact with one another; these interactions give rise to emergent properties that are not fully explained by simply understanding the individual components of the system (Luke \& Stamatakis, 2012). To better comprehend the full assortment of influences at work, an interdisciplinary systems approach allows for the study of interventions to reflect, rather than mask, the complex reality of the world surrounding the myriad issues related to health and well-being (L. W. Green, 2006).

Esensoy and Carter (2015) utilized collaborative, system-level modeling to capture a "whole-system qualitative model" perspective for their work on the system-wide effects of patient flow-related interventions. This wide-ranging approach to facilitate systems thinking enabled an exploration of a range of relationships that aided in breaking down specialized silos within a health care system and highlighted the interdependencies among various disciplines. Systems-level thinking was used in this research to explore the interactions between health services and the educational environment. This lens allowed for the root 
causes of problems to be better understood, and for the levers, opportunities, barriers, and facilitators to become more apparent. A systems approach provided a foundational understanding of the inherent dynamic complexity inherent in this exploration (Biesta, 2010).

Equifinality, which refers to different pathways within a system that can lead to the same outcome, is a basic principle of systems theory (Katz \& Kahn, 1978; Roig-Tierno et al., 2017), and a core principle of configurational comparative methods, known as CCMs (Ragin, 1999). As discussed in the next section, this research applied coincidence analysis (abbreviated as CNA), a relatively new member of the CCMs family, both as a research approach and data analysis technique. The techniques used in CNA, and in CCMs more broadly, allow for the complexity in real-world system states to be distilled to identify a "minimal theory" - a unique combination of nonredundant conditions whose joint presence links directly to an outcome of interest (Baumgartner, 2015; Berg-Schlosser et al., 2009; Cragun et al., 2016). In the context of this research, the analysis considered different configurations of specific structural and process elements related to SBHS delivery to help explain student absenteeism, while accounting for the fundamental complexity inherent in this cross-sectoral, systems-level exploration.

\section{Research Approach: Configurational Comparative Methods and Regularity Theory}

In the 1980s, Ragin $(1987,2014)$, a comparative sociologist, was frustrated by the limitations of understanding social phenomena using either strictly qualitative or quantitative methods. Case-oriented, qualitative research approaches sought to study a small number of cases in which a specific outcome occurred by highlighting the complexity found within each case, while being cautious to not overgeneralize findings (Ragin, 1987, 1999, 2014). With 
variable-oriented, quantitative research, multivariate statistical techniques placed restrictions on more complex patterns of statistical interaction, such that "generality is given precedence over complexity" (Ragin, 2014, p. 54). Neither option seemed entirely feasible for answering the questions Ragin was posing; in his attempts to reconcile between the case-oriented and variable-oriented approaches, Ragin recognized the need for something new (Ragin, 1987, 2014). The resulting case-comparative approach that Ragin developed is called qualitative comparative analysis (QCA). As described by Jambor (2009), QCA combined "some of the methodological discipline and rigor of quantitative analysis to qualitative analysis and some of the causal complexity and inductive sensitivity of qualitative analysis to quantitative analysis” (p. 66). With its development as a new methodological approach, QCA allowed researchers to deal with the effects of system states, while understanding "these system states to be the product of complex AND multiple generative mechanisms” (Byrne, 2011, p. 89). QCA is a case-oriented comparative method that belongs to the larger CCM family (Kahwati \& Kane, 2020; Rihoux \& Ragin, 2009). As described by Rihoux and Ragin (2009), CCMs in general enable the systematic comparative analysis of complex cases, with each case being transformed into a configuration of properties, or conditions, that in different configurations may lead to the same outcome (Berg-Schlosser et al., 2009; Rihoux \& Marx, 2013). More generally, CCMs seek to combine the advantages of case-oriented qualitative work and variable-oriented quantitative techniques by providing a mathematical means for studying the categorical attributes of cases (Berg-Schlosser et al., 2009; Ragin, 1987; Rihoux \& Ragin, 2009; Vogt et al., 2011; Whitaker et al., 2020). Case-based units of analysis allow for the identification of interventions that work in different contexts (Whitaker et al., 2020), with case-based configurations serving "as multidimensional constellations of attributes 
orchestrated together by central themes or integrative mechanisms" (Furnari et al., 2020, p. 4). The intent of this research approach is to gather in-depth information and insight about cases selected for study, while simultaneously constructing a level of generalizability across cases (Rihoux \& Marx, 2013).

CCMs draw from the related fields of formal logic, Boolean (rather than linear) algebra, and set theory, with foundations built upon the regularity theory of causality (Cragun, 2020; Kahwati \& Kane, 2020; Palinkas et al., 2019; Ragin, 1987, 2014; Schneider \& Wagemann, 2013; Thiem, 2017; Whitaker et al., 2020). Whereas correlation-based and regression-based theories and methods assess the incremental effect that a unit difference in $X$ (the independent variable) has on $Y$ (the dependent variable) while controlling for other variables to examine the net effects of $X$, the use of the regularity theory of causality posits that with all other things being equal, $A$ is a cause of $B$, if and only if $A$ is part of a set of conditions $A X$ that is regularly followed by B (Baumgartner, 2008, 2009, 2020; Cragun, 2020; Furnari et al., 2020; Whitaker et al., 2020). A configurational theoretical approach grounded in regularity theory examines how specific conditions combine into different configurations, or "recipes," to explain an outcome, with the additional understanding that complex causal explanations may include more than one pathway leading to the outcome of interest (Furnari et al., 2020).

Configurational analysis applies a modern version of the regularity theory of causation known as Boolean difference-making. Boolean difference-making encompasses both necessary and sufficient conditions for outcomes, as well as "INUS" conditions, which are Insufficient but Necessary parts of a configuration that is itself $\mathbf{U n n e c e s s a r y}$ but Sufficient for the outcome (Baumgartner, 2008, 2020; Cragun, 2020; Mackie, 1965; Thiem, 
2017). A common example used to illustrate INUS conditions with CCMs is that of a house fire (Cragun, 2020). A house fire might start because of the combination of a flammable couch sitting next to faulty electrical wiring. Each condition alone is insufficient to start a fire, but together they jointly provide a sufficient configuration for a fire to start. Moreover, there are other combinations of conditions which may also lead to the same outcome: a bathroom candle next to a roll of toilet paper, or a gas leak sparked by a match. In this example, a flammable couch and faulty electrical wiring are both INUS conditions in that neither by itself is sufficient to start a fire, and neither by itself is necessary for starting a house fire (as other pathways exist). They are Boolean difference-makers, as they jointly provide the minimally sufficient and necessary combination of conditions that constitute one pathway for the outcome to appear (i.e., the house fire to start).

Different methods exist to explore and evaluate causation. The examination of caselevel causal complexity in relation to an outcome of interest requires a method that is grounded in a theory that allows for conjunctural causation, equifinality and asymmetry (Baumgartner, 2020; Cragun, 2020; Kahwati \& Kane, 2020; Schneider \& Wagemann, 2013; Whitaker et al., 2020). Conjunctural causation recognizes that a single condition's effect may only be recognized in combination with other conditions (Baumgartner, 2020; Cragun, 2020; Kahwati \& Kane, 2020; Ragin, 1999; Whitaker et al., 2020). Equifinality is rooted in systems theory, and suggests that different paths can produce the same outcome (Baumgartner, 2020; Cragun, 2020; Kahwati \& Kane, 2020; Ragin, 1999, 2008; Whitaker et al., 2020). Asymmetry explains that when an explanatory set of conditions produces the outcome, the absence of the explanatory set cannot be assumed to lead to the nonoccurrence of the outcome (Kahwati \& Kane, 2020; Ragin, 1999, 2008; Schneider \& Wagemann, 2013). CCMs, which 
are grounded in regularity theory, are capable of incorporating those three dimensions. This is the case with this research which addresses SBHS delivery systems and features of secondary schools, and their potential role in both higher and lower rates of student absenteeism.

Given their theoretical grounding in regularity theory, CCMs such as QCA and CNA can serve as both research approaches and data analysis techniques. As mentioned earlier, this research used CNA; as a relatively new, developing method, the terminology used to describe the method with its corresponding documentation is also evolving. Every effort has been made throughout the discussion to provide citations from the literature to match prior practices and to employ language used by leaders in this methodological field. For example, CCMs are often referred to as "mathematical," rather than quantitative, given that the method is numerically based, but differs from more traditional statistical analyses one thinks of with the use of the term "quantitative" (E. Miech, personal communication, January 29, 2021). Additionally, these methods also employ a cross-case design, which involve comparisons across and within cases, but differs from the case-based focus of what is considered more traditional qualitative methods. Based on its grounding in and operation from a regularity framework perspective, this "young," rapidly developing method requires the use of different vocabulary and a different understanding for factor selection, data reduction, and modeling.

CCMs, including CNA, investigate different hypotheses and uncover different properties of causal structures by offering the means through which a sufficient and appropriate explanation of a phenomenon can be identified along with recognizing and allowing for levels of complexity common in social causation (Berg-Schlosser et al., 2009; 
Rohlfing \& Zuber, 2019; Thiem, 2017; Whitaker et al., 2020). Rather than quantifying the strength of a relationship between variables, CCMs seek to identify the combination of conditions whose collective presence is directly linked to an outcome of interest (Yakovchenko et al., 2020).

\section{Pragmatic Orientation}

A pragmatic orientation to this work emphasized the importance of the problem and the pluralistic approaches for the acquisition of knowledge with the underlying intention of seeking real-world, practice-oriented solutions (Creswell, 2014). The iterative process used in the CCMs approach is grounded in an understanding of systems thinking and provided a way for the researcher to examine the interactions, communication, role expectations and social control within and among the groups studied (Albright et al., 2013; Luke \& Stamatakis, 2012) - in this case, schools, their structural elements, and the processes by which SBHS are delivered. Moreover, this understanding aided in the researcher's ability to appreciate and interpret the dynamic nature of organizational and systems behavior concerning the delivery of health services in educational settings and how elements of these systems influence efforts to address student absenteeism.

\section{Conceptual Framework}

The Donabedian framework of health services organization $(1966,1978,1981)$ was used as the overarching foundational model for this analysis. Key elements within the school system and SBHS delivery were organized into Donabedian's categories of structure, process, and outcome. While the Donabedian model has been extensively applied in the assessment of health services delivery and quality, it has never been used before to explore 
the delivery of health services within schools, with the external school environment serving as the structure by which the processes of SBHS delivery were employed.

The three components of Donabedian's model (structure, process, and outcome) provided the framework for exploring how features embedded within a system may influence a school's ability to deliver quality, meaningful SBHS in its specific environment. SBHS can potentially serve as the process for mitigating the effects of HBLs. The structural and process elements examined in this present study in relation to the single educational outcome of absenteeism are shown in Figure 3.2 (which is a subset of the components illustrated in Figure 3.1). Table 3.1 lists operational definitions for each element.

Figure 3.2. Focused Structure, Process, Outcome Framework for This Research
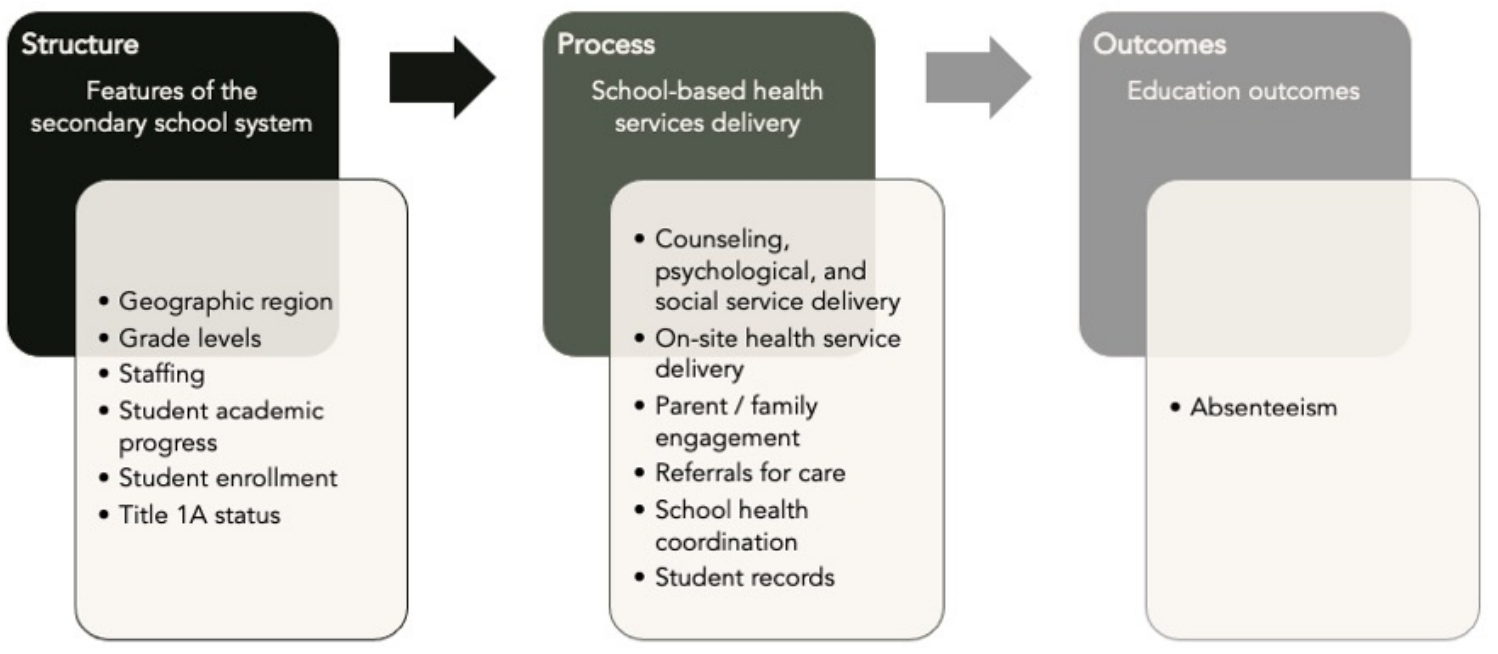
Table 3.1. Operational Definitions

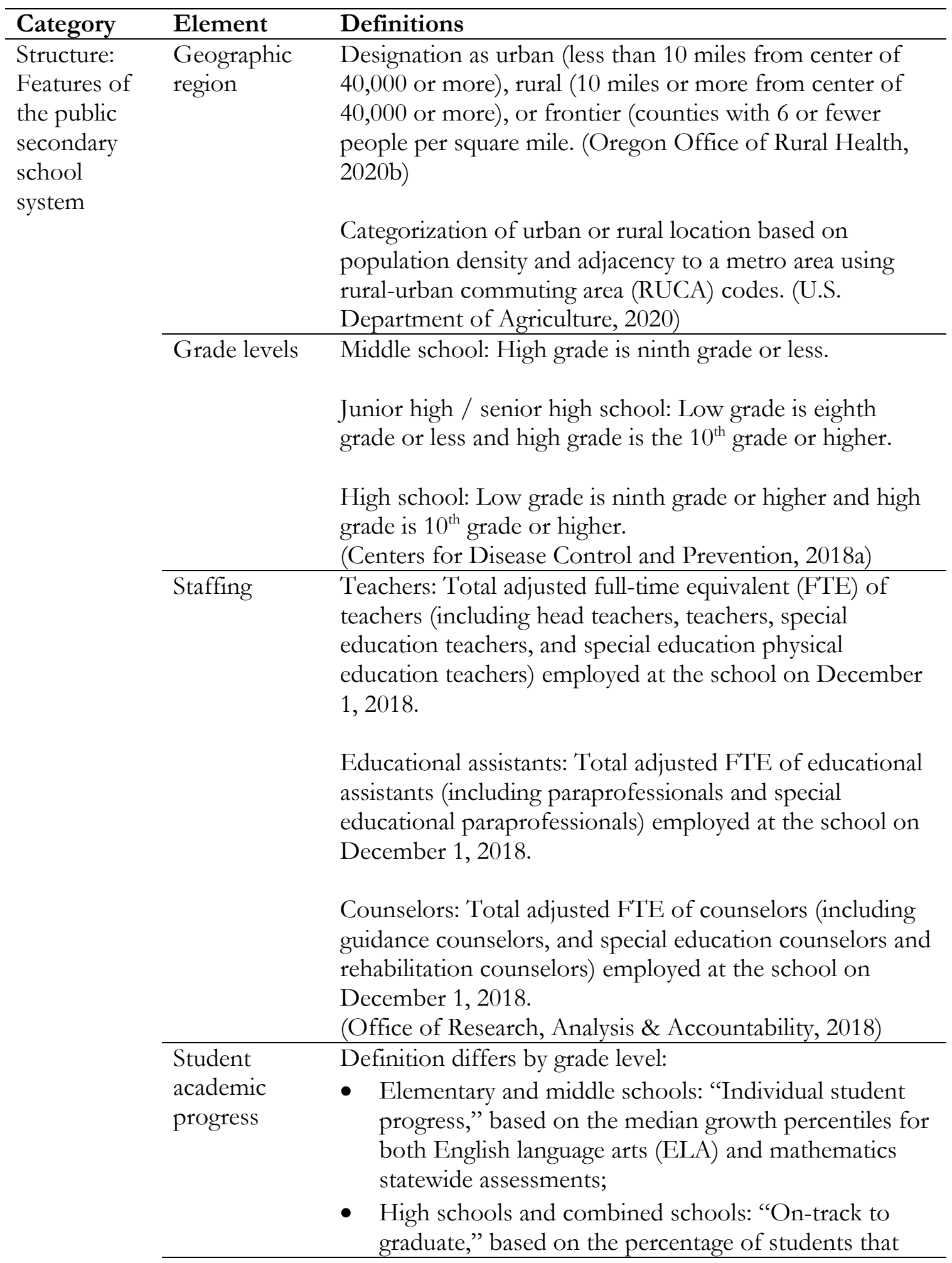




\begin{tabular}{|c|c|c|}
\hline & \multicolumn{2}{|c|}{$\begin{array}{l}\text { have earned at least one-quarter of required credits for } \\
\text { graduation in their first year in high school. } \\
\text { (Office of Research, Analysis \& Accountability, 2018) }\end{array}$} \\
\hline & $\begin{array}{l}\text { Student } \\
\text { enrollment }\end{array}$ & $\begin{array}{l}\text { Count of students enrolled in a school as captured on the } \\
\text { first school day in May. (Office of Research, Analysis \& } \\
\text { Accountability, 2018) }\end{array}$ \\
\hline & $\begin{array}{l}\text { Title 1-A } \\
\text { status }\end{array}$ & $\begin{array}{l}\text { A federal designation of a school with a high number or } \\
\text { high percentage of low-income children, based on the } \\
\text { Title 1, Part A federal education program under the Every } \\
\text { Student Succeeds Act. (U.S. Department of Education, 2018) }\end{array}$ \\
\hline \multirow[t]{5}{*}{$\begin{array}{l}\text { Process: } \\
\text { School- } \\
\text { based health } \\
\text { services } \\
\text { delivery }\end{array}$} & $\begin{array}{l}\text { Counseling, } \\
\text { psychological, } \\
\text { and social } \\
\text { services } \\
\text { delivery }\end{array}$ & $\begin{array}{l}\text { Provision of services offered according to one of three } \\
\text { models: } \\
\text { - School-supported with a separate mental health unit in } \\
\text { the school, } \\
\text { - Formal community connections and linkages through } \\
\text { contracts with mental health professionals, and/or } \\
\text { - Comprehensive and integrated health and mental } \\
\text { health services through SBHCs and programs that } \\
\text { address prevention, screening, referral, and direct care. } \\
\text { (American Academy of Pediatrics \& Council on School } \\
\text { Health, 2004; Centers for Disease Control and Prevention, } \\
\text { 2017b) }\end{array}$ \\
\hline & $\begin{array}{l}\text { On-site } \\
\text { health } \\
\text { services } \\
\text { delivery }\end{array}$ & $\begin{array}{l}\text { Provision of services that range from first aid and } \\
\text { emergency care to chronic health condition management } \\
\text { to sexual and reproductive health services. May include an } \\
\text { infrastructure that includes SBHCs or school nurses for } \\
\text { the direct provision of on-site care delivery. (Centers for } \\
\text { Disease Control and Prevention, 2017b, 2019h) }\end{array}$ \\
\hline & $\begin{array}{l}\text { Parent / } \\
\text { family } \\
\text { engagement }\end{array}$ & $\begin{array}{l}\text { Policies and practices that support students through } \\
\text { decision-making opportunities, classroom volunteering, } \\
\text { and routine communication, and support for families in } \\
\text { implementing health promotion practices at home. } \\
\text { (Centers for Disease Control and Prevention, } 2019 \mathrm{~h} \text { ) }\end{array}$ \\
\hline & $\begin{array}{l}\text { Referrals for } \\
\text { care }\end{array}$ & $\begin{array}{l}\text { Procedures and mechanisms for referrals to community- } \\
\text { based providers for more comprehensive care. (Centers } \\
\text { for Disease Control and Prevention, 2019h) }\end{array}$ \\
\hline & $\begin{array}{l}\text { School health } \\
\text { coordination }\end{array}$ & $\begin{array}{l}\text { Presence of an individual within the school to oversee the } \\
\text { school health program (school health coordinator), who } \\
\text { coordinates school health program activities, leads a } \\
\text { school health team, and integrates community-based } \\
\text { programs with school-based programs. (Centers for } \\
\text { Disease Control and Prevention, 2019h) }\end{array}$ \\
\hline
\end{tabular}




\begin{tabular}{|c|c|}
\hline $\begin{array}{l}\text { Student } \\
\text { records }\end{array}$ & $\begin{array}{l}\text { Use of student records (including student emergency } \\
\text { cards, medication records, health room visit information, } \\
\text { emergency care and daily management plans, physical } \\
\text { exam forms, and/or parent notes) to identify and track } \\
\text { student health. (Centers for Disease Control and } \\
\text { Prevention, 2019h) }\end{array}$ \\
\hline Absenteeism & $\begin{array}{l}\text { Percentage of students who attend } 90 \% \text { or fewer of their } \\
\text { enrolled days including excused, unexcused, and } \\
\text { discipline-related absences. (Attendance Works, n.d.; } \\
\text { Sprick \& Sprick, 2018) }\end{array}$ \\
\hline
\end{tabular}

\section{Research Design}

Given the complexity of the issue, the cross-sectoral context, and the desire to create actionable recommendations, a mathematical, cross-case design was most appropriate in this study for identifying school features that may influence the provision of health services in public secondary schools, and how the combination of the structural features and the SBHS delivery may affect student absenteeism (Albright et al., 2013; Cragun, 2020; Hay, 2016; Whitaker et al., 2020). To address the multifaceted research question posed in this study, the research design involved summarizing data on cases (individual secondary schools), transforming cases into configurations of specific conditions, then mathematically conducting cross-case comparisons for the purpose of identifying models to understand how distinct elements of structure and process exist, operate and work together in real-world settings (Albright et al., 2013; Biesta, 2010).

This approach contributed both breadth and depth to understanding health-based policy implementation in educational settings (J. Green \& Thorogood, 2014). A mathematical, cross-case design (shown in Figure 3.3) allowed for the investigation of the current systems landscape for public secondary schools and how the process and structural features of schools may influence the delivery of SBHS and student absenteeism. 
Figure 3.3. Research Design

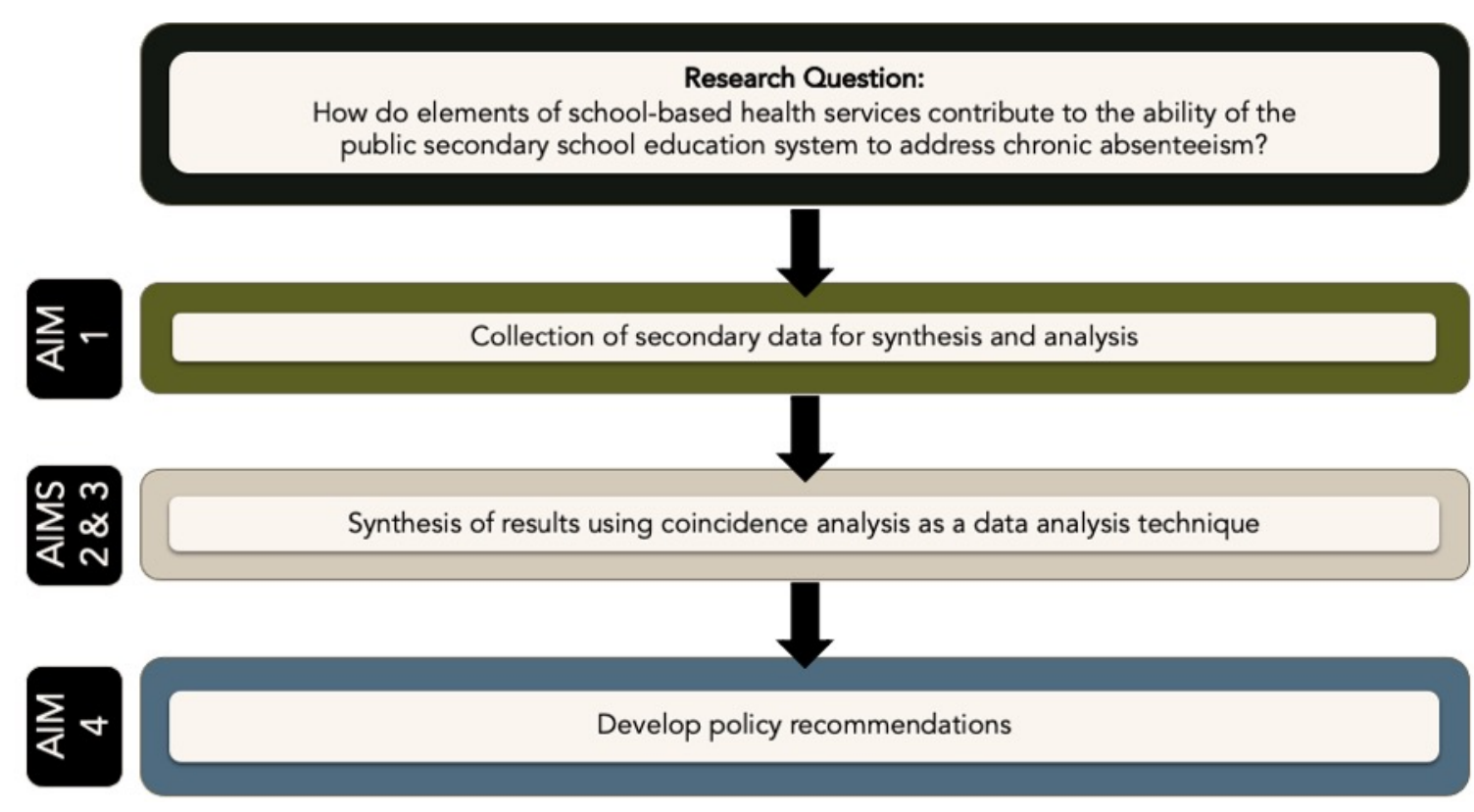

\section{Secondary Data Collection and Case Selection}

Using CNA as a mathematical, cross-case data analysis technique required collecting and analyzing data on different features of schools to describe and explain how different structural features of a school operate in conjunction with various process features of SBHS to affect student absenteeism. The original intention of the dissertation was to conduct this work and its analysis through a unique survey of Oregon's public K-12 system. Given the COVID-19 pandemic, this research was adapted to use data sources from the 2017-2018 school year to match the school-specific secondary data to the school health data obtained via the Oregon Health Authority (described in detail below).

\section{Secondary Data File}

School-specific secondary data were collected from various data sources for all public middle and high schools in Oregon $(\mathrm{N}=655)$ to create a master data file (see 
Appendix A for a mock-up of the data file). All data, except for the SBHS delivery data, were collected from the following publicly available sources:

- Oregon Department of Education “2017-2018 Oregon Title 1-A Schools” Word document (Oregon Department of Education, n.d.-c);

- Oregon Department of Education “2017-2018 Regular Attenders Report” (Oregon Department of Education, 2019a);

- Oregon Department of Education “2017-2018 Report Care Media Schools Aggregate" Excel file (Oregon Department of Education, 2018a);

- Oregon Department of Education “Institution Lookup Search” from Institution Boundary Database (Oregon Department of Education, 2021);

- Oregon Office of Rural Health "Spreadsheet of Oregon zip codes, towns, cities and service areas and their ORH urban/rural/frontier designation" (Oregon Office of Rural Health, 2020a); and,

- United States Department of Agriculture “2018 RUCA Codes” (U.S. Department of Agriculture, 2020).

The researcher categorized these data into main groups: 1) structural features of the secondary school system (e.g., zip code, urban/rural/frontier designation, grade levels, Title 1-A status), 2) school-based health services delivery, and 3) absenteeism rates (e.g., regular attenders' rate, chronically absent rate). All data were aggregated at the school level. A full list of all variables for the structural features of the secondary school system, along with their corresponding data source and citation, is provided in Appendix B. 


\section{School-Based Health Services Secondary Data Source}

The 2018 administration of the Centers for Disease Control and Prevention's (CDC’s) Department of Adolescent and School Health's School Health Profiles Surveys (SHPS) for Oregon provided the needed SBHS data, which were matched with the other secondary school-based data. This system of surveys is conducted biennially by education and health agencies among middle and high school principals and lead health education teachers to assess school health policies and practices (Centers for Disease Control and Prevention, 2019g). The CDC's 2018 SHPS Oregon data used for secondary data analysis in this study provided a reasonable proxy, at a time when school leaders were occupied with other pressing priorities and would have been unlikely to complete a survey that was not central to their work.

SHPS questionnaires have been administered by the CDC every two years since 1996, and are sent to a sample of schools in a state, large urban school district, or territory (Centers for Disease Control and Prevention, 2019e). The principal and lead health education teacher from each sampled school completes the self-administered questionnaires (Centers for Disease Control and Prevention, 2019e). The CDC SHPS monitor the current status of a number of school health policies and practices, including SBHS, school health education requirements and content, and school health coordination (Centers for Disease Control and Prevention, 2019e). The CDC SHPS provide information on seven of the 10 components of the Whole School, Whole Community, Whole Child model discussed in Chapter Two: health education, physical education and physical activity, nutrition environment and services, social and emotional climate, health services, family engagement, and community involvement (Centers for Disease Control and Prevention, 2019h). 
The 2018 CDC SHPS dataset for the state of Oregon had to be specially requested, as it is not publicly available. A data file containing school demographics, factors within the school, and absenteeism rates was sent to the Adolescent and School Health Program contact at the Oregon Health Authority (OHA), who agreed to populate the data file with survey responses from school principals and/or health education teachers responding to the 2018 administration of the SHPS in Oregon. The OHA contact matched survey responses from the 2018 SHPS Oregon weighted sample to those in the original dataset, which included all secondary schools in Oregon. The dataset was stripped by OHA of the following specific identifying variables: school name, ODE-issued school ID number, district name, ODE-issued district ID number, zip code, and county. If a variable contained data on fewer than five schools, the response was suppressed with a *. Access to the 2018 SHPS Oregon data provided by the OHA was managed according to the guidelines provided in a mutually signed data use agreement (see Appendix C).

The 2018 SHPS Principal Questionnaire included 50 questions, and the Lead Health Education Teacher Questionnaire included 27 questions. Many questions on both questionnaires had multiple parts. For the purposes of this study, 14 of the 50 questions on the Principal Questionnaire and two of the 27 questions on the Lead Health Teacher Questionnaire were used to provide detailed insight into key elements of SBHS delivery within each school. In some cases, a question may have had several sub-parts, and only some of the sub-parts were included in the analysis. A complete list of the 16 questions and their sub-parts used in this research can be found in Appendix D. More detail about the collection and integration of these data is addressed below. 


\section{Case Selection Rationale and Initial Exclusion Criteria}

For the purposes of this research, an individual secondary school served as a defined case, the primary focus of this analysis. Secondary data obtained from sources identified in the Secondary Data File section above were used to summarize and categorize specific features for each school. The cases included in this research were homogenous based on background characteristics (i.e., public secondary schools in Oregon), but heterogeneous with a large degree of variability regarding the various structural and process features of interest in this research, as well as the absenteeism outcome.

As stated above, all 655 public secondary schools in Oregon were originally identified for use in this study, such that data for all variables identified in Appendix A were included in the original data file. The SHPS deidentified data (provided by the OHA contact) were combined with the original data file, resulting in the inclusion of 282 secondary schools that completed one or both of the 2018 SHPS questionnaires. Of 282 secondary school responses, 20 were completed only by a lead health education teacher, 21 were completed only by the school principal, and 241 were completed by both. Schools that did not have a completed questionnaire from both the lead health education teacher and the school principal were excluded from the study. Additionally, two schools were dropped from the list of 241 schools due to suppressed absenteeism data. A total of 239 schools were used in the initial data analyses.

To ensure that this study's sample reflected the larger population of Oregon public secondary schools from the original data file, data for variables associated with structural features of the schools are displayed in Table 3.2. Percentages are calculated for each of the variables in each column. 
Table 3.2. Features of Secondary Schools Data by Exclusion Criteria

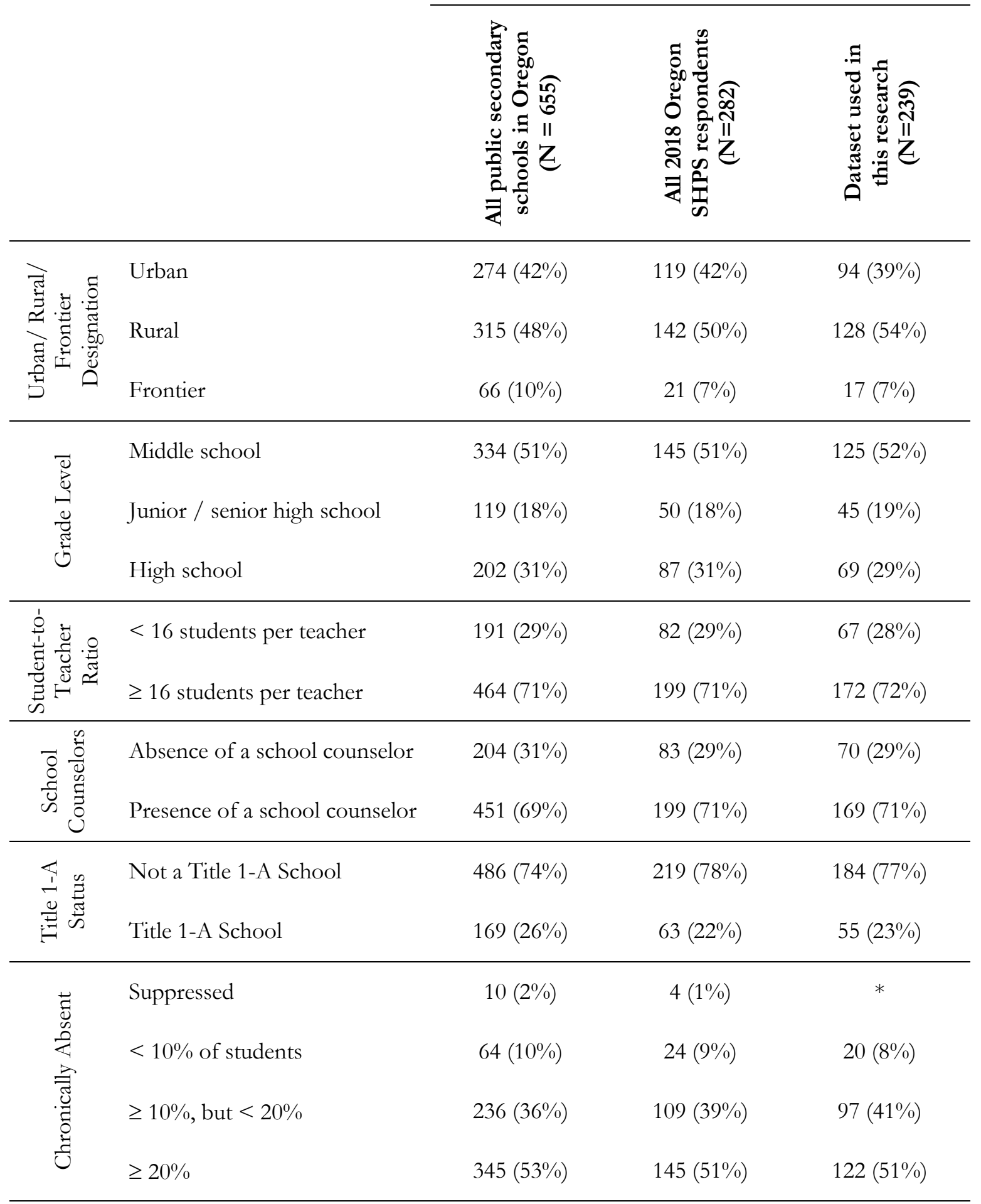

* Schools with suppressed chronically absent data were removed from the analysis. 


\section{Coincidence Analysis}

Certain structural and process features of schools were identified for consideration in the configurational analysis based on their theoretical, empirical, and practical relationships to the outcome of absenteeism. The data were analyzed using CNA, an analytic method whereby each observation is a case-based unit that is a whole, bounded, complex entity: an individual secondary public school. This data analysis technique provided a mathematical, cross-case analysis of the individual schools. All analyses with CNA were conducted using the R package "cna," as well as the software applications R and R Studio (Ambuehl \& Baumgartner, 2020).

A key element of conducting CNA is a process known as "calibration," which can be performed at different stages in the process. Each case (in this study, an individual school) is assessed with regard to its membership in each of the identified factors and the outcome of interest using a set membership score. Set membership scores for each factor were defined and assigned using rules that translate the raw summary data into scores based on theoretical reasoning, the distribution of cases in the data, and substantive knowledge about the context for the data (Schneider \& Wagemann, 2013). Set membership scores can be assigned using one of three different calibration techniques: crisp-set (binary; full membership or full nonmembership in a condition), multi-value (categorical; multinomial conditions), or fuzzy-set (differentiation from 0 to 1 , expressing degree of presence of absence of a condition;

Schneider \& Wagemann, 2013; Whitaker et al., 2020). All data used in this analysis were calibrated using either the crisp-set technique or the multi-value technique. More detail about the operationalization and calibration for factors and the outcome is provided below. 
Whitaker et al.'s (2020) three-step approach for conducting CNA was modified for use in this research into a seven-step process that is detailed below. The elaboration to seven steps provides more information and detail on data reduction and factor selection.

\section{Step 1: Define, Operationalize and Calibrate the Outcome of Interest}

To address the question of how features of schools and SBHS contribute to the secondary school education system's ability to address chronic absenteeism, school-level chronic student absenteeism was designated as the outcome of interest. Each school's absenteeism rate was calculated by dividing the total number of students who were chronically absent (missed more than $10 \%$ of school days) by the total number of students in the school. For the 2017-2018 school year (the time period which corresponds with all data used for this research), Oregon defined students as being chronically absent if they attended 90\% or fewer of their enrolled days (Oregon Department of Education, n.d.-b, 2018b).

The ODE’s Chronic Absenteeism Statewide Plan (2016), enacted by House Bill 4002, created a tiered system by which schools are classified based on their need for support to improve attendance. Tier I schools were those with less than $10 \%$ absenteeism rates, Tier II schools were those with absenteeism rates that were greater than or equal to $10 \%$ but less than $20 \%$, and Tier III schools were schools with absenteeism rates $20 \%$ or higher. For this research, the ODE tiered classification was used as a guide; upon review of the distribution of cases across the three tiers, schools in this dataset were assigned a crisp set membership score that classified Tier I ( $=20)$ and Tier II ( $=97)$ as schools with "lower" schoollevel chronic absenteeism, and Tier III schools $(\mathrm{N}=122)$ as schools with "higher" schoollevel chronic absenteeism (0: Tier I or Tier II schools; 1: Tier III schools). 


\section{Step 2: Perform Initial Data Reduction and Calibration to Create Data Matrix}

Factors related to the absenteeism outcome were selected using theoretical knowledge and empirical evidence through an iterative data analysis process. The original dataset included seven structural school features (e.g., Title 1-A status, student-to-teacher ratio, urban/rural/frontier designation) and 16 questions from the SPHS questionnaires. Many of the questions from the SPHS questionnaires had several sub-parts, resulting in 69 total questions. Some of the SPHS questions with sub-parts were grouped into larger metafactors when the sub-parts were logically similar. For example, the school principal's questionnaire asked if the school provided students with various health services. This question had 14 sub-parts. These 14 sub-parts were grouped into five categories: 1) human immunodeficiency virus (HIV)/sexually transmitted disease (STD)/pregnancy/ contraception-related services (9 sub-parts), 2) human papillomavirus (HPV) vaccine administration (1 sub-part), 3) alcohol or other drug use, abuse, or dependency assessment (1 sub-part), 4) chronic health condition daily medication administration or case management (2 sub-parts), and 5) provision of rescue or "as needed" medication for students experiencing a health emergency (1 sub-part) to create five different meta-factors.

The data were reduced using theoretical, logical and practical considerations to redefine the data with a total 37 explanatory factors for each school: five school features (e.g., urban/rural/frontier designation, presence of a school counselor, student-to-teacher ratio, Title 1-A status and grade level) and 32 combined questions from the SHPS questionnaires.

Each of the 37 explanatory factors was calibrated into a set membership score based on theory and research for that given condition. For example, grade levels were assigned a 
set membership score using multi-value calibration based on the categorization used in the SHPS Data User's Guide (Centers for Disease Control and Prevention, 2018d, 2018e, 2018a): 1: middle school (highest grade level is Grade 9 or below); 2: junior high/senior high school (lowest grade level is Grade 8 or lower, and the highest grade level is greater than or equal to Grade 10); 3: high school (lowest grade level is Grade 9 or higher, and highest grade level is Grade 10 or higher).

For questions from the SHPS questionnaires that were used in this analysis, several factors were assigned a set membership score allowing for binary differentiation between yes and no responses (0: no; 1 : yes), as well as a dummy value for coding missing data (99: missing or incorrectly answered). For each question where the answers to the sub-parts of the question were grouped, a sum score was calculated, and then a value was assigned $(0$ : zero; 1: one or more; 99: missing).

A complete list of the 37 explanatory factors, with each factor's calibration criteria and citations as appropriate, is presented in Appendix E.

Once the calibration process was complete, the data were transformed from the raw summary form to a data matrix (Schneider \& Wagemann, 2013; Whitaker et al., 2020). The data matrix is displayed as a .csv table with each case as a row, and the explanatory factors and the outcome are the subsequent columns. The set membership scores for a case's membership in each explanatory factor and the outcome are presented in the cells across the row (Schneider \& Wagemann, 2013). An excerpt of this study's data matrix is shown in Figure 3.4 for illustrative purposes, which shows 10 of the 37 total factors (columns) and 14 of the total 239 schools (rows) at this stage of the analysis. The complete data matrix used in 
the next step of data reduction and factor selection thus spanned 239 rows by 38 columns (not counting headers), which included the 37 explanatory factors and one outcome.

Figure 3.4. Excerpt from Data Matrix

\begin{tabular}{|c|c|c|c|c|c|c|c|c|c|c|}
\hline & & & & & Explanatory Facto & & & & & \\
\hline & $\begin{array}{c}\text { Coded Urban / } \\
\text { Rural / Frontier } \\
\text { Designation }\end{array}$ & $\begin{array}{c}\text { Coded Grade } \\
\text { Level }\end{array}$ & $\begin{array}{c}\text { Coded } \\
\text { Students-to- } \\
\text { Teacher Ratio }\end{array}$ & $\begin{array}{l}\text { Coded Total } \\
\text { Counselors }\end{array}$ & $\begin{array}{c}\text { Coded Title 1-A } \\
\text { status }\end{array}$ & \begin{tabular}{|c|} 
Coded PQ2F \\
Written SIP \\
includes health \\
services
\end{tabular} & $\begin{array}{c}\text { Coded PQ2G } \\
\text { Written SIP } \\
\text { includes } \\
\text { counseling, } \\
\text { psychological, } \\
\text { social services } \\
\end{array}$ & $\begin{array}{l}\text { Coded PO2J } \\
\text { Written SIP } \\
\text { includes family } \\
\text { engagement }\end{array}$ & $\begin{array}{c}\text { Coded PQ5 } \\
\text { Person to } \\
\text { oversee school } \\
\text { health / safety } \\
\text { programs and } \\
\text { actvities }\end{array}$ & $\begin{array}{c}\text { Coded PQ6 } \\
\text { Group to give } \\
\text { guidance on } \\
\text { policy } \\
\text { development / } \\
\text { activities } \\
\text { coordination }\end{array}$ \\
\hline Study ID & URL & GL & STR & TC & T1AS & $\mathrm{PQ} 2 \mathrm{~F}$ & $\mathrm{PQ} 2 \mathrm{G}$ & $P O 2 \mathrm{~J}$ & PQ5 & $P Q 6$ \\
\hline 101 & 2 & 3 & 0 & 0 & 0 & 0 & 0 & 1 & 1 & 0 \\
\hline 103 & 3 & 1 & 0 & 0 & 0 & 2 & 2 & 2 & 1 & 0 \\
\hline 104 & 1 & 1 & 1 & 0 & 0 & 0 & 1 & 1 & 1 & 0 \\
\hline 108 & 2 & 1 & 0 & 0 & 1 & 0 & 1 & 1 & 1 & 0 \\
\hline 109 & 1 & 1 & 1 & 0 & 0 & 1 & 1 & 1 & 1 & 99 \\
\hline 111 & 2 & 1 & 1 & 1 & 0 & 0 & 1 & 1 & 1 & 0 \\
\hline 112 & 1 & 2 & 1 & 1 & 0 & 1 & 1 & 1 & 1 & 0 \\
\hline 113 & 1 & 1 & 1 & 1 & 0 & 0 & 0 & 1 & 0 & 0 \\
\hline 114 & 2 & 3 & 1 & 1 & 0 & 99 & 99 & 99 & 99 & 99 \\
\hline 115 & 1 & 1 & 1 & 0 & 0 & 0 & 0 & 1 & 1 & 0 \\
\hline 117 & 3 & 3 & 0 & 1 & 0 & 0 & 0 & 1 & 0 & 0 \\
\hline 118 & 3 & 1 & 1 & 0 & 0 & 0 & 1 & 0 & 0 & 0 \\
\hline 119 & 2 & 1 & 1 & 1 & 0 & 99 & 99 & 99 & 99 & 99 \\
\hline 120 & 2 & 3 & 1 & 1 & 0 & 0 & 0 & 0 & 1 & \\
\hline
\end{tabular}

\section{Step 3: Identify Initial Key Factors Through Condition Table Creation}

As the number of factors included in an analysis increases, the number of logically plausible combinations of all possible conditions (configurations) increases exponentially (Kahwati \& Kane, 2020; Whitaker et al., 2020). This can lead to high dimensionality as well as limited diversity, whereby many theoretically possible configurations of conditions are not represented by any empiric cases in the dataset (Kahwati \& Kane, 2020; Rihoux \& Ragin, 2009; Schneider \& Wagemann, 2013). For example, for each binary factor included in a model $k$, there are $2^{k}$ logically possible configurations; therefore, with 37 binary factors, more than 137 billion configurational possibilities exist (Kahwati \& Kane, 2020; Rihoux \& Ragin, 2009; Schneider \& Wagemann, 2013). The factors used in this dataset were more complicated, given that some factors were calibrated using multi-value calibration, thereby creating three or more possible values for a factor. 
As discussed in Step 2, the calibrated dataset contained 37 explanatory factors, which included five school features, and 32 SBHS-related questions from the SHPS questionnaires. As each factor had been identified as being feasibly related to the absenteeism outcome, there were no compelling theoretical reasons to select certain explanatory factors over others in model development. To reduce the data from the 37 potential explanatory factors to a smaller analytic dataset suitable for use in model development and iteration, factor reduction was achieved using the "minimally sufficient conditions" (msc) function in the cna package in R following an analytic approach documented in Yakovchenko et al. (2020), Hickman et al. (2020), Petrik et al. (2020), and Coury et al. (2021). The msc routine is a configurational approach which operates within the regularity framework, and allowed for all 37 factors and all 239 cases to be examined at once to identify strategic configurations with the strongest apparent connections to the outcome.

Consistency and coverage are two parameters often used to measure the strength of set relationships, and both were used as key specifications in this data reduction phase of the analysis (Coury et al., 2021; Hickman et al., 2020; Kahwati \& Kane, 2020; Petrik et al., 2020; Yakovchenko et al., 2020). Consistency is the number of cases that have the outcome present and are covered by a given configurational solution divided by all cases covered by that given configurational solution (expressed as a number between 0 and 1). As described by Thygeson et al. (2012), "the consistency of the set-theoretical relationship is analogous to the $p$-value," whereby a higher consistency indicates an empirically significant set relationship, just as a $p$-value less than 0.05 demonstrates that statistical findings are likely to be due to chance. Coverage is the number of cases that have the outcome present and are 
covered by a given configurational solution divided by all cases with the outcome (also expressed as a number between 0 and 1$)$.

Using a process detailed in prior literature, a "condition table" was generated to list and organize the output from the msc routine (Coury et al., 2021; Hickman et al., 2020; Petrik et al., 2020; Yakovchenko et al., 2020). In a condition table, a row represents a configuration of conditions that meet a specified consistency level, with columns representing outcome, condition, consistency, coverage, and complexity (the number of separate conditions in a given configuration; Yakovchenko et al., 2020). Analyses to create the condition table were started by setting the consistency to 0.75 . Additionally, " $r$ " was set to a maximum of 4 , where $r$ stands for the number of objects to be selected at the same time from a larger set of $n$ objects (i.e., the 37 potential explanatory factors, each with at least two possible values). In setting $r$ to 4 , all 1 -condition, 2-condition, 3-condition, and 4-condition configurations across the 37 possible explanatory factors were considered, and all configurations that met the consistency threshold were retained in the condition table. Examining all possible 1-condition, 2-condition, 3-condition, and 4-condition configurations represented in a dataset is a computationally intensive process yet viable and within the capabilities of present-day computers. Computational limitations eliminated the possibility of examining more than 5-condition configurations with this dataset.

Once the various 1-condition, 2-condition, 3-condition, and 4-condition msc analyses had been completed, the condition table was reviewed in order to identify configurations of conditions that met all of the following criteria: 1) coverage scores $\geq 0.25$ (to avoid overfitting), 2) at least one mutable condition (in order to be policy-relevant), and 3) plausible theoretical, logical and empirical links to the outcome. 
For example, through this analysis, the researcher identified school grade level as a factor to select during subsequent model development. As displayed below in Figures 3.5 and 3.6, values related to school grade level repeatedly appeared in configurations for both higher chronic absenteeism as well as for lower chronic absenteeism, always combined with at least one mutable condition. In addition to being identified from the msc analysis, grade level also aligned with both background knowledge and logic; younger students may have less autonomy given the influence a parent may have over their school attendance (lower absenteeism rates), whereas older students my feel that they have more autonomy and are less subject to a parent's purview around school attendance. Since grade level met all criteria, it was retained within the smaller subset of factors to be used in subsequent model development.

Configurations in the condition table that met all three of these initial criteria are displayed in Figures 3.5 for the positive outcome $(\mathrm{O}=1)$ and Figure 3.6 for the negative outcome $(\mathrm{O}=0)$.

Figure 3.5. Condition Table for Positive Outcome $(\mathrm{O}=1)$

\begin{tabular}{|c|c|c|c|c|c|c|}
\hline Conflgurations of conditions & Outcome & Condition 1 & Condition 2 & Condition 3 & Consistency & Coverage \\
\hline GL-3*PQ36-1->0-1 & $\mathrm{O}-1$ & $G L=3$ & $P Q 36=1$ & & 0.827 & 0.352 \\
\hline$G L=3 \star P Q 50-0->0=1$ & $\mathrm{O}=1$ & $G L=3$ & $P Q 50=0$ & & 0.804 & 0.336 \\
\hline $\mathrm{GL}=3 \star P Q 38 K=1->0=1$ & $\mathrm{O}-1$ & $G L=3$ & PQ38K=1 & & 0.800 & 0.328 \\
\hline GL=3*TQ18-1->0-1 & $\mathrm{O}=1$ & $G L=3$ & TQ18=1 & & 0.826 & 0.311 \\
\hline PQ39K=1*TQ17A_I=0->O=1 & $\mathrm{O}=1$ & PQ39K=1 & TQ17A_I=0 & & 0.805 & 0.270 \\
\hline PQ39A_J=1*TQ17A_I=0->O=1 & $\mathrm{O}-1$ & PQ39A_J-1 & TQ17A_I=0 & & 0.780 & 0.262 \\
\hline GL-3*TC-1*PQ41A_G=1->0-1 & $\mathrm{O}=1$ & $G L=3$ & $\mathrm{TC}=1$ & PQ41A_G=1 & 0.800 & 0.328 \\
\hline PQ38LN=1*PQ39L=1*TQ17A_I=0->O=1 & $\mathrm{O}=1$ & PQ38LN=1 & PQ39L-1 & TQ17A_I & 0.760 & 0.311 \\
\hline
\end{tabular}


Figure 3.6. Condition Table for Negative Outcome $(\mathrm{O}=0)$

\begin{tabular}{|c|c|c|c|c|c|c|c|}
\hline Configurations of conditions & Outcome & Condition 1 & Condition 2 & Condition 3 & Condition 4 & Consistency & Coverage \\
\hline $\mathrm{GL}=1 * \mathrm{PQ} 42 \mathrm{G}=0->0=0$ & $\mathrm{O}=0$ & $G L=1$ & $P Q 42 G=0$ & & & 0.750 & 0.256 \\
\hline $\mathrm{GL}=1 \star T 1 \mathrm{AS}=0 \star \mathrm{PQ} 5-1->\mathrm{O}=0$ & $\mathrm{O}=0$ & $G L=1$ & T1AS $=0$ & PQ5 $=1$ & & 0.750 & 0.462 \\
\hline $\mathrm{GL}=1^{\star} \mathrm{T} 1 \mathrm{AS}=0^{\star} \mathrm{PQ} 38 \mathrm{~J}=1->\mathrm{O}=0$ & $\mathrm{O}=0$ & $G L=1$ & T1AS=0 & $P Q 38 \mathrm{~J}=1$ & & 0.781 & 0.427 \\
\hline $\mathrm{GL}=1 \star \mathrm{T} 1 \mathrm{AS}=0 \star \mathrm{PQ} 38 \mathrm{~K}=1->\mathrm{O}=0$ & $\mathrm{O}=0$ & $G L=1$ & T1AS $=0$ & PQ38K=1 & & 0.789 & 0.385 \\
\hline $\mathrm{GL}=1$ *PQ38J=1*PQ38M-0->0-0 & $\mathrm{O}=0$ & $G L=1$ & PQ38J $=1$ & $\mathrm{PQ} 38 \mathrm{M}=0$ & & 0.776 & 0.385 \\
\hline$G L=1 \star P Q 38 \mathrm{~J}=1$ *PQ39K=0->0=0 & $\mathrm{O}=0$ & $G L=1$ & $P Q 38 \mathrm{~J}=1$ & PQ39K=1 & & 0.789 & 0.385 \\
\hline $\mathrm{GL}=1$ *PQ38J=1*PQ39A_J=0->0=0 & $\mathrm{O}=0$ & $G L=1$ & $P Q 38 \mathrm{~J}=1$ & PQ39A_J=1 & & 0.772 & 0.376 \\
\hline $\mathrm{GL}=1 * \mathrm{PQ} 38 \mathrm{~K}=1$ *PQ45C-0->0-0 & $\mathrm{O}=0$ & GL-1 & $\mathrm{PQ} 38 \mathrm{~K}=1$ & $P Q 45 C=0$ & & 0.755 & 0.342 \\
\hline$G L=1 * P Q 38 K=1$ *PQ38M-0->0-0 & $\mathrm{O}=0$ & $G L=1$ & PQ38K=1 & $P Q 38 M=0$ & & 0.765 & 0.333 \\
\hline $\mathrm{GL}=1 \star \mathrm{PQ} 38 \mathrm{~K}=1 * \mathrm{PQ} 39 \mathrm{~K}=0->0=0$ & $\mathrm{O}=0$ & GL=1 & $P Q 38 K=1$ & $P Q 39 K=0$ & & 0.780 & 0.333 \\
\hline $\mathrm{GL}=1 * \mathrm{PQ} 5-1 * \mathrm{TQ} 18-1->\mathrm{O}=0$ & $\mathrm{O}=0$ & $G L=1$ & PQ5-1 & TQ18=1 & & 0.750 & 0.333 \\
\hline $\mathrm{GL}=1$ *PQ38K=1*PQ39A_J=0->0=0 & $\mathrm{O}=0$ & $G L=1$ & $P Q 38 K=1$ & PQ39A_J=1 & & 0.760 & 0.325 \\
\hline $\mathrm{GL}=1$ *T1AS=0*PQ39L $=1->0=0$ & $\mathrm{O}=0$ & $G L=1$ & T1AS $=0$ & PQ39L-1 & & 0.792 & 0.325 \\
\hline URL $=1 \star G L=1 * T 1 A S=0->0=0$ & $\mathrm{O}=0$ & URL=1 & $G L=1$ & T1AS=0 & & 0.776 & 0.325 \\
\hline $\mathrm{GL}=1 * \mathrm{~T} 1 \mathrm{AS}=0 * \mathrm{TQ} 18=1->\mathrm{O}=0$ & $\mathrm{O}=0$ & $G L=1$ & T1AS $=0$ & TQ18-1 & & 0.792 & 0.325 \\
\hline URL=1*GL=1*PQ38J=1->0-0 & $\mathrm{O}=0$ & URL-1 & $G L=1$ & $P Q 38 \mathrm{~J}=1$ & & 0.766 & 0.308 \\
\hline $\mathrm{GL}=1 * \mathrm{PQ} 38 \mathrm{M}=0$ *PQ42A_F $=0->\mathrm{O}=0$ & $\mathrm{O}=0$ & $G L=1$ & $\mathrm{PQ} 38 \mathrm{M}=0$ & PQ42A_F $=0$ & & 0.756 & 0.291 \\
\hline $\mathrm{GL}=1 \star T 1 \mathrm{AS}=0 * \mathrm{PQ} 38 \mathrm{~J}=1 * \mathrm{PQ} 46=1->0=0$ & $\mathrm{O}=0$ & $G L=1$ & T1AS=0 & $P Q 38 \mathrm{~J}=1$ & PQ46-1 & 0.800 & 0.376 \\
\hline $\mathrm{GL}=1$ *T1AS=0*PQ38K=1 ${ }^{*} \mathrm{PQ} 46=1->\mathrm{O}=0$ & $\mathrm{O}=0$ & $G L=1$ & T1AS=0 & PQ38K=1 & $P Q 46=1$ & 0.820 & 0.350 \\
\hline GL=1*T1AS=0*PQ5=1*PQ38J=1->0=0 & $\mathrm{O}=0$ & $G L=1$ & T1AS $=0$ & PQ5-1 & PQ38J=1 & 0.816 & 0.342 \\
\hline $\mathrm{GL}=1$ *PQ5=1*PQ38 J-1*PQ45C-0->0=0 & $\mathrm{O}=0$ & $G L=1$ & $P Q 5=1$ & $P Q 38 \mathrm{~J}=1$ & $P Q 45 C=0$ & 0.804 & 0.316 \\
\hline GL=1*T1AS=0*PQ38J =1*PQ45C-0->O=0 & $\mathrm{O}=0$ & GL=1 & T1AS $=0$ & $P Q 38 \mathrm{~J}=1$ & PQ45C $=0$ & 0.822 & 0.316 \\
\hline $\mathrm{GL}=1 * \mathrm{PQ} 38 \mathrm{~J}=1 * \mathrm{PQ} 39 \mathrm{~K}=0 * \mathrm{PQ} 50-0->0=0$ & $\mathrm{O}=0$ & $G L=1$ & PQ38J-1 & $P Q 39 K=0$ & PQ50-0 & 0.804 & 0.316 \\
\hline $\mathrm{GL}=1 \star T_{1} \mathrm{AS}=0 \star \mathrm{PQ} 5=1 \star \mathrm{PQ} 38 \mathrm{~K}=1->0=0$ & $\mathrm{O}=0$ & GL=1 & T1AS=0 & PQ5 $=1$ & $P Q 38 K=1$ & 0.818 & 0.308 \\
\hline $\mathrm{GL}=1$ 1*T1AS=0*PQ37=0*PQ39L=1->O=0 & $\mathrm{O}=0$ & $G L=1$ & T1AS $=0$ & $P Q 37=0$ & PQ39L-1 & 0.814 & 0.299 \\
\hline
\end{tabular}

Asymmetry is a key element of CCMs, which recognizes that when an explanatory

set of conditions produces the outcome, the absence of the explanatory set cannot be assumed to lead to the nonoccurrence of the outcome. Given the dual importance of identifying the structural and process elements within a school that may contribute to higher chronic absenteeism, as well as those that contribute to lower chronic absenteeism, the factors contributing to the positive outcome $(\mathrm{O}=1$; higher chronic absenteeism) as well as the factors contribution to the negative outcome $(\mathrm{O}=0$; lower chronic absenteeism) were explored in the analysis. 


\section{Step 4: Interpret Condition Table Results}

The condition table output (see Figures 3.5 and 3.6) was reviewed to identify all factors represented in configurations, narrowing the original list of potential explanatory factors to a smaller subset of discrete candidate factors to use in modeling.

Condition Table Interpretation for the Positive Outcome $(O=1)$

The condition-level output narrowed the original 37 potential explanatory factors to a smaller subset of 12 discrete candidate factors used for preliminary model iteration and development for the positive outcome. These 12 factors are listed in Table 3.3.

Table 3.3. Candidate Factors for Positive Outcome Preliminary Model Iteration

\begin{tabular}{|c|c|}
\hline Code & Factor \\
\hline GL & Grade level \\
\hline PQ36 & Presence of a part-time registered nurse who provided health services to students \\
\hline PQ38K & $\begin{array}{l}\text { Direct health services provided to students: Assessment for alcohol or other drug } \\
\text { use, abuse, or dependency }\end{array}$ \\
\hline PQ38LN & $\begin{array}{l}\text { Direct health services provided to students: Chronic health disease management, } \\
\text { including daily medication administration and case management }\end{array}$ \\
\hline PQ39A_J & $\begin{array}{l}\text { School-provided referrals to an organization or health care professional not on } \\
\text { school property: HIV/STD/pregnancy/contraception }\end{array}$ \\
\hline PQ39K & $\begin{array}{l}\text { School-provided referrals to an organization or health care professional not on } \\
\text { school property: HPV vaccine administration }\end{array}$ \\
\hline PQ39L & $\begin{array}{l}\text { School-provided referrals to an organization or health care professional not on } \\
\text { school property: Alcohol or other drug abuse treatment }\end{array}$ \\
\hline PQ41A_G & $\begin{array}{l}\text { Use of records to identify and track students with a current diagnosis of a chronic } \\
\text { condition (asthma, food allergies, diabetes, epilepsy or seizure disorder, obesity, } \\
\text { and/or hypertension/high blood pressure) }\end{array}$ \\
\hline PQ50 & $\begin{array}{l}\text { Students' families helped in the last two years to develop or implement policies and } \\
\text { programs related to school health }\end{array}$ \\
\hline TC & School counselors \\
\hline TQ17A_I & $\begin{array}{l}\text { School-provided health information to increase parent and family knowledge on } \\
\text { various health topics }\end{array}$ \\
\hline TQ18 & $\begin{array}{l}\text { Teachers gave students health education homework assignments or activities to do at } \\
\text { home with their parents }\end{array}$ \\
\hline
\end{tabular}


To further narrow factor selection, a preliminary model iteration routine was applied using the configurations as they appeared in the condition tables in $\mathrm{R}$. The purpose of this iterative routine was to identify factors for final model development that contributed to an overall model consistency level of 0.75 and that improved overall model coverage. The analytic routine began with the configuration with the highest coverage score, then proceeding down the rank-ordered condition table one row at a time. Simple models were developed by adding any new factors represented in the next row of the table. In each run of the preliminary model iteration, new additional factors were retained if the overall model coverage was improved by at least 0.030 points. For example, with the positive outcome model iterations, the addition of TQ18 only provided a model coverage score improvement of 0.025 , whereas the addition of PQ50 improved the model coverage score by 0.074 . Therefore, PQ50 was retained as a factor for final model development for the positive outcome, whereas TQ18 was not.

Through this preliminary model iteration routine, seven factors were retained for final model development for the positive outcome $(\mathrm{O}=1)$, which are listed in Table 3.4.

Table 3.4. Factors for Final Model Development for the Positive Outcome $(\mathrm{O}=1)$

\begin{tabular}{|c|c|}
\hline Code & Factor \\
\hline GL & Grade level \\
\hline PQ36 & Presence of a part-time registered nurse who provided health services to students \\
\hline PQ38K & $\begin{array}{l}\text { Direct health services provided to students: Assessment for alcohol or other drug use, } \\
\text { abuse, or dependency }\end{array}$ \\
\hline PQ39A_J & $\begin{array}{l}\text { School-provided referrals to an organization or health care professional not on school } \\
\text { property: HIV/STD/pregnancy/contraception }\end{array}$ \\
\hline PQ39K & $\begin{array}{l}\text { School-provided referrals to an organization or health care professional not on school } \\
\text { property: HPV vaccine administration }\end{array}$ \\
\hline PQ50 & $\begin{array}{l}\text { Students' families helped in the last two years to develop or implement policies and } \\
\text { programs related to school health }\end{array}$ \\
\hline TQ17A_I & $\begin{array}{l}\text { School-provided health information to increase parent and family knowledge on } \\
\text { various health topics }\end{array}$ \\
\hline
\end{tabular}




\section{Condition Table Interpretation for the Negative Outcome $(\mathrm{O}=0)$}

The same process was repeated for the negative outcome. The condition-level output narrowed the original 37 potential explanatory factors to a smaller subset of 17 discrete candidate factors used for preliminary model iteration and development for the negative outcome. These 17 factors are listed in Table 3.5.

Table 3.5. Candidate Factors for Negative Outcome Preliminary Model Iteration

\begin{tabular}{|c|c|}
\hline Code & Factor \\
\hline GL & Grade level \\
\hline PQ5 & $\begin{array}{l}\text { Presence of someone at the school to oversee or coordinate school health and safety } \\
\text { programs and activities }\end{array}$ \\
\hline PQ37 & Presence of a school-based health center that offers health services to students \\
\hline PQ38J & Direct health services provided to students: HPV vaccine administration \\
\hline PQ38K & $\begin{array}{l}\text { Direct health services provided to students: Assessment for alcohol or other drug use, } \\
\text { abuse, or dependency }\end{array}$ \\
\hline PQ38M & $\begin{array}{l}\text { Direct health services provided to students: Provision of rescue or "as needed" } \\
\text { medication for students experiencing a health emergency }\end{array}$ \\
\hline PQ39A_J & $\begin{array}{l}\text { School-provided referrals to an organization or health care professional not on school } \\
\text { property: HIV/STD/pregnancy/contraception }\end{array}$ \\
\hline PQ39K & $\begin{array}{l}\text { School-provided referrals to an organization or health care professional not on school } \\
\text { property: HPV vaccine administration }\end{array}$ \\
\hline PQ39L & $\begin{array}{l}\text { School-provided referrals to an organization or health care professional not on school } \\
\text { property: Alcohol or other drug abuse treatment }\end{array}$ \\
\hline PQ42A_F & $\begin{array}{l}\text { School-provided referrals to an organization or health care professional not on school } \\
\text { property for students diagnosed with or suspected to have a chronic condition } \\
\text { (asthma, food allergies, diabetes, epilepsy or seizure disorder, obesity, and/or } \\
\text { hypertension/high blood pressure) }\end{array}$ \\
\hline PQ45C & $\begin{array}{l}\text { School activity for family involvement: Involved parents as school volunteers in the } \\
\text { delivery of health education activities and services }\end{array}$ \\
\hline PQ46 & $\begin{array}{l}\text { Use of electronic, paper, or oral communication to inform parents about school } \\
\text { health services and programs }\end{array}$ \\
\hline PQ50 & $\begin{array}{l}\text { Students' families helped in the last two years to develop or implement policies and } \\
\text { programs related to school health }\end{array}$ \\
\hline T1AS & Title 1-A status \\
\hline TQ18 & $\begin{array}{l}\text { Teachers gave students health education homework assignments or activities to do at } \\
\text { home with their parents }\end{array}$ \\
\hline URL & Urban/rural/frontier designation \\
\hline
\end{tabular}


Similar to the process employed with the positive outcome candidate factors, a preliminary model iteration routine was applied using the configurations of factors as they appeared in the condition table in $\mathrm{R}$. The purpose of this iterative routine was to identify the factors for final model development that contributed to a model consistency level of 0.75 and that improved the overall model coverage level. The same threshold of model coverage improvement by 0.030 points was used in each run of the preliminary model iteration.

Through the preliminary model iteration routine, seven factors were retained for final model development for the negative outcome $(\mathrm{O}=0)$, which are listed in Table 3.6.

Table 3.6. Factors for Final Model Development for the Negative Outcome $(\mathrm{O}=0)$

\begin{tabular}{|c|c|}
\hline Code & Factor \\
\hline GL & Grade level \\
\hline PQ5 & $\begin{array}{l}\text { Presence of someone at the school to oversee or coordinate school health and safety } \\
\text { programs and activities }\end{array}$ \\
\hline PQ38J & Direct health services provided to students: HPV vaccine administration \\
\hline PQ38M & $\begin{array}{l}\text { Direct health services provided to students: Provision of rescue or "as needed" } \\
\text { medication for students experiencing a health emergency }\end{array}$ \\
\hline PQ39A_J & $\begin{array}{l}\text { School-provided referrals to an organization or health care professional not on school } \\
\text { property: HIV/STD/pregnancy/contraception }\end{array}$ \\
\hline PQ39K & $\begin{array}{l}\text { School-provided referrals to an organization or health care professional not on school } \\
\text { property: HPV vaccine administration }\end{array}$ \\
\hline T1AS & Title 1-A status \\
\hline
\end{tabular}

\section{Step 5: Create Final Data Set for Model Development}

Before applying CNA to each of the datasets, a close examination of the resulting case data can help to identify areas where the creation of a meta-factor may be helpful to decrease the number of overall factors in the analytic dataset. Disjunctive aggregation is a common CCM approach for reducing the number of conditions without completely 
eliminating the properties represented by either of the factors from the analysis (Whitaker et al., 2020). Disjunctive aggregation creates a new meta-factor that is coded as 1 if at least one of the factors is present, and as 0 if neither of the factors is present.

Disjunctive aggregation was performed on the same factors that were used in both the positive outcome dataset and the negative outcome dataset: PQ39A_J (school-provided referrals to an organization or health care professional not on school property for HIV/STD/pregnancy/contraception-related services) and PQ39K (school-provided referrals to an organization or health care professional not on school property for HPV vaccine administration). A meta-factor, PQ39A_K, that disjunctively aggregated PQ39A_J and PQ39K, was created for both datasets, such that the new factor indicated schoolprovided referrals to an organization or health care professional not on school property for $\mathrm{HIV} / \mathrm{STD} /$ pregnancy/contraception-related services and/or HPV vaccine administration. Of the 99 cases that had either PQ39A_J and/or PQ39K present, 92 (92.9\%) of them had both present.

During final model development, cases with missing data for any of the factors used in the final modeling need to be excluded. For the positive outcome dataset, a total of 51 cases were excluded, leaving a total of 188 cases in the dataset. For the negative outcome dataset, a total of 47 cases were excluded, leaving a total of 192 cases in the dataset.

To summarize the data reduction and factor selection process, the original set of 76 explanatory factors was first reduced to 37 factors using theoretical, logical and practical considerations. For the positive model, through the generation and interpretation of the condition table, this set of 37 factors was then reduced to a smaller subset of 12 discrete candidate factors for the positive outcome (higher absenteeism). The set of 37 was factors 
was reduced to a smaller subset of 17 discrete candidate factors for the negative outcome (lower absenteeism). Next, through a preliminary model iteration routine, the number of factors was further reduced, resulting in seven factors retained for use in final model development for the positive outcome $(\mathrm{O}=1)$ and seven factors retained for the negative outcome $(\mathrm{O}=0)$. Then two factors were disjunctively aggregated into a meta-factor, further reducing the number of factors by one. In the end, guided by configurational output, the initial set of 76 factors was reduced to six factors to use in final modeling for both the positive and negative outcomes. Figure 3.7 illustrates the summary of the data reduction and factor selection process.

Figure 3.7. Data Reduction and Factor Selection

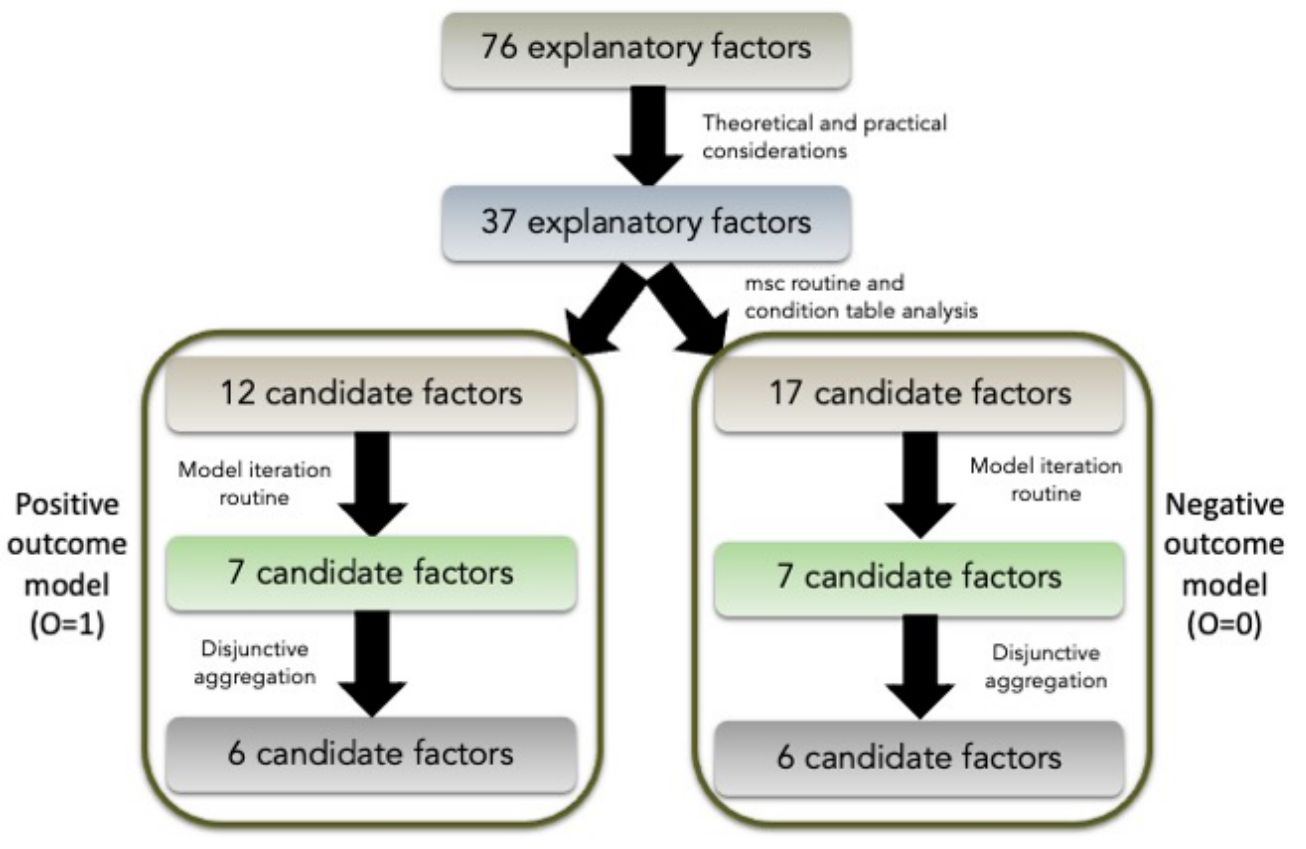




\section{Step 6: Perform Coincidence Analysis Using the cna Package in $\mathbf{R}$}

For configurational model development, consistency and coverage are two parameters of fit that provide insight into the strength of the dependence between conditions and the outcome (Ragin, 2008; Whitaker et al., 2020). As discussed above, a consistency score can range from 0 to 1 , and is calculated by dividing the number of cases that have the outcome present and are covered by a given configurational solution by all cases covered by that given configurational solution (Kahwati \& Kane, 2020; Schneider \& Wagemann, 2013). A lower consistency score indicates that the dependence between a condition or a model and the outcome does not follow a strict Boolean or deterministic dependence (Whitaker et al., 2020). Coverage can also range from 0 to 1, and is calculated by dividing the number of cases that have the outcome present and are covered by a given configurational solution by all cases with the outcome (Coury et al., 2021; Hickman et al., 2020; Petrik et al., 2020; Yakovchenko et al., 2020). A lower coverage score demonstrates that a configuration or a model is potentially not as empirically important based on the dataset. In other words, consistency is how reliably a set of conditions is linked with a given outcome, and coverage is the extent to which a given outcome is explained by a particular set of conditions (Ragin, 2008).

When applying CNA to a dataset, the algorithm starts with conditions and combinations of conditions that meet the default consistency and coverage thresholds of 1.0 programmed within the cna software package for $\mathrm{R}$ (Ambuehl \& Baumgartner, 2020; Whitaker et al., 2020). However, very high consistency and coverage thresholds can potentially lead to overfitting model solutions when using maximal thresholds (Whitaker et al., 2020). Given that this dataset was relatively "noisy" (e.g., coding for missing values, 
factors that may not be associated with the absenteeism outcome), the researcher systematically varied consistency and coverage thresholds while iteratively modeling the six factors associated with the positive outcome, and the six factors associated with the negative outcome. As described in Step 5, two separate datasets, one for the positive outcome with six factors and another for the negative outcome with six factors, were used with the CNA model development, with 188 cases and 192 cases respectively.

\section{Step 7: Interpret Results}

The results of the CNA are presented below with an interpretation of the mathematical output from R to explain which model provides the best solution. For both the positive outcome $(\mathrm{O}=1)$ and negative outcome $(\mathrm{O}=0)$ models, solution pathways were dropped if they did not explain at least $10 \%$ of the as-of-yet unexplained cases; these pathways were eliminated in the interest of parsimony, as they only contributed marginally to the overall model. Additionally, to avoid overfitting the model, pathway conditions were removed from solution terms if: 1) removal of those conditions increased overall model coverage by at least $0.050,2)$ the solution pathway maintained a consistency of $\geq 0.750$, and

3) the overall model maintained a consistency of $\geq 0.750$.

All models use the following identical terms as part of their solution: "+" symbolizes the Boolean operator OR, “*” symbolizes AND, and “< $>$ > ” expresses sufficiency and necessity.

\section{Positive Outcome Model: Chronic Absenteeism Greater Than or Equal to 20\%}

Using the subset of factors associated with schools displaying the positive outcome $(\mathrm{O}=1)$, or $20 \%$ or more of the student population being chronically absent throughout the school year, one model was identified, as shown in Figure 3.8. 


\section{Figure 3.8. Positive Outcome Solution Model with Solution Pathways}

\begin{tabular}{|c|c|c|}
\hline \multirow{2}{*}{$\begin{array}{l}\text { Higher Absenteeism }(\mathrm{O}=1) \text { Solution Model } \\
\text { PQ39A_K=1*TQ17A_I=0 + GL=3*PQ36=1 +GL=2*PQ36=1*PQ38K=1 <->O=1 }\end{array}$} & Consistency & Coverage \\
\hline & $0.807(80.7 \%)$ & $0.684(68.4 \%)$ \\
\hline \multicolumn{3}{|l|}{ Higher Absenteeism Solution Pathway \#1 } \\
\hline PQ39A_K=1*TQ17A_I $=0<->O=1$ & $0.810(81.0 \%)$ & $0.347(34.7 \%)$ \\
\hline \multicolumn{3}{|l|}{ Higher Absenteeism Solution Pathway \#2 } \\
\hline $\mathrm{GL}=3 * \mathrm{PQ} 36=1<->\mathrm{O}=1$ & $0.818(81.8 \%)$ & $0.367(36.7 \%)$ \\
\hline \multicolumn{3}{|l|}{ Higher Absenteeism Solution Pathway \#3 } \\
\hline $\mathrm{GL}=2 * \mathrm{PQ} 36=1 * \mathrm{PQ} 38 \mathrm{~K}=1<->\mathrm{O}=1$ & $0.769(76.9 \%)$ & $0.102(10.2 \%)$ \\
\hline
\end{tabular}

This solution model had high consistency (consistency $=0.807$ or $80.7 \%$ of cases

with that configuration expressed the outcome), and reasonable coverage (coverage $=0.684$, or $68.4 \%$ of all cases with the outcome were explained with this configuration). Five of the six factors used for model development for $\mathrm{O}=1$ were present in this model: 1) grade level (GL), 2) presence of a part-time registered nurse who provides health services to students (PQ36), 3) direct health services provided to students: Assessment for alcohol or other drug use, abuse, or dependency (PQ38K), 4) school-provided referrals to an organization or health care professional not on school property for HIV/STD/pregnancy/contraceptionrelated services and/or HPV vaccine administration (PQ39A_K), and 5) school-provided health information to increase parent and family knowledge on various health topics (TQ17A_I). The factor that did not appear in the final model was PQ50: "Students' families helped in the last two years to develop or implement policies and programs related to school health.” In plain language, this model had three solution paths:

- High absenteeism solution pathway \#1 (HASP1): School-provided referrals to an organization or health care professional not on school property for HIV/STD/pregnancy/contraception-related services and/or HPV vaccination services (PQ39A_K) AND no school-provided health information to increase parent and family knowledge on various health topics (TQ17A_I=0); OR 
- High absenteeism solution pathway \#2 (HASP2): High school (GL=3) AND the presence of a part-time registered nurse who provides health services to students less than 5 days a week, less than all school hours, or both (PQ36=1); OR

- High absenteeism solution pathway \#3 (HASP3): Junior high/senior high school $(G L=2)$ AND the presence of a part-time registered nurse who provides health services to students less than 5 days a week, less than all school hours, or both (PQ36=1), AND direct health services provided to students: assessment for alcohol or other drug use, abuse, or dependency (PQ38K=1).

In brief, this three-pathway solution model featured one pathway (HASP1) that spanned all grade levels, and two that were grade-level dependent (HASP2 for GL=3 and HASP3 for GL=2). Additionally, the presence of a part-time registered nurse (PQ36=1) was sufficient in high schools $(\mathrm{GL}=3)$ to produce the higher absenteeism outcome, but in junior high/senior high schools (GL=2), it needed to be additionally combined with the direct service provision of alcohol or other drug use, abuse or dependency assessment to produce the outcome. More in-depth substantive discussion of the findings related to the higher absenteeism outcome is presented in Chapter Four.

\section{Negative Outcome Model: Chronic Absenteeism Less Than 20\%}

Using the subset of factors associated with schools displaying the absence of the outcome $(\mathrm{O}=0)$, or less than $20 \%$ of the student population being chronically absent throughout the school year, eight models were identified (see Appendix E). The eight solution models for the negative outcome each explained a majority of the cases that expressed the absence of the outcome of high student absenteeism using a different group of factors. Of the eight solution models, one solution model, shown in Figure 3.9, was 
selected as the preferred model for further explanation and discussion. The final solution model was selected given that it had a higher consistency level than the other models (consistency $=0.789$ or $78.9 \%$ of cases with that configuration expressed the absence of the outcome), and similarly high coverage (coverage $=0.755$, or $75.5 \%$ of all cases with $\mathrm{O}=0$ were explained with this configuration).

Figure 3.9. Negative Outcome Solution Model with Solution Pathways

\begin{tabular}{|c|c|c|}
\hline Lower Absenteeism $(\mathrm{O}=0)$ Solution Model & Consistency & Coverage \\
\hline$T 1 A S=1 * P Q 38 J=1 * P Q 39 A \_K=0+G L=1 * T 1 A S=0 * P Q 5=1+G L=1 * P Q 38 J=1 * P Q 39 A \_K=0+G L=2 * T 1 A S=1 * P Q 38 J=0<->O=0$ & $0.789(78.9 \%)$ & $0.755(75.5 \%$ \\
\hline Lower Absenteeism Solution Pathway \#1 & & \\
\hline $\mathrm{T} 1 \mathrm{AS}=1 * \mathrm{PQ} 38 \mathrm{~J}=1 * \mathrm{PQ} 39 \mathrm{~A} \_\mathrm{K}=0<->\mathrm{O}=0$ & $0.789(78.9 \%)$ & $0.160(16.0 \%$ \\
\hline Lower Absenteeism Solution Pathway \#2 & & \\
\hline $\mathrm{GL}=1 * T 1 \mathrm{AS}=0 * \mathrm{PQ} 5=1<->\mathrm{O}=0$ & $0.776(77.6 \%)$ & $0.479(47.9 \%$ \\
\hline Lower Absenteeism Solution Pathway \#3 & & \\
\hline $\mathrm{GL}=1$ *PQ38J=1*PQ39A_K=0 <->O=0 & $0.782(78.2 \%)$ & $0.457(45.7 \%$ \\
\hline Lower Absenteeism Solution Pathway \#4 & & \\
\hline $\mathrm{GL}=2 * \mathrm{~T} 1 \mathrm{AS}=1 * \mathrm{PQ} 38 \mathrm{~J}=0<->\mathrm{O}=0$ & $1.000(100 \%)$ & $0.043(4.3 \%)$ \\
\hline
\end{tabular}

Five of the six factors used for model development for the absence of the outcome were present in this solution model: 1) grade level (GL), 2) Title 1-A status (T1AS), 3) presence of someone at the school to oversee or coordinate school health and safety programs and activities (PQ5), 4) direct health services provided to students: HPV vaccine administration (PQ38J), and 5) school-provided referrals to an organization or health care professional not on school property: HIV/STD/pregnancy/contraception-related services and/or HPV vaccine administration (PQ39A_K). The factor that did not appear in the final model was PQ38M: "Direct health services provided to students: Provision of rescue or "as needed" medication for students experiencing a health emergency." In plain language, this model had four solutions paths:

- Lower absenteeism solution pathway \#1 (LASP1): Title 1-A school (T1AS=1) AND direct health services provided to students: HPV vaccine administration (PQ38J=1) AND no school-provided referrals to an organization or health care professional not 
on school property for HIV/STD/pregnancy/contraception-related services and/or HPV vaccination services (PQ39A_K=0), OR

- Lower absenteeism solution pathway \#2 (LASP2): Middle school (GL=1) AND not a Title 1-A school (T1AS=0) AND presence of someone at the school to oversee or coordinate school health and safety programs and activities (PQ5=1), OR

- Lower absenteeism solution pathway \#3 (LASP3): Middle school (GL=1) AND direct health services provided to students: HPV vaccine administration (PQ38J=1) AND no school-provided referrals to an organization or health care professional not on school property for HIV/STD/pregnancy/contraception-related services and/or HPV vaccination services (PQ39A_K=0), OR

- Lower absenteeism solution pathway \#4 (LASP4): Junior high/senior high school $(\mathrm{GL}=2)$ AND a Title 1-A school (T1AS=1) AND no direct health services provided to students: HPV vaccine administration $(\mathrm{PQ} 38 \mathrm{~J}=0)$.

In brief, this four-pathway solution model covered all but four of the middle school cases $(G L=1)$. Additionally, one pathway (LASP1) spanned all grade levels, whereas the other three pathways (LASP2, LASP3, and LASP4) were grade-level dependent. As with the higher absenteeism outcome model, a more in-depth substantive discussion of the findings is presented in Chapter Four.

\section{General Observations About Positive and Negative Outcome Findings}

Some general observations are worth noting about both the positive and negative models. First, with both models, a "signal" was identified within a noisy dataset not originally designed to explain chronic absenteeism. Second, only a relatively small number of factors were needed to explain $>67.0 \%$ of the cases that displayed the positive outcome, 
and $>75.0 \%$ of the cases that displayed the negative outcome, both at high consistency levels $(80.7 \%$ and $78.9 \%$, respectively). Third, the two models both demonstrated complex causality, equifinality and asymmetry, all key features and characteristics of CCMs. Finally, both models can be directly observed and verified in the datasets themselves (see Appendix F for the positive outcome $(\mathrm{O}=1)$ and Appendix $\mathrm{G}$ for the negative outcome $(\mathrm{O}=0))$. More in-depth substantive discussion of the findings is presented in Chapter Four.

\section{Protection of Human Participants}

The research process was supervised by the doctoral dissertation committee chair and committee and adhered to the ethical standards for research involving human participants as outlined by Portland State University (Portland State University, n.d.). Per the Portland State University Human Research Protection protocols, the researcher obtained and maintained certification in Human Subjects Research from the Collaborative

Institutional Training Initiative (Portland State University, n.d.). All data collection methods and instruments were jointly submitted by the researcher and dissertation committee chair to the Portland State University Institutional Review Board (IRB) for approval on December 22, 2020, and the research was granted an exemption determination on January 5, 2021 (HRPP\# 207148-18). The IRB Notice of Exempt Certification can be found in Appendix H.

All information obtained through the secondary data collection was anonymized. Each school (case) was assigned a unique study identification (ID) number to protect the school's privacy. When the fully populated data file was received from OHA, all school identifying information had been stripped from the data file. This ensured that school identity was protected, a requirement of the OHA's agreement for the researcher's use of the 
data. During the data analysis, only a school's study ID was used. Use of the 2018 SHPS data provided by the OHA was managed according to the guidelines provided in a mutually signed data use agreement, dated December 22, 2020 (see Appendix C). The data security

plan was approved by the Office of Research and Graduate Studies at Portland State University. All secondary data appeared in aggregated or de-identified form in the presentation of findings.

\section{Conclusion}

This research study was designed to answer the following question: How do elements of school-based health services contribute to the ability of the secondary school education system to address chronic absenteeism? A comprehensive understanding of the full range of SBHS as a means of mitigating the effects that health problems and illness have on a student's ability to attend school regularly is largely missing from the literature. Understanding the variations of SBHS that are situated between HBLs and the causal pathways that can create poor educational outcomes, in combination with features of a school, is needed. Using individual schools as diverse but representative cases to explore how the structure and delivery of SBHS can facilitate opportunities to diminish the effects students' HBLs have on a student's ability to attend school will aid in addressing this gap.

Given the complexity of the issue, the cross-sectoral context, and the desire to create actionable recommendations, the explanatory, systematic, mathematical cross-case design and methods described in this chapter were used to develop an understanding of where factors that potential influence SBHS delivery may exist, and how those factors may interact to be difference makers for the determination of the student absenteeism outcome. A 
comprehensive discussion of the research implications of these findings is presented in Chapter Five.

The data collection strategy was modified to respond to the COVID-19 pandemic, since schools were in modified operations and attempting to maintain educational delivery in a virtual environment. All public schools in Oregon ceased in-person education in midMarch 2020; when data collection for this study was going to begin, it became apparent that there would likely be poor responses to a new survey fielded to schools, and that it would be intrusive to attempt to conduct any interviews or surveys with principals and other educators who were preoccupied with delivering educational services during the pandemic. The methods described here reflect the adaptations the researcher made to respect the current situation, while still enabling progress to be made on the dissertation. As described in this chapter, the research question and aims were also modified to reflect this revised research strategy. 


\section{Chapter Four - Discussion}

\section{Overview}

A student's ability to attend school regularly can be directly affected by unaddressed poor health-related behaviors, illness, and chronic disease. Days of missed school can be a major contributor to poor student academic achievement, which has potentially serious implications for outcomes across the life course with subsequent effects on an individual's socioeconomic status, earning potential, problem-solving skills, and, ultimately, health. The integration of health services in schools may serve as the means by which chronic absenteeism, diminished educational outcomes, and poor health can be addressed. The confluence of factors related to characteristics of public secondary schools and the systemlevel environment influence school-based health services (SBHS) delivery as a means for addressing the health barriers to learning (HBLs) experienced by students.

The literature summarized in Chapter Two demonstrated that although there is widespread acknowledgement and understanding of the intersectionality between health and education, no research to date provides a comprehensive overview of how different structures and processes within a school work (or do not work) together to achieve educational and health performance outcomes. More specifically, a comprehensive description of the structures and systems within schools that influence SBHS delivery as a means for mitigating the effects that health problems and illness have on a student's ability to attend school regularly does not exist. This research seeks to fill that gap.

Chapter Three described how models for both higher and lower school-level chronic absenteeism rates were developed. Both models used coincidence analysis (CNA) to identify 
the combination of factors within the public secondary school system and SBHS delivery that contribute to higher or lower chronic absenteeism. This chapter discusses the Chapter Three findings in greater detail, and identifies where these findings relate to and/or extend the literature reviewed in Chapter Two. The chapter is organized to address the first three research aims of this study:

1. Create a unique categorization of the structures and systems of school-based health services delivery in Oregon's public secondary schools;

2. Identify elements that potentially influence the availability, delivery, and quality of health services in secondary schools in Oregon; and

3. Examine and compare configurations of the structural and process elements derived from this understanding of school-based health services delivery that contribute to the outcome of absenteeism.

The policy recommendations from Aim Four will be addressed in Chapter Five, along with study limitations and implications for future research.

\section{Aim One: Unique Categorization of Structures and Systems of School-Based Health Services Delivery}

The work supporting the investigation of Aim One of this research created a unique categorization of the structural elements of the secondary school system and the process elements of SBHS delivery within that system among Oregon's public middle and high schools. To address Aim One, this section synthesizes and discusses key findings from the secondary data collection used for subsequent analysis in this research, and the ways in which that data were uniquely focused and categorized. 
As discussed in Chapter Three, Donabedian's framework of health services organization $(1966,1978,1981)$ as a means for understanding and assessing health care quality served as the overarching framework for structuring the elements used in the subsequent analysis in this study. His landmark 1966 article provided the structure, process, outcome triad to assess quality of health care (Donabedian, 1966); more than five decades later, it continues to be the foundation of quality assessment, including its use and endorsement by many health care certification and accreditation organizations (Ayanian \& Markel, 2016; Berwick \& Fox, 2016). While the Donabedian model has been extensively used and applied in the assessment of health services delivery and quality, this study analyzes the first report that describes the delivery of health services within structures and systems of public education (absent any unpublished studies that may not have been identified).

Donabedian originally wrote about the quality of medical care, and defined structure as the settings and administrative systems that support and direct the provision of care; process as the delivery of different components of care; and outcome as concrete elements of care in regard to functional restoration, recovery and survival (Donabedian, 1966). These definitions were refined to apply to the scope of this work. Application of the three-part framework served as the foundation to explore how features embedded within a school's system (structures) may shape and influence the features of SBHS delivery (processes) within its school-specific environment, with subsequent consideration for their interactive ability to shape education and health outcomes. Figure 3.1 (presented earlier) illustrates this framework as a means for articulating the structural features of the secondary school system, process features of SBHS delivery, and education and health outcomes. 
In the context of this work, the different school-level features cumulatively create the structural environment by which SBHS are offered to students. These structural elements are predominantly demographic characteristics of a school, including grade levels, geographic region, and Title 1-A status, and may be either modifiable or nonmodifiable. The schoollevel structures, in combination, give rise to the administrative systems and settings that may support and direct the provision of SBHS delivery activities within a school.

Various components of SBHS delivery, including on-site health services delivery, referrals for care, and student health coordination, comprise the process elements of the structure-process-outcome framework. A large degree of variability exists within SBHS, and these process elements are largely dependent on a school's structural elements, including its characteristics and defining features. The interaction among the school-level settings, systems and structures, and the intermediary process elements of SBHS delivery can lead to different student health or education outcomes.

A variety of structural, process and outcome elements could be studied to answer the larger research question in this study. The availability of data largely determined the initial selection of elements used for the purposes of this research (which also was affected by the COVID-19 pandemic). However, the elements considered in this study were also selected based on their demonstrated relevance to health services availability and quality, as well as their connection to the absenteeism outcome.

A review of various publicly available data sources describing specific structural elements of the secondary school system narrowed the list in Figure 3.1 to five structural elements: geographic region, grade levels, staffing, student enrollment, and Title 1-A status. The process elements of SBHS delivery chosen for use in this analysis were based on the 
questions used in the Centers for Disease Control and Prevention's (CDC's) 2018 School Health Profiles Survey (SHPS) questionnaires. The use of this secondary data source limited the aspects of SBHS delivery chosen for inclusion, given that school-level responses were provided as answers to a standardized set of questionnaires. Use of these secondary data narrowed the list of process elements included in the analysis from six elements to four: onsite health services delivery, parent and family engagement, referrals for care, and school health coordination.

As described in Chapter Two, a number of education and health outcomes could be considered to examine the effects of HBLs on academic achievement and longer-term health issues. Given its demonstrated connection to other health and education outcomes, as well as the availability of school-level secondary data through the Oregon Department of Education, absenteeism was chosen as the single outcome measure. The resultant categorization of the school-based structural elements, the process elements of SBHS delivery, and the absenteeism outcome is illustrated in Figure 4.1, as a refined and focused reiteration of Figure 3.1. These structure, process, and outcome elements will be discussed in additional detail in the next section regarding Aim Two of this research.

Figure 4.1. Focused Structure, Process, Outcome Framework for This Research
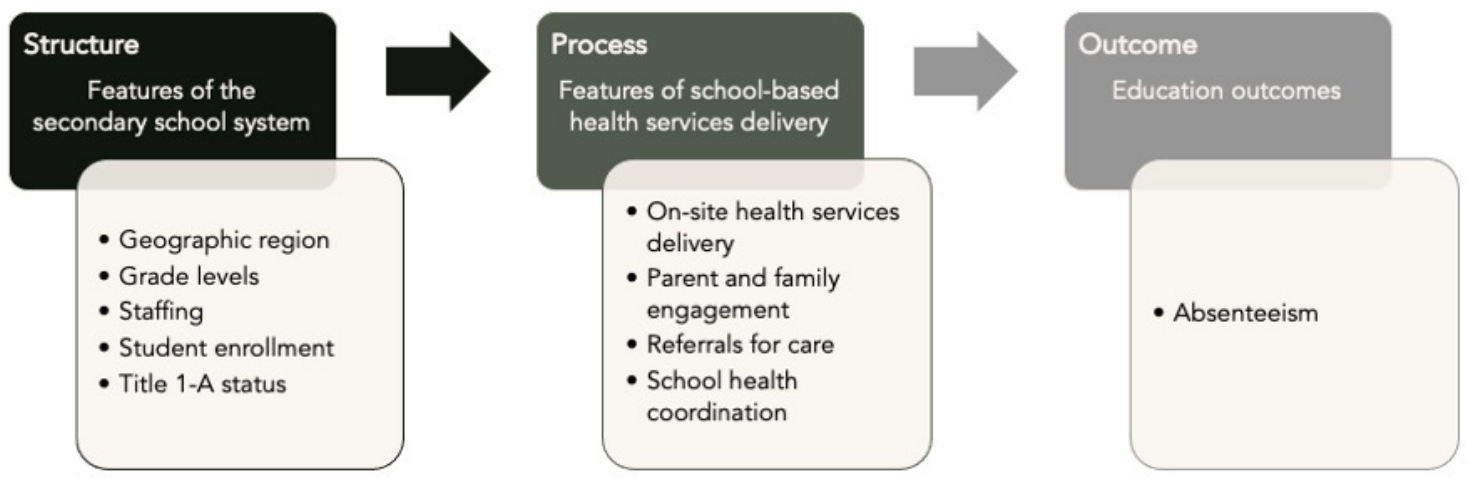
The selection of distinct structure-process-outcome elements for this study, despite some limitations given the data sources used, provided the means for the development of a more robust answer to the research question: How do elements of school-based health services contribute to the ability of the public secondary school education system to address chronic absenteeism? As Donabedian states in his 1966 work: "More often one needs to ask, 'What goes on here?' rather than 'What is wrong; and how can it be made better?”' (p. 196). Based on Donabedian's framework, this research allowed for the creation of a unique categorization by which school-level structural elements were identified for their role in creating the specific environmental context through which process elements of SBHS delivery can be initiated and maintained in that setting. The intentional separation of structural school elements and SBHS delivery process elements into distinct, but interactive, groupings provided a categorization which permitted an examination of the potential effects of structural elements or process elements on their own, as well as the interplay between the two. To answer the question of "what goes on here" in different public secondary school settings throughout the state, the structure-process interaction was explored in the subsequent case-based configurational analysis in this study as a means for addressing Aim Three. In summary, the unique categorization illustrated in Figure 4.1 demonstrates the investigation of Aim One.

\section{Aim Two: Elements Affecting Health Services Availability, Delivery, and Quality}

The investigation of Aim Two of this research described and identified the elements that influence health services availability, delivery, and quality in secondary schools using the 
unique categorization designed to address Aim One. To address Aim Two, this section provides a description of the various structural and process elements identified for inclusion in the subsequent analysis.

As discussed in Chapter Three, the original dataset for this research contained data for 239 individual schools (cases), 37 explanatory factors, and one outcome. The 37 potential explanatory factors addressed varying features of the five structural elements and four SBHS-related process elements from Figure 4.1. The 37 potential explanatory factors are summarized in Table 4.1 below, and are categorized according to their associated structural or process element from Figure 4.1.

\section{Table 4.1. Explanatory Factors}

\begin{tabular}{|c|c|c|}
\hline & Elements & Factors \\
\hline \multirow{5}{*}{ 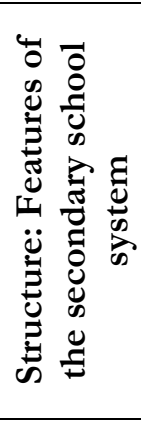 } & $\begin{array}{l}\text { Geographic } \\
\text { region }\end{array}$ & Urban/rural/frontier designation \\
\hline & Grade level & Grade level \\
\hline & Staffing & School counselors \\
\hline & $\begin{array}{c}\text { Student } \\
\text { enrollment }\end{array}$ & Students-to-teacher ratio \\
\hline & $\begin{array}{l}\text { Title 1-A } \\
\text { status }\end{array}$ & Title 1-A status \\
\hline \multirow{8}{*}{ 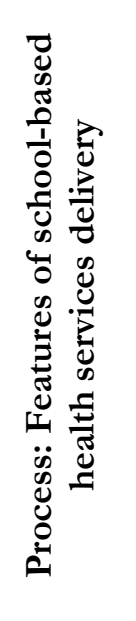 } & \multirow{8}{*}{$\begin{array}{l}\text { On-site } \\
\text { health } \\
\text { services } \\
\text { delivery }\end{array}$} & Full-time school nurse \\
\hline & & Part-time school nurse \\
\hline & & School-based health center \\
\hline & & Direct health services: HIV/STD/pregnancy/contraception \\
\hline & & Direct health services: HPV vaccine administration \\
\hline & & $\begin{array}{l}\text { Direct health services: Alcohol/drug use, abuse, or dependency } \\
\text { assessment }\end{array}$ \\
\hline & & Direct health services: Chronic health disease management \\
\hline & & $\begin{array}{l}\text { Direct health services: Rescue or "as needed" medication delivery for } \\
\text { health emergencies }\end{array}$ \\
\hline
\end{tabular}




\begin{tabular}{|c|c|}
\hline \multirow{9}{*}{$\begin{array}{l}\text { Parent and } \\
\text { family } \\
\text { engagement }\end{array}$} & $\begin{array}{l}\text { School activity for family involvement: Information to communicate with } \\
\text { children about sex }\end{array}$ \\
\hline & $\begin{array}{l}\text { School activity for family involvement: Information about child } \\
\text { monitoring }\end{array}$ \\
\hline & $\begin{array}{l}\text { School activity for family involvement: Parents involved as volunteers for } \\
\text { health education activities and services }\end{array}$ \\
\hline & $\begin{array}{l}\text { School activity for family involvement: Linking parents/families to } \\
\text { community health services and programs }\end{array}$ \\
\hline & $\begin{array}{l}\text { School activity for family involvement: Disease-specific information for } \\
\text { parents with students who have chronic health conditions }\end{array}$ \\
\hline & $\begin{array}{l}\text { Use of electronic, paper, or oral communication with parents about } \\
\text { school health services and programs }\end{array}$ \\
\hline & $\begin{array}{l}\text { Students' families involved in developing and implementing school health } \\
\text { policies and programs }\end{array}$ \\
\hline & School-provided health information to increase parent/family knowledge \\
\hline & $\begin{array}{l}\text { Health education homework assignments or activities for students to do } \\
\text { with their parents }\end{array}$ \\
\hline \multirow{5}{*}{$\begin{array}{l}\text { Referrals for } \\
\text { care }\end{array}$} & Referrals for HIV/STD/pregnancy/contraception \\
\hline & Referrals for HPV vaccine administration \\
\hline & Referrals for Alcohol or other drug abuse treatment \\
\hline & $\begin{array}{l}\text { Referrals for students diagnosed with/suspected to have a chronic health } \\
\text { condition }\end{array}$ \\
\hline & $\begin{array}{l}\text { Referrals for students diagnosed with/suspected to have oral health } \\
\text { condition }\end{array}$ \\
\hline \multirow{10}{*}{$\begin{array}{l}\text { School } \\
\text { health } \\
\text { coordination }\end{array}$} & Written School Improvement Plan (SIP) with health services objectives \\
\hline & Written SIP with counseling, psychological, and social services objectives \\
\hline & Written SIP with family engagement objectives \\
\hline & $\begin{array}{l}\text { Person to oversee/coordinate school health and safety programs and } \\
\text { activities }\end{array}$ \\
\hline & $\begin{array}{l}\text { One or more group to offer policy development guidance or activity } \\
\text { coordination on health topics }\end{array}$ \\
\hline & $\begin{array}{l}\text { School health council, committee, or team activity: Student health need } \\
\text { identification using review of relevant data }\end{array}$ \\
\hline & $\begin{array}{l}\text { School health council, committee, or team activity: Health and safety } \\
\text { policy and activity recommendations to school administrators or school } \\
\text { improvement team }\end{array}$ \\
\hline & $\begin{array}{l}\text { School health council, committee, or team activity: Sought funding or } \\
\text { leveraged resources to support health and safety priorities }\end{array}$ \\
\hline & $\begin{array}{l}\text { School health council, committee, or team activity: Communicated } \\
\text { importance of health and safety policies and activities to various entities }\end{array}$ \\
\hline & $\begin{array}{l}\text { Use of records to identify and track students with chronic health } \\
\text { conditions }\end{array}$ \\
\hline
\end{tabular}


The five structural and four process elements from Figure 4.1 are separately discussed in detail below with regard to their relevance in affecting health services availability, delivery, and quality, and in some cases, their connection to higher or lower student absenteeism.

\section{Structural Elements: Features of the Secondary School System}

The five specific structural elements of the secondary school system identified for inclusion in this study were geographic region, grade levels, staffing, student enrollment, and Title 1-A status.

\section{Geographic Region}

Despite being an unmodifiable structural element, a school's urban, rural, or frontier designation can provide important insights about a student's ability to access services and the range of services that are available within their geographic area. Individuals living in rural communities generally experience lower access to care with regard to affordability, proximity, and quality, when compared to those in urban settings (Jones et al., 2009). Specifically with regard to the study population for this study, the literature acknowledges that many children and adolescents underuse the health care system due to various accessrelated barriers, including health insurance restrictions, limited transportation, decreased appointment availability and/or lack of age-appropriate care (Fothergill \& Ballard, 1998;

Gibson et al., 2013; Gregg et al., 2019). This confluence of barriers and issues with access are likely to be worse in rural and frontier settings, which suggests that the availability of health services in schools may serve as a critical, effective and convenient opportunity for addressing needs that are not otherwise being met. 
Additionally, a school's geographic designation can largely dictate access to services and the availability of different types of partnerships among community-based organizations, businesses, and schools. Adolescents who live in rural areas experience substantial health status disparities and face additional challenges in accessing needed services (Institute of Medicine, 2009). Engaging students and their families with the larger community helps to foster connections to share and maximize resources (Michael et al., 2015); however, depending on the geographic designation of a particular school, access to those community services may be more limited.

Geographic designation has also been associated with differential effects on student absenteeism in certain communities. According to Henderson, Hill, and Norton (2014), chronic absenteeism is a consistent problem for students in urban, suburban, and rural areas; however, for students in earlier grades, chronic absenteeism is higher for students in rural areas. Rates of absenteeism may differ by geographic designation, as well as by grade level in those areas, which provides opportunities for focused intervention.

\section{Grade Levels}

Grade levels ${ }^{1}$ served by a school have implications for students' age-related behavior with regard to access to care, as well as absenteeism. Grade level, as a proxy for student age, may be important in regard to an adolescent's ability to and need for access to primary care services. As discussed above, adolescents face a number of access-related barriers, including issues around a lack of age-appropriate care, which often causes them to underuse the health

\footnotetext{
1 The three-tiered grade level structure used in this research included the following categorization: middle school (high grade is Grade 9 or less), junior high/senior high school (low grade is Grade 8 or less and high grade is Grade 10 or higher), and high school (low grade is Grade 9 or higher and high grade is Grade 10 or higher).
} 
care system (Fothergill \& Ballard, 1998; Gibson et al., 2013; Gregg et al., 2019). Adolescents are less likely to utilize primary care services (Rand \& Goldstein, 2018); however, health services in schools may serve as an age-specific means for focused attention on needs that are not otherwise being met in more traditional primary care settings.

In addition to the connection between grade level (student age) and access to health services, data reported in the literature demonstrate a correlation between grade level and rates of student absenteeism. Chronic absenteeism rates are highest among students in ninth through $12^{\text {th }}$ grade (Falcon et al., 2016). In their report on chronic absenteeism, Balfanz and Byrnes (2012) stated that while absenteeism rates improve in elementary grades, they tend to reverse course in middle grades. Steady and substantial increases in student absenteeism are seen throughout high school, indicating that new factors in the middle grades progressively lead more students to miss more school. It is plausible that younger students may have less autonomy given parental influence over school attendance, whereas older students may be less subject to a parent's purview. Therefore, older adolescents may require increased attention and programming for focused strategic interventions to keep them engaged in and connected to school. This literature demonstrates a correlation between grade level and student absenteeism.

\section{Staffing}

School staff, including teachers, instructional assistants, administrators, support staff and school counselors, provide more than just educational services to students; they provide support and attention, which encourage a safe and healthy environment that can promote student connectedness, engagement and overall well-being (Basch, 2011e; Lewallen et al., 2015). A school social environment focused on encouragement, support, and engagement 
can promote healthy behaviors and protect against risky behaviors, including the ways in which school staff can serve as positive role models for students (Basch, 2011e; Michael et al., 2015). When students feel disconnected and disengaged, they can be more likely to get involved with activities and behaviors that can adversely affect both educational and health outcomes (Basch, 2011e).

School counselors, a specific type of staff, can play an especially critical role in student perception of school connectedness and engagement. School counselors largely focus on three areas of student growth: academic development, career development and social/emotional development (American School Counselor Association, 2019). With regard to health services availability and delivery, the presence of a school counselor provides students with access to a qualified individual who can, among other responsibilities, provide assessment for their mental health needs (American School Counselor Association, 2020). The presence of a school counselor in the school environment serves as a key structural element that can shape the awareness of the accessibility and availability of health services.

\section{Student Enrollment}

As discussed in the prior section, increased, positive student engagement and connectedness with school can be critical for both educational and health outcomes. In a larger school with high student enrollment, those feelings of inclusion and involvement can be improved through smaller class sizes. Lower student-to-teacher ratios have been shown to result in higher test scores, fewer dropouts, and a more equitable learning environment, through increased, focused teacher attention (Kieschnick, 2018). Small classes afford teachers the opportunity to engage in more individualized teaching, and at the secondary school level, this has been shown to be even more impactful for lower attaining students 
(Blatchford et al., 2011). While not only being beneficial for educational outcome

achievement, the individualized attention may also benefit students by encouraging teachers to be increasingly attuned to their students' health needs (Lewallen et al., 2015). Student-toteacher ratio provided a key indicator for class size, teacher attention, and connectedness to health services, resources, and availability, and it was reasonable to expect student-to-teacher ratios to be associated as a factor that is causally connected to student absenteeism rates.

\section{Title 1-A Status}

Title 1, Part A (Title 1-A) of the Elementary and Secondary Education Act of 1965 seeks to improve educational opportunities for low achieving students by supporting reforms and innovations to close educational achievement gaps by providing all children opportunities to receive a fair, equitable, and high-quality education (U.S. Department of Education, 2016b). Designated Title 1-A schools receive financial assistance due to higher numbers of low-income children within that school, and this designation can be considered a reasonable proxy for a school's low-income status (Oregon Department of Education, n.d.e). Title 1-A schools can use their funding for strategies designed to improve student achievement, as identified by the school's comprehensive needs assessment, including activities to improve student attendance (U.S. Department of Education, 2016b). The increased attention and focus provided by school administrators through the planning, documentation, and monitoring required of Title 1-A schools may imply differential conditions for higher or lower student absenteeism. Moreover, depending on a school's needs assessment and its improvement strategies, administrators and Title 1-A coordinators may deem the emphasis of school health services to be warranted for focused school improvement efforts as an education and health mitigation strategy. 


\section{Process Elements: Features of School-Based Health Services Delivery}

The four process elements that described features of SBHS delivery included in this study were on-site health services delivery (including school nurses, school-based health centers (SBHCs), and direct care delivery), parent and family engagement, referrals for care, and school health coordination.

\section{On-Site Health Services Delivery}

School health services, on-site preventive primary care services and/or chronic disease tracking and management services, are provided with the intention of intervening and addressing actual, and potential, health problems among students (Lewallen et al., 2015). These services can be delivered through a number of different means, including the direct provision of care either through a school nurse or by health professionals at a SBHC. The provision of these services on-site can be especially critical for students who might otherwise have problems accessing such services outside the school environment (Institute of Medicine, 2009).

Health services provided to students on-site can range from first aid and emergency care to the management of chronic health conditions to preventive primary care (Centers for Disease Control and Prevention, 2019h; Lewallen et al., 2015; Michael et al., 2015). The provision of these services on-site can help address the various access-related barriers experienced by adolescents, with care provided by various types of qualified professionals including school nurses, nurse practitioners, dentists, dental hygienists, physician assistants and/or allied health personnel (Fothergill \& Ballard, 1998; Gibson et al., 2013; Gregg et al., 2019; Lewallen et al., 2015). 
Since the beginning of the $20^{\text {th }}$ century, school nurses have provided varying degrees of treatment, education, diagnostic and preventive services to students (Allensworth et al., 1997; Gustafson, 2005). School nurses not only serve as an extension of the public health system in the school setting, they also are important gatekeepers who support student success, connectedness and engagement by providing assessment, intervention and followup (American Academy of Pediatrics, 2016; Centers for Disease Control and Prevention, 2019h; National Association of School Nurses, 2018). Both the American Academy of Pediatrics (AAP) and the National Association of School Nurses recommend staffing by one full-time professional school nurse in every school, all day every day (American Academy of Pediatrics, 2016; National Association of School Nurses, 2018).

The use of schools as health access sites for students has grown with the increased prevalence of SBHCs throughout the United States over the last three decades (American Academy of Pediatrics, 2001; Love et al., 2018; Love, Schlitt, Soleimanpour, et al., 2019). SBHCs can provide students with comprehensive physical, mental and preventive health services on school property, while simultaneously addressing many of the barriers identified by adolescents and their families face with accessing care (Albright et al., 2016; O'Leary et al., 2014). Moreover, SBHCs integrate several characteristics of the patient-centered medical home in the delivery of services to students and their families, including the provision of access to high quality primary care, service as a continuous and comprehensive access point, and the coordination of primary care using an interdisciplinary team (Agency for Healthcare Research and Quality, n.d.; Albright et al., 2016; American Academy of Pediatrics, 2002; O'Leary et al., 2014). The presence of a school nurse and/or a SBHC may have direct effects 
on the availability, delivery, and quality of preventive and chronic disease management services for students.

\section{Parent and Family Engagement}

By engaging parents and families in school health activities through take-home lessons and parent-directed information or communications, schools can reinforce practices learned in school to promote healthy behaviors at home (Centers for Disease Control and Prevention, 2019h). Additionally, schools can actively engage parents as volunteers in the creation of school health policies and practices (i.e., decision-making opportunities) to further increase parental support. These activities can directly influence a student's behavior and academic achievement through increased school connectedness and engagement (Centers for Disease Control and Prevention, 2019h; Epstein \& Sheldon, 2002). Parental and family engagement can directly influence and affect the provision of school health services availability, delivery, and quality through their support and involvement.

\section{Referrals for Care}

Community engagement and involvement can provide schools with resources and services to help meet the health-related needs of students that a school cannot provide on its own. School-provided referrals to student-friendly, community-based providers not only facilitates key connections for students to entities in the larger community, but also fosters the community's investment in the promotion of student health and well-being (Centers for Disease Control and Prevention, 2019h; Michael et al., 2015). When direct health services are not able to be provided on-site, referrals for care provide a meaningful alternative for care delivery, availability and access. 


\section{School Health Coordination}

Oversight of school health efforts either by an individual (i.e., a school health coordinator) or a team, council or committee is critical for the coordination of various school health program and activities (Basch, 2011e; Centers for Disease Control and Prevention, 2019h; Michael et al., 2015). Individual efforts that are focused on key health priorities should be contextualized and integrated into the larger school health priorities to ensure that efforts are linked and coordinated and aimed at achieving key strategic goals and objectives in the most comprehensive and coordinated ways possible (Basch, 2011e). Coordination of school health programs and activities includes not only assessing, monitoring and making adjustments to internal school health events and actions, but also takes into account the partnerships and community engagement activities that exist with the groups, organizations and entities beyond the school walls (Centers for Disease Control and Prevention, 2019h). This comprehensive approach and perspective with regard to both internal school health services, and those available through external relationships can influence health services availability, delivery and quality.

\section{Inclusion of Factors in Association with Higher or Lower Absenteeism}

To address Aim Two, the previous discussion presented a narrative for each of the five structure and four process elements that were recognized as potentially influencing health services availability, delivery, and quality in secondary schools. Although the various structural and process elements were determined to be theoretically and empirically relevant to health services availability, delivery, and quality, and in some cases to student absenteeism, a discussion of each element in isolation would not provide a holistic, systems-level perspective. The purpose of the case-oriented configurational comparative methods (CCMs) 
used in this research was to examine the ways in which the various factors in combination may be implicated in producing the outcome of either higher absenteeism or lower absenteeism. To being the configurational exploration, the list of potential explanatory factors needed to be mathematically selected, such that the data could be appropriately reduced.

Of the 37 potential explanatory factors, 10 distinct factors were mathematically associated with the higher and/or the lower absenteeism outcome (six related to higher absenteeism and six related to lower absenteeism with two in common). These 10 factors are associated with two structural elements and four process elements, which were described in the Aim One discussion. The factors were used in the subsequent CCM analysis for final model development to address Aim Three (described below). These structural and process elements, along with the 10 distinct factors included in final model development, are summarized in Table 4.2. Variable names are provided in parentheses to simplify tracking to the discussion in Chapter Three. 


\section{Table 4.2. Summary of Factors Included in Final Model Development}

\begin{tabular}{|c|c|c|c|c|}
\hline & \multirow{2}{*}{ Elements } & \multirow{2}{*}{ Factors } & \multicolumn{2}{|c|}{$\begin{array}{c}\text { Included in Final Model } \\
\text { Development }\end{array}$} \\
\hline & & & $\begin{array}{c}\text { Higher } \\
\text { Absenteeism }\end{array}$ & $\begin{array}{c}\text { Lower } \\
\text { Absenteeism }\end{array}$ \\
\hline \multirow{2}{*}{$\begin{array}{c}\text { Structure: } \\
\text { Features } \\
\text { of the } \\
\text { secondary } \\
\text { school } \\
\text { system }\end{array}$} & Grade level & Grade level (GL) & $\bullet$ & $\bullet$ \\
\hline & $\begin{array}{l}\text { Title 1-A } \\
\text { status }\end{array}$ & Title 1-A status (T1AS) & & $\bullet$ \\
\hline \multirow{8}{*}{$\begin{array}{c}\text { Process: } \\
\text { Features } \\
\text { of school- } \\
\text { based } \\
\text { health } \\
\text { services } \\
\text { delivery }\end{array}$} & \multirow{4}{*}{$\begin{array}{l}\text { On-site } \\
\text { health } \\
\text { services } \\
\text { delivery }\end{array}$} & Part-time school nurse (PQ36) & $\bullet$ & \\
\hline & & $\begin{array}{l}\text { Direct health services: HPV } \\
\text { vaccine administration (PQ38J) }\end{array}$ & & $\bullet$ \\
\hline & & $\begin{array}{l}\text { Direct health services: } \\
\text { Alcohol/drug use, abuse, or } \\
\text { dependency assessment (PQ38K) }\end{array}$ & $\bullet$ & \\
\hline & & $\begin{array}{l}\text { Direct health services: Rescue or } \\
\text { "as needed" medication delivery } \\
\text { for health emergencies (PQ38M) }\end{array}$ & & $\bullet$ \\
\hline & \multirow{2}{*}{$\begin{array}{l}\text { Parent and } \\
\text { family } \\
\text { engagement }\end{array}$} & $\begin{array}{l}\text { Students' family involvement in } \\
\text { developing/implementing school } \\
\text { health policies/programs (PQ50) }\end{array}$ & $\bullet$ & \\
\hline & & $\begin{array}{l}\text { School-provided health } \\
\text { information to increase } \\
\text { parent/family knowledge } \\
\text { (TQ17A_I) }\end{array}$ & $\bullet$ & \\
\hline & $\begin{array}{l}\text { Referrals for } \\
\text { care }\end{array}$ & $\begin{array}{l}\text { School-provided referrals: HIV/ } \\
\text { STD/pregnancy/contraception } \\
\text { or HPV vaccine administration } \\
\text { (PQ39A_K) }\end{array}$ & $\bullet$ & • \\
\hline & $\begin{array}{l}\text { School } \\
\text { health } \\
\text { coordination } \\
\end{array}$ & $\begin{array}{l}\text { Person to oversee or coordinate } \\
\text { school health and safety } \\
\text { programs and activities (PQ5) }\end{array}$ & & • \\
\hline
\end{tabular}

Two of the five structural elements (grade level and Title 1-A status) and all four of the process elements (on-site health services delivery, parent and family engagement, referrals for care, and school health coordination) were mathematically associated with the higher and/or lower absenteeism outcome. Grade level was identified as a nonmodifiable, relevant factor with regard to both higher and lower absenteeism, as is evident by its 
presence in both columns of Table 4.2. Additionally, Title 1-A status was identified as a factor relevant to lower student absenteeism.

Four factors associated with on-site health services delivery were relevant for model development: two for the higher absenteeism model (part-time school nurse and alcohol or other drugs use, abuse, or dependency assessment) and two for the lower absenteeism model (human papillomavirus (HPV) vaccine administration and rescue or "as needed" medication delivery for health emergencies). For this study, parent and family engagement was included in model development in two forms: 1) students' families helped to develop or implement policies and programs related to school health, and 2) evidence of school-provided health information to increase parent and family knowledge on various health topics. Both factors appeared in the model explaining higher rates of school-level chronic absenteeism. Based on the analyses described in Chapter Three, referrals for care for human immunodeficiency virus (HIV)/sexually transmitted disease (STD)/pregnancy/contraception-related care and/or HPV vaccination services appeared as a factor in both the positive and negative models, as demonstrated by its presence in both columns of Table 4.2. The coordination and oversight of school health and safety programs and activities by a designated staff member was demonstrated as a factor related to lower absenteeism, according to the analysis described in Chapter Three.

\section{Absence of Factors in Association with Higher or Lower Absenteeism}

While the inclusion of various elements and their associated factors in subsequent model development is worth noting, it is also important to acknowledge the structural and process elements that were not included. Geographic designation, staffing, and school enrollment were three structural elements that did not have a factor included in the final 
model development. As an indicator of community connection and as a factor related to student absenteeism, the evidence was not strong enough for geographic designation to be included in either solution model, as demonstrated by its absence in Table 4.2. Despite their relevance in the literature as a key staff role for student connectedness and engagement, school counselors, as a factor representing the structural element of staffing, were also not associated as a key factor in relation to either the higher or lower absenteeism outcome. Student-to-teacher ratio provided a key indicator for class size, teacher attention, and connectedness to health services, resources, and availability, and it was reasonable to expect student-to-teacher ratios to be associated as a factor that is causally connected to student absenteeism rates. However, this factor was also not present in the results of the analysis presented in Chapter Three.

In addition, although certain factors associated with on-site health services delivery were included in the subsequent model development, the presence of comprehensive SBHS delivery, SBHCs, and full-time school nurses were not evident in these research results, as shown by their absence from the list in Table 4.2. Their absence from the modeling is worth noting, as all three factors were specifically identified in the AAP policy statement on health and absenteeism (Allison \& Attisha, 2019). These specific health-focused strategies have been demonstrated to reduce student absenteeism as a means by which health professionals can improve school attendance, yet they were not evident in the configurational models.

\section{Aim Three: Configurations of Conditions That Contribute to Absenteeism}

The goal of this research was to answer a question that involved causal complexity among cases and an outcome. To achieve this goal, a research approach grounded in systems 
thinking and case-oriented CCMs was used to recognize and embrace the real-world complexity inherent in the cases used for analysis. To address Aim Three, configurations of the structural and process elements related to SBHS delivery were identified in relationship with each other to produce both the higher and lower student absenteeism outcome.

\section{Key Dimensions of Configurational Comparative Methods in This Research}

The capability of CCMs to incorporate asymmetry, conjunctural causation and equifinality in the exploration of this complex phenomena was useful. With asymmetry, an outcome may be explained by one set of conditions, but the absence of those conditions does not necessarily create the absence of the outcome. With conjunctural causation, outcomes may be explained by combinations of specific conditions that occur together. With equifinality, multiple pathways may yield the same outcome. In both the model for the higher absenteeism outcome and the model for the lower absenteeism outcome, all three of these key dimensions of CCMs were present in the analyses presented in Chapter Three and in the discussion of those results below.

Asymmetry recognizes that given an explanatory set of conditions that produce the outcome, it cannot be assumed that the absence of those same conditions leads to the nonoccurrence of the outcome (Kahwati \& Kane, 2020; Ragin, 1999, 2008; Schneider \& Wagemann, 2013). Configurations of conditions that contributed to higher absenteeism and to lower absenteeism were equally important in understanding how the structures within schools and the process of SBHS delivery were connected to the outcome of interest, therefore each was analyzed, explored and discussed separately. Moreover, the conditions associated with the higher absenteeism outcome were not the same as those associated with the lower absenteeism outcome. The structural and process elements that described schools 
with higher rates of student absenteeism were different than those that described schools with lower rates.

Conjunctural causation, where a single condition's effect may only be recognized in combination with other conditions, is also present in both solution models (Baumgartner, 2020; Cragun, 2020; Kahwati \& Kane, 2020; Ragin, 1999; Whitaker et al., 2020). Every disjunct, or solution pathway, in both models in Chapter Three included more than one condition, which demonstrated that a condition's effect may only be felt when considered in combination with another condition. For this research, each condition needed to be combined with the presence or absence of a different condition to lead to either higher or lower rates of absenteeism. As will be discussed in more detail below, the factor of grade levels offered by a school was not, in and of itself, sufficient for explaining higher or lower absenteeism. Grade level in combination with other structural and process elements led to the different rates of students missing school.

Each model also demonstrated equifinality. Equifinality acknowledges that different paths can produce the same outcome (Baumgartner, 2020; Cragun, 2020; Kahwati \& Kane, 2020; Ragin, 1999, 2008; Whitaker et al., 2020). Both solution models each had four distinct solution pathways (described below), thereby demonstrating equifinality. For example, high schools with a part-time school nurse had higher rates of student absenteeism, as did schools that provided referrals for certain types of care but that did not provide health information to increase parent and family knowledge. These two solution pathways were both important in understanding the combination of factors that can lead to higher rates of student absenteeism. 


\section{Schools with $20 \%$ or More Students Chronically Absent}

For schools with $20 \%$ or more of the student population chronically absent throughout the school year, the associated subset of factors associated with schools that had these higher rates of student absenteeism were illustrated in three different solution pathways. These three solution pathways are illustrated in Figure 4.2. The individual factors within each configurational solution pathway are categorized based on their membership in the larger structure and process categories, and then within the various subcategories provided in the framework identified in Figure 4.1.

\section{Figure 4.2. Solution Pathways Attributed to Higher Student Absenteeism}

\begin{tabular}{|c|c|c|c|c|c|}
\hline & & & \multicolumn{3}{|c|}{$\begin{array}{c}\text { Higher Absenteeism } \\
\text { Solution Pathways }\end{array}$} \\
\hline & & & HASP1 & HASP2 & HASP3 \\
\hline \multirow{3}{*}{ 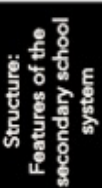 } & \multirow{3}{*}{ Grade level } & Middle school & & & \\
\hline & & Junior high/senior high school & & & • \\
\hline & & High school & & • & \\
\hline \multirow{4}{*}{ 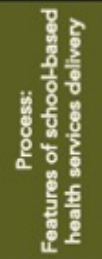 } & \multirow{2}{*}{ On-site health services delivery } & Delivery of on-site health services by a part-time registered nurse & & $\bullet$ & - \\
\hline & & $\begin{array}{l}\text { Direct health services: Alcohol or other drug use, abuse, dependency } \\
\text { assessment }\end{array}$ & & & • \\
\hline & Referrals for care & $\begin{array}{l}\text { School-provided referral: HIV/STD/pregnancy/contraception-related services } \\
\text { and/or HPV vaccine administration services }\end{array}$ & $\bullet$ & & \\
\hline & Parent and family engagement & $\begin{array}{l}\text { School-provided health information to increase parent/family knowledge on } \\
\text { various health topics }\end{array}$ & $\circ$ & & \\
\hline
\end{tabular}

Schools that provided referrals for sexual health services (HIV, STD, pregnancy, and contraception-related services and/or HPV vaccine administration) and did not provide health information to parents and families to increase knowledge about various health topics had higher rates of chronic absenteeism (higher absenteeism solution pathway 1 (HASP1)). High schools that employed a part-time registered nurse had higher rates of chronic absenteeism, which is higher absenteeism solution pathway 2 (HASP2). Finally, junior 
high/senior high schools with a part-time registered nurse on-site and that provided alcohol or other drug use, abuse, or dependency assessments also had higher chronic absenteeism rates (higher absenteeism solution pathway 3 (HASP3)).

Two of the pathways were grade-level dependent (HASP2 for high school and HASP3 for junior high/senior high school), whereas the third pathway (HASP1) spanned all grade levels. These findings demonstrate that in some cases, grade level, despite being a nonmodifiable factor, can inform where programs and resources are targeted. In addition, the delivery of on-site health services by a part-time registered nurse was sufficient in high schools to produce higher rates of student absenteeism; however, in junior high/senior high schools, it also needed to be combined with the direct health services provision of assessments for alcohol or other drug use, abuse, or dependency to produce the outcome. This may indicate that the presence of a part-time registered nurse is sufficient in high school settings with older students to make it easier for student absences due to health problems or illnesses to go undetected or unmonitored. On the other hand, in schools that serve younger grades, the part-time school nurse in combination with offering some direct health services creates an environment whereby when students miss school, there is no consistent oversight to encourage them to attend or to remove barriers that are keeping them from attending.

\section{Schools with Less Than 20\% Students Chronically Absent}

For schools with less than $20 \%$ of the student population chronically absent throughout the school year, four distinct solution pathways were created using the subset of factors associated with schools displaying the lower rates of chronic absenteeism. These four solution pathways are illustrated in Figure 4.3. As with Figure 4.2 for the pathways associated with higher chronic absenteeism, the individual factors within each solution model are 
identified using the categories and subcategories provided in the framework previously presented in Figure 4.1.

\section{Figure 4.3. Solution Pathways Attributed to Lower Student Absenteeism}

\begin{tabular}{|c|c|c|c|c|c|c|}
\hline & & & \multicolumn{4}{|c|}{$\begin{array}{l}\text { Lower Absenteeism } \\
\text { Solution Pathways }\end{array}$} \\
\hline & & & LASP1 & LASP2 & LASP3 & LASP4 \\
\hline \multirow{4}{*}{ 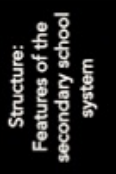 } & \multirow{3}{*}{ Grade Level } & Middle school & & - & - & \\
\hline & & Junior high/senior high school & & & & - \\
\hline & & High school & & & & \\
\hline & \multicolumn{2}{|l|}{ Title 1-A status } & - & 。 & & - \\
\hline \multirow{3}{*}{ 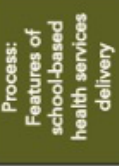 } & On-site health services delivery & Direct health services: $\mathrm{HPV}$ vaccine administration & - & & - & 。 \\
\hline & Referrals for care & $\begin{array}{l}\text { School-provided referral: HIV/STD/pregnancy/contraception care } \\
\text { and/or HPV vaccine administration }\end{array}$ & $\circ$ & & 。 & \\
\hline & School health coordination & $\begin{array}{l}\text { Coordination and oversight of school health and safety programs } \\
\text { and activities by a designated staff member }\end{array}$ & & $\bullet$ & & \\
\hline
\end{tabular}

- $=$ presence of condition; $0=$ absence of condition

Title 1-A schools that administer HPV vaccine on-site but do not provide sexual health services referrals had lower student chronic absenteeism rates (lower absenteeism solution pathway 1 (LASP1)). Non-Title 1-A middle schools that have a person responsible for school health coordination had lower rates of student absenteeism (lower absenteeism solution pathway 2 (LASP2)). Other schools with lower rates of student absenteeism were middle schools that provide HPV vaccinations on-site and that do not provide sexual health services referrals (lower absenteeism solution pathway 3 (LASP3)). Finally, junior high/senior high schools that are Title 1-A schools that do not provide HPV vaccines onsite also had lower chronic absenteeism (lower absenteeism solution pathway 4 (LASP4)).

All but four of the middle school cases included in this study that had lower rates of student absenteeism are covered using pathways found in this solution model (LASP2, LASP3, and LASP4). This indicates that some combination of Title 1-A status in conjunction with various process elements for school-based health services delivery may provide circumstances which lead to lower rates of students missing school. Additionally, in 
middle schools, the solution is different for schools that do not receive Title 1-A funds (LASP2) versus middle schools that have the presence of other factors but where Title 1-A status is not indicated as a relevant condition (LASP3). Finally, just as with the solution model for higher chronic absenteeism, some pathways in the lower chronic absenteeism model were grade-level dependent (LASP2, LASP3, and LASP4), and one pathway had findings that spanned all grade levels (LASP1). These findings further demonstrate that the focus of programs and resources may be informed by the grade levels served by a particular school.

\section{Conditions Linked to Higher and Lower Student Absenteeism}

Overall, the CNA results for the positive outcome $(\mathrm{O}=1)$ and the negative outcome $(\mathrm{O}=0)$ provided information about the barriers, facilitators, and conditions associated with student chronic absenteeism, including elements that may affect SBHS availability, delivery and quality. Modifiable and nonmodifiable conditions were causally implicated as related to both the higher and lower absenteeism outcomes, and the presence or absence of these factors, and the ways in which they combine with other factors, provide important points for discussion and consideration. The identification of the mechanisms by which factors work together through their presence or absence was not the intention of this exploration. However, the identification of factors that in combination create circumstances within public secondary schools that are associated with higher or lower chronic absenteeism rates may point to elements that can be addressed to gain a better understanding of the mechanisms.

A summary of these elements and their absence and/or presence with regard to higher or lower chronic absenteeism are presented in Table 4.3 using the categorical framework provided in Figure 4.1. The presence or absence of elements across solution 
pathways is indicated using symbols: $\bullet=$ presence; $\mathrm{O}=$ absence. Elements that were both present and absent in separate pathways are designated as $\bullet / O$.

Table 4.3. Elements Attributed to Higher and Lower Chronic Absenteeism

\begin{tabular}{|c|c|c|c|}
\hline & & $\begin{array}{l}\text { Higher chronic } \\
\text { absenteeism }\end{array}$ & $\begin{array}{c}\text { Lower chronic } \\
\text { absenteeism }\end{array}$ \\
\hline \multirow{2}{*}{$\begin{array}{c}\text { Structure: } \\
\text { Features of } \\
\text { secondary } \\
\text { school systems }\end{array}$} & Grade level & $\begin{array}{l}\text { - JH/SH school } \\
\text { - High school }\end{array}$ & $\begin{array}{l}\text { - Middle school } \\
\text { - JH/SH school }\end{array}$ \\
\hline & Title 1-A status & ---- & $\bullet / 0$ \\
\hline \multirow{5}{*}{$\begin{array}{c}\text { Process: } \\
\text { School-based } \\
\text { health services } \\
\text { delivery }\end{array}$} & School nurses & • & ---- \\
\hline & On-site health services delivery & $\bullet$ & -10 \\
\hline & Referrals for care & - & O \\
\hline & School health coordination & $-{ }_{-1}--$ & 0 \\
\hline & Parent/family engagement & 0 & ---- \\
\hline
\end{tabular}

Note. $\mathrm{JH}=$ junior high; $\mathrm{SH}=$ senior high.

\section{Structural Elements Associated with Higher and Lower Chronic Absenteeism}

Grade Level. For both the higher and lower chronic absenteeism models, two of the three solution pathways in the higher absenteeism model and three of the four solution pathways in the lower absenteeism model included grade level as a structural secondary school feature. In combination with other factors, this may suggest that differential attention should be paid based upon the grade levels that schools serve. Schools with older students were more likely to have higher chronic absenteeism rates, whereas schools with younger students were more likely to have lower rates of absenteeism. This aligns with information in the literature, which recognizes that chronic absenteeism tends to increase as students get older, with the highest rates among students in ninth through $12^{\text {th }}$ grade (Falcon et al., 2016). Findings from this research reinforce other related literature, suggesting that students in higher grades may require increased attention and programming for focused strategic 
interventions to keep them in school. Additionally, given that junior high/senior high schools can span a wider range of grades, those schools' presence in both the higher and lower chronic absenteeism models could indicate a deeper need for more nuanced and focused approaches for reaching students across the various grades in order to encourage regular school attendance.

Title 1-A Status. Schools deemed as Title 1-A schools were associated with lower chronic absenteeism in two solution pathways, and non-Title 1-A schools were linked with lower chronic absenteeism in one solution pathway, indicating a more mixed pattern for the influence Title 1-A status may have on the process elements of SBHS delivery and student absenteeism.

Title 1-A schools were likely to have lower chronic absenteeism in two scenarios: 1) schools with direct health services but no referrals for care, and 2) high schools with no direct health services. The logical assumption may be that lower income schools without access to health services would be more likely to have high rates of student absenteeism. However, this research shows that the combination of schools in lower income settings with the lack of available access to a wider range of health services, either through direct on-site service provision or through referrals for care, may have lower chronic absenteeism rates. This may be due, in part, to the increased attention provided by the planning, documentation, and monitoring required of Title 1-A schools. Therefore, the delivery of specific types of health services as a means for addressing student absenteeism became less important, given that student engagement, connectedness and tracking are being addressed by other means. 
Non-Title 1-A schools that had lower chronic absenteeism were middle schools with someone at the school who coordinated school health programs and activities. Having one person appointed to oversee a school's health programs and activities ensures that the various components of school health are properly coordinated, managed and integrated throughout school activities and programming (Centers for Disease Control and Prevention, 2019h). Whether coordinating within-school health activities or integrating school-based programs with community-based programs, this increased health-related focus and support for students throughout the school may help with student engagement, thereby increasing the value students assign to attending school (Balfanz \& Byrnes, 2012; Falcon et al., 2016; Henderson et al., 2014). Further interpretation about school health coordination is discussed below.

\section{Process Elements Associated with Higher and Lower Chronic Absenteeism}

The results with regard to the presence and absence of particular elements of SBHS delivery were also mixed with regard to higher and lower student absenteeism. Overall, this study demonstrated that school nurses, direct access to on-site health services, referrals for care, school health coordination, and parent and family engagement were relevant in varying degrees to higher and lower rates of student absenteeism. When certain elements were not delivered in the most comprehensive manner, student absenteeism tended to be higher, indicating that more thorough approaches may be needed to better meet the needs of students. Key elements of this research that support the literature are described below.

School nurses. Although the literature strongly supports the role school nurses can play in aiding students to be engaged that may help with student absenteeism (Jacobsen et al., 2016; Michael et al., 2015; National Association of School Nurses, 2018), this research 
suggested that health services delivery from a part-time registered school nurse in high schools or junior high/senior high schools may not be sufficient for meeting the needs of students who cannot attend school due to illness or disease (Balfanz \& Byrnes, 2012). Although some degree of health services may be offered through an on-site, part-time registered nurse, a comprehensive approach for SBHS delivery on-site may not have been available without a more regular health professional presence. Without consistent access to services, students may not be able to have their health-related needs met at school; moreover, without that regular access, oversight and monitoring, they may be less likely to attend school.

On-site health services delivery. The presence of limited health services delivery, when combined with other conditions, was associated with higher rates of chronic absenteeism. Conversely, the presence and absence of the provision of on-site health services were also associated with lower rates of student absenteeism. Consequently, the direct connections between on-site health services delivery and absenteeism produced inconsistent results. Furthermore, the combination of health services delivery with other structural or process elements also did not provide any direct insights related to student absenteeism. Thus, conclusions were difficult to ascertain from this study's findings.

As with the provision of consistent, on-site nursing services, more comprehensive approaches to on-site health services delivery have demonstrated the ability to aid students in attending school regularly (Michael et al., 2015). Specifically, the effects of chronic conditions, which can substantially increase a student's risk of missing school when not managed appropriately, may be effectively mitigated with on-going, consistent medical coaching, medication or treatment through SBHS that can comprehensively and reliably 
monitor and track students' disease states and attendance patterns (Centers for Disease Control and Prevention, 2019h; Henderson et al., 2014). Without dependable and inclusive SBHS, the provision of limited on-site health services may not be sufficient to keep students in school. The inconclusive nature of this study's findings suggests the needs for additional future investigation.

Referrals for care. In this research, referrals for care for certain conditions and issues, in combination with other conditions, yielded relatively inconsistent findings with regard to student absenteeism. The presence of referrals for care was associated with higher rates of chronic absenteeism, and the absence of referrals for care was associated with lower rates of chronic absenteeism. These mixed results may indicate that in some cases, having a referral is better than no services at all, and in other cases, referrals remove the student from the school environment for the provision of care, which may limit student school engagement and the perceived need for a student to be in school.

Students experiencing health problems or issues may be more likely to miss school because they cannot attend school due to the illness, or they do not attend because of lack of perceived value and feelings of being disconnected (Balfanz \& Byrnes, 2012). If services are not available on-site, students are encouraged to go into the community for the provision of health-related services. This type of access to care may further discourage student connectedness or engagement with the school, leading students to be more likely to miss school.

Past research also demonstrates that when referrals for care are managed through partner organizations and community groups, students not only receive the desired services but are also able to more strongly link themselves to the larger community (Lewallen et al., 
2015; Michael et al., 2015). The strength of the relationships between the schools in this study and the community groups and partner organizations to which they provide referrals was not explored, given the limitations of the data sources used for this research. Additional future investigation into the types of partnerships and relationships between a school and the organizations with which they partner may elucidate additional information about referrals for care.

School health coordination. In this study, the presence of a designated individual who oversaw the various elements of school health coordination was demonstrated as associated with lower chronic absenteeism. This finding closely aligns with the literature. Critical to a school's ability to coordinate the components of school health, an appointed individual to oversee the school health program can take on multiple responsibilities related to various school health and safety programs and activities (Basch, 2011e; Centers for Disease Control and Prevention, 2019h). According to Lewallen et al. (2015) and Basch (2011e), administrator support, in conjunction with policies and practices that reinforce school health coordination, is critical for the integration and promotion of synergistic health and education efforts. Additionally, as described by the Whole School, Whole Community, Whole Child model, process coordination is critical to ensure that all pieces of the model work in concert with each other (Lewallen et al., 2015); this was reinforced by the findings of this study.

Parent and family engagement. In this study, schools that did not provide health information to increase knowledge on various health topics, in combination with schoolprovided referrals, were associated with higher rates of chronic absenteeism. This finding 
aligns with the literature regarding the effects of parent and family engagement on student absenteeism.

Parent and family engagement, as a shared responsibility of both school staff and students' families, reinforces student health and learning beyond the school walls (Lewallen et al., 2015). Strong school-family partnerships and engagement have been shown to effectively decrease chronic absenteeism (Henderson et al., 2014). This study showed that higher rates of chronic absenteeism were present in schools that did not provide healthrelated information to parents and families. Although providing health information to parents and families is a relatively focused demonstration of engagement in a student's schooling, it may provide deeper opportunities for students to share knowledge and encourage conversation with their parents and families.

\section{Structure and Process Elements Not Present in Study Results}

The structure and process elements present in both the higher and lower absenteeism outcome solution models were noteworthy and important. Perhaps of equal importance are the various structural and process elements that were not present in these findings. As was discussed related to Aim Two, three structural elements of the secondary school system that were expected to be associated with SBHS delivery and/or chronic student absenteeism were: 1) geographic designation, as determined by either an urban/rural/frontier areas or rural-urban commuting area (RUCA) codes, 2) student-toteacher ratios as a measurement for student enrollment and 3) the presence of school counselors related to school staffing.

In addition, three SBHS delivery-related factors that are widely discussed in the literature were also missing from the higher and lower chronic absenteeism models produced 
by the CNA results: 1) comprehensive direct SBHS delivery, 2) on-site service delivery coordination through school-based health centers (SBHCs), and 3) allocation of a full-time school nurse. The absence of each of these structure and process elements from these results may indicate that other unobserved or unmeasured causes are missing from the analysis. If those missing elements were added to the analysis, then it is plausible that these research findings would include any one of those different factors. This will be discussed further in Chapter Five with a closer examination of the limitations of this type of analysis.

\section{Conclusion}

The presence of the three key dimensions of CCMs in this research validate the use of a mathematical, cross-case research approach and design to investigate the current systems landscape for public secondary schools and explore how the process and structural features of schools may influence the delivery of SBHS and student absenteeism. In addressing Aim One of this research, the unique categorization of structural school features and SBHS delivery processes was created, and this framework provided a foundation for a deeper analysis of how the two, in combination, can create meaningful outcomes with regard to health services delivery, availability, and quality, as well as student absenteeism (Aim Two). Using CNA to address Aim Three revealed different combinations of structural and process elements that public secondary schools had in common, with resultant insights into "typologies" of schools with higher and lower chronic absenteeism rates. To address Aim Four, subsequent recommendations that stem from this research's findings for various organizational entities will be discussed in Chapter Five, along with the study's limitations and suggestions for future research. 


\section{Chapter Five - Recommendations and Conclusions}

\section{Overview}

The intentional, comprehensive integration of school-based health services (SBHS) delivery into existing school structures may provide opportunities to specifically address various health barriers to learning (HBLs), which, in turn, may directly affect poor educational and health outcomes of students, including absenteeism. To date, the literature has not included a comprehensive description of the structures and systems within schools that influence SBHS delivery with the intention of mitigating the effects of HBLs on a student's ability to attend school regularly; this research sought to fill that existing gap in the literature. In general, the findings of this research align with prior calls from leaders in both the education and health sector for the provision of coordinated, comprehensive, consistent school-based health services as a holistic means for achieving desired health and educational outcomes.

Chapter Four presented a synthesis and discussion of the initial findings described in Chapter Three, and identified where these findings relate to and/or extend the literature reviewed in Chapter Two. As an extension of the findings, this chapter is organized to address Aim Four of this study: Develop policy recommendations that will inform systemlevel redesign of school-based health services and help integrate delivery across education and health services systems. These recommendations are presented for consideration by federal, state, and local organizational entities and authoritative bodies in both the education and health sectors for the integration of comprehensive, coordinated SBHS into school systems and structures. 
In addition to policy recommendations to address Aim Four, this chapter includes a discussion of the study's limitations and suggests topics for future research. This study was conducted with attention to methodological rigor and the use of best practices for research grounded in configurational comparative methods (CCMs) theory and methodologies; however, the study design and data sources introduced potential research limitations, which will be discussed. Suggestions for future research are explored as opportunities for building upon the foundational findings from this study.

\section{Implications of the Current Social Context}

Acknowledgement of the current state of U.S. culture and society seems particularly relevant to begin this concluding chapter, given various significant events over the last year. At the time of the writing of this chapter (Spring 2021), the world is more than one year into the COVID-19 pandemic, enduring the dramatic effects it has had on every aspect of daily life, including, but not limited to, the workforce, schools, travel, and social gatherings. The United States is now in the middle of a large-scale vaccine roll-out in an attempt to achieve herd immunity. Moreover, the defense of this dissertation (May 2021) takes place on the one-year anniversary of the murder of George Floyd. His death sparked worldwide social unrest and calls for widespread social and racial justice, and this discontent is still very much at the forefront of the minds of many individuals and communities. Finally, many public schools are just beginning to reopen, including in Oregon where this research takes place, with great trepidation, enthusiasm and anxiety felt by students, educators, and parents alike. Each of these cultural and societal issues serve as the backdrop for how the policy 
recommendations, study limitations, and proposals for future research can be understood, interpreted and applied.

It should also be acknowledged that the data used in this study were from the 20172018 school year, which was before the pandemic. COVID-19 has dramatically shifted educational practices, as well as various in-school and out-of-school student interactions, including extracurricular activities, club involvement, and sports participation. Policies and procedures for back-to-school practices are still being discussed and determined, often on a day-to-day basis. There have been similar pandemic-related shifts in health services delivery, such as the shift to, and acceptance of, telehealth for primary care, and it is unknown what impact this will have on future patterns of primary care delivery. Therefore, the recommendations posited here are based on the best knowledge the researcher has at this time, and may ultimately need to be adjusted as more becomes known once children are back in the classroom on a more consistent, regular basis, and both schools and health services adjust to a "new normal."

\section{Aim Four: Policy Recommendations}

Aim Four of this research was addressed with development of recommendations that stem from this research's findings. With regard to both higher and lower rates of absenteeism, the results with regard to the presence or absence of any one structural element or any one process element of SBHS delivery were mixed. Generally, this research found that when certain elements were not delivered in the most comprehensive, consistent and intentional manner, student absenteeism tended to be higher, which supports prior literature about the ways in which SBHS delivery can support student health, well-being, and ability to 
learn. Additionally, coordination of efforts and focused attention on activities within the school tended to be associated with lower rates of absenteeism. These findings indicated that more thorough, coordinated, and comprehensive approaches may be needed to intervene and address the effects HBLs have on student educational outcomes. This will be addressed in the specific recommendations that follow in this chapter.

As discussed in Chapter Two, the uniquely fragmented, complicated structure of the U.S. education system has been created by its federalist, state-focused heritage, which has led to multiple points of accountability and responsibility (Richardson, 2007; Rippner, 2016). Many different policy-making and political entities are able to exert power and prerogative over public school governance. Concurrently, the health care system faces its own set of unique issues, including fragmented care delivery and increased focus on individualized medical care. These issues have created inconsistencies, gaps, and duplications in the provision and delivery of health care, with subsequent implications for the health of populations (Axelsson \& Axelsson, 2006; Dzau et al., 2017). The recommendations from this research attempt to account for the complexities which arise within these two fragmented, complicated structures and systems.

Each of these recommendations must be supported with adequate resources; therefore, it is important to acknowledge that the ability for these recommendations to be accepted and implemented is largely predicated and reliant upon funding. The financing structures for both the education system and the health system are complicated, with dollars spent at the local level largely contingent upon federal-level priorities and pressures, which can be grounded in political areas of focus. These recommendations are not intended to seem naive with regard to the funding, human, and logistical resources that might be 
required for full implementation but, rather, are meant to serve as a starting point for further discussion.

In addition, implementing recommendations across the health and education systems and policy-making arenas suggests the need for a cross-sectoral approach for problemsolving and solution creation. To the greatest extent possible, specific agencies, legislative bodies, and organizational entities are identified as the group(s) responsible for a specific recommendation. However, an interdisciplinary, collaborative orientation to all of the problems and their corresponding solutions is likely necessary for widespread change. As suggested by Campbell's "fish-scale model of omniscience" (1969), although the health and education sectors are unique unto themselves, their overlapping population focus and topic interests create circumstances whereby shared, interdisciplinary, cross-sectoral perspectives can create more meaningful, intersectional solutions within existing complex real-world settings.

Prior work focused on the intersectionality of health and education has sought to be intentional with a unified approach that is acceptable to both the health and education communities to ensure that students are both healthy and ready to learn (Basch, 2011d, 2011e; Lewallen et al., 2015; Michael et al., 2015). As described in Chapter Two, the Whole School, Whole Community, Whole Child Model provides educators, administrators, health practitioners, and public health professionals with a comprehensive, holistic view of students, schools, and the larger community by using a single framework aimed at improving student health and learning (Lewallen et al., 2015). The findings from this study largely echo those calls for comprehensive and coordinated approaches that acknowledge the interconnected nature of student academic achievement and health outcomes over the life 
course. When process elements of SBHS delivery were not delivered in the most

comprehensive manner, student absenteeism tended to be higher, and when elements were delivered using more cohesive means, student absenteeism tended to be lower. In combination, these findings indicate that more thorough approaches may be necessary to meet student needs to address HBLs.

Policy and system-level recommendations are presented below with these findings in mind, directed to audiences at three levels: 1) federal governmental agencies focused on education and/or health, 2) state governmental agencies focused on education and/or health, and 3) local school districts and/or community health agencies that support health and education efforts. As discussed above, these recommendations target particular groups for the suggested action; however, it is likely that other entities should be consulted with or involved for a more comprehensive, collective approach.

\section{Education and Health Equity}

Prior to a discussion of the specific recommendations for each level of the larger system, an overarching recommendation applies to the structures and policies at all levels of the education and health systems:

Recommendation \#1: All research, policy, and programmatic work done in the cross-sectoral space of health services delivery in the school environment needs an approach centered on an intersectionality praxis.

As a theoretical framework, intersectionality acknowledges, investigates and addresses the influence of "the intersecting structural factors, social and historical processes, and systems of power and oppression" (Agénor, 2020, p. 803). Research and interventions intended to address educational and health disparities need to go beyond simply documenting that intersectionality is associated with worse outcomes; they must adopt an 
intersectionality approach and praxis that incorporates the complex interplay between various dimensions of social inequality (Agénor, 2020; Alvidrez et al., 2021; Bowleg, 2021). By comprehensively and intentionally capturing the simultaneous influence that multiple interpersonal and structural dimensions of discrimination have within systems of power and oppression, education and health researchers, practitioners and administrators can create and shape higher quality, comprehensive, transformational programs, policies, and activities intended to achieve true educational and health equity (Agénor, 2020; Alvidrez et al., 2021; Bowleg, 2021). For example, SBHS delivery targeting the needs of LGBTQ youth should include perspectives and insights from those students the services seek to support and help, such that other intersectional elements of the students' existence are also addressed and acknowledged in the delivery of those services. Those students are not unilaterally defined by their sexual orientation and gender identity; an intersectional approach recognizes their multi-faceted existence, as well as provides policy-makers and program implementers with the ability to address other elements of interpersonal and structural discrimination and oppression experienced by those youth.

\section{Recommendations for Federal Governmental Agencies}

With regard to the public education system, the purview of the federal government is largely focused on, and tied to, the allocation of, and incentives related to, school funding (Richardson, 2007). The federal government has broad powers to protect the public's health and safety, including, but not limited to, policymaking, financing and regulation (Institute of Medicine, 2002). The following recommendations are provided with these understandings in mind. 


\section{Departments of Education and Health and Human Services Inter-Agency Collaboration}

The U.S. Department of Education (DOE) and the U.S. Department of Health and Human Services (HHS) are two large federal entities with broad areas of focus; however, school-aged children are a demonstrated priority area for both federal-level departments (U.S. Department of Education, 2011; U.S. Department of Health \& Human Services, 2018).

Recommendation \#2: Cross-sectoral, inter-departmental, focused efforts should be employed and prioritized to ensure collaborative school-based health services delivery efforts that allocate resources, programs and incentives designed to improve student academic achievement and health.

The DOE and the Centers for Disease Control and Prevention (CDC), a major operating component of the HHS, have collaborated in recent months to address the COVID-19 pandemic through efforts such as the National Safe School Reopening Summit help on March 24, 2021 (U.S. Department of Education, 2021). Although the two federallevel entities will likely face challenges and tension to work collaboratively, given their different terminology and vocabulary, understanding of roles, and responsibility purview, the ongoing extension of their collaborative efforts to prioritize and address comprehensive SBHS delivery is an appropriate extension of their recent work on COVID-19. By continuing conversations and collaboration beyond the pandemic-focused efforts, the breaking down of health and education silos at the federal level can provide a roadmap for inter-agency partnerships and teamwork at other levels within the government.

\section{School-Based Health Services Delivery Components in Infrastructure Package}

Despite the demonstrated benefit of on-site, full-time school nurses and/or an onsite school-based health center (SBHC), only 11 percent of public schools across the United 
States provide access to SBHS, and only 40 percent have a full-time school nurse available for on-site service delivery (Ramirez \& Buher, 2020).

Recommendation \#3: School-based health services should be funded as a critical component of any federal infrastructure plan.

An infrastructure plan, such as the Biden Administration’s \$2 trillion infrastructure and climate plan which was unveiled on March 31, 2021 (Sullivan, 2021), could include funding to double the number of SBHCs, modernize existing facilities, incentivize the provision of full-time school nurses, and upgrade hardware and software for the ongoing delivery of telehealth services. Other kinds of support and relief are also being proposed in Biden’s $\$ 1.8$ trillion American Families Plan, including the provision of universal prekindergarten access to 3- and 4-year-olds, the expansion of nutrition programs to provide free meals, and funding teacher training and support programs (Blad, 2021b); however, neither the infrastructure plan, nor the American Families Plan, specifically designate schoolfocused dollars aimed at improving health services delivery (Blad, 2021a, 2021b; Sullivan, 2021). Findings from this research suggest that these comprehensive approaches are important means for mitigating the effects HBLs have on student academic and health outcomes.

\section{Health Insurance Screenings in Schools}

Similar to how the workplace is a critical physical location for addressing issues that address adult health, schools also serve as an important and influential leverage point for child health (Grzywacz \& Fuqua, 2000).

Recommendation \#4: Through joint funding from the U.S. Department of Education and the U.S. Department of Health and Human Services Centers for Medicare and Medicaid Services, state departments of education should be provided with resources to integrate health insurance screenings into school- 
level processes that already exist, with this funding extended to train school staff to advise families on how to access public health insurance programs.

Insurance screening and resource support in schools, as the entity with the most sustained contact with children outside of the family setting, makes sense from a logistical perspective, and offers another opportunity for the provision of more comprehensive and coordinated service delivery. This recommendation is not directly tied to findings from this study, but is complementary and addresses an essential element of health care access (insurance).

\section{Federally Provided Resources and Technical Assistance for Public Awareness Campaigns}

As the COVID-19 pandemic closed schools across the country, in many cases for more than a year, parents, students, educators and administrators became increasingly concerned about the toll the dramatic shift in the learning environment from in-person to remote or online had on student learning and academic achievement (Center for Research on Education Outcomes, 2020).

Recommendation \#5: Federal agencies should dedicate resources, funding and technical assistance to create public awareness campaigns to help parents, students and the general public understand the interrelated nature of health, well-being, and academic achievement to build confidence and allay anxiety related to resuming in-person learning.

Encouraging public consensus about the importance of comprehensive SBHS delivery can address the concerns many feel about COVID-19 and getting students back on track academically in the short-term, but can also help to further long-term discussions about the continued need for increased resources and access. 


\section{Recommendations for State-Level Governmental Agencies}

State-level agencies and organizations have the greatest oversight of, and responsibility for, schools and the provision of public K-12 education (Richardson, 2007). Similarly, state governments retain the primary responsibility for health through regulatory and oversight activities (Institute of Medicine, 2002). The recommendations for state-level governmental agencies consider this oversight with regard to the provision of comprehensive SBHS delivery. Moreover, these state-level recommendations are largely focused on activities within the state of Oregon, given that Oregon data were used in this study. However, these state-level recommendations and their generalizability may apply in other states.

\section{Examination of Student Success Act Budget Allocation}

Oregon Governor Kate Brown signed House Bill 3427, the Student Success Act (SSA), into law in May 2019 (Oregon Department of Education, n.d.-d). Beginning in the 2020-2021 school year, the SSA was expected to invest $\$ 2$ billion in each biennium, with $50 \%$ of those funds to be invested in the Student Investment Account (SIA; Oregon Department of Education, n.d.). The SIA's two-fold purpose was to meet students' mental or behavioral health needs and to increase academic achievement for student groups that have historically experienced academic disparities (Oregon Department of Education, n.d.d). The COVID-19 pandemic affected the full implementation of the directives and provisions provided by the SSA, though a complete description of the pandemic's effects on the SSA roll-out is missing from any publicly available resources.

Recommendation \#6: As agencies and individuals consider the effects of the pandemic on the Student Success Act roll-out, the Oregon Department of Education, in partnership with the Oregon Health Authority, should include 
the provision of comprehensive school-based health services in its postpandemic Student Success Act recalibration efforts, including increased attention, resources and dollars allocated to expanded on-site physical health services or referrals for care.

New and exacerbated health challenges will make getting some students back to their academic grade level more difficult (Ramirez \& Buher, 2020), and the specific allocation of money will help districts and schools meet that need. Funds from the SIA retain a focus on student mental and behavioral health needs, given the increasing rates of anxiety and depression in six- to 17-year-olds (McClurg, 2020). Beyond a focus on mental and behavioral health, a reexamination of the allocation of SSA dollars given population-wide shifts in physical health related to the pandemic should also be a priority.

\section{Reinvestment in Student Absenteeism Efforts with Health Services Prioritization}

In 2015, the Oregon Legislature passed House Bill 4002, which directed the Oregon Department of Education (ODE) to develop a statewide plan to address student chronic absenteeism in public schools (Falcon et al., 2016). Using absenteeism rates and outcome indicators, schools were identified for support based on a tiered system, and this initiative was funded again through 2021 with a statewide approach and individual grants (Falcon et al., 2016; Oregon Department of Education, n.d.-b, n.d.-a).

Recommendation \#7: State agencies should commit increased attention to, and a reinvestment in, efforts related student absenteeism, as students are reintroduced to the in-person learning environment.

Some estimates suggest that student absences have nearly doubled during the pandemic (Lieberman, 2020), and concerns related to student absenteeism will not be quickly relieved with in-person learning. With returns to in-person classrooms, student 
absenteeism monitoring and action will require on-going vigilance by educators and administrators.

Recommendation \#8: State agencies should prioritize the delivery of comprehensive, coordinated school-based health services delivery to mitigate student absenteeism, especially given the after-effects of the pandemic.

SBHS availability may help to address student absenteeism specific to health-related problems, illnesses and conditions.

\section{Focused Efforts and Investments Through the Patient-Center Primary Care Home Program for School-Based Health Centers}

The delivery of comprehensive health services through SBHCs can be a critical action for addressing the primary care needs of children. This research supported the literature, which recognizes that children's complex, overlapping, interrelated health-related issues and problems drive the need for comprehensive services that are delivered with greater coordination and collaboration (Basch, 2011e; Chiang et al., 2015; B. C. Fusarelli \& Lindle, 2011; Michael et al., 2015; Smrekar, 1998). As of July 1, 2019, 79 certified SBHCs existed in 26 of Oregon's 36 counties, and $48 \%$ are recognized by the state as a patientcentered primary care home (PCPCH; Oregon Health Authority, 2020).

Recommendation \#9: The Oregon Health Authority's Patient-Center Primary Care Home Program and the School-Based Health Centers State Program Office should engage in cross-program, focused, intentional collaborations to not only increase the number of school-based health centers, but also to increase the number of those school-based health centers that are recognized as patient-center primary care homes.

This emphasis and focus are critical to ensuring comprehensive, patient-centered, coordinated care delivery for public school students throughout Oregon. 


\section{Regional Partnerships Among Social Service Agencies, the Oregon Health Authority and the Oregon Department of Education}

In an effort to provide comprehensive services, partnerships with social service agencies may bridge the gap for services that cannot be delivered on-site, but could be provided through referrals for care. Referrals for care were a SBHS process element that was present in both the higher and lower absenteeism models. Effectively designed regional partnerships between state-level agencies and community-based organizations for referrals for care may ensure more seamless care delivery to students and their families. Although local resources and connections are important, state-level agencies may be able to leverage statewide partnerships that could benefit school-based SBHCs and/or school nursing staff work throughout the state.

Recommendation \#10: The Oregon Health Authority and/or the Oregon Department of Education should develop and foster partnerships with organizations and agencies that provide services throughout the state to remove the administrative burden of partnership development and maintenance from school-level staff.

Partnership development at the state level will free up school staff time and resources, such that individual schools and school districts still benefit from these partnerships without having to invest effort into the partnership development.

\section{Recommendations for Local-Level Entities}

Local structures, including school boards, school districts, and district superintendents have the most direct control over a school's activities and priorities, with existing pressure from state and federal level organizations, agencies and entities to meet certain academic outcomes in order to receive resources and funding (Darling-Hammond, 2010; Michael et al., 2015). With regard to health, Oregon implemented coordinated care 
organizations (CCOs) in 2012 to facilitate local coordination of care with accountability

measured through various metrics relevant to the health outcomes of the local populations they served (Oregon Health Authority, n.d.). These recommendations are designed with these local educational and health structures in mind.

\section{School Health Metrics for School Board Review}

Just as CCOs are expected to use metrics to reduce health disparities and measure their accountability, a similar approach could be employed in school districts.

Recommendation \#11: School boards should use school health metrics to ensure that comprehensive, coordinated care is being delivered throughout their district.

Use of specific school health-focused metrics would aid in the identification of areas for concern, such that appropriate, effective solutions could be employed. Although national survey efforts through tools such as the Centers for Disease Control and Prevention's (CDC) School Health Profiles Survey (SHPS) used in this research are important, focused efforts around specific locally focused SBHS delivery metrics could not only allow for the tailoring of those metrics to meet the district's needs, but can also monitor movement toward larger health and/or education goals.

\section{School District-Wide Provision of School-Based Health Services Delivery}

Comprehensive SBHS delivery in a school is a reasonable goal for any school. However, coordination of efforts at the district level may better meet the needs of all students in any given district. A district may have other types of networked activity, beyond SBHS delivery, to coordinate efforts between schools in their service area.

Recommendation \#12: Extend existing district-wide networks to coordinate the provision of school-based health services delivery among schools to 
minimize duplicated efforts and increase opportunities for synergistic benefits for all students within a district.

The provision of certain staff or services may be best delivered in each individual school, but it may be more logical for some staff or services to reside at one school, with the access and availability provided to all schools within the district to streamline resources and efforts. For example, resource and services delivery at a high school within the district may provide that area's elementary and middle schools with access to the services, without needing to allocate resources for those services on their own campus. School district-wide coordination of SBHS delivery can ensure increased utilization of those services and improved district-wide student health outcomes.

\section{Mandated Employment of a School Health Coordinator}

Recommendation \#13: The Oregon Department of Education should require every school in Oregon to employ an individual as a school health coordinator.

This requirement would ensure leadership within the school to provide oversight, facilitate processes, and reinforce cohesive efforts for various school health programs, policies, practices and activities (Basch, 2011e; Centers for Disease Control and Prevention, 2019h; Lewallen et al., 2015). This recommendation specifically acknowledges the findings of one of the solution pathways for lower absenteeism (LASP2), and as demonstrated in the solution pathway, may be more impactful in affecting student absenteeism when made a requirement in middle schools. School health activities may range from health education curriculum to on-site health services delivery to partnerships with outside organizations for care referrals, and the coordination of these efforts ensures that they are conceptualized within the context of the school's established mission for student and employee health. In this study, 212 of the $283(74.9 \%)$ schools in the SHPS dataset had someone at their school 
who oversaw or coordinated school health and safety programs and activities. Increased focus and funding, as well as a requirement by the state's education agency, to ensure that all schools have a school health coordinator could be critical for comprehensive SBHS delivery.

\section{Design Delivery of School-Based Health Services Based on Grade Level}

Recommendation \#14: School district administrators and health services professionals should design and modify the combination of school-based health services delivered within a specific school setting to meet the needs of the grade levels of the students in that school.

With regard to both higher and lower absenteeism, grade level repeatedly appeared as a factor in the configurational modeling, always in conjunction with a modifiable condition. The grade levels served by a school have implications for age-related behavior with regard to accessing health services, as well as in regard to absenteeism. The targeting of school-based health services, programs and resources should be refined to meet the needs of the grade levels of the students in a particular school, with the recognition that what works in high school settings may be different than the needs in middle schools, and vice versa.

\section{Limitations of This Research}

Limitations created by the COVID-19 pandemic are addressed first in this section, given its widespread effects on this research. Other limitations of this research and limitations inherent to the CCMs and the coincidence analysis methodology are also discussed below.

\section{Limitations as a Result of the COVID-19 Pandemic}

The proposal for this dissertation research was defended in May 2020, slightly more than two months after the COVID-19 pandemic began in the United States. The original 
plan was to conduct a unique survey with distribution to all K-12 schools throughout Oregon. Since schools were in modified operations and attempting to maintain quality educational delivery in an online or virtual environment, the data collection strategy was modified to use the 2018 administration of the CDC's Department of Adolescent and School Health's SPHS for Oregon.

Although these data provided the needed information about SBHS delivery, there were limitations to the use of this secondary data source. Given that these were secondary data, the opportunity to follow-up on cases that were missing data to collect missing information, or for additional inquiry or investigation, was not an option. Moreover, the SHPS data were blinded so the researcher also did not have the ability to trace the SBHS data back to the unblinded school demographic data. Finally, these data were collected for other purposes, not specifically for this analysis. Additional factors that might have been included in the analysis (e.g., staffing and hours of operation of a school-based health center, health screenings delivered on-site, etc.) could not be considered, given the nature of the use of blinded secondary data (i.e., the ability to collect that information was eliminated as a possibility).

The COVID-19 pandemic also limits the format for policy recommendations based on the research findings. The U.S. educational landscape has fundamentally changed for years to come due to the effects of the pandemic, and although one of the primary findings of this research is that SBHS delivery can have the most direct effects when offered in a comprehensive, coordinated manner, the ability for that to be achieved at present is not clear. At the time of the writing of this chapter, schools in Oregon are just beginning to resume in-person classes. The full after-effects of the pandemic on schools, children, and 
parents will not be fully realized for many years, and despite attempts to craft policy recommendations with that in mind, they may not be fully applicable or actionable in the short-term.

\section{Limitations of This Research}

A limitation of this research is that it was conducted for an individual doctoral dissertation. Given that the analysis and synthesis of findings were by a single researcher, this approach did not allow for the use of outside perspectives to enhance the reliability and internal validity of findings. Although the dissertation committee provided oversight and consultation, the single researcher could have systematically influenced the results of the study through her perspective or knowledge. Additionally, the researcher's prior and current knowledge and experiences of both the health and education fields could have systematically biased the research findings. These potential biases were mitigated wherever possible through discussions with committee members and documentation of assumptions, rules, and decisions made throughout the data collection and analysis processes.

Another limitation of this research is the use of data for public secondary schools only located in Oregon. The generalizability of this study's findings and conclusions may not be applicable to other types of schools, including elementary schools, charter schools, private schools, or other alternative educational institutions. In addition, given that the data set only included schools in Oregon, it may be difficult to generalize the study's findings to other areas of the United States, or outside the United States, although issues related to absenteeism may have some commonality regardless of jurisdiction. 


\section{Limitations of Configurational Comparative Methods}

CCMs generally have several limitations. First, CCMs, and coincidence analysis (CNA) specifically, are relatively new methods that can provide different kinds of insights into real-world, system-level phenomena. CCMs began to be described in the literature in the mid-1980s, with Charles C. Ragin's introduction of qualitative comparative analysis as a new research approach for the social sciences (Marx et al., 2014; Ragin, 1987). CNA has been developed more recently, and has just begun to appear in the health care or education literature (Coury et al., 2021; Hickman et al., 2020; Petrik et al., 2020; Whitaker et al., 2020; Yakovchenko et al., 2020). Although every effort has been made to use current language and analytic approaches that are described in the literature, this methodological approach continues to evolve. As more is learned about this class of methods, and CNA in particular, these analytic techniques will continue to be refined.

Second, as described in the literature, CNA, as with other CCMs, supports causal inference; however, the extent to which results may be generalized is limited (Whitaker et al., 2020). Although there was evidence for the solution pathways in relation to student absenteeism from the CNA approach, which met consistency and coverage requirements and were consistent with prior research, logic and theory, additional work may be needed to further establish the causal relationship strength between specific factors and the absenteeism outcome. Case familiarity helps to evaluate generalizability by allowing the researcher to justifying cases included in the analysis (Whitaker et al., 2020); however, given the use of a blinded data set with no opportunities for follow-up, case familiarity did not apply in this research. 
Finally, as mentioned in Chapter Four, there may have been unmeasured factors related to absenteeism beyond those present in the dataset. Structural elements of the secondary school system and/or process elements of SBHS delivery that were not captured in this dataset could potentially provide alternative explanations for higher or lower absenteeism. The dataset used in this research may have revealed only portions of the underlying causal structures, indicating the need for further research in this area, such that other elements can be addressed or investigated. Both models also had coverage scores well below $100 \%$, indicating that factors beyond those included in the dataset had a role to play in explaining chronic absenteeism rates.

In summary, specific limitations existed with this research approach, including the effects of the COVID-19 pandemic, use of a secondary dataset, reliance on a single researcher, the use of a novel analytic methodology, and potential for missing, unmeasured elements. These study weaknesses were mitigated when possible; however, future research could improve and further these research findings with a unique data set that captures a more complete set of structural and process elements.

\section{Recommendations for Future Research}

Opportunities exist to expand on these research findings through additional studies. In some cases, future research could strengthen the policy recommendations identified to address Aim Four. In other cases, the implementation of the policy recommendation may inform future research plans. 


\section{Unblind the Data for a More In-Depth Analysis}

As discussed above, data used in this study were blinded. Unblinding the case data would potentially allow for better answers to the question: Why do some things work better in certain combinations in certain scenarios and contexts? By enabling the researcher to follow-up with contacts in each school, questions could be directly asked to those individuals to fill in gaps within the data. Additionally, it would also allow for insights to be gathered about an individual school's situational context, include proximity to resources based on geography, which may not be obvious based on geographical designation, or detailed information about existing partnerships that aid with SBHS delivery which might not have been evident based on the CDC SHPS data. A better understanding of the promising structural and process elements associated with lower absenteeism could also be ascertained, in addition to a closer investigation of what is going on with schools that have higher absenteeism to identify unmeasured factors that may need to be included in the analysis. Finally, unblinding of the data would also provide the opportunity for the researcher to supplement the findings with a qualitative component to the research by exploring teachers', administrators', school principals', district superintendents', school nurses', parents', and/or students' perceptions of the findings. Given the data use agreement for this research, the researcher was not able to unblind the data; however, those with access to the unblinded data could pursue that opportunity to gain in-depth insight using interviews or focus groups.

\section{Replicate the Analysis with Inclusion of Other Endogenous Factors or Cases}

Replication of the analysis with the inclusion of other factors may aid in the identification of unmeasured factors that point to the mechanisms that exist between and among the structural and process elements to produce the absenteeism outcome. This could 
be approached in a few ways. First, the originally planned unique survey could be conducted to gather different types of data to describe the structural and process elements that exist in each school. Second, a number of cases from this data set were removed from the analysis due to missing data. Although every attempt was made to keep as many cases as possible in the analysis, the loss of cases may have affected the findings. The inclusion of these cases with the addition of the missing data could lead to the emergence of additional solution pathways. Third, repeating the analysis with inclusion of all K-12 schools in Oregon, or all secondary schools in Oregon, and/or all elementary schools in Oregon might provide different understandings of the relationship between structural and process elements to the absenteeism outcome. Fourth, replicating the analysis with inclusion of SHPS data from other states could provide opportunities to compare and contrast the Oregon findings to other states or geographic regions. This approach may identify other regional factors not considered in a study focused on a single state.

\section{Exploration Using Primary Schools}

According to the literature on student absenteeism, students in earlier primary grades (i.e., preschool and kindergarten) have absenteeism rates almost as high as those in later high school grades (Jordan \& Chang, 2015). An exploration using the same analysis approach with a similar set of cases from primary schools may provide an explanation of the structural and process elements related to students missing school in elementary school. The elements

present in elementary schools could be compared to those in secondary schools to determine where similarities and differences exist for the creation of more meaningful interventions across multiple levels of schooling. 


\section{In-Depth Analysis of Schools at the Absenteeism Extremes}

For the purposes of case inclusion, this study focused on schools along the full spectrum of absenteeism rates. Another opportunity for future research is a study focused on those at the extremes of the spectrum: schools with the highest absenteeism rates and schools with the lowest absenteeism rates. This focus on the schools with absenteeism rates at the far ends of the spectrum may identify different solution pathways for the combination of factors that contribute to both higher and lower absenteeism.

\section{Research Summary}

In summary, the purpose of this research was to answer the following question: How do elements of school-based health services contribute to the ability of the public secondary school education system to address chronic absenteeism? Chapter One provided background and context for this research, including how a better understanding of the structural school system elements and the process elements of SBHS delivery can provide critical insights into the barriers and facilitators that mitigate and moderate the effects of HBLs on student education and health outcomes.

Chapter Two provided a comprehensive literature review which demonstrated that although widespread acknowledgement and understanding of the intersectionality between health and education exists, no research to date has provided a comprehensive overview of how different structures and processes within a school work (or do not work) together to achieve certain student performance outcomes. An answer to the question posed in this research sought to fill that gap by providing an exploration of the structural elements of the 
school system and the process elements of SBHS delivery can mitigate the HBLs that affect a student's ability to attend school regularly.

Chapter Three described in detail the CCM approach and CNA analytic methods used to address the research question and aims, along with an explanation of the data used in this study. This chapter ended with initial findings from the CNA, including solution pathways for both the higher and lower absenteeism outcome. Chapter Four provided a synthesis of the findings from Chapter Three with a detailed discussion of the first three research aims, including a unique categorization of the structures and systems of SBHS delivery in Oregon's secondary schools; identification of influential elements related to the availability, delivery and quality of health services in secondary schools; and an examination and comparison of configurations of structural and process elements that contribute to the absenteeism outcome.

The findings from Chapters Three and Four were synthesized into policy recommendations to address the fourth aim of this research in Chapter Five. These recommendations provided suggestions for system-level redesign of school-based health services to help integrate delivery across education and health services systems. Chapter Five concluded with the limitations of this research approach and design, as well as potential areas for future research.

\section{Conclusion}

Poor health-related behaviors, illness, and chronic disease can affect a student's ability to attend school regularly when left unaddressed and unattended. The comprehensive integration of health services in schools can interrupt the effects HBLs have on chronic 
absenteeism, diminished educational outcomes, and poor health. This research sought to explore the context and structure of how health services embedded in the school environment might mitigate the effects that health problems and illness have on a student's ability to attend school regularly. This research found that providing comprehensive, coordinated, consistent, and convenient SBHS may serve as the most appropriate and effective means for achieving lower rates of student absenteeism. This closely aligns with the literature and with prior calls from both education and health sector leadership.

Students miss school for myriad reasons, and these reasons can be categorized into three broad groups: 1) students cannot come to school due to circumstances or obligations to be somewhere else, 2) students will not come to school to avoid school-based interactions or events, or 3) students prefer to be somewhere else or do not want to make the effort to go to school (Balfanz \& Byrnes, 2012). The comprehensive implementation and coordination of health services focused in the school environment can actively address students in each of these categories in various ways. SBHS can address the effects specific health problems and issues have on school attendance. The delivery of health services in schools can also eliminate barriers related to seeking care elsewhere. Finally, care coordination in the school environment can also better address issues that arise from interactions and happenings specific to that space.

As policymakers and leaders within the health and education sectors seek novel ways to address the intersectionality among student health, well-being, and educational outcomes, this research suggests that increased focus needs to be given to the ways in which health services are provided and coordinated within the school environment. Moreover, emphasis needs to be made that this is not a "zero-sum game," whereby investments in health and 
well-being will detract from strides made to improve student academic achievement. Instead, the synergistic effect may far outweigh any short-term organizational strain on resources, which ultimately leads to a healthier, more resilient student body that is better equipped to learn and succeed in school as children and in work as adults. 


\section{References}

Adler, L. (1993). Introduction and overview. In L. Adler \& S. Garner (Eds.), The politics of linking schools and social services: The 1993 yearbook of the Politics of Education Association (pp. 1-18). Taylor \& Francis.

Agency for Healthcare Research and Quality. (n.d.). Defining the PCMH. https://pcmh.ahrq.gov/page/defining-pcmh

Agénor, M. (2020). Future directions for incorporating intersectionality into quantitative population health research. American Journal of Public Health, 110(6), 803-806. https://doi.org/10.2105/AJPH.2020.305610

Albright, K., Barnard, J., O’Leary, S., Federico, S., Saville, A., Lockhart, S., Lee, M., Eblovi, D., Dickinson, M., Kile, D., \& Kempe, A. (2016). School-based health centers as medical homes: Parents' and adolescents' perspectives. Academic Pediatrics, 16(4), 381386. https://doi.org/10.1016/j.acap.2015.06.004

Albright, K., Gechter, K., \& Kempe, A. (2013). Importance of mixed methods in pragmatic trials and dissemination and implementation research. Academic Pediatrics, 13(5), 400407. https://doi.org/10.1016/j.acap.2013.06.010

Allensworth, D. D., \& Kolbe, L. J. (1987). The comprehensive school health program: Exploring an expanded concept. Journal of School Health, 57(10), 409-412. https://doi.org/10.1111/j.1746-1561.1987.tb03183.x

Allensworth, D. D., Lawson, E., Nicholson, L., \& Wyche, J. (Eds.). (1997). Schools and health: Our nation's investment. National Academy of Sciences.

Allison, M. A., \& Attisha, E. (2019). The link between school attendance and good health. Pediatrics, 143(2), 1-13. https://doi.org/10.1542/peds.2018-3648 
Alvidrez, J., Greenwood, G. L., Johnson, T. L., \& Parker, K. L. (2021). Intersectionality in public health research: A view from the National Institutes of Health. American Journal of Public Health, 111(1), 95-97. https://doi.org/10.2105/AJPH.2020.305986

Ambuehl, M., \& Baumgartner, M. (2020). cna: Causal modeling with coincidence analysis (R package version 3.0.1).

American Academy of Pediatrics. (2001). School health centers and other integrated school health servcies. Pediatrics, 107(1), 198-201. https://doi.org/10.1542/peds.107.1.198

American Academy of Pediatrics. (2002). American Academy of Pediatrics policy statement: Organizational principles to guide and define the child health care system and/or improve the health of all children. Pediatrics, 110(1), 184-186. https://doi.org/10.1542/peds.110.1.184

American Academy of Pediatrics. (2016). Role of the school nurse in providing school health services (policy statement). Pediatrics, 137(6). https://doi.org/10.1542/peds.2016-0852 American Academy of Pediatrics, \& Council on School Health. (2004). School-based mental health services. Pediatrics, 113(6), 1839-1845. https://doi.org/10.1542/peds.113.6.1839 American School Counselor Association. (2019). ASCA national model: A framework for school counseling programs (4th ed.). American School Counselor Association.

American School Counselor Association. (2020). The school counselor and student mental health (position statement). https://www.schoolcounselor.org/Standards-Positions/PositionStatements/ASCA-Position-Statements/The-School-Counselor-and-Student-MentalHealth 
Andrews, P., Atkinson, L., Ball, S. J., Barber, M., Beckett, L., Berardi, J., Berliner, D., Bloom, E., Boland, N., Boudet, D., Burris, C., Cauthen, N., Cerrone, C., Ciaran, S., Deutermann, J., Devine, N., Dodge, A., Farley, T., Fellicello, S., ... Zhao, Y. (2014, May 6). OECD and Pisa tests are damaging education worldwide - academics. The Guardian. https://www.theguardian.com/education/2014/may/06/oecd-pisa-testsdamaging-education-academics

Annie E. Casey Foundation. (2019a). 2019 Kids count data book: State trends in child well-being. https://www.aecf.org/m/resourcedoc/aecf-2019kidscountdatabook-2019.pdf

Annie E. Casey Foundation. (2019b). Oregon indicators. KIDS COUNT Data Center. https://datacenter.kidscount.org/data\#OR/2/0/char/0

Annie E. Casey Foundation. (2020a). 2020 KIDS COUNT data book: State trends in child wellbeing.

Annie E. Casey Foundation. (2020b). 2020 KIDS COUNT data book interactive. https://www.aecf.org/interactive/databook/?c= race\&d $=\mathrm{ed} \& \mathrm{l}=502$

Annie E. Casey Foundation. (2020c). Oregon indicators. KIDS COUNT Data Center. Association for Supervision and Curriculum Development. (2007). The learning compact redefined: $A$ call to action. www.ascd.org/learningcompact

Attendance Works. (n.d.). Chronic absence: The problem. https://www.attendanceworks.org/chronic-absence/the-problem/

Axelsson, R., \& Axelsson, S. B. (2006). Integration and collaboration in public health: A conceptual framework. International Journal of Health Planning and Management, 21(1), 7588. https://doi.org/10.1002/hpm.826 
Ayanian, J. Z., \& Markel, H. (2016). Donabedian's lasting framework for health care quality. New England Journal of Medicine, 375(3), 205-207. https://doi.org/10.1056/nejmp1605101

Balfanz, R., \& Byrnes, V. (2012). The importance of being in school: A report on absenteeism in the nation's public schools. Johns Hopkins Center for Social Organization of Schools. https://new.every1graduates.org/wpcontent/uploads/2012/05/FINALChronicAbsenteeismReport_May16.pdf

Bartley, M., Ferrie, J., \& Montgomery, S. M. (1999). Living in a high-unemployment economy: Understanding the health consequences. In M. Marmot \& R. G. Wilkinson (Eds.), Social determinants of health (pp. 81-104). Oxford University Press.

Basch, C. E. (2011a). Aggression and violence and the achievement gap among urban minority youth. Journal of School Health, 81(10), 619-625. https://doi.org/10.1111/j.1746-1561.2011.00636.x

Basch, C. E. (2011b). Asthma and the achievement gap among urban minority youth. Journal of School Health, 81(10), 606-613. https://doi.org/10.1111/j.1746-1561.2011.00634.x

Basch, C. E. (2011c). Breakfast and the achievement gap among urban minority youth. Journal of School Health, 81(10), 635-640. https://doi.org/10.1111/j.17461561.2011.00638.x

Basch, C. E. (2011d). Healthier students are better learners: A missing link in school reforms to close the achievement gap. Journal of School Health, 81(10), 593-598. https://doi.org/10.1111/j.1746-1561.2011.00632.x 
Basch, C. E. (2011e). Healthier students are better learners: High-quality, strategically planned, and effectively coordinated school health programs must be a fundamental mission of schools to help close the achievement gap. Journal of School Health, 81(10), 650-662. https://doi.org/10.1111/j.1746-1561.2011.00640.x

Basch, C. E. (2011f). Inattention and hyperactivity and the achievement gap among urban minority youth. Journal of School Health, 81(10), 641-649. https://doi.org/10.1111/j.1746-1561.2011.00639.x

Basch, C. E. (2011g). Physical activity and the achievement gap among urban minority youth. Journal of School Health, 81(10), 626-634. https://doi.org/10.1111/j.17461561.2011.00637.x

Basch, C. E. (2011h). Teen pregnancy and the achievement gap among urban minority youth. Journal of School Health, 81(10), 614-618. https://doi.org/10.1111/j.17461561.2011.00635.x

Basch, C. E. (2011i). Vision and the achievement gap among urban minority youth. Journal of School Health, 81(10), 599-606.

Baumgartner, M. (2008). Regularity theories reassessed. Philosophia, 36, 327-354. https://doi.org/10.1007/s11406-007-9114-4

Baumgartner, M. (2009). Inferring causal complexity. Sociological Methods \& Research, 38(1), 71-101. https://doi.org/10.1177/0049124109339369

Baumgartner, M. (2015). Parsimony and causality. Quality and Quantity, 49(2), 839-856. https://doi.org/10.1007/s11135-014-0026-7

Baumgartner, M. (2020). Causation. In D. Berg-Schlosser, B. Badie, \& L. Morlino (Eds.), The SAGE handbook of political science (pp. 305-321). 
Beem, A. A., Batlivala, C., \& Norwood, A. A. (2019). School-based health centers as the pediatric expanded medical home. Journal of School Health, 89(11), 934-937. https://doi.org/10.1111/josh.12825

Berg-Schlosser, D., De Meur, G., Rihoux, B., \& Ragin, C. C. (2009). Qualitative comparative analysis (QCA) as an approach. In B. Rihoux \& C. C. Ragin (Eds.), Configurational comparative methods: Qualitative comparative analysis (QCA) and related techniques (pp. 1-18). SAGE Publications, Inc. https://doi.org/10.4135/9781452226569.n1

Bersamin, M., Garbers, S., Gaarde, J., \& Santelli, J. (2016). Assessing the impact of schoolbased health centers on academic achievement and college preparation efforts: Using propensity score matching to assess school-level data in California. Journal of School Nursing, 32(4), 241-245. https://doi.org/10.1177/1059840516634805

Berwick, D., \& Fox, D. M. (2016). “Evaluating the quality of medical care”: Donabedian’s classic article 50 years later. The Milbank Quarterly, 94(2), 237-241. https://www.jstor.org/stable/24869165

Best, A., Moor, G., Holmes, B., Clark, P. I., Bruce, T., Leischow, S., Buchholz, K., \& Krajnak, J. (2003). Health promotion dissemination and systems thinking: Towards an integrative model. American Journal of Health Behavior, 27(Suppl. 3), 206-216. https://doi.org/10.5993/AJHB.27.1.s3.4

Biesta, G. (2010). Pragmatism and the philosophical foundations of mixed methods research. In A. Tashakkori \& C. Teddlie (Eds.), SAGE handbook of mixed methods in social \& behavior research (2nd ed., pp. 95-117). SAGE Publications, Inc. 
Blad, E. (2021a, March 31). Biden infrastructure plan calls for $\$ 100$ billion for school construction, upgrades. Education Week. https://www.edweek.org/policypolitics/biden-infrastructure-plan-calls-for-100-billion-for-school-constructionupgrades $/ 2021 / 03$

Blad, E. (2021b, April 28). Biden pitches plan to expand universal pre-K, free school meal programs, teacher training. Education Week. https://www.edweek.org/policypolitics/biden-pitches-plan-to-expand-universal-pre-k-free-school-meal-programsteacher-training/2021/04

Blatchford, P., Bassett, P., \& Brown, P. (2011). Examining the effect of class size on classroom engagement and teacher-pupil interaction: Differences in relation to pupil prior attainment and primary vs. secondary schools. Learning and Instruction, 21(6), 715730. https://doi.org/10.1016/j.learninstruc.2011.04.001

Bonell, C., Humphrey, N., Fletcher, A., Moore, L., Anderson, R., \& Campbell, R. (2014). Why schools should promote students' health and wellbeing: Education policy shouldn't focus solely on academic achievement. British Medical Journal, 348, g3078. https://doi.org/10.1136/bmj.g3078

Booske, B. C., Athens, J. K., Kindig, D. A., \& Remington, P. L. (2010). Different perspectives for assigning weights to determinants of health (County Health Rankings Working Paper). https://www.countyhealthrankings.org/sites/default/files/differentPerspectivesForAs signingWeights'ToDeterminantsOfHealth.pdf

Bowleg, L. (2021). Evolving intersectionality within public health: From analysis to action. American Journal of Public Health, 111(1), 88-90. https://doi.org/10.2105/AJPH.2020.306031 
Bradley, B. J., \& Greene, A. C. (2013). Do health and education agencies in the United States share responsibility for academic achievement and health? A review of 25 years of evidence about the relationship of adolescents' academic achievement and health behaviors. Journal of Adolescent Health, 52(5), 523-532. https://doi.org/10.1016/j.jadohealth.2013.01.008

Braveman, P., \& Barclay, C. (2009). Health disparities beginning in childhood: A life-course perspective. Pediatrics, 124(Supplement 3), S163-S175. https://doi.org/10.1542/peds.2009-1100D

Burns, L. R., Bradley, E. H., \& Weiner, B. J. (2012). Shortell and Kaluzny's health care management: Organization design and behavior (6th ed.). Delmar, Cengage Learning.

Busch, V., Loyen, A., Lodder, M., Schrijvers, A. J. P., van Yperen, T. A., \& de Leeuw, J. R. J. (2014). The effects of adolescent health-related behavior on academic performance: A systematic review of the longitudinal evidence. Review of Educational Research, 84(2), 245274. https://doi.org/10.3102/0034654313518441

Butts, R. F. (1978). Public education in the United States: From revolution to reform. Holt, Rinehart and Winston.

Byrne, D. (2011). What is an effect? Coming at causality backwards. In M. Williams \& W. P. Vogt (Eds.), The SAGE handbook of innovation in social research methods (pp. 80-94). SAGE Publications Ltd. https://doi.org/10.4135/9781446268261

Campbell, D. T. (1969). Ethnocentrism of disciplines and the fish-scale model of omniscience. In M. Sherif \& C. W. Sherif (Eds.), Interdisciplinary relationships in the social sciences (pp. 328-348). Aldine. 
Center for Research on Education Outcomes. (2020). Estimates of Learning Loss in the 20192020 School Year.

https://credo.stanford.edu/sites/g/files/sbiybj6481/f/short_brief_on_learning_loss_f inal_v.3.pdf

Centers for Disease Control and Prevention. (n.d.). About DASH.

https://www.cdc.gov/healthyyouth/about/index.htm

Centers for Disease Control and Prevention. (2016). Division of Adolescent and School Health 2015 annual peport.

https://www.cdc.gov/healthyyouth/about/pdf/DASH2015AnnualReport.pdf

Centers for Disease Control and Prevention. (2017a). CDC's summary of youth surveillance activities. https://www.cdc.gov/healthyyouth/data/pdf/2017surveillance_summary.pdf

Centers for Disease Control and Prevention. (2017b). Results from the School Health

Policies and Practices Study 2016. In School Health Policies and Practices Study (SHPPS).

https://www.cdc.gov/healthyyouth/data/shpps/pdf/shpps-

results_2016.pdf\#page=63\%0Ahttp://www.cdc.gov/healthyyouth/shpps $/ 2012 /$ pdf/s hpps-results_2012.pdf

Centers for Disease Control and Prevention. (2018a). 2018 data users guide.

https://www.cdc.gov/healthyyouth/data/profiles/pdf/2018/2018_Data_Users_Guide .pdf

Centers for Disease Control and Prevention. (2018b). 2018 School Health Profiles lead health education teacher questionnaire (pp. 1-15).

https://www.cdc.gov/healthyyouth/data/profiles/pdf/2018/2018_questionnairet.pdf 
Centers for Disease Control and Prevention. (2018c). 2018 School Health Profiles principal questionnaire (pp. 1-18). https://www.cdc.gov/healthyyouth/data/profiles/pdf/2018/2018_questionnairep.pdf

Centers for Disease Control and Prevention. (2018d). 2018 School Health Profiles Report: Oregon lead health education teacher codebook.

Centers for Disease Control and Prevention. (2018e). 2018 School Health Profiles Report: Oregon principal codebook.

Centers for Disease Control and Prevention. (2018f). How CDC prepares healthy youth for successful futures.

https://www.cdc.gov/healthyyouth/about/pdf/DASH_Snapshot.508.pdf

Centers for Disease Control and Prevention. (2019a). Acute \& emergency care. https://www.cdc.gov/healthyschools/shs/acute_emergency_care.htm

Centers for Disease Control and Prevention. (2019b). Care coordination. https://www.cdc.gov/healthyschools/shs/care_coordination.htm

Centers for Disease Control and Prevention. (2019c). Chronic disease management. https://www.cdc.gov/healthyschools/shs/chronic_disease_management.htm Centers for Disease Control and Prevention. (2019d). Family engagement. https://www.cdc.gov/healthyschools/shs/family_engagement.htm

Centers for Disease Control and Prevention. (2019e). Profiles overview. https://www.cdc.gov/healthyyouth/data/profiles/overview.htm Centers for Disease Control and Prevention. (2019f). School Health Policies and Practices Study (SHPPS). https://www.cdc.gov/healthyyouth/data/shpps/index.htm 
Centers for Disease Control and Prevention. (2019g). School Health Profiles.

https://www.cdc.gov/healthyyouth/data/profiles/index.htm

Centers for Disease Control and Prevention. (2019h). School Health Profiles 2018: Characteristics of health programs among secondary schools. https://www.cdc.gov/healthyyouth/data/profiles/pdf/2018/CDC-Profiles-2018.pdf

Centers for Disease Control and Prevention. (2019i). School health services. https://www.cdc.gov/healthyschools/schoolhealthservices.htm

Chandra, A., Miller, C. E., Acosta, J. D., Weilant, S., Trujillo, M., \& Plough, A. (2016). Drivers of health as a shared value: Mindset, expectations, sense of community, and civic engagement. Health Affairs, 35(11), 1959-1963. https://doi.org/10.1377/hlthaff.2016.0603

Chiang, R. J., Meagher, W., \& Slade, S. (2015). How the Whole School, Whole Community, Whole Child Model works: Creating greater alignment, integration, and collaboration between health and education. Journal of School Health, 85(11), 775-784. https://doi.org/10.1111/josh.12308

Child and Adolsescent Health Measurement Initiative. (n.d.). 2018-2019 National Survey of Children's Health data query - Child and family health measures: Health care access and quality. www.childhealthdata.org

Cohen-Vogel, L., Goldring, E., \& Smrekar, C. (2011). The influence of local conditions on social service partnerships, parent involvement, and community engagement in neighborhood schools. American Journal of Education, 117(1), 51-78.

https://doi.org/10.1086/656346 
Coleman, J. S., Campbell, E. Q., Hobson, C. J., McPartland, J., Mood, A. M., Weinfeld, F. D., \& York, R. L. (1966). Equality of educational opportunity. National Center for Educational Statistics. https://doi.org/10.1016/0038-0121(69)90029-9

Coury, J., Miech, E. J., Styer, P., Petrik, A. F., Coates, K. E., Green, B. B., Baldwin, L.-M., Shapiro, J. A., \& Coronado, G. D. (2021). What's the "secret sauce"? How implementation variation affects the success of colorectal cancer screening outreach. Implementation Science Communications, 2(1), 1-11. https://doi.org/10.1186/s43058-02000104-7

Cragun, D. (2020). Configurational comparative methods. In P. Nilsen \& S. A. Birken (Eds.), Handbook on implementation science (pp. 497-504). Edward Elgar Publishing.

Cragun, D., Pal, T., Vadaparampil, S. T., Baldwin, J., Hampel, H., \& DeBate, R. D. (2016). Qualitative comparative analysis: A hybrid method for identifying factors associated with program effectiveness. Journal of Mixed Methods Research, 10(3), 251-272. https://doi.org/10.1177/1558689815572023

Creswell, J. W. (2014). Research design: Qualitative, quantitative, and mixed methods approaches (4th ed.). SAGE Publications, Inc.

Cutler, D. M., \& Lleras-Muney, A. (2006). Education and health: Evaluating theories and evidence. National Bureau of Economic Research. https://doi.org/10.3386/w12352

Cutler, D. M., \& Lleras-Muney, A. (2010). Understanding differences in health behaviors by education. Journal of Health Economics, 29(1), 1-28. https://doi.org/10.1016/j.jhealeco.2009.10.003

Dahlgren, G., \& Whitehead, M. (1991). Policies and strategies to promote social equity in health. Background document to WHO - Strategy paper for Europe (Issue September 1991). 
Darling-Hammond, L. (2010). The flat world and education: How America's commitment to equity will determine our future. Teachers College Press.

Dilley, J. (2009). Research review: School-based health interventions and academic achievement. http://here.doh.wa.gov/materials/research-review-school-based-health-interventionsand-academic-achievement/12_HealthAcademic_E09L.pdf

Donabedian, A. (1966). Evaluating the quality of medical care. The Milbank Memorial Fund Quarterly, 44(3), 166-206. https://doi.org/10.2307/3348969

Donabedian, A. (1978). The quality of medical care. Science, 200(4344), 856-864. www.jstor.org/stable/1746374?seq=1\&cid=pdf-reference\#references_tab_contents Donabedian, A. (1981). Criteria, norms and standards of quality: What do they mean? American Journal of Public Health, 71(4), 409-412. https://doi.org/10.2105/AJPH.71.4.409

Donabedian, A. (1990). The seven pillars of quality. Archives of Pathology \& Laboratory Medicine, 114(11), 1115-1118.

Dzau, V. J., McClellan, M. B., McGinnis, J. M., Burke, S. P., Coye, M. J., Diaz, A., Daschle, T. A., Frist, W. H., Gaines, M., Hamburg, M. A., Henney, J. E., Kumanyika, S., Leavitt, M. O., Parker, R. M., Sandy, L. G., Schaeffer, L. D., Steele, G. D., Thompson, P., \& Zerhouni, E. (2017). Vital directions for health and health care priorities from a National Academy of Medicine initiative. Journal of the American Medical Association, 317(14), 1461-1470. https://doi.org/10.1001/jama.2017.1964

Education Commission of the States. (2017). K-12 governance structures: State profile - Oregon. http:/ / ecs.force.com/mbdata/mbstprofile?Rep=KG17\&st=Oregon 
Egerter, S., Braveman, P., Sadegh-Nobari, T., Grossman-Kahn, R., \& Dekker, M. (2011). Education and health. In Issue brief \#5: Exploring the social determinants of health (Vol. 5). Robert Wood Johnson Foundation. https://www.rwjf.org/en/library/research/2011/05/education-matters-for-health.html Epstein, J. L., \& Sheldon, S. B. (2002). Present and accounted for: Improving student attendance through family and community involvement. The Journal of Educational Research, 95(5), 308-318. https://doi.org/10.1080/00220670209596604

Esensoy, A. V., \& Carter, M. W. (2015). Health system modelling for policy development and evaluation: Using qualitative methods to capture the whole-system perspective. Operations Research for Health Care, 4, 15-26. https://doi.org/10.1016/j.orhc.2014.12.002

Falcon, S., Perry, S., \& Oregon Department of Education. (2016). HB 4002: Chronic absenteeism statewide plan. https://www.oregon.gov/ode/reports-anddata/LegReports/Documents/2016---december---chronic-absenteeism-report-(hb4002).pdf

Ferguson, K. T., Kim, P., Dunn, J. R., \& Evans, G. W. (2009). An ecological model of urban child health. In N. Freudenberg, S. Klitzman, \& S. Saegert (Eds.), Urban Health and Society: Interdisciplinary Approaches to Research and Pracitce2 (1 st ed.). John Wiley \& Sons.

Fiscella, K., \& Kitzman, H. (2009). Disparities in academic achievement and health: The intersection of child education and health policy. Pediatrics, 123(3), 1073-1080. https://doi.org/10.1542/peds.2008-0533

Fischer, K. (2017, December 29). Why education matters to your health -- literally. Chronicle of Higher Education. https://www.chronicle.com/article/why-education-matters-to-yourhealth/ 
Fothergill, K., \& Ballard, E. (1998). The school-linked health center: A promising model of community-based care for adolescents. Journal of Adolescent Health, 23(1), 29-38. https://doi.org/10.1016/S1054-139X(98)00012-3

Friedrich, M. J. (1999). 25 Years of School-Based Health Centers. Journal of the American Medical Association, 281(9), 781-782. https://doi.org/10.1001/jama.281.9.781

Furnari, S., Crilly, D., Misangyi, V. F., Greckhamer, T., Fiss, P. C., \& Aguilera, R. V. (2020). Capturing causal complexity: Heuristics for configurational theorizing. Academy of Management Review. https://doi.org/10.5465/amr.2019.0298

Fusarelli, B. C., \& Lindle, J. C. (2011). The politics, problems and potential promise of school-linked social services: Insights and new directions from the work of William Lowe Boyd. Peabody Journal of Education, 86(4), 402-415. https://doi.org/10.1080/0161956X.2011.597270

Fusarelli, L. D., \& Fusarelli, B. C. (2015). Federal education policy from Reagan to Obama: Convergence, divergence, and “control.” In B. S. Cooper, J. G. Cibulka, \& L. D. Fusarelli (Eds.), Handbook of education politics and policy (2nd ed., pp. 189-210). Routledge.

Gibson, E. J., Santelli, J. S., Minguez, M., Lord, A., \& Schuyler, A. C. (2013). Measuring school health center impact on access to and quality of primary care. Journal of Adolescent Health, 53(6), 699-705. https://doi.org/10.1016/j.jadohealth.2013.06.021

Glymour, M. M., Avendano, M., \& Kawachi, I. (2014). Socioeconomic status and health. In L. F. Berkman, I. Kawachi, \& M. M. Glymour (Eds.), Social Epidemiology (2nd ed., pp. 17-62). Oxford University Press.

Goldstein, D. (2014). The teacher wars: A bistory of America's most embattled profession. Anchor Books. 
Gottfried, M. A. (2014). Chronic absenteeism and its effects on students' academic and socioemotional outcomes. Journal of Education for Students Placed at Risk, 19(2), 53-75. https://doi.org/10.1080/10824669.2014.962696

Gottfried, M. A. (2019). Chronic absenteeism in the classroom context: Effects on achievement. Urban Education, 54(1), 3-34. https://doi.org/10.1177/0042085915618709

Gracy, D., Fabian, A., Basch, C. H., Scigliano, M., MacLean, S. A., MacKenzie, R. K., \& Redlener, I. E. (2018). Missed opportunities: Do states require screening of children for health conditions that interfere with learning? PLoS ONE, 13(1), 1-13. https://doi.org/10.1371/journal.pone.0190254

Gracy, D., Fabian, A., Rongcaglione, V., Savage, K., \& Redlener, I. (2017). Health barriers to learning: The prevalence and educational consequences in disadvantaged children $A$ review of the literature. Children's Health Fund. https://www.childrenshealthfund.org/wpcontent/uploads/2017/01/Health-Barriers-to-Learning.pdf

Green, J., \& Thorogood, N. (2014). Qualitative methods for health research (3rd ed.). SAGE Publications.

Green, L. W. (2006). Public health asks of systems science: To advance our evidence-based practice, can you help us get more practice-based evidence? American Journal of Public Health, 96, 406-409. https://doi.org/10.2105/AJPH.2005.066035

Gregg, A., Chen, L. W., Kim, J., Tak, H. J., \& Tibbits, M. (2019). Patient-centered medical home measurement in school-based health centers. Journal of School Nursing, 35(3), 189_ 202. https://doi.org/10.1177/1059840517746728 
Grossman, M. (2008). The relationship between health and schooling. Eastern Economic Journal, 34, 281-292. https://doi.org/10.1057/eej.2008.13

Grzywacz, J. G., \& Fuqua, J. (2000). The social ecology of health: Leverage points and linkages. Behavioral Medicine, 26(3), 101-115. https://doi.org/10.1080/08964280009595758

Gustafson, E. M. (2005). History and overview of school-based health centers in the US. Nursing Clinics of North America, 40(4), 595-606. https://doi.org/10.1016/j.cnur.2005.08.001

Halfon, N., Wise, P. H., \& Forrest, C. B. (2014). The changing nature of children's health development: New challenges require major policy solutions. Health Affairs, 33(12), 2116-2124. https://doi.org/10.1377/hlthaff.2014.0944

Hanushek, E. A. (2017). What matters for student achievement. Education Next, 16(2), 18-26. Hassett, S., \& Austin, M. J. (1997). Service integration: Something old and somethig new. Administration in Social Work, 21(3/4), 9-29. https://doi.org/10.1300/J147v21n03_02

Hay, M. C. (2016). Ethnography in need of numbers: Mixing methods to build partnerships and understand tigers. In Methods that matter: Integrating mixed methods for more effective social science research (pp. 41-48). The University of Chicago Press.

Henderson, T., Hill, C., \& Norton, K. (2014). The connection between missing school and health: A review of chronic absenteeism and student health in Oregon. http://www.attendanceworks.org/wordpress/wp-content/uploads/2014/10/ChronicAbsence-and-Health-Review-10.8.14-FINAL-REVISED.pdf Hernandez, D. J. (2012). Double jeopardy: How third-grade reading skills and poverty influence high school graduation. https://www.aecf.org/resources/double-jeopardy/ 
Hickman, S. E., Miech, E. J., Stump, T. E., Fowler, N. R., \& Unroe, K. T. (2020). Identifying the implementation conditions associated with positive outcomes in a successful nursing facility demonstration project. Gerontologist, 60(8), 1566-1574. https://doi.org/10.1093/geront/gnaa041

House Bill 2267, (2019). https://olis.leg.state.or.us/liz/2019R1/Downloads/MeasureDocument/HB2267/Enro lled

House Bill 3427, (2019). https://olis.leg.state.or.us/liz/2019R1/Downloads/MeasureDocument/HB3427/Enro lled

Humphrey, N., Lendrum, A., \& Wigelsworth, M. (2013). Making the most out of schoolbased prevention: Lessons from the social and emotional aspects of learning (SEAL) programme. Emotional and Behavioural Difficulties, 18(3), 248-260.

https://doi.org/10.1080/13632752.2013.819251

Igoe, J. B. (1975). The school nurse practitioner. Nursing Outlook, 23(6), 381-384.

Institute of Medicine. (2002). The governmental public health infrastructure. In The Future of the Public's Health in the 21st Century. National Academies Press.

Institute of Medicine. (2009). Adolescent health services: Missing opportunities. In R. S. Lawrence, J. Appleton Gootman, \& L. J. Sim (Eds.), Adolescent Health Services. The National Academies Press. https://doi.org/10.17226/12063

Jackson, M. I. (2015). Cumulative inequality in child health and academic achievement. Journal of Health and Social Behavior, 56(2), 262-280. https://doi.org/10.1177/0022146515581857 
Jacobsen, K., Meeder, L., \& Voskuil, V. R. (2016). Chronic student absenteeism: The critical role of school nurses. NASN School Nurse, 31(3), 178-185. https://doi.org/10.1177/1942602X16638855

Jambor, E. E. (2009). Quality of life of deaf and hard of hearing individuals in northern Nevada [Doctoral dissertation, University of Nevada, Reno]. https://scholarworks.unr.edu/bitstream/handle/11714/4105/Jambor_unr_0139D_10 195.pdf?sequence $=1$

Jones, C. A., Parker, T. S., Ahearn, M., Mishra, A. K., \& Variyam, J. N. (2009). Health status and health care access of farm and rural populations. In Economic Infomration Bulletin (Issue 57).

Jordan, P., \& Chang, H. (2015). Mapping the early attendance gap: Charting a course for school success. https://www.attendanceworks.org/wp-content/uploads/2017/05/Mapping-the-EarlyAttendance-Gap_Final-4.pdf

Kahwati, L. C., \& Kane, H. L. (2020). Qualitative comparative analysis in mixed methods research and evaluation (N. V. Ivankova \& V. L. Plano Clark (Eds.), Mixed Methods Research Series). SAGE Publications, Inc.

Katz, D., \& Kahn, R. L. (1978). The social psychology of organizations (Second Edi). Wiley.

Kawachi, I., Adler, N. E., \& Dow, W. H. (2010). Money, schooling, and health: Mechanisms and causal evidence. Annals of the New York Academy of Sciences, 1186, 56-68. https://doi.org/10.1111/j.1749-6632.2009.05340.x

Kearney, C. A., \& Graczyk, P. (2014). A response to intervention model to promote school attendance and decrease school absenteeism. Child and Youth Care Forum, 43(1), 1-25. https://doi.org/10.1007/s10566-013-9222-1 
Keeley, B. (2007). Human capital: How what you know shapes your life. OECD Publishing. https://doi.org/https://doi.org/10.1787/9789264029095-en

Kieschnick, W. (2018). Does class size matter? The answer is yes. https://www.hmhco.com/blog/class-size-matters

Kolbe, L. J. (1986). Increasing the impact of school health promotion programs: Emerging research perspectives. Journal of Health Education, 17(7), 47-52.

Kolbe, L. J. (2002). Education reform \& the goals of modern school health programs. The State Education Standard, 3(4), 4-11.

Kolbe, L. J. (2005). A framework for school health programs in the 21st century. Journal of School Health, 75(6), 226-228. https://doi.org/j.1746-1561.2005.00028.x10.1111/j.17461561.2005.tb06677.x

Lantz, P. M., Lichtenstein, R. L., \& Pollack, H. A. (2007). Health policy approaches to population health: The limits of medicalization. Health Affairs, 26(5), 1253-1257. https://doi.org/10.1377/hlthaff.26.5.1253

Lasker, R. D., Weiss, E. S., \& Miller, R. (2001). Partnership synergy: A practical framework for studying and strengthening the collaborative advantage. The Milbank Quarterly, 79(2), 179-205.

Lawrence, P. R., \& Lorsch, J. W. (1967). Differentiation and integration in complex organizations. Administrative Science Quarterly, 12(1), 1-47. http://www.jstor.org/stable/2391211

Leroy, Z. C., Wallin, R., \& Lee, S. (2017). The role of school health services in addressing the needs of students with chronic health conditions: A systematic review. Journal of School Nursing, 33(1), 64-72. https://doi.org/10.1177/1059840516678909 
LeVine, R. A. (2016). Repairing the fractured social sciences:An introduction from a historical point of view. In M. C. Hay (Ed.), Methods that matter: Integrating mixed methods for more effective social science research (pp. 3-12). The University of Chicago Press.

Lewallen, T. C., Hunt, H., Potts-Datema, W., Zaza, S., \& Giles, W. (2015). The whole school, whole community, whole child model: A new approach for improving educational attainment and healthy development for students. Journal of School Health, 85(11), 729-739. https://doi.org/10.1111/josh.12310

Lieberman, M. (2020). 5 things you need to know about student absences during COVID-19. Education Week.

Lorsch, J. W., \& Lawrence, P. R. (1970). Studies in organization design. Richard D. Irwin, Inc.

Love, H. E., Schlitt, J., Panchal, N., \& Grandmont, J. (2019). A mapping tool to address bealth and education disparities and improve access to school-based health care. Health Affairs. https://doi.org/10.1377/hblog20190808.517170

Love, H. E., Schlitt, J., Soleimanpour, S., Panchal, N., \& Behr, C. (2019). Twenty years of school-based health care growth and expansion. Health Affairs, 38(5), 755-764. https://doi.org/10.1377/hlthaff.2018.05472

Love, H. E., Soleimanpour, S., Panchal, N., Schlitt, J., Behr, C., \& Even, M. (2018). 2016-17 national school-based health care census. https://www.sbh4all.org/wpcontent/uploads/2019/05/2016-17-Census-Report-Final.pdf

Luke, D. A., \& Stamatakis, K. A. (2012). Systems science methods in public health: Dynamics, networks, and agents. Annual Review of Public Health, 33(1), 357-376. https://doi.org/10.1146/annurev-publhealth-031210-101222 
Mackie, J. L. (1965). Causes and conditions. American Philosophical Quarterly, 2(4), 245-264. http://www.jstor.org/stable/20009173

Marmot, M. (1999). Introduction. In M. Marmot \& R. G. Wilkinson (Eds.), Social determinants of health (pp. 1-16). Oxford University Press.

Marx, A., Rihoux, B., \& Ragin, C. (2014). The origins, development, and application of qualitative comparative analysis: The first 25 years. European Political Science Review, 6(1), 115-142. https://doi.org/10.1017/S1755773912000318

Mawhinney, H. B. (1993). Discovering shared values: Ecological models to support interagency collaboration. Journal of Education Policy, 8(5/6), 33-47.

McClurg, L. (2020). Pandemic takes toll on children's mental health. NPR Weekend Edition Saturday.

McGinnis, J. M., Williams-Russo, P., \& Knickman, J. R. (2002). The case for more active policy attention to health promotion. Health Affairs, 21(2), 78-93. https://doi.org/10.1377/hlthaff.21.2.78

McGovern, L., Miller, G., \& Hughes-Cromwick, P. (2014, August 21). Health policy brief: The relative contribution of multiple determinants to health outcomes. Health Affairs. http://www.healthaffairs.org/healthpolicybriefs/

McGowan Lowrey, K. (2018). What school nurses really do: Realizing the power of school nursing in public health. The Network for Public Health Law. https://www.networkforphl.org/news-insights/what-school-nurses-really-do-realizingthe-power-of-school-nursing-in-public-health/ 
Michael, S. L., Merlo, C. L., Basch, C. E., Wentzel, K. R., \& Wechsler, H. (2015). Critical connections: Health and academics. Journal of School Health, 85(11), 740-758. https://doi.org/10.1111/josh.12309

Morse, L. L., \& Allensworth, D. D. (2015). Placing students at the center: The Whole School, Whole Community, Whole Child Model. Journal of School Health, 85(11), 785794. https://doi.org/10.1111/josh.12313

National Academies of Sciences Engineering and Medicine. (2020). Reopening K-12 schols during the COVID-19 pandemic: Prioritizing health, equity, and communities. In Reopening K-12 Schools During the COVID-19 Pandemic. https://doi.org/10.17226/25858

National Association of School Nurses. (2018). The role of the 21st century school nurse (position statement). https://www.nasn.org/nasn/advocacy/professional-practicedocuments/position-statements/ps-role

National Center for Education Statistics. (n.d.). Back to school statistics. https://nces.ed.gov/fastfacts/display.asp?id=372

National Center for Education Statistics. (2020). Public school revenue sources. https://nces.ed.gov/programs/coe/indicator_cma.asp

Niyozov, S., \& Hughes, W. (2019, June). Problems with PISA: Why Canadians should be skeptical of the global test. The Conversation. http://theconversation.com/problemswith-pisa-why-canadians-should-be-skeptical-of-the-global-test-118096

No Child Left Behind Act of 2001, (2002). https://www.congress.gov/bill/107thcongress/house-bill/1 
O’Leary, S. T., Lee, M., Federico, S., Barnard, J., Lockhart, S., Albright, K., Shmueli, D., Allison, M. A., \& Kempe, A. (2014). School-based health centers are patient-centered medical homes. Pediatrics, 134(5), 957-964. https://doi.org/10.1542/peds.2014-0296

Office of Research Analysis \& Accountability. (2018). At-a-glance school and district profiles: 2017-2018 technical manual. https://www.oregon.gov/ode/schools-anddistricts/reportcards/reportcards/Documents/rc_At-A-Glance_Technical_Manual.pdf Oregon Department of Education. (n.d.-a). Chronic absenteeism in Oregon 2018-2019.

Oregon Department of Education. (n.d.-b). Every Day Matters - Increasing regular attendance and reducing chronic absenteeism. https://www.oregon.gov/ode/students-andfamily/healthsafety/Pages/Chronic-Absenteeism.aspx

Oregon Department of Education. (n.d.-c). Resources and guidance for Title 1-A. https://www.oregon.gov/ode/schools-and-districts/grants/ESEA/IA/Pages/TitleIA-Resources.aspx

Oregon Department of Education. (n.d.-d). Student Success Act. oregon.gov/ode/studentsuccess

Oregon Department of Education. (n.d.-e). Title 1-A improving basic programs. https://www.oregon.gov/ode/schools-anddistricts/grants/ESEA/IA/Pages/default.aspx

Oregon Department of Education. (2018a). 2017-2018 RC schools - Aggregated. https://www.ode.state.or.us/data/reportcard/media.aspx

Oregon Department of Education. (2018b). Oregon statewide report card 2017-2018. https://www.oregon.gov/ode/schools-anddistricts/reportcards/Documents/rptcard2018.pdf 
Oregon Department of Education. (2019a). Attendance and absenteeism.

https://www.oregon.gov/ode/reports-and-data/students/Pages/Attendance-andAbsenteeism.aspx

Oregon Department of Education. (2019b). Oregon statewide report card 2018-2019. http://www.ode.state.or.us/data/annreportcard/rptcard2013.pdf

Oregon Department of Education. (2020). Oregon Statewide Report Card 2019-2020. http://www.ode.state.or.us/data/annreportcard/rptcard2013.pdf

Oregon Department of Education. (2021). Institution lookup search. https://www.ode.state.or.us/instid/

Oregon Health Authority. (n.d.). Coordinated care: The Oregon difference. https://www.oregon.gov/oha/HPA/Pages/CCOs-Oregon.aspx

Oregon Health Authority. (2012). Coordinated care organizations: Implementation proposal. https://www.oregonlegislature.gov/citizen_engagement/Reports/2012_OHA_Coordi nated Care Organizations Implementation Proposal.pdf

Oregon Health Authority. (2020). Oregon school-based health centers: Status update 2020. https://www.oregon.gov/oha/PH/HEALTHYPEOPLEFAMILIES/YOUTH/HEA LTHSCHOOL/SCHOOLBASEDHEALTHCENTERS/Documents/2020-SBHCStatus-Update.pdf

Oregon Health Policy Board. (2018a). Appendix C: CCO 2.0 and children's health. https://www.oregon.gov/oha/OHPB/CCODocuments/2018-OHA-CCO-2.0Report-Appendix-C.PDF

Oregon Health Policy Board. (2018b). CCO 2.0 recommendations of the Oregon Health Policy Board. https://apps.state.or.us/Forms/Served/le9830.pdf 
Oregon Office of Rural Health. (2020a). Oregon Office of Rural Health geographic definitions.

https://www.ohsu.edu/oregon-office-of-rural-health/about-rural-and-frontier-data

Oregon Office of Rural Health. (2020b). ORH defined urban, rural, and frontier areas (map). ohsu.edu/media/881

Organisation for Economic Co-operation and Development. (n.d.). What is PISA? http://www.oecd.org/pisa/

Padula, W. V., Connor, K. A., Mueller, J. M., Hong, J. C., Velazquez, G. C., \& Johnson, S. B. (2018). Cost benefit of comprehensive primary and preventive school-based health care. American Journal of Preventive Medicine, 54(1), 80-86. https://doi.org/10.1016/j.amepre.2017.08.025

Palinkas, L. A., Mendon, S. J., \& Hamilton, A. B. (2019). Innovations in mixed methods evaluations. Annual Review of Public Health, 40, 423-442. https://doi.org/10.1146/annurev-publhealth-040218-044215

Perrin, J. M., Anderson, L. E., \& Van Cleave, J. (2014). The rise in chronic conditions among infants, children, and youth can be met with continued health system innovations. Health Affairs, 33(12), 2099-2105. https://doi.org/10.1377/hlthaff.2014.0832

Perrow, C. (2014). Complex organizations: A critical essay (3rd ed.). Echo Point Books \& Media, LLC.

Petrik, A. F., Green, B., Schneider, J., Miech, E. J., Coury, J., Retecki, S., \& Coronado, G. D. (2020). Factors influencing implementation of a colorectal cancer screening improvement program in community health centers: An applied use of configurational comparative methods. Journal of General Internal Medicine, 35(Suppl 2), 815-822. https://doi.org/10.1007/s11606-020-06186-2 
Pfeffer, J., \& Salancik, G. R. (2003). The external control of organizations: A resource dependence perspective. Stanford University Press.

Portland State University. (n.d.). Research integrity \& compliance programs: Human research protection program. https://sites.google.com/a/pdx.edu/research/integrity

Public School Review. (2021). Average public school student: teacher ratio. https://www.publicschoolreview.com/average-student-teacher-ratio-stats/nationaldata

Ragin, C. C. (1987). The comparative method: Moving beyond qualitative and quantitative strategies. University of California Press.

Ragin, C. C. (1999). Using qualitative comparative analysis to study causal complexity. Health Services Research, 34(5 Pt 2), 1225-1239.

Ragin, C. C. (2008). Redesigning social inquiry: Furay sets and beyond. The University of Chicago Press.

Ragin, C. C. (2014). The comparative method: Moving beyond qualitative and quantitative strategies (2nd ed.). University of California Press.

Ramirez, M., \& Buher, A. (2020, December 18). The Biden administration must dramatically expand school-based health care. The Hill.

Rand, C. M., \& Goldstein, N. P. N. (2018). Patterns of primary care physician visits for US adolescents in 2014: Implications for vaccination. Academic Pediatrics, 18(2), S72-S78. https://doi.org/10.1016/j.acap.2018.01.002

Rasberry, C. N., Tiu, G. F., Kann, L., Mcmanus, T., \& Michael, S. L. (2017). Health-related behaviors and academic achievement among high school students - United States, 2015 (Vol. 66, Issue 35). https://doi.org/10.15585/mmwr.mm6635a1 
Reardon, S. F. (2011). The widening academic achievement gap between the rich and the poor: New evidence and possible explanations. In G. J. Duncan \& R. J. Murnane (Eds.), Whither Opportunity?: Rising Inequality, Schools, and Children's Life Chances (1st ed., pp. 91-115). Russell Sage Foundation.

Repetti, R. L., Taylor, S. E., \& Seeman, T. E. (2002). Risky families: Family social environments and the mental and physical health of offspring. Psychological Bulletin, 128(2), 330-366. https:/ / doi.org/10.1037/0033-2909.128.2.330

Richardson, J. W. (2007). Building bridges between school-based health clinics and schools. Journal of School Health, 77(7), 337-343. https://doi.org/10.1111/j.17461561.2007.00217.x

Rihoux, B., \& Marx, A. (2013). Qualitative comparative analysis at 25: State of play and agenda. Political Research Quarterly, 66(1), 167-171. https://doi.org/10.1177/1065912912468269a

Rihoux, B., \& Ragin, C. C. (2009). Why compare? Why configurational comparative methods? In B. Rihoux \& C. C. Ragin (Eds.), Configurational comparative methods: Qualitative comparative analysis (QCA) and related techniques. SAGE Publications, Inc. https://doi.org/https://dx-doi-org.proxy.lib.pdx.edu/10.4135/9781452226569

Riley, M., Laurie, A. R., Plegue, M. A., \& Richardson, C. R. (2016). The adolescent “expanded medical home": School-based health centers partner with a primary care clinic to improve population health and mitigate social determinants of health. The Journal of the American Board of Family Medicine, 29(3), 339-347.

https://doi.org/10.3122/jabfm.2016.03.150303

Rippner, J. A. (2016). The American education policy landscape. Routledge. 
Robert Wood Johnson Foundation. (2019a). About a Culture of Health. https://www.rwjf.org/en/cultureofhealth/about.html

Robert Wood Johnson Foundation. (2019b). Taking action. https://www.rwjf.org/en/cultureofhealth/taking-action.html

Rohlfing, I., \& Zuber, C. I. (2019). Check your truth conditions! Clarifying the relationship between theories of causation and social science methods for causal inference. Sociological Methods \& Research. https://doi.org/10.1177/0049124119826156

Roig-Tierno, N., Gonzalez-Cruz, T. F., \& Llopis-Martinez, J. (2017). An overview of qualitative comparative analysis: A bibliometric analysis. Journal of Innovation \& Knowledge, 2(1), 15-23. https://doi.org/10.1016/j.jik.2016.12.002

Sacks, P. (2007). Tearing down the gates: Confronting the class divide in American education. University of California Press.

Schleicher, A. (2019). PIS A 2018: Insights and interpretations. Organisation for Economic Cooperation and Development. https://www.oecd.org/pisa/PISA 2018 Insights and Interpretations FINAL PDF.pdf

Schneider, C. Q., \& Wagemann, C. (2013). Set-theoretic methods for the social sciences: A guide to qualitative comparative analysis. Cambridge University Press.

Scott, W. R. (2003). Organizations: Rational, natural, and open systems (5th ed.). Prentice Hall. Smrekar, C. (1998). The organizational and political threats to school-linked integrated services. Educational Policy, 12(3), 284-304. https://doi.org/10.1177/0895904898012003004 Sprick, J., \& Sprick, R. (2018). School leader's guide to tackling attendance challenges. ACSD. 
Starfield, B., Shi, L., \& Macinko, J. (2005). Contribution of primary care to health systems and health. The Milbank Quarterly, 83(3), 457-502. https://doi.org/10.1111/j.14680009.2005.00409.x

State of Oregon. (n.d.-a). Education service districts transparency. https://www.oregon.gov/transparency/Pages/ESDTransparency.aspx State of Oregon. (n.d.-b). Oregon State Board of Education. https://www.oregon.gov/ode/about-us/stateboard/Pages/default.aspx State of Oregon. (n.d.-c). The Oregon Department of Education - About us. https://www.oregon.gov/ode/about-us/Pages/default.aspx

Stempel, H., Cox-Martin, M., Bronsert, M., Dickinson, L. M., \& Allison, M. A. (2017). Chronic school absenteeism and the role of adverse childhood experiences. Academic Pediatrics, 17(8), 837-843. https://doi.org/10.1016/j.acap.2017.09.013

Strolin-Goltzman, J., Sisselman, A., Melekis, K., \& Auerbach, C. (2014). Understanding the relationship between school-based health center use, school connection, and academic performance. Health and Social Work, 39(2), 83-91.

https://doi.org/10.1093/hsw/hlu018

Sullivan, K. (2021, March). Biden promises “once-in-a-generation” investment during pitch for $\$ 2$ trillion infrastructure and climate plan. In cnn.com. CNN.

Thiem, A. (2017). Conducting configurational comparative research with qualitative comparative analysis: A hands-on tutorial for applied evaluation scholars and practitioners. American Journal of Evaluation, 38(3), 420-433.

https://doi.org/10.1177/1098214016673902 
Thomas, G. (2016). After the gold rush: Questioning the "gold standard" and reappraising the status of experiment and randomized controlled trials in education. Harvard Educational Review, 86(3), 390-412. https:/ / doi.org/10.17763/1943-5045-86.3.390

Thompson, J. D. (1967). Organizations in action: Social science bases of administrative theory. McGraw-Hill Book Company.

Thygeson, N. M., Solberg, L. I., Asche, S. E., Fontaine, P., Pawlson, L. G., \& Hudson Scholle, S. (2012). Using fuzzy set qualitative comparative analysis (fs/QCA) to explore the relationship between medical "homeness" and quality. Health Services Research, 47(1, Part 1), 22-45. https://doi.org/10.1111/j.1475-6773.2011.01303.x

Towe, V. L., Leviton, L., Chandra, A., Sloan, J. C., Tait, M., \& Orleans, T. (2016). Crosssector collaborations and partnerships: Essential ingredients to help shape health and well-being. Health Affairs, 35(11), 1964-1969.

https://doi.org/10.1377/hlthaff.2016.0604

Trujillo, M. D., \& Plough, A. (2016). Building a culture of health: A new framework and measures for health and health care in America. Social Science and Medicine, 165, 206-213. https://doi.org/10.1016/j.socscimed.2016.06.043

U.S. Const. amend. X.

U.S. Department of Agriculture. (2020). Rural-urban commuting area codes. https://www.ers.usda.gov/data-products/rural-urban-commuting-area-codes /

U.S. Department of Education. (2009). Race to the Top program executive summary. https://www2.ed.gov/programs/racetothetop/executive-summary.pdf

U.S. Department of Education. (2011). Mission. 
U.S. Department of Education. (2016a). New data show chronic absenteeism is widespread and prevalent among all student groups. U.S. Department of Education. https://www.ed.gov/news/press-releases/new-data-show-chronic-absenteeismwidespread-and-prevalent-among-all-student-groups

U.S. Department of Education. (2016b). Supporting school reform by leveraging federal funds in a schoolwide program.

U.S. Department of Education. (2018). Improving basic programs operated by local education agencies (Title 1, Part A). https://www2.ed.gov/programs/titleiparta/index.html

U.S. Department of Education. (2019). Chronic absenteeism in the nation's schools: A bidden educational crisis. https://www2.ed.gov/datastory/chronicabsenteeism.html

U.S. Department of Education. (2021). National Safe School Reopening Summit. https://web.cvent.com/event/8da3e1c7-f15c-4979-b2e9-f0490a589714/summary

U.S. Department of Health \& Human Services. (2018). Overview: HHS strategic plan, FY 20182022.

Van Cleave, J., Gortmaker, S. L., \& Perrin, J. M. (2010). Dynamics of obesity and chronic health conditions among children and youth. Journal of the American Medical Association, 303(7), 623-630. https://doi.org/10.1001/jama.2010.104

Van Lerberghe, W., Manuel, A., Matthews, Z., \& Wolfheim, C. (2005). The World Health report 2005: Make every mother and child count. https://doi.org/10.1596/978-0-8213-6133-7

Viner, R. M., Ozer, E. M., Denny, S., Marmot, M., Resnick, M., Fatusi, A., \& Currie, C. (2012). Adolescence and the social determinants of health. The Lancet, 379(9826), 16411652. https://doi.org/10.1016/s0140-6736(12)60149-4 
Virginia Commonwealth University Center on Society and Health. (2014). Education: It matters more to bealth than ever before. http:// societyhealth.vcu.edu/media/societyhealth/pdf/test-folder/CSH-EHI-Issue-Brief-1.pdf

Vogt, W. P., Gardner, D., Haeffele, L., \& Baker, P. J. (2011). Innovations in program evaluation: Comparative case studies as an alternative to RCTs. In M. Williams \& W. P. Vogt (Eds.), The SAGE handbook of innovation in social research methods (pp. 293-324).

SAGE Publications, Ltd. https://doi.org/10.4135/9781446268261

Wadsworth, M. (1999). Early life. In M. Marmot \& R. G. Wilkinson (Eds.), Social determinants of health (pp. 44-63). Oxford University Press.

Weil, A. R. (2014). Caring for children. Health Affairs, 33(12), 2094. https://doi.org/10.1377/hlthaff.2014.1291

Weil, A. R. (2016). Building a culture of health. Health Affairs, 35(11), 1953-1958. https://doi.org/10.1007/978-3-319-43723-1_1

Whitaker, R. G., Sperber, N., Baumgartner, M., Thiem, A., Cragun, D., Damschroder, L., Miech, E., Slade, A., \& Birken, S. (2020). Coincidence analysis: A new method for causal inference in implementation science. Implementation Science, 15(108), 1-10. https://doi.org/10.21203/rs.3.rs-30466/v1

Wong, K. K. (2015). Federalism, equity, and accountability in education. In B. S. Cooper, J. G. Cibulka, \& L. D. Fusarelli (Eds.), Handbook of education politics and policy (2nd ed., pp. 211-228). Routledge.

Woolf, S. H. (2009). Social policy as health policy. Journal of the American Medical Association, 301(11), 1166-1169. https://doi.org/10.1001/jama.2009.320 
World Health Organization. (n.d.). About social determinants of health.

https://www.who.int/social_determinants/en/

World Health Organization. (1946). Constitution of the World Health Organization.

http:/ /apps.who.int/gb/bd/PDF/bd47/EN/constitution-en.pdf?ua=1

Yakovchenko, V., Miech, E. J., Chinman, M. J., Chartier, M., Gonzalez, R., Kirchner, J. E., Morgan, T. R., Park, A., Powell, B. J., Proctor, E. K., Ross, D., Waltz, T. J., \& Rogal, S. S. (2020). Strategy configurations directly linked to higher hepatitis C virus Treatment Starts. Medical Care, 58(5), e31-e38. https://doi.org/10.1097/mlr.0000000000001319

Yogan, L. J. (2000). School tracking and student violence. Annals of the American Academy of Political and Social Science, 567, 108-122.

https://doi.org/https:/ /doi.org/10.1177/000271620056700108 


\section{Appendix A: Data File Mock-Up}

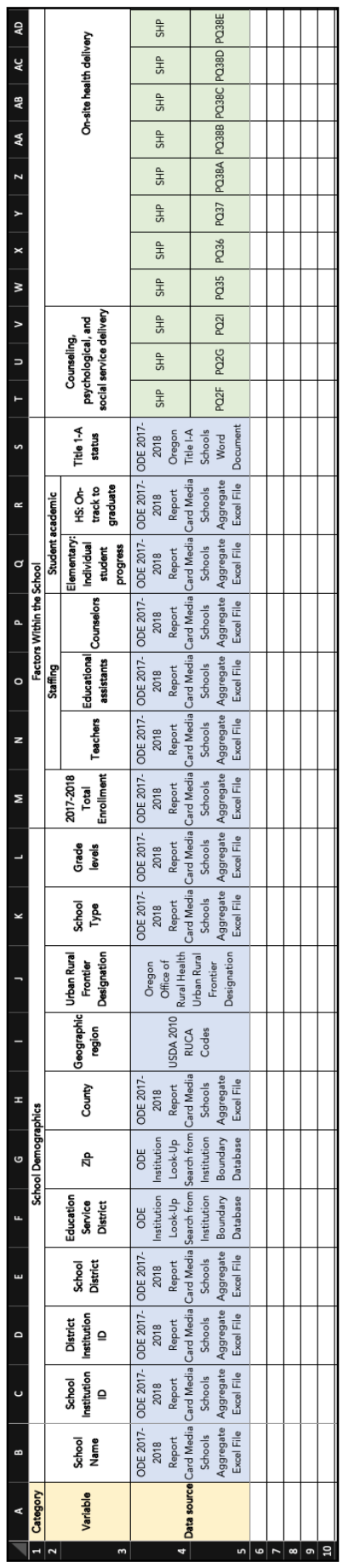




\section{Appendix B: Variables, Data Sources and Citations}

\begin{tabular}{|c|c|c|c|}
\hline & Variable & Data Source & Citation \\
\hline \multirow{15}{*}{ 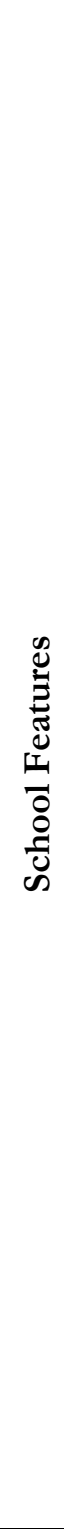 } & School institution ID & $\begin{array}{l}\text { ODE 2017-2018 Report Card } \\
\text { Media Schools Aggregate Excel file }\end{array}$ & $\begin{array}{l}\text { (Oregon Department of } \\
\text { Education, 2018a) }\end{array}$ \\
\hline & School name & $\begin{array}{l}\text { ODE 2017-2018 Report Card } \\
\text { Media Schools Aggregate Excel file }\end{array}$ & $\begin{array}{l}\text { (Oregon Department of } \\
\text { Education, 2018a) }\end{array}$ \\
\hline & District institution ID & $\begin{array}{l}\text { ODE 2017-2018 Report Card } \\
\text { Media Schools Aggregate Excel file }\end{array}$ & $\begin{array}{l}\text { (Oregon Department of } \\
\text { Education, 2018a) }\end{array}$ \\
\hline & School district & $\begin{array}{l}\text { ODE 2017-2018 Report Card } \\
\text { media Schools Aggregate Excel file }\end{array}$ & $\begin{array}{l}\text { (Oregon Department of } \\
\text { Education, 2018a) }\end{array}$ \\
\hline & Education service district & $\begin{array}{l}\text { ODE Institution Look-Up Search } \\
\text { from Institution Boundary } \\
\text { Database }\end{array}$ & $\begin{array}{l}\text { (Oregon Department of } \\
\text { Education, 2021) }\end{array}$ \\
\hline & ZIP code & $\begin{array}{l}\text { ODE Institution Look-Up Search } \\
\text { from Institution Boundary } \\
\text { Database }\end{array}$ & $\begin{array}{l}\text { Oregon Department of } \\
\text { Education, 2021) }\end{array}$ \\
\hline & County & $\begin{array}{l}\text { ODE 2017-2018 Report Card } \\
\text { Media Schools Aggregate Excel file }\end{array}$ & $\begin{array}{l}\text { (Oregon Department of } \\
\text { Education, 2018a) }\end{array}$ \\
\hline & Geographic region & USDA 2010 RUCA Codes & $\begin{array}{l}\text { (U.S. Department of } \\
\text { Agriculture, 2020) }\end{array}$ \\
\hline & $\begin{array}{l}\text { Urban/rural/frontier } \\
\text { designation }\end{array}$ & $\begin{array}{l}\text { Oregon Office of Rural Health } \\
\text { spreadsheet of Oregon ZIP codes, } \\
\text { towns, cities and service areas and } \\
\text { their ORH urban/rural/frontier } \\
\text { designation }\end{array}$ & $\begin{array}{l}\text { (Oregon Office of Rural } \\
\text { Health, 2020a) }\end{array}$ \\
\hline & School type & $\begin{array}{l}\text { ODE 2017-2018 Report Card } \\
\text { Media Schools Aggregate Excel file }\end{array}$ & $\begin{array}{l}\text { (Oregon Department of } \\
\text { Education, 2018a) }\end{array}$ \\
\hline & Grade levels & $\begin{array}{l}\text { ODE 2017-2018 Report Card } \\
\text { Media Schools Aggregate Excel file }\end{array}$ & $\begin{array}{l}\text { (Oregon Department of } \\
\text { Education, 2018a) }\end{array}$ \\
\hline & $\begin{array}{l}\text { 2017-2018 total } \\
\text { enrollment }\end{array}$ & $\begin{array}{l}\text { ODE 2017-2018 Report Card } \\
\text { Media Schools Aggregate Excel file }\end{array}$ & $\begin{array}{l}\text { (Oregon Department of } \\
\text { Education, 2018a) }\end{array}$ \\
\hline & Teachers FTE & $\begin{array}{l}\text { ODE 2017-2018 Report Card } \\
\text { Media Schools Aggregate Excel file }\end{array}$ & $\begin{array}{l}\text { (Oregon Department of } \\
\text { Education, 2018a) }\end{array}$ \\
\hline & Counselors & $\begin{array}{l}\text { ODE 2017-2018 Report Card } \\
\text { Media Schools Aggregate Excel file }\end{array}$ & $\begin{array}{l}\text { (Oregon Department of } \\
\text { Education, 2018a) }\end{array}$ \\
\hline & Title 1-A status & $\begin{array}{l}\text { ODE 2017-2018 Oregon Title 1-A } \\
\text { Schools Word document }\end{array}$ & $\begin{array}{l}\text { (Oregon Department of } \\
\text { Education, n.d.-c) }\end{array}$ \\
\hline \multirow{2}{*}{ 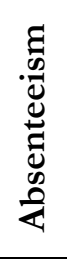 } & Regular attenders & $\begin{array}{l}\text { ODE 2017-2018 Regular } \\
\text { Attenders Report and ODE 2017- } \\
2018 \text { Report Card Media Schools } \\
\text { Aggregate Excel file }\end{array}$ & $\begin{array}{l}\text { (Oregon Department of } \\
\text { Education, 2018a, 2019a) }\end{array}$ \\
\hline & Chronically absent & $\begin{array}{l}\text { ODE 2017-2018 Regular } \\
\text { Attenders Report }\end{array}$ & $\begin{array}{l}\text { (Oregon Department of } \\
\text { Education, 2019a) }\end{array}$ \\
\hline
\end{tabular}




\section{Appendix C: Oregon Health Authority Data Use Agreement}

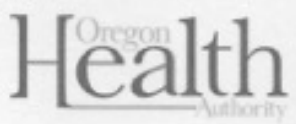

Public Health Division

\section{Data Use Agreement: School Health Profiles Survey (SHPS)}

Oregon Public Health Division: Adolescent \& School Health Unit

\section{Confidentiality Rules}

Researchers (including all those who will use or have access to the requested dataset) who are requesting the School Health Profile Survey (SHPS) data must agree to the rules below:

1. Data may be used only for the purposes stated in the approved Data Use Agreement. Any changes in planned use of data must be written as a supplemental request and receive written approval from the Adolescent \& School Health Unit, as well as the Oregon Public Health Division Institutional Review Board (PH-IRB) where necessary.

2. Because researchers will have access to potentially identifiable individual record information, researchers must agree to assess the impact on privacy and confidentiality before publishing aggregated results. Identifiable information includes, but is not limited to, demographic identifier information, which will identify or may reasonably lead to the identification of one or more specific individuals. Researchers will apply the same rules of confidentiality when reporting non-identified aggregates, where disclosure of detailed geographic information could make it possible to identify the person in local communities.

3. Researcher agrees that only those who have signed this data use agreement can access the Oregon SHPS data. The Principal Investigator/Manager is responsible for assuring that all users follow the restrictions and conditions specified in this confidentiality statement.

4. Researcher will protect confidentiality by using appropriate safeguards to prevent use or disclosure of the SHPS data by any person not specified in the Data Use Agreement (e.g. use a password protected screensaver when possible, store data on encrypted memory, and keeping laptops, records and materials in a secure location with controlled access so that persons not connected with the study cannot access these records). Control of these records is to continue at the completion of the study by destroying the electronic files or listings.

5. Researcher will not attempt to identify individual schools from this dataset, nor link them with other information from any other dataset without specific written permission or approval from the Oregon PH-IRB. Linkage of information from multiple databases is a potential threat to confidentiality.

6. Researcher will destroy the relevant dataset within 6 months of its final use.

7. Prohibition against follow-up: The researcher will not follow up or attempt to follow up with any school based on their assumed participation/data from the survey, and no data will be published or disclosed from which an individual school can be identified except upon written authorization of the Oregon OHA-HS IRB. 


\section{Health}

Public Health Division

\section{Data Use Agreement}

Requestor name: Kelly Coates, MPH - OHSU/PSU School of Public Health

Principal Investigator: Dr. Sherril Gelmon - OHSU/PSU School of Public Health

Oregon Public Health Division approving staff: Sarah Knipper - School Health Epidemiologist, Adolescent \& School Health Unit

Request of the 2018 School Health Profiles Survey (SHPS) data is approved for use by Kelly Coates and Dr. Sherril Gelmon for the purposes of completing Ms. Coates' doctoral dissertation in Health Systems and Policy at the OHSU/PSU School of Public Health, examining the role of school health policies and programs in supporting student health and educational outcomes.

Specifically, Ms. Coates has requested 84 variables from the 2018 SHPS survey for schools where she has pre-populated geographical and school-level variables related to location and school enrollment. The Oregon Adolescent \& School Health Unit will provide these 84 variables, strip the data set of school, district and zip code identifiers, and return the data to Ms. Coates for analysis.

By signing below, researchers agree to comply with the rules outlined in this data use agreement.

Kelly Coates, MPH

Krecouth

OHSU/PSU SPH PhD Student

Sherril Gelmon
Dr. Sherril Gelmon, DrPH

Program Director, Health Systems \& Policy PhD Program OHSU/PSU SPH Professor

Approved:

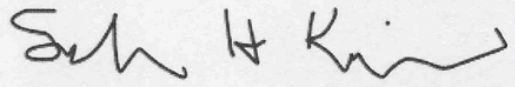

Sarah Knipper, MSW

OHA ASH School Health Epidemiologist
$12-22-2020$

Date

Date

Date 


\section{Appendix D: Questions From 2018 School Health Profiles Surveys}

The questions and their sub-parts listed below are those used in the initial stages of this research from the 2018 School Health Profiles Surveys (SHPS) School Principal

Questionnaire (Centers for Disease Control and Prevention, 2018c) and from the 2018

SHPS Lead Health Education Teacher Questionnaire (Centers for Disease Control and

Prevention, 2018b).

Questions From the 2018 SHPS School Principal Questionnaire

2. The Elementary and Secondary Education Act requires certain schools to have a written School Improvement Plan (SIP). Many states and school districts also require schools to have a written SIP. Does your school's written SIP include health-related objectives on any of the following topics? [Each subpart of the question could be answered with "Yes," "No," or "No SIP."]

Topic

f. Health services

g. Counseling, psychological, and social services

j. Family engagement

5. Currently, does someone at your school oversee or coordinate school health and safety programs and activities? [Question could be answered with "Yes" or "No.']

6. Is there one or more group (e.g., school health council, committee, team) at your school that offers guidance on the development of policies or coordinates activities on health topics? Question could be answered with "Yes" or "No."] 
7. During the past year, has any school health council, committee, or team at your school done any of the following activities? [Question could be answered with "Yes" or "No."]

Activity

a. Identified student health needs based on a review of relevant data

b. Recommended new or revised health and safety policies and activities to school administrators or the school improvement team

c. Sought funding or leveraged resources to support health and safety priorities for students and staff

d. Communicated the importance of health and safety policies and activities to district administrators, school administrators, parent-teacher groups, or community members

35. Is there a full-time registered nurse who provides health services to students at your school? (A full-time nurse means that a nurse is at the school during all school hours, 5 days per week.) [Question could be answered with "Yes" or "No."]

36. Is there a part-time registered nurse who provides health services to students at your school? (A part-time nurse means that a nurse is at the school less than 5 days a week, less than all school hours, or both.) [Question could be answered with "Yes" or "No."]

37. Does your school have a school-based health center that offers health services to students? (School-based health centers are places on school campus where enrolled students can receive primary care, including diagnostic and treatment services. These services are usually provided by a nurse practitioner or physician's assistant.) [Question could be answered with "Yes" or "No."] 
38. Does your school provide the following services to students? [Each sub-part of the question could be answered with "Yes" or "No."]

\section{Service}

a. HIV testing

b. HIV treatment (ongoing medical care for persons living with HIV)

c. STD testing

d. STD treatment

e. Pregnancy testing

f. Provision of condoms

g. Provision of condom-compatible lubricants (i.e., water- or silicone-based)

h. Provision of contraceptives other than condoms (e.g., birth control pill, birth control shot, intrauterine device [IUD])

i. Prenatal care

j. Human papillomavirus (HPV) vaccine administration

k. Assessment for alcohol or other drug use, abuse or dependency

1. Daily medication administration for students with chronic health conditions (e.g., asthma, diabetes)

m. Stock rescue or "as needed" medication for any student experiencing a health emergency (e.g., asthma episode, severe allergic reaction)

n. Case management for students with chronic health conditions (e.g., asthma, diabetes) 
39. Does your school provide students with referrals to any organizations or health care professionals not on school property for the following services? [Each sub-part of the question could be answered with "Yes" or "No."]

\section{Service}

a. HIV testing

b. HIV treatment (ongoing medical care for persons living with HIV)

c. nPEP (non-occupational post-exposure prophylaxis for HIV - a short course of medication given within 72 hours of exposure to infectious bodily fluids from a person known to be HIV positive)

d. STD testing

e. STD treatment

f. Pregnancy testing

g. Provision of condoms

h. Provision of condom-compatible lubricants (i.e., water- or silicone-based)

i. Provision of contraceptives other than condoms (e.g., birth control pill, birth control shot, intrauterine device [IUD])

j. Prenatal care

k. Human papillomavirus (HPV) vaccine administration

1. Alcohol or other drug abuse treatment

m. Daily medication administration for students with chronic health conditions (e.g., asthma, diabetes)

n. Stock rescue or "as needed" medication for any student experiencing a health emergency (e.g., asthma episode, severe allergic reaction)

o. Case management for students with chronic health conditions (e.g., asthma, diabetes)

41. Does your school routinely use school records to identify and track students with a current diagnosis of the following chronic conditions? School records might include student emergency cards, medication records, health room visit information, emergency care and daily management plans, physical exam forms, or parent notes. EEach sub-part of the question could be answered with "Yes" or "No."]

\section{Condition}
a. Asthma
b. Food allergies
c. Diabetes
d. Epilepsy or seizure disorder
e. Obesity
f. Hypertension/high blood pressure
g. Oral health condition (e.g., abscess, tooth decay) 
42. Does your school provide referrals to any organizations or health care professionals not on school property for students diagnosed with or suspected to have any of the following chronic conditions? Include referrals to schoolbased health centers, even if they are located on school property. [Each sub-part of the question could be answered with "Yes" or "No."]

Condition

a. Asthma

b. Food allergies

c. Diabetes

d. Epilepsy or seizure disorder

e. Obesity

f. Hypertension/high blood pressure

g. Oral health condition (e.g., abscess, tooth decay)

45. During this school year, has your school done any of the following activities? [Each sub-part of the question could be answered with "Yes" or "No."]

\section{Activity}

a. Provided parents and families with information about how to communicate with their child about sex

b. Provided parents with information about how to monitor their child (e.g., setting parental expectations, keeping track of their child, responding when their child breaks the rules)

c. Involved parents as school volunteers in the delivery of health education activities and services

d. Linked parents and families to health services and programs in the community

e. Provided disease-specific education for parents and families of students with chronic health conditions (e.g., asthma, diabetes)

46. Does your school use electronic (e.g., e-mails, school web site), paper (e.g., flyers, postcards), or oral (e.g., phone calls, parent seminars) communication to inform parents about school health services and programs? QQuestion could be answered with "Yes" or "No."]

50. During the past two years, have students' families helped develop or implement policies and programs related to school health? Question could be answered with "Yes" or "No."] 
Questions From the 2018 SHPS Lead Health Education Teacher Questionnaire

17. During this school year, did your school provide parents and families with health information designed to increase parent and family knowledge of each of the following topics?_[Each sub-part of the question could be answered with "Yes" or "No."]

Topic

a. HIV, other STD, or pregnancy prevention

b. Tobacco-use prevention

c. Alcohol- or other drug-use prevention

d. Physical activity

e. Nutrition and health eating

f. Asthma

g. Food allergies

h. Diabetes

i. Preventing student bullying and sexual harassment, including electronic aggression (i.e., cyber-bullying)

18. During this school year, have teachers in this school given students health education homework assignments or activities to do at home with their parents? [Question could be answered with "Yes" or "No."] 


\section{Appendix E: Calibration for Assignment of Set Membership Scores}

\begin{tabular}{|c|c|c|}
\hline Factor & $\begin{array}{c}\text { Calibration for Set Membership } \\
\text { Score Assignment }\end{array}$ & $\begin{array}{l}\text { Citation for } \\
\text { Calibration } \\
\text { Criteria } \\
\text { (if appropriate) }\end{array}$ \\
\hline Urban/rural/frontier designation & $\begin{array}{l}\text { 1: Urban } \\
\text { 2: Rural } \\
\text { 3: Frontier } \\
\end{array}$ & $\begin{array}{l}\text { (Oregon Office of } \\
\text { Rural Health, 2020a) }\end{array}$ \\
\hline Grade level & $\begin{array}{l}\text { 1: Middle school (high grade } \leq 9 \text { ) } \\
\text { 2: Junior high / senior high school } \\
\text { (low grade } \leq 8 ; \text { high grade } \geq 10 \text { ) } \\
\text { 3: High school (low grade } \geq 9 ; \text { high } \\
\text { grade } \geq 10 \text { ) }\end{array}$ & $\begin{array}{l}\text { (Centers for Disease } \\
\text { Control and } \\
\text { Prevention, 2018e) }\end{array}$ \\
\hline Students-to-teacher ratio & $\begin{array}{l}0:<16 \text { students to } 1 \text { teacher } \\
1: \geq 16 \text { students to } 1 \text { teacher }\end{array}$ & $\begin{array}{l}\text { (Kieschnick, 2018; } \\
\text { Public School } \\
\text { Review, 2021) }\end{array}$ \\
\hline School counselors & $\begin{array}{l}0: \text { Absence } \\
\text { 1: Presence }\end{array}$ & \\
\hline Title 1-A status & $\begin{array}{l}\text { 0: Not a Title 1-A school } \\
\text { 1: Title 1-A school }\end{array}$ & $\begin{array}{l}\text { Oregon } \\
\text { Department of } \\
\text { Education, n.d.-c) }\end{array}$ \\
\hline $\begin{array}{l}\text { School's written School } \\
\text { Improvement Plan (SIP) includes } \\
\text { objectives regarding health services }\end{array}$ & $\begin{array}{l}0: \text { No } \\
\text { 1: Yes } \\
\text { 2: No SIP }\end{array}$ & \\
\hline $\begin{array}{l}\text { School's written SIP includes } \\
\text { objectives regarding counseling, } \\
\text { psychological, and social services }\end{array}$ & $\begin{array}{l}0: \text { No } \\
\text { 1: Yes } \\
\text { 2: No SIP }\end{array}$ & \\
\hline $\begin{array}{l}\text { School's written SIP includes } \\
\text { objectives regarding family } \\
\text { engagement }\end{array}$ & $\begin{array}{l}0: \text { No } \\
\text { 1: Yes } \\
\text { 2: No SIP }\end{array}$ & \\
\hline $\begin{array}{l}\text { Presence of someone at the school to } \\
\text { oversee or coordinate school health } \\
\text { and safety programs and activities }\end{array}$ & $\begin{array}{l}0: \text { No } \\
1: \text { Yes }\end{array}$ & \\
\hline $\begin{array}{l}\text { Presence of one or more than one } \\
\text { group (e.g., school health council, } \\
\text { committee, team) to offer guidance } \\
\text { on the development of policies or } \\
\text { coordinates activities on health topics }\end{array}$ & $\begin{array}{l}0: \text { No } \\
1: \text { Yes }\end{array}$ & \\
\hline $\begin{array}{l}\text { School health council, committee, or } \\
\text { team activity: Identified student } \\
\text { health needs based on a review of } \\
\text { relevant data }\end{array}$ & $\begin{array}{l}0: \text { No } \\
1: \text { Yes }\end{array}$ & \\
\hline $\begin{array}{l}\text { School health council, committee, or } \\
\text { team activity: Recommended new or } \\
\text { revised health and safety policies and } \\
\text { activities to school administrators or } \\
\text { the school improvement team }\end{array}$ & $\begin{array}{l}0: \text { No } \\
1: \text { Yes }\end{array}$ & \\
\hline
\end{tabular}




\begin{tabular}{|c|c|}
\hline $\begin{array}{l}\text { School health council, committee, or } \\
\text { team activity: Sought funding or } \\
\text { leveraged resources to support health } \\
\text { and safety priorities for students and } \\
\text { staff }\end{array}$ & $\begin{array}{l}0: \text { No } \\
1: \text { Yes }\end{array}$ \\
\hline $\begin{array}{l}\text { School health council, committee, or } \\
\text { team activity: Communicated the } \\
\text { importance of health and safety } \\
\text { policies and activities to district } \\
\text { administrators, school administrators, } \\
\text { parent-teacher groups, or community } \\
\text { members }\end{array}$ & $\begin{array}{l}0: \text { No } \\
1: \text { Yes }\end{array}$ \\
\hline $\begin{array}{l}\text { Presence of a full-time registered } \\
\text { nurse who provides health services to } \\
\text { students }\end{array}$ & $\begin{array}{l}0: \text { No } \\
1: \text { Yes }\end{array}$ \\
\hline $\begin{array}{l}\text { Presence of a part-time registered } \\
\text { nurse who provides health services to } \\
\text { students }\end{array}$ & $\begin{array}{l}0: \text { No } \\
1: \text { Yes }\end{array}$ \\
\hline $\begin{array}{l}\text { Presence of a school-based health } \\
\text { center that offers health services to } \\
\text { students }\end{array}$ & $\begin{array}{l}0: \text { No } \\
1: \text { Yes }\end{array}$ \\
\hline $\begin{array}{l}\text { Direct health services provided to } \\
\text { students: HIV/STD/pregnancy/ } \\
\text { contraception }\end{array}$ & $\begin{array}{l}0: \text { Zero } \\
1: \geq 1 \text { service offered }\end{array}$ \\
\hline $\begin{array}{l}\text { Direct health services provided to } \\
\text { students: HPV vaccine } \\
\text { administration }\end{array}$ & $\begin{array}{l}0: \text { No } \\
1: \text { Yes }\end{array}$ \\
\hline $\begin{array}{l}\text { Direct health services provided to } \\
\text { students: Assessment for alcohol or } \\
\text { other drug use, abuse, or dependency }\end{array}$ & $\begin{array}{l}0: \text { No } \\
1: \text { Yes }\end{array}$ \\
\hline $\begin{array}{l}\text { Direct health services provided to } \\
\text { students: Chronic health disease } \\
\text { management, including daily } \\
\text { medication administration and case } \\
\text { management }\end{array}$ & $\begin{array}{l}0: \text { No } \\
1: \geq 1 \text { service offered }\end{array}$ \\
\hline $\begin{array}{l}\text { Direct health services provided to } \\
\text { students: Provision of rescue or "as } \\
\text { needed" medication for students } \\
\text { experiencing a health emergency }\end{array}$ & $\begin{array}{l}0: \text { No } \\
1: \text { Yes }\end{array}$ \\
\hline $\begin{array}{l}\text { School-provided referrals to an } \\
\text { organization or health care } \\
\text { professional not on school property: } \\
\text { HIV/STD/pregnancy/contraception }\end{array}$ & $\begin{array}{l}0: \text { Zero } \\
1: \geq 1 \text { referral provided }\end{array}$ \\
\hline $\begin{array}{l}\text { School-provided referrals to an } \\
\text { organization or health care } \\
\text { professional not on school property: } \\
\text { HPV vaccine administration }\end{array}$ & $\begin{array}{l}0: \text { No } \\
1: \text { Yes }\end{array}$ \\
\hline $\begin{array}{l}\text { School-provided referrals to an } \\
\text { organization or health care }\end{array}$ & $\begin{array}{l}0: \text { No } \\
\text { 1: Yes }\end{array}$ \\
\hline
\end{tabular}


professional not on school property:

Alcohol or other drug abuse

treatment

Use of records to identify and track $0:$ Zero

students with a current diagnosis of a $1: \geq 1$ condition tracked

chronic condition (asthma, food

allergies, diabetes, epilepsy or seizure

disorder, obesity, and/or

hypertension/high blood pressure)

School-provided referrals to an

$0:$ Zero

organization or health care

$1: \geq 1$ referral provided

professional not on school property

for students diagnosed with or

suspected to have a chronic

condition (asthma, food allergies,

diabetes, epilepsy or seizure disorder,

obesity, and/or hypertension/high

blood pressure)

School-provided referrals to an $\quad 0:$ No

organization or health care 1: Yes

professional not on school property

for students diagnosed with or

suspected to have an oral health

condition

\begin{tabular}{|c|c|}
\hline $\begin{array}{l}\text { School activity for family } \\
\text { involvement: Provided parents and } \\
\text { families with information about how } \\
\text { to communicate with their child } \\
\text { about sex }\end{array}$ & $\begin{array}{l}\text { 0: No } \\
\text { 1: Yes }\end{array}$ \\
\hline $\begin{array}{l}\text { School activity for family } \\
\text { involvement: Provided parents with } \\
\text { information about how to monitor } \\
\text { their child }\end{array}$ & $\begin{array}{l}\text { 0: No } \\
\text { 1: Yes }\end{array}$ \\
\hline $\begin{array}{l}\text { School activity for family } \\
\text { involvement: Involved parents as } \\
\text { school volunteers in the delivery of } \\
\text { health education activities and } \\
\text { services }\end{array}$ & $\begin{array}{l}\text { 0: No } \\
1: \text { Yes }\end{array}$ \\
\hline $\begin{array}{l}\text { School activity for family } \\
\text { involvement: Linked parents and } \\
\text { families to health services and } \\
\text { programs in the community }\end{array}$ & $\begin{array}{l}0: \text { No } \\
1: \text { Yes }\end{array}$ \\
\hline $\begin{array}{l}\text { School activity for family } \\
\text { involvement: Provided disease- } \\
\text { specific education for parents and } \\
\text { families of students with chronic } \\
\text { health conditions (e.g., asthma, } \\
\text { diabetes) }\end{array}$ & $\begin{array}{l}0: \text { No } \\
1: \text { Yes }\end{array}$ \\
\hline
\end{tabular}




\begin{tabular}{|c|c|}
\hline $\begin{array}{l}\text { Use of electronic, paper, or oral } \\
\text { communication to inform parents } \\
\text { about school health services and } \\
\text { programs }\end{array}$ & $\begin{array}{l}0: \text { No } \\
1: \text { Yes }\end{array}$ \\
\hline $\begin{array}{l}\text { Students' families helped in the last } \\
\text { two years to develop or implement } \\
\text { policies and programs related to } \\
\text { school health }\end{array}$ & $\begin{array}{l}\text { 0: No } \\
1: \text { Yes }\end{array}$ \\
\hline $\begin{array}{l}\text { School-provided health information } \\
\text { to increase parent and family } \\
\text { knowledge on various health topics }\end{array}$ & $\begin{array}{l}0: \text { Zero } \\
1: \geq 1 \text { topic offered }\end{array}$ \\
\hline $\begin{array}{l}\text { Teachers gave students health } \\
\text { education homework assignments or } \\
\text { activities to do at home with their } \\
\text { parents }\end{array}$ & $\begin{array}{l}0: \text { No } \\
1: \text { Yes }\end{array}$ \\
\hline
\end{tabular}




\section{Appendix E: Negative Outcome Models}

Using the subset of factors associated with schools displaying the absence of the outcome $(\mathrm{O}=0)$, or less than $20 \%$ of the student population being chronically absent throughout the school year, eight models were identified (see Figure E.1 below). The eight solution models for the negative outcome each explained a majority of the cases that expressed the absence of the outcome of high student absenteeism using a different group of factors. Of the eight solution models, one solution model, highlighted in Figure E.1, was selected, and subsequently modified, as the preferred model for further explanation and discussion.

\section{Figure E.1. Negative Outcome Solution Models}

\begin{tabular}{|c|c|c|}
\hline Solution & Consistency & Coverage \\
\hline $\mathrm{GL}=1 * \mathrm{~T} 1 \mathrm{AS}=0 * \mathrm{PQ} 5=1+\mathrm{GL}=2 * \mathrm{~T} 1 \mathrm{AS}=1 * \mathrm{PQ} 38 \mathrm{~J}=0+\mathrm{GL}=1 * \mathrm{PQ} 38 \mathrm{~J}=1 * \mathrm{PQ} 39 \mathrm{~A} \_\mathrm{K}=0+\mathrm{T} 1 \mathrm{AS}=1 * \mathrm{PQ} 38 \mathrm{~J}=1 * \mathrm{PQ} 39 \mathrm{~A} \_\mathrm{K}=0<->\mathrm{O}=0$ & 0.789 & 0.755 \\
\hline 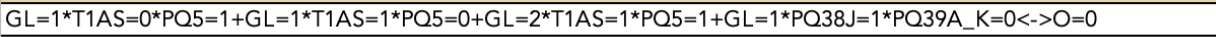 & 0.772 & 0.755 \\
\hline $\mathrm{GL}=1$ *T1AS=0*PQ5=1+GL=2*T1AS=1*PQ5=1+GL=2*PQ38J=0*PQ38M=0+GL=1*PQ38J=1*PQ39A_K=0<->O=0 & 0.772 & 0.755 \\
\hline $\mathrm{GL}=1 * \mathrm{~T} 1 \mathrm{AS}=0$ *PQ5=1+GL=2*T1AS=1*PQ5=1+GL=1*PQ38J=1*PQ39A_K=0+GL=3*PQ38M=0*PQ39A_K=1<->O=0 & 0.772 & 0.755 \\
\hline $\mathrm{GL}=1 * \mathrm{~T} 1 \mathrm{AS}=0$ *PQ5=1+GL=2*T1AS=1*PQ5=1+GL=1*PQ38J=1*PQ39A_K=0+T1AS=1*PQ38J=1*PQ39A_K=0<->O=0 & 0.772 & 0.755 \\
\hline $\mathrm{GL}=1 * \mathrm{~T} 1 \mathrm{AS}=0$ *PQ5=1+GL=2*T1AS=1*PQ5=1+GL=1*PQ38J=1*PQ39A_K=0+PQ5=0*PQ38J=0*PQ38M=1<->O=0 & 0.772 & 0.755 \\
\hline $\mathrm{GL}=1 * \mathrm{~T} 1 \mathrm{AS}=0 * \mathrm{PQ} 5=1+\mathrm{GL}=2 * \mathrm{~T} 1 \mathrm{AS}=1 * \mathrm{PQ} 5=1+\mathrm{GL}=1 * \mathrm{PQ} 38 \mathrm{~J}=1 * P Q 39 \mathrm{~A} \_\mathrm{K}=0+\mathrm{PQ} 5=0$ *PQ38J=0*PQ39A_K=1<->O=0 & 0.772 & 0.755 \\
\hline $\mathrm{GL}=1 * \mathrm{~T} 1 \mathrm{AS}=0$ *PQ5=1+GL=1*T1AS=0*PQ38J=1+GL=2*T1AS=1*PQ38J=0+T1AS=1*PQ38J=1*PQ39A_K=0<->O=0 & 0.772 & 0.755 \\
\hline
\end{tabular}

It is worth noting that there are three common disjuncts across all eight of the negative outcome models: $\mathrm{GL}=1 * \mathrm{~T} 1 \mathrm{AS}=0, \mathrm{GL}=2 * \mathrm{~T} 1 \mathrm{AS}=1$, and $\mathrm{GL}=1 * \mathrm{PQ} 38 \mathrm{~J}=1$. These three common disjuncts are present in all eight negative outcome models (in some cases, they are part of larger conjuncts). Therefore, these are not eight completely different models, but rather eight models with many commonalities and few differences, whereby the commonalities likely explain most of the cases, and the differences cover just a few of the remaining cases. In other words, the eight models are variants of a common underlying model. 
Appendix F: Positive Outcome Dataset with Solution Pathways and Model

\begin{tabular}{|c|c|c|c|c|c|c|c|c|}
\hline \multirow{2}{*}{ ID } & \multirow{2}{*}{ OUTCOME } & \multicolumn{2}{|c|}{ Pathway 1} & \multicolumn{2}{|c|}{ Pathway 2} & \multicolumn{3}{|c|}{ Pathway 3} \\
\hline & & PQ39A_K & Ta17A & GL & P0.36 & GL & PQ36 & POSBK \\
\hline 120 & 1 & 0 & 1 & $\overline{3}$ & $\frac{1}{1}$ & 3 & 1 & 1 \\
\hline 144 & 1 & 0 & 0 & 3 & 1 & 3 & 1 & 1 \\
\hline 199 & 1 & 0 & 0 & 3 & 1 & 3 & 1 & 1 \\
\hline 275 & 1 & 0 & 0 & 3 & 1 & 3 & 1 & 1 \\
\hline 305 & 1 & 0 & 0 & 3 & 1 & 3 & 1 & 1 \\
\hline 322 & 1 & 0 & 0 & 3 & 1 & 3 & 1 & 1 \\
\hline 139 & 1 & 0 & 1 & 3 & 1 & 3 & 1 & 1 \\
\hline 157 & 1 & 0 & 1 & 3 & 1 & 3 & 1 & 1 \\
\hline 286 & 1 & 0 & 1 & 3 & 1 & 3 & 1 & 1 \\
\hline 302 & 1 & 0 & 1 & 3 & 1 & 3 & 1 & 1 \\
\hline 228 & 1 & 0 & 1 & 3 & 1 & 3 & 1 & 0 \\
\hline 343 & 1 & 0 & 0 & 3 & 1 & 3 & 1 & 0 \\
\hline 352 & 1 & 0 & 0 & 3 & 1 & 3 & 1 & 0 \\
\hline 185 & 1 & 0 & 1 & 3 & 1 & 3 & 1 & 0 \\
\hline 271 & 1 & $\overline{1}$ & $\overline{0}$ & 3 & 1 & 3 & 1 & 1 \\
\hline 276 & 1 & 1 & 0 & 3 & 1 & 3 & 1 & 1 \\
\hline 223 & 1 & 1 & 1 & 3 & 1 & 3 & 1 & 1 \\
\hline 319 & 1 & 1 & 1 & 3 & 1 & 3 & 1 & 1 \\
\hline 117 & 1 & 1 & $\overline{0}$ & 3 & 1 & 3 & 1 & 1 \\
\hline 183 & 1 & 1 & 0 & 3 & 1 & 3 & 1 & 1 \\
\hline 196 & 1 & 1 & 0 & 3 & 1 & 3 & 1 & 1 \\
\hline 251 & 1 & 1 & 0 & 3 & 1 & 3 & 1 & 1 \\
\hline 254 & 1 & 1 & 0 & 3 & 1 & 3 & 1 & 1 \\
\hline 301 & 1 & 1 & 0 & 3 & 1 & 3 & 1 & 1 \\
\hline 338 & 1 & 1 & 0 & 3 & 1 & 3 & 1 & 1 \\
\hline 358 & 1 & 1 & 0 & 3 & 1 & 3 & 1 & 1 \\
\hline 101 & 1 & 1 & 1 & 3 & 1 & 3 & 1 & 1 \\
\hline 143 & 1 & 1 & 1 & 3 & 1 & 3 & 1 & 1 \\
\hline 162 & 1 & 1 & 1 & 3 & 1 & 3 & 1 & 1 \\
\hline 243 & 1 & 1 & 1 & 3 & 1 & 3 & 1 & 1 \\
\hline 259 & 1 & 1 & 1 & 3 & 1 & 3 & 1 & 1 \\
\hline 262 & 1 & 1 & 1 & 3 & 1 & 3 & 1 & 1 \\
\hline 334 & 1 & 1 & 1 & 3 & 1 & 3 & 1 & 1 \\
\hline 344 & 1 & 1 & 0 & 3 & 1 & 3 & 1 & 0 \\
\hline 163 & 1 & 1 & 1 & 3 & 1 & 3 & 1 & 0 \\
\hline 362 & 1 & 1 & 1 & 3 & 1 & 3 & 1 & 0 \\
\hline 151 & 1 & 1 & 0 & 3 & 0 & 3 & 0 & 1 \\
\hline 155 & 1 & 1 & 0 & 3 & 0 & 3 & 0 & 1 \\
\hline 249 & 1 & 1 & 0 & 3 & 0 & 3 & 0 & 1 \\
\hline 256 & 1 & 1 & 0 & 3 & 0 & 3 & 0 & 1 \\
\hline 365 & 1 & 1 & 0 & 3 & 0 & 3 & 0 & 1 \\
\hline 366 & 1 & 1 & 0 & 3 & 0 & 3 & 0 & 1 \\
\hline 184 & 1 & 1 & 0 & 1 & 1 & 1 & 1 & 1 \\
\hline 333 & 1 & 1 & 0 & 1 & 1 & 1 & 1 & 1 \\
\hline 232 & 1 & 1 & 0 & 1 & 1 & 1 & 1 & 1 \\
\hline 311 & 1 & 1 & 0 & 1 & 1 & 1 & 1 & 1 \\
\hline 159 & 1 & 1 & 0 & 1 & 1 & 1 & 1 & 0 \\
\hline 233 & 1 & 1 & 0 & 1 & 1 & 1 & 1 & 0 \\
\hline 300 & 1 & 1 & 0 & 1 & 0 & 1 & 0 & 1 \\
\hline 141 & 1 & 1 & 0 & 2 & 1 & 2 & 1 & 0 \\
\hline 176 & 1 & 1 & 0 & 2 & 1 & 2 & 1 & 0 \\
\hline 326 & 1 & 1 & 0 & 2 & 1 & 2 & 1 & 0 \\
\hline 217 & 1 & 1 & 0 & 1 & 0 & 1 & 0 & 1 \\
\hline 260 & 1 & 1 & 0 & 2 & 0 & 2 & 0 & 1 \\
\hline 290 & 1 & 1 & 0 & 2 & 0 & 2 & 0 & 1 \\
\hline 135 & 1 & 1 & 0 & 2 & 0 & 2 & 0 & 1 \\
\hline 287 & 1 & 1 & 0 & 2 & 1 & 2 & 1 & 0 \\
\hline 258 & 1 & 0 & 1 & 2 & 1 & 2 & 1 & 1 \\
\hline 279 & 1 & 0 & 1 & 2 & 1 & 2 & 1 & 1 \\
\hline 150 & 1 & 0 & 1 & 2 & 1 & 2 & 1 & 1 \\
\hline 172 & 1 & 0 & 1 & 2 & 1 & 2 & 1 & 1 \\
\hline 189 & 1 & 0 & 1 & 2 & 1 & 2 & 1 & 1 \\
\hline 252 & 1 & 0 & 1 & 2 & 1 & 2 & 1 & 1 \\
\hline
\end{tabular}




\begin{tabular}{|c|c|c|c|c|c|c|c|c|}
\hline \multirow{2}{*}{ ID } & \multirow{2}{*}{ OUTCOME } & \multicolumn{2}{|c|}{ Pathway 1} & \multicolumn{2}{|c|}{ Pathway 2} & \multicolumn{3}{|c|}{ Pathway 3} \\
\hline & & PO39A_K & TQ17A & GL & PQ36 & GL & PO36 & POSBK \\
\hline 321 & 1 & 1 & 0 & 2 & 1 & 2 & 1 & 1 \\
\hline 277 & 1 & 1 & 1 & 2 & 1 & 2 & 1 & 1 \\
\hline 340 & 1 & 1 & 1 & 2 & 1 & 2 & 1 & 1 \\
\hline 351 & 1 & 1 & 1 & 2 & 1 & 2 & 1 & 1 \\
\hline 240 & 1 & 1 & 1 & 2 & 1 & 2 & 1 & 0 \\
\hline 140 & 1 & 0 & 0 & 1 & 1 & 1 & 1 & 1 \\
\hline 296 & 1 & 0 & 0 & 2 & 0 & 2 & 0 & 1 \\
\hline 124 & 1 & 1 & 1 & 3 & 0 & 3 & 0 & 1 \\
\hline 291 & 1 & 1 & 1 & 3 & 0 & 3 & 0 & 1 \\
\hline 353 & 1 & 0 & 1 & 3 & 0 & 3 & 0 & 1 \\
\hline 315 & 1 & 1 & 1 & 3 & 0 & 3 & 0 & 1 \\
\hline 171 & 1 & 0 & 1 & 2 & 0 & 2 & 0 & 1 \\
\hline 359 & 1 & 0 & 0 & 2 & 0 & 2 & 0 & 0 \\
\hline 244 & 1 & 0 & 1 & 1 & 1 & 1 & 1 & 1 \\
\hline 213 & 1 & 0 & 1 & 1 & 1 & 1 & 1 & 1 \\
\hline 215 & 1 & 0 & 1 & 1 & 1 & 1 & 1 & 1 \\
\hline 229 & 1 & 0 & 1 & 1 & 1 & 1 & 1 & 1 \\
\hline 239 & 1 & 0 & 1 & 1 & 1 & 1 & 1 & 1 \\
\hline 268 & 1 & 0 & 1 & 1 & 1 & 1 & 1 & 1 \\
\hline 336 & 1 & 0 & 1 & 1 & 1 & 1 & 1 & 1 \\
\hline 161 & 1 & 0 & 0 & 1 & 1 & 1 & 1 & 0 \\
\hline 164 & 1 & 0 & 0 & 1 & 1 & 1 & 1 & 0 \\
\hline 177 & 1 & 0 & 0 & 1 & 1 & 1 & 1 & 0 \\
\hline 136 & 1 & 0 & 1 & 1 & 1 & 1 & 1 & 0 \\
\hline 195 & 1 & 0 & 1 & 1 & 1 & 1 & 1 & 0 \\
\hline 211 & 1 & 0 & 1 & 1 & 1 & 1 & 1 & 0 \\
\hline 255 & 1 & 0 & 1 & 1 & 1 & 1 & 1 & 0 \\
\hline 327 & 1 & 0 & 1 & 1 & 1 & 1 & 1 & 0 \\
\hline 179 & 1 & 1 & 1 & 1 & 1 & 1 & 1 & 1 \\
\hline 335 & 1 & 1 & 1 & 1 & 1 & 1 & 1 & 1 \\
\hline 357 & 1 & 1 & 1 & 1 & 1 & 1 & 1 & 1 \\
\hline 363 & 1 & 1 & 1 & 1 & 1 & 1 & 1 & 1 \\
\hline 174 & 1 & 1 & 1 & 1 & 1 & 1 & 1 & 0 \\
\hline 236 & 1 & 0 & 1 & 1 & 0 & 1 & 0 & 1 \\
\hline 204 & 1 & 0 & 1 & 1 & 0 & 1 & 0 & 1 \\
\hline 382 & 0 & $\overline{0}$ & 1 & 3 & $\overline{0}$ & 3 & $\overline{0}$ & 1 \\
\hline 173 & 0 & 1 & 1 & 3 & 0 & 3 & 0 & 1 \\
\hline 309 & 0 & 0 & 1 & 3 & 1 & 3 & 1 & 1 \\
\hline 364 & 0 & 0 & 0 & 3 & 1 & 3 & 1 & 0 \\
\hline 207 & 0 & 1 & 1 & 3 & 1 & 3 & 1 & 1 \\
\hline 152 & 0 & 1 & 0 & 3 & 1 & 3 & 1 & 1 \\
\hline 250 & 0 & 1 & 0 & 3 & 1 & 3 & 1 & 1 \\
\hline 242 & 0 & 1 & 1 & 3 & 1 & 3 & 1 & 1 \\
\hline 372 & 0 & 1 & 0 & 3 & 1 & 3 & 1 & 0 \\
\hline 146 & 0 & 1 & 1 & 3 & 1 & 3 & 1 & 0 \\
\hline 272 & 0 & 0 & 1 & 3 & 0 & 3 & 0 & 1 \\
\hline 265 & 0 & 1 & 1 & 3 & 0 & 3 & 0 & 1 \\
\hline 158 & 0 & 1 & 1 & 3 & 0 & 3 & 0 & 0 \\
\hline 266 & 0 & 1 & 1 & 3 & 0 & 3 & 0 & 0 \\
\hline 209 & 0 & 0 & 1 & 2 & 1 & 2 & 1 & 1 \\
\hline 112 & 0 & 0 & 1 & 2 & 1 & 2 & 1 & 0 \\
\hline 235 & 0 & 1 & 1 & 2 & 1 & 2 & 1 & 1 \\
\hline 245 & 0 & 1 & 1 & 2 & 1 & 2 & 1 & 1 \\
\hline 285 & 0 & 1 & 1 & 2 & 1 & 2 & 1 & 0 \\
\hline 200 & 0 & 1 & 1 & 2 & 1 & 2 & 1 & 0 \\
\hline 134 & 0 & 0 & 0 & 2 & 0 & 2 & 0 & 1 \\
\hline 216 & 0 & 0 & 1 & 2 & 0 & 2 & 0 & 1 \\
\hline 273 & 0 & 0 & 0 & 2 & 0 & 2 & 0 & 1 \\
\hline 234 & 0 & 0 & 1 & 2 & 0 & 2 & 0 & 1 \\
\hline 325 & 0 & 0 & 0 & 2 & 0 & 2 & 0 & 0 \\
\hline 154 & 0 & 1 & 0 & 2 & 0 & 2 & 0 & 0 \\
\hline 346 & 0 & 1 & 1 & 2 & 0 & 2 & 0 & 0 \\
\hline 377 & 0 & 0 & 0 & 1 & 1 & 1 & 1 & 1 \\
\hline
\end{tabular}




\begin{tabular}{|c|c|c|c|c|c|c|c|c|}
\hline \multirow{2}{*}{ ID } & \multirow{2}{*}{ OUTCOME } & \multicolumn{2}{|c|}{ Pathway 1} & \multicolumn{2}{|c|}{ Pathway 2} & \multicolumn{3}{|c|}{ Pathway 3} \\
\hline & & PQ39A_K & Ta17A & GL & PQ36 & GL & PO36 & PQSBK \\
\hline 269 & 0 & 0 & 1 & 1 & 1 & 1 & 1 & 1 \\
\hline 280 & 0 & 0 & 1 & 1 & 1 & 1 & 1 & 1 \\
\hline 129 & 0 & 0 & 0 & 1 & 1 & 1 & 1 & 1 \\
\hline 274 & 0 & 0 & 0 & 1 & 1 & 1 & 1 & 1 \\
\hline 341 & 0 & 0 & 0 & 1 & 1 & 1 & 1 & 1 \\
\hline 348 & 0 & 0 & 0 & 1 & 1 & 1 & 1 & 1 \\
\hline 113 & 0 & 0 & 1 & 1 & 1 & 1 & 1 & 1 \\
\hline 121 & 0 & 0 & 1 & 1 & 1 & 1 & 1 & 1 \\
\hline 128 & 0 & 0 & 1 & 1 & 1 & 1 & 1 & 1 \\
\hline 132 & 0 & 0 & 1 & 1 & 1 & 1 & 1 & 1 \\
\hline 145 & 0 & 0 & 1 & 1 & 1 & 1 & 1 & 1 \\
\hline 194 & 0 & 0 & 1 & 1 & 1 & 1 & 1 & 1 \\
\hline 201 & 0 & 0 & 1 & 1 & 1 & 1 & 1 & 1 \\
\hline 212 & 0 & 0 & 1 & 1 & 1 & 1 & 1 & 1 \\
\hline 225 & 0 & 0 & 1 & 1 & 1 & 1 & 1 & 1 \\
\hline 298 & 0 & 0 & 1 & 1 & 1 & 1 & 1 & 1 \\
\hline 310 & 0 & 0 & 1 & 1 & 1 & 1 & 1 & 1 \\
\hline 320 & 0 & 0 & 1 & 1 & 1 & 1 & 1 & 1 \\
\hline 332 & 0 & 0 & 1 & 1 & 1 & 1 & 1 & 1 \\
\hline 347 & 0 & 0 & 1 & 1 & 1 & 1 & 1 & 1 \\
\hline 356 & 0 & 0 & 1 & 1 & 1 & 1 & 1 & 1 \\
\hline 367 & 0 & 0 & 1 & 1 & 1 & 1 & 1 & 1 \\
\hline 380 & 0 & 0 & 1 & 1 & 1 & 1 & 1 & 1 \\
\hline 224 & 0 & 0 & 0 & 1 & 1 & 1 & 1 & 0 \\
\hline 230 & 0 & 0 & 1 & 1 & 1 & 1 & 1 & 0 \\
\hline 130 & 0 & 0 & 0 & 1 & 1 & 1 & 1 & 0 \\
\hline 149 & 0 & 0 & 0 & 1 & 1 & 1 & 1 & 0 \\
\hline 261 & 0 & 0 & 0 & 1 & 1 & 1 & 1 & 0 \\
\hline 263 & 0 & 0 & 0 & 1 & 1 & 1 & 1 & 0 \\
\hline 122 & 0 & 0 & 1 & 1 & 1 & 1 & 1 & 0 \\
\hline 175 & 0 & 0 & 1 & 1 & 1 & 1 & 1 & 0 \\
\hline 328 & 0 & 0 & 1 & 1 & 1 & 1 & 1 & 0 \\
\hline 370 & 0 & 0 & 1 & 1 & 1 & 1 & 1 & 0 \\
\hline 115 & 0 & 1 & 0 & 1 & 1 & 1 & 1 & 1 \\
\hline 138 & 0 & 1 & 1 & 1 & 1 & 1 & 1 & 1 \\
\hline 205 & 0 & 1 & 1 & 1 & 1 & 1 & 1 & 1 \\
\hline 257 & 0 & 1 & 1 & 1 & 1 & 1 & 1 & 1 \\
\hline 247 & 0 & 1 & 0 & 1 & 1 & 1 & 1 & 1 \\
\hline 371 & 0 & 1 & 0 & 1 & 1 & 1 & 1 & 1 \\
\hline 104 & 0 & 1 & 1 & 1 & 1 & 1 & 1 & 1 \\
\hline 111 & 0 & 1 & 1 & 1 & 1 & 1 & 1 & 1 \\
\hline 292 & 0 & 1 & 1 & 1 & 1 & 1 & 1 & 1 \\
\hline 330 & 0 & 1 & 1 & 1 & 1 & 1 & 1 & 1 \\
\hline 375 & 0 & 1 & 1 & 1 & 1 & 1 & 1 & 1 \\
\hline 379 & 0 & 1 & 1 & 1 & 1 & 1 & 1 & 1 \\
\hline 314 & 0 & 1 & 0 & 1 & 1 & 1 & 1 & 0 \\
\hline 123 & 0 & 0 & 0 & 1 & 0 & 1 & 0 & 1 \\
\hline 246 & 0 & 0 & 0 & 1 & 0 & 1 & 0 & 1 \\
\hline 342 & 0 & 0 & 1 & 1 & 0 & 1 & 0 & 1 \\
\hline 193 & 0 & 0 & 0 & 1 & 0 & 1 & 0 & 1 \\
\hline 339 & 0 & 0 & 0 & 1 & 0 & 1 & 0 & 1 \\
\hline 109 & 0 & 0 & 1 & 1 & 0 & 1 & 0 & 1 \\
\hline 125 & 0 & 0 & 1 & 1 & 0 & 1 & 0 & 1 \\
\hline 178 & 0 & 0 & 1 & 1 & 0 & 1 & 0 & 1 \\
\hline 312 & 0 & 0 & 1 & 1 & 0 & 1 & 0 & 1 \\
\hline 361 & 0 & 0 & 1 & 1 & 0 & 1 & 0 & 1 \\
\hline 369 & 0 & 0 & 1 & 1 & 0 & 1 & 0 & 1 \\
\hline 282 & 0 & 1 & 1 & 1 & 0 & 1 & 0 & 1 \\
\hline 303 & 0 & 1 & 1 & 1 & 0 & 1 & 0 & 1 \\
\hline 324 & 0 & 1 & 1 & 1 & 0 & 1 & 0 & 1 \\
\hline 317 & 0 & 1 & 1 & 1 & 0 & 1 & 0 & 0 \\
\hline 267 & 0 & 1 & 1 & 1 & 0 & 1 & 0 & 0 \\
\hline
\end{tabular}


Appendix G: Negative Outcome Dataset with Solution Pathways and Model

\begin{tabular}{|c|c|c|c|c|c|c|c|c|c|c|c|c|c|}
\hline \multirow{2}{*}{ ID } & \multirow{2}{*}{ OUTCOME } & \multicolumn{3}{|c|}{ Pattiway 1} & & Pathwar & & & Pathwary & & & attiwne: & \\
\hline & & TIAS & POS\& & PQ39AKK & GL & T1AS & PO5 & GL & PQ381 & POS9A_K & GL & T1AS & PO238 \\
\hline 109 & 0 & 0 & 1 & 0 & 1 & 0 & 1 & 1 & 1 & 0 & 1 & 0 & 1 \\
\hline 121 & 0 & 0 & 1 & 0 & 1 & 0 & 1 & 1 & 1 & 0 & 1 & 0 & 1 \\
\hline 123 & 0 & 0 & 1 & 0 & 1 & 0 & 1 & 1 & 1 & 0 & 1 & 0 & 1 \\
\hline 129 & 0 & 0 & 1 & 0 & 1 & 0 & 1 & 1 & 1 & 0 & 1 & 0 & 1 \\
\hline 132 & 0 & 0 & 1 & 0 & 1 & 0 & 1 & 1 & 1 & 0 & 1 & 0 & 1 \\
\hline 145 & 0 & 0 & 1 & 0 & 1 & 0 & 1 & 1 & 1 & 0 & 1 & 0 & 1 \\
\hline 149 & 0 & 0 & 1 & 0 & 1 & 0 & 1 & 1 & 1 & 0 & 1 & 0 & 1 \\
\hline 175 & 0 & 0 & 1 & 0 & 1 & 0 & 1 & 1 & 1 & 0 & 1 & 0 & 1 \\
\hline 178 & 0 & 0 & 1 & 0 & 1 & 0 & 1 & 1 & 1 & 0 & 1 & 0 & 1 \\
\hline 193 & 0 & 0 & 1 & 0 & 1 & 0 & 1 & 1 & 1 & 0 & 1 & 0 & 1 \\
\hline 197 & 0 & 0 & 1 & 0 & 1 & 0 & 1 & 1 & 1 & 0 & 1 & 0 & 1 \\
\hline 201 & 0 & 0 & 1 & 0 & 1 & 0 & 1 & 1 & 1 & 0 & 1 & 0 & 1 \\
\hline 212 & 0 & 0 & 1 & 0 & 1 & 0 & 1 & 1 & 1 & 0 & 1 & 0 & 1 \\
\hline 246 & 0 & 0 & 1 & 0 & 1 & 0 & 1 & 1 & 1 & 0 & 1 & 0 & 1 \\
\hline 269 & 0 & 0 & 1 & $0[v]$ & 1 & 0 & 1 & 1 & 1 & 0 & 1 & 0 & 1 \\
\hline 280 & 0 & 0 & 1 & A & $\frac{1}{30}$ & $\frac{a}{2}$ & 1 & 1 & 1 & 0 & 1 & 0 & 1 \\
\hline 298 & 0 & 0 & tel:010 & $620010 \%$ & 010 & $010 \%$ & 10[ & 1 & 1 & 0 & 1 & 0 & 1 \\
\hline 328 & 0 & 0 & 1 & 0 & $T$ & 0 & 5 & 1 & 1 & 0 & 1 & 0 & 1 \\
\hline 332 & 0 & 0 & 1 & 0 & 1 & 0 & 1 & 1 & 1 & 0 & 1 & 0 & 1 \\
\hline 339 & 0 & 0 & 1 & 0 & 1 & 0 & 1 & 1 & 1 & 0 & 1 & 0 & 1 \\
\hline 341 & 0 & 0 & 1 & 0 & 1 & 0 & 1 & 1 & 1 & 0 & 1 & 0 & 1 \\
\hline 342 & 0 & 0 & 1 & 0 & 1 & 0 & 1 & 1 & 1 & 0 & 1 & 0 & 1 \\
\hline 348 & 0 & 0 & 1 & 0 & 1 & 0 & 1 & 1 & 1 & 0 & 1 & 0 & 1 \\
\hline 367 & 0 & 0 & 1 & 0 & 1 & 0 & 1 & 1 & 1 & 0 & 1 & 0 & 1 \\
\hline 370 & 0 & 0 & 1 & 0 & 1 & 0 & 1 & 1 & 1 & 0 & 1 & 0 & 1 \\
\hline 377 & 0 & 0 & 1 & 0 & 1 & 0 & 1 & 1 & 1 & 0 & 1 & 0 & 1 \\
\hline 104 & 0 & 0 & 1 & 1 & 1 & 0 & 1 & 1 & 1 & 1 & 1 & 0 & 1 \\
\hline 111 & 0 & 0 & 1 & 1 & 1 & 0 & 1 & 1 & 1 & 1 & 1 & 0 & 1 \\
\hline 138 & 0 & 0 & 1 & 1 & 1 & 0 & 1 & 1 & 1 & 1 & 1 & 0 & 1 \\
\hline 205 & 0 & 0 & 1 & 1 & 1 & 0 & 1 & 1 & 1 & 1 & 1 & 0 & 1 \\
\hline 247 & 0 & 0 & 1 & 1 & 1 & 0 & 1 & 1 & 1 & 1 & 1 & 0 & 1 \\
\hline 257 & 0 & 0 & 1 & 1 & 1 & 0 & 1 & 1 & 1 & 1 & 1 & 0 & 1 \\
\hline 282 & 0 & 0 & 1 & 1 & 1 & 0 & 1 & 1 & 1 & 1 & 1 & 0 & 1 \\
\hline 303 & 0 & 0 & 1 & 1 & 1 & 0 & 1 & 1 & 1 & 1 & 1 & 0 & 1 \\
\hline 324 & 0 & 0 & 1 & 1 & 1 & 0 & 1 & 1 & 1 & 1 & 1 & 0 & 1 \\
\hline 371 & 0 & 0 & 1 & 1 & 1 & 0 & 1 & 1 & 1 & 1 & 1 & 0 & 1 \\
\hline 379 & 0 & 0 & 1 & 1 & 1 & 0 & 1 & 1 & 1 & 1 & 1 & 0 & 1 \\
\hline 122 & 0 & 0 & 0 & 0 & 1 & 0 & 1 & 1 & 0 & 0 & 1 & 0 & 0 \\
\hline 160 & 0 & 0 & 0 & 0 & 1 & 0 & 1 & 1 & 0 & 0 & 1 & 0 & 0 \\
\hline 224 & 0 & 0 & 0 & 0 & 1 & 0 & 1 & 1 & 0 & 0 & 1 & 0 & 0 \\
\hline 248 & 0 & 0 & 0 & 0 & 1 & 0 & 1 & 1 & 0 & 0 & 1 & 0 & 0 \\
\hline 261 & 0 & 0 & 0 & 0 & 1 & 0 & 1 & 1 & 0 & 0 & 1 & 0 & 0 \\
\hline 274 & 0 & 0 & 0 & 0 & 1 & 0 & 1 & 1 & 0 & 0 & 1 & 0 & 0 \\
\hline 267 & 0 & 0 & 0 & 1 & 1 & 0 & 1 & 1 & 0 & 1 & 1 & 0 & 0 \\
\hline 317 & 0 & 0 & 0 & 1 & 1 & 0 & 1 & 1 & 0 & 1 & 1 & 0 & 0 \\
\hline 113 & 0 & 0 & 1 & 0 & 1 & $\overline{0}$ & 0 & 7 & 7 & 0 & 1 & 0 & 1 \\
\hline 118 & 0 & 0 & 1 & 0 & 1 & 0 & 0 & 1 & 1 & 0 & 1 & 0 & 1 \\
\hline 125 & 0 & 0 & 1 & 0 & 1 & 0 & 0 & 1 & 1 & 0 & 1 & 0 & 1 \\
\hline 166 & 0 & 0 & 1 & 0 & 1 & 0 & 0 & 1 & 1 & 0 & 1 & 0 & 1 \\
\hline 306 & 0 & 0 & 1 & 0 & 1 & 0 & 0 & 1 & 1 & 0 & 1 & 0 & 1 \\
\hline 310 & 0 & 0 & 1 & 0 & 1 & 0 & 0 & 1 & 1 & 0 & 1 & 0 & 1 \\
\hline 380 & 0 & 0 & 1 & 0 & 1 & 0 & 0 & 1 & 1 & 0 & 1 & 0 & 1 \\
\hline 206 & 0 & 0 & 0 & 1 & 1 & 0 & 0 & 1 & 0 & 1 & 1 & 0 & 0 \\
\hline 128 & 0 & 1 & 1 & 0 & 1 & 1 & 1 & 1 & 1 & 0 & 1 & 1 & 1 \\
\hline 194 & 0 & 1 & 1 & 0 & 1 & 1 & 1 & 1 & 1 & 0 & 1 & 1 & 1 \\
\hline 225 & 0 & 1 & 1 & 0 & 1 & 1 & 1 & 1 & 1 & 0 & 1 & 1 & 1 \\
\hline 312 & 0 & 1 & 7 & 0 & 1 & 1 & 1 & 1 & 1 & 0 & 1 & 1 & 1 \\
\hline 320 & 0 & 1 & 1 & 0 & 1 & 1 & 1 & 1 & 1 & 0 & 1 & 1 & 1 \\
\hline 347 & 0 & 1 & 1 & 0 & 1 & 1 & 1 & 1 & 1 & 0 & 1 & 1 & 1 \\
\hline 361 & 0 & 1 & 1 & 0 & 1 & 1 & 1 & 1 & 1 & 0 & 1 & 1 & 1 \\
\hline 375 & 0 & 7 & 7 & 1 & 1 & 1 & 1 & 1 & 7 & 1 & 1 & 1 & 1 \\
\hline 313 & 0 & 1 & 0 & 0 & 1 & 1 & 1 & 1 & 0 & 0 & 1 & 1 & 0 \\
\hline 130 & 0 & 1 & 1 & 0 & 1 & 1 & 0 & 1 & 1 & 0 & 1 & 1 & 1 \\
\hline 263 & 0 & 1 & 7 & 0 & 1 & 1 & 0 & 7 & 7 & 0 & 1 & 1 & 1 \\
\hline 369 & 0 & 1 & 1 & 0 & 1 & 1 & 0 & 1 & 1 & 0 & 1 & 1 & 1 \\
\hline 230 & 0 & 1 & 0 & 0 & 1 & 1 & 0 & 1 & 0 & 0 & 1 & 1 & 0 \\
\hline 273 & 0 & 0 & 1 & 0 & 2 & 0 & 1 & 2 & 1 & 0 & 2 & 0 & 1 \\
\hline 154 & 0 & 0 & 1 & 1 & 2 & 0 & 1 & 2 & 1 & 1 & 2 & 0 & 1 \\
\hline 325 & 0 & 0 & 0 & 0 & 2 & 0 & 1 & 2 & 0 & 0 & 2 & 0 & 0 \\
\hline 285 & 0 & 0 & 0 & 1 & 2 & 0 & 1 & 2 & 0 & 1 & 2 & 0 & 0 \\
\hline 200 & 0 & 0 & 1 & 1 & 2 & 0 & 0 & 2 & 1 & 1 & 2 & 0 & 1 \\
\hline 202 & 0 & 1 & 0 & 0 & 2 & 1 & 1 & 2 & 0 & 0 & $\overline{2}$ & 7 & $\overline{0}$ \\
\hline 234 & 0 & 1 & 0 & 0 & 2 & 1 & 1 & 2 & 0 & 0 & 2 & 1 & 0 \\
\hline 170 & 0 & 1 & 0 & 1 & 2 & 1 & 1 & 2 & 0 & 1 & 2 & 1 & 0 \\
\hline 235 & 0 & 1 & 0 & 1 & 2 & 1 & 1 & 2 & 0 & 1 & 2 & 1 & 0 \\
\hline 134 & 0 & 1 & 1 & 0 & 2 & 1 & 1 & 2 & 1 & 0 & 2 & 1 & 1 \\
\hline
\end{tabular}




\begin{tabular}{|c|c|c|c|c|c|c|c|c|c|c|c|c|c|}
\hline \multirow{2}{*}{ ID } & \multirow{2}{*}{ OUTCOME } & \multicolumn{3}{|c|}{ Pathway 1} & & athway & & & Pathway & & & attrway & \\
\hline & & T1AS & POS\& & PQ39A_K & GL & TIAS & PO5 & GL & PQ381 & PO39A_K & GL & T1AS & PO38 \\
\hline 209 & 0 & 1 & 1 & 0 & 2 & 1 & 1 & 2 & 1 & 0 & 2 & 1 & 1 \\
\hline 216 & 0 & 1 & 1 & 0 & 2 & 1 & 1 & 2 & 1 & 0 & 2 & 1 & 1 \\
\hline 307 & 0 & 1 & 1 & 0 & 2 & 1 & 1 & 2 & 1 & 0 & 2 & 1 & 1 \\
\hline 272 & 0 & 0 & 1 & 0 & 3 & 0 & 1 & 3 & 1 & 0 & 3 & 0 & 1 \\
\hline 309 & 0 & 0 & 1 & 0 & 3 & 0 & 1 & 3 & 1 & 0 & 3 & 0 & 1 \\
\hline 382 & 0 & 0 & 1 & 0 & 3 & 0 & 1 & 3 & 1 & 0 & 3 & 0 & 1 \\
\hline 146 & 0 & 0 & 1 & 1 & 3 & 0 & 1 & 3 & 1 & 1 & 3 & 0 & 1 \\
\hline 158 & 0 & 0 & 1 & 1 & 3 & 0 & 1 & 3 & 1 & 1 & 3 & 0 & 1 \\
\hline 207 & 0 & 0 & 1 & 1 & 3 & 0 & 1 & 3 & 1 & 1 & 3 & 0 & 1 \\
\hline 242 & 0 & 0 & 1 & 1 & 3 & 0 & 1 & 3 & 1 & 1 & 3 & 0 & 1 \\
\hline 250 & 0 & 0 & 1 & 1 & 3 & 0 & 1 & 3 & 1 & 1 & 3 & 0 & 1 \\
\hline 265 & 0 & 0 & 1 & 1 & 3 & 0 & 1 & 3 & 1 & 1 & 3 & 0 & 1 \\
\hline 372 & 0 & 0 & 1 & 1 & 3 & 0 & 1 & 3 & 1 & 1 & 3 & 0 & 1 \\
\hline 381 & 0 & 0 & 1 & 1 & 3 & 0 & 1 & 3 & 1 & 1 & 3 & 0 & 1 \\
\hline 152 & 0 & 0 & 0 & 1 & 3 & 0 & 1 & 3 & 0 & 1 & 3 & 0 & 0 \\
\hline 173 & 0 & 0 & 0 & 1 & 3 & 0 & 1 & 3 & 0 & 1 & 3 & 0 & 0 \\
\hline 266 & 0 & 0 & 0 & 1 & 3 & 0 & 1 & 3 & 0 & 1 & 3 & 0 & 0 \\
\hline 364 & 0 & $\frac{1}{1}$ & 7 & 0 & 3 & 1 & 1 & 3 & 1 & 0 & 3 & 1 & 1 \\
\hline 140 & $\frac{-1}{1}$ & 0 & 1 & 0 & -1 & $\overline{0}$ & -1 & $-\frac{1}{1}$ & 7 & 0 & $\frac{1}{1}$ & -5 & $\overline{1}-1$ \\
\hline 204 & 1 & 0 & 1 & 0 & 1 & 0 & 1 & 1 & 1 & 0 & 1 & 0 & 1 \\
\hline 211 & 1 & 0 & 1 & 0 & 1 & 0 & 1 & 1 & 1 & 0 & 1 & 0 & 1 \\
\hline 244 & 1 & 0 & 1 & 0 & 1 & 0 & 1 & 1 & 1 & 0 & 1 & 0 & 1 \\
\hline 268 & 1 & 0 & 1 & 0 & 1 & 0 & 1 & 1 & 1 & 0 & 1 & 0 & 1 \\
\hline 281 & 1 & 0 & 1 & 0 & 1 & 0 & 1 & 1 & 1 & 0 & 1 & 0 & 1 \\
\hline 363 & 1 & 0 & 1 & 1 & 1 & 0 & 1 & 1 & $\overline{1}$ & 7 & 1 & 0 & 1 \\
\hline 103 & 1 & 0 & 0 & 0 & 1 & 0 & 1 & 1 & 0 & 0 & 1 & 0 & 0 \\
\hline 161 & 1 & 0 & 0 & 0 & 1 & 0 & 1 & 1 & 0 & 0 & 1 & 0 & 0 \\
\hline 164 & 1 & 0 & 0 & 0 & 1 & 0 & 1 & 1 & 0 & 0 & 1 & 0 & 0 \\
\hline 195 & 1 & 0 & 0 & 0 & 1 & 0 & 1 & 1 & 0 & 0 & 1 & 0 & 0 \\
\hline 255 & 1 & 0 & 0 & 0 & 1 & 0 & 1 & 1 & 0 & 0 & 1 & 0 & 0 \\
\hline 174 & 1 & 0 & 0 & 1 & 1 & 0 & 1 & 1 & 0 & 1 & 1 & 0 & 0 \\
\hline 335 & 1 & 0 & 1 & 1 & 1 & 0 & 0 & 1 & 1 & 1 & 1 & 0 & 1 \\
\hline 159 & 1 & 0 & 1 & 1 & 1 & 0 & 0 & 1 & 1 & 1 & 1 & 0 & 1 \\
\hline 237 & 1 & 0 & 0 & 0 & 1 & 0 & 0 & 1 & 0 & 0 & 1 & 0 & 0 \\
\hline 229 & 1 & 0 & 1 & 0 & 1 & 0 & 0 & 1 & 7 & $\overline{0}$ & 1 & 0 & 1 \\
\hline 336 & 1 & 0 & 1 & 0 & 1 & 0 & 0 & 1 & 1 & 0 & 1 & 0 & 1 \\
\hline 177 & 1 & 1 & 0 & 0 & 1 & 1 & 1 & 1 & 0 & 0 & 1 & 1 & 0 \\
\hline 208 & 1 & 1 & 7 & 0 & 1 & 1 & 1 & 1 & 1 & 0 & 1 & 1 & 1 \\
\hline 213 & 1 & 1 & 1 & 0 & 1 & 1 & 1 & 1 & 1 & 0 & 1 & 1 & 1 \\
\hline 236 & 1 & 1 & 1 & 0 & 1 & 1 & 1 & 1 & 1 & 0 & 1 & 1 & 1 \\
\hline 179 & 1 & 7 & 7 & $\overline{1}$ & 1 & 1 & 1 & 1 & 7 & $\overline{1}$ & 1 & 1 & 1 \\
\hline 184 & 1 & 1 & 1 & 1 & 1 & 1 & 1 & 1 & 1 & 1 & 1 & 1 & 1 \\
\hline 232 & 1 & 1 & 1 & 1 & 1 & 1 & 1 & 1 & 1 & 1 & 1 & 1 & 1 \\
\hline 357 & 1 & 1 & 1 & 1 & 1 & 1 & 1 & 1 & 1 & 1 & 1 & 1 & 1 \\
\hline 360 & 1 & 1 & 1 & 1 & 1 & 1 & 1 & 1 & 1 & 1 & 1 & 1 & 1 \\
\hline 108 & 1 & 1 & 0 & 0 & 1 & 1 & 1 & 1 & 0 & 0 & 1 & 1 & 0 \\
\hline 136 & 1 & 1 & 0 & 0 & 1 & 1 & 1 & 1 & 0 & 0 & 1 & 1 & 0 \\
\hline 215 & 1 & 1 & 0 & 0 & 1 & 1 & 1 & 1 & 0 & 0 & 1 & 1 & 0 \\
\hline 327 & 1 & 1 & 0 & 0 & 1 & 1 & 1 & 1 & 0 & 0 & 1 & 1 & 0 \\
\hline 217 & 1 & 1 & 0 & 1 & 1 & 1 & 1 & 1 & 0 & 1 & 1 & 1 & 0 \\
\hline 239 & 1 & 7 & 7 & $\overline{0}$ & 1 & 1 & 0 & 1 & $\overline{1}$ & 0 & 1 & 1 & 1 \\
\hline 172 & 1 & $\overline{0}$ & 7 & $\overline{0}$ & 2 & 0 & 1 & $\frac{1}{2}$ & 7 & $\overline{0}$ & 2 & 0 & 1 \\
\hline 189 & 1 & 0 & 1 & 0 & 2 & 0 & 1 & 2 & 1 & 0 & 2 & 0 & 1 \\
\hline 258 & 1 & 0 & 1 & 0 & 2 & 0 & 1 & 2 & 1 & 0 & 2 & 0 & 1 \\
\hline 279 & 1 & 0 & 1 & 0 & 2 & 0 & 1 & 2 & 1 & 0 & 2 & 0 & 1 \\
\hline 277 & 1 & 0 & 1 & 1 & 2 & 0 & 1 & 2 & 1 & 1 & 2 & 0 & 1 \\
\hline 290 & 1 & 0 & 1 & 1 & 2 & 0 & 1 & 2 & 1 & 1 & 2 & 0 & 1 \\
\hline 321 & 1 & 0 & 1 & 1 & 2 & 0 & 1 & 2 & 1 & 1 & 2 & 0 & 1 \\
\hline 340 & 1 & 0 & 1 & 1 & 2 & 0 & 1 & 2 & 1 & 1 & 2 & 0 & 1 \\
\hline 351 & 1 & 0 & 1 & 1 & 2 & 0 & 1 & 2 & 1 & 1 & 2 & 0 & 1 \\
\hline 252 & 1 & 0 & 0 & 0 & 2 & 0 & 1 & 2 & 0 & 0 & 2 & 0 & 0 \\
\hline 240 & 1 & 0 & 0 & 1 & 2 & 0 & 1 & 2 & 0 & 1 & 2 & 0 & 0 \\
\hline 287 & 1 & 0 & 0 & 1 & 2 & 0 & 1 & 2 & 0 & 1 & 2 & 0 & 0 \\
\hline 326 & 1 & 0 & 0 & 1 & 2 & 0 & 1 & 2 & 0 & 1 & 2 & 0 & 0 \\
\hline 373 & 1 & 0 & 0 & 1 & 2 & 0 & 1 & 2 & 0 & 1 & 2 & 0 & 0 \\
\hline 150 & 1 & 0 & 1 & 0 & 2 & 0 & 0 & 2 & 1 & 0 & 2 & 0 & 1 \\
\hline 171 & 1 & 0 & 1 & 0 & 2 & 0 & 0 & 2 & 1 & 0 & 2 & 0 & 1 \\
\hline 296 & 1 & 0 & 1 & 0 & 2 & 0 & 0 & 2 & 1 & 0 & 2 & 0 & 1 \\
\hline 359 & 1 & 0 & 1 & 0 & 2 & 0 & 0 & 2 & 1 & 0 & 2 & 0 & 1 \\
\hline 135 & 1 & 1 & 1 & 1 & 2 & 1 & 1 & 2 & 1 & 1 & 2 & 1 & 1 \\
\hline 260 & 1 & 1 & 1 & 1 & 2 & 1 & 1 & 2 & 1 & 1 & 2 & 1 & 1 \\
\hline 141 & 1 & 1 & 1 & 1 & 2 & 1 & 0 & 2 & 1 & 1 & 2 & 1 & 1 \\
\hline 120 & 1 & 0 & 1 & 0 & 3 & 0 & 1 & 3 & 1 & 0 & 3 & 0 & 1 \\
\hline 139 & 1 & 0 & 1 & 0 & 3 & 0 & 1 & 3 & 1 & 0 & 3 & 0 & 1 \\
\hline 144 & 1 & 0 & 1 & 0 & 3 & 0 & 1 & 3 & 1 & 0 & 3 & 0 & 1 \\
\hline 157 & 1 & 0 & 1 & 0 & 3 & 0 & 1 & 3 & 1 & 0 & 3 & 0 & 1 \\
\hline
\end{tabular}




\begin{tabular}{|c|c|c|c|c|c|c|c|c|c|c|c|c|c|}
\hline \multirow{2}{*}{ ID } & \multirow{2}{*}{ OUTCOME } & \multicolumn{3}{|c|}{ Pathway 1} & \multicolumn{3}{|c|}{ Pathway 2} & \multicolumn{3}{|c|}{ Pathiway 3} & \multicolumn{3}{|c|}{ Pathway 4} \\
\hline & & T1AS & PC28 & PQ39A_K & GL & TIAS & PO5 & GL & POs8 & PO39A_K & GL & T1AS & PC38 \\
\hline 199 & 1 & 0 & 1 & 0 & 3 & 0 & 1 & 3 & 1 & 0 & 3 & 0 & 1 \\
\hline 275 & 1 & 0 & 1 & 0 & 3 & 0 & 1 & 3 & 1 & 0 & 3 & 0 & 1 \\
\hline 286 & 1 & 0 & 1 & 0 & 3 & 0 & 1 & 3 & 1 & 0 & 3 & 0 & 1 \\
\hline 302 & 1 & 0 & 1 & 0 & 3 & 0 & 1 & 3 & 1 & 0 & 3 & 0 & 1 \\
\hline 322 & 1 & 0 & 1 & 0 & 3 & 0 & 1 & 3 & 1 & 0 & 3 & 0 & 1 \\
\hline 353 & 1 & 0 & 1 & 0 & 3 & 0 & 1 & 3 & 1 & 0 & 3 & 0 & 1 \\
\hline 124 & 1 & 0 & 1 & 1 & 3 & 0 & 1 & 3 & 1 & 1 & 3 & 0 & 1 \\
\hline 151 & 1 & 0 & 1 & 1 & 3 & 0 & 1 & 3 & 1 & 1 & 3 & 0 & 1 \\
\hline 162 & 1 & 0 & 1 & 1 & 3 & 0 & 1 & 3 & 1 & 1 & 3 & 0 & 1 \\
\hline 223 & 1 & 0 & 1 & 1 & 3 & 0 & 1 & 3 & 1 & 1 & 3 & 0 & 1 \\
\hline 249 & 1 & 0 & 1 & 1 & 3 & 0 & 1 & 3 & 1 & 1 & 3 & 0 & 1 \\
\hline 251 & 1 & 0 & 1 & 1 & 3 & 0 & 1 & 3 & 1 & 1 & 3 & 0 & 1 \\
\hline 254 & 1 & 0 & 1 & 1 & 3 & 0 & 1 & 3 & 1 & 1 & 3 & 0 & 1 \\
\hline 271 & 1 & 0 & 1 & 1 & 3 & 0 & 1 & 3 & 1 & 1 & 3 & 0 & 1 \\
\hline 276 & 1 & 0 & 1 & 1 & 3 & 0 & 1 & 3 & 1 & 1 & 3 & 0 & 1 \\
\hline 291 & 1 & 0 & 1 & 1 & 3 & 0 & 1 & 3 & 1 & 1 & 3 & 0 & 1 \\
\hline 301 & 1 & 0 & 1 & 1 & 3 & 0 & 1 & 3 & 1 & 1 & 3 & 0 & 1 \\
\hline 315 & 1 & 0 & 1 & 1 & 3 & 0 & 1 & 3 & 1 & 1 & 3 & 0 & 1 \\
\hline 319 & 1 & 0 & 1 & 1 & 3 & 0 & 1 & 3 & 1 & 1 & 3 & 0 & 1 \\
\hline 338 & 1 & 0 & 1 & 1 & 3 & 0 & 1 & 3 & 1 & 1 & 3 & 0 & 1 \\
\hline 344 & 1 & 0 & 1 & 1 & 3 & 0 & 1 & 3 & 1 & 1 & 3 & 0 & 1 \\
\hline 358 & 1 & 0 & 1 & 1 & 3 & 0 & 1 & 3 & 1 & 1 & 3 & 0 & 1 \\
\hline 366 & 1 & 0 & 1 & 1 & 3 & 0 & 1 & 3 & 1 & 1 & 3 & 0 & 1 \\
\hline 228 & 1 & 0 & 0 & 0 & 3 & 0 & 1 & 3 & 0 & 0 & 3 & 0 & 0 \\
\hline 305 & 1 & 0 & 0 & 0 & 3 & 0 & 1 & 3 & 0 & 0 & 3 & 0 & 0 \\
\hline 343 & 1 & 0 & 0 & 0 & 3 & 0 & 1 & 3 & 0 & 0 & 3 & 0 & 0 \\
\hline 101 & 1 & 0 & 0 & 1 & 3 & 0 & 1 & 3 & 0 & 1 & 3 & 0 & 0 \\
\hline 362 & 1 & 0 & 0 & 1 & 3 & 0 & 1 & 3 & 0 & 1 & 3 & 0 & 0 \\
\hline 365 & 1 & 0 & 0 & 1 & 3 & 0 & 1 & 3 & 0 & $\frac{1}{1}$ & 3 & 0 & 0 \\
\hline 155 & 1 & 0 & 1 & 1 & 3 & 0 & 0 & 3 & 1 & 1 & 3 & 0 & 1 \\
\hline 163 & 1 & 0 & 1 & 1 & 3 & 0 & 0 & 3 & 1 & 1 & 3 & 0 & 1 \\
\hline 196 & 1 & 0 & 1 & 1 & 3 & 0 & 0 & 3 & 1 & 1 & 3 & 0 & 1 \\
\hline 259 & 1 & 0 & 1 & 1 & 3 & 0 & 0 & 3 & 1 & 1 & 3 & 0 & 1 \\
\hline 262 & 1 & 0 & 1 & 1 & 3 & 0 & 0 & 3 & 1 & 1 & 3 & 0 & 1 \\
\hline 334 & 1 & 0 & 1 & 1 & 3 & 0 & 0 & 3 & 1 & 1 & 3 & 0 & 1 \\
\hline 352 & 1 & 0 & 0 & 0 & 3 & 0 & 0 & 3 & 0 & 0 & 3 & 0 & 0 \\
\hline 143 & 1 & 1 & 1 & 1 & 3 & 1 & 1 & 3 & 1 & 1 & 3 & 1 & 1 \\
\hline 148 & 1 & 1 & 1 & 1 & 3 & 1 & 1 & 3 & 1 & 1 & 3 & 1 & 1 \\
\hline 183 & 1 & 1 & 1 & 1 & 3 & 1 & 1 & 3 & 1 & 1 & 3 & 1 & 1 \\
\hline 185 & 1 & 1 & 0 & 0 & 3 & 1 & 0 & 3 & 0 & 0 & 3 & 1 & 0 \\
\hline
\end{tabular}




\section{Appendix H: Institutional Review Board Exemption Certificate}

\section{蛋 Portland State}

Office of Research Integrity 1600 SW 4th Avenue, Suite 620 Portland, OR 97201

(503) 725-5484 psuirb@pdx.edu

\section{Notice of Exempt Certification}

January 5, 2021

Dear Investigator,

The PSU Human Research Protection Program (HRPP) reviewed the following submission:

\begin{tabular}{|l|l|}
\hline Investigators & Sherrill Gelmon and Kelly Coates \\
\hline HRPP \# & 207148-18 \\
\hline Fundle & $\begin{array}{l}\text { Affecting Absenteeism Through School-Based Health Services Delivery: A } \\
\text { Configurational Comparative Methods Study of Oregon's Public Middle and } \\
\text { High Schools }\end{array}$ \\
\hline $\begin{array}{l}\text { Determination Date } \\
\text { Expiration Date }\end{array}$ & N/A \\
\hline Review Category & N/A \\
\hline
\end{tabular}

IMPORTANT: In-person interactions for the purposes of conducting human subjects research is suspended until further notice. Data collection must be through remote/virtual methodologies until this restriction is lifted OR an exception to perform in-person data collection is granted by Research \& Graduate Studies.

Research Integrity determined this study qualifies as exempt and is satisfied the provisions for protecting the rights and welfare of all subjects participating in research are adequate. The study may now proceed in accordance with the plans submitted (HRPP Forms enclosed). Please note the following ongoing Human Research Protection Program (HRPP) requirements:

Changes to Study Activities: Any changes to the study must be submitted to Research Integrity for review and determination prior to implementation.

Unanticipated Problems or Adverse Events: Notify Research Integrity within 5 days of any unanticipated problems or adverse events that occur as a result of the study.

Study Completion: Notify Research Integrity when the study is complete; Research Integrity will request annual updates on the study status. Study materials must be kept for at least three years following completion.

Compliance: The PSU IRB (FWA00000091; IRB00000903) and Research Integrity comply with 45 CFR Part 46, 21 CFR Parts 50 and 56, and other federal and Oregon laws and regulations, as applicable.

If there are any questions, please contact the ORI at psuirb@pdx.edu or call 503-725-5484.

Sincerely,

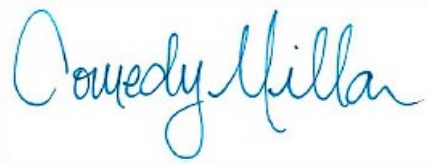

Comedy Millar, HRPP Administrator, Research Integrity 